TULIO VITOR MACHADO FARIA

Mindboard: sistema para colaboração durante a aula e fora dela

São Paulo

2015 
TULIO VITOR MACHADO FARIA

\section{Mindboard: sistema para colaboração durante a aula e fora dela}

Dissertação apresentada à Escola de Artes, Ciências e Humanidades da Universidade de São Paulo para obtenção do título de Mestre em Ciências pelo Programa de Pós-graduação em Sistemas de Informação.

Área de Concentração: Sistemas de Informação

Versão corrigida contendo as alterações solicitadas pela comissão julgadora em 09 de Setembro de 2015. A versão original encontra-se em acervo reservado na Biblioteca da EACH-USP e na Biblioteca Digital de Teses e Dissertações da USP (BDTD), de acordo com a Resolução CoPGr 6018, de 13 de outubro de 2011.

Orientador: Prof. Dr. João Luiz Bernardes Junior

São Paulo

2015 
Autorizo a reprodução e divulgação total ou parcial deste trabalho, por qualquer meio convencional ou eletrônico, para fins de estudo e pesquisa, desde que citada a fonte.

CATALOGAÇÃO-NA-PUBLICAÇÃO

(Universidade de São Paulo. Escola de Artes, Ciências e Humanidades. Biblioteca)

Faria, Tulio Vitor Machado

Mindboard : sistema para colaboração durante a aula e fora dela / Tulio Vitor Machado Faria ; orientador, João Luiz

Bernardes Junior. - São Paulo, 2015 $188 \mathrm{f}$. : il.

Dissertação (Mestrado em Ciências) - Programa de PósGraduação em Sistemas de Informação, Escola de Artes,

Ciências e Humanidades, Universidade de São Paulo Versão corrigida

1. Tecnologia educacional. 2. Computadores no ensino.

3. Computadores - Aplicações - Educação. I. Bernardes Junior, João Luiz, orient. II. Título

CDD 22.ed. -371.33 
Dissertação de autoria de Tulio Vitor Machado Faria, sob o título "Mindboard: sistema para colaboração durante a aula e fora dela", apresentada à Escola de Artes, Ciências e Humanidades da Universidade de São Paulo, para obtenção do título de Mestre em Ciências pelo Programa de Pós-graduação em Sistemas de Informação, na área de concentração Sistemas de Informação, aprovada em 09 de Setembro de 2015 pela comissão julgadora constituída pelos doutores:

Prof. Dr. João Luiz Bernardes Junior

Presidente

Escola de Artes, Ciências e Humanidades - Universidade de São Paulo

Prof. Dr. Norton Trevisan Roman

Escola de Artes, Ciências e Humanidades - Universidade de São Paulo

Prof. Dr. Romero Tori

Escola Politécnica - Universidade de São Paulo 


\section{Agradecimentos}

Agradeço a Deus, minha família e minha noiva Anny Fernandes pela paciência e apoio incondicional. Agradeço também a todos os meus amigos pelo apoio e pela compreensão em minhas sucessivas ausências em eventos sociais. Gostaria também de agradecer meu orientador professor Dr. João Luiz Bernardes Junior pela grande parceria e amizade que foi indispensável para a realização deste trabalho.

Gostaria também de agradecer a CAPES pelo financiamento da pesquisa e por viabilizar este trabalho. Aos amigos do grupo de pesquisas LInE do IME-USP, em especial ao professor Dr. Leônidas Brandão e ao amigo Romenig Ribeiro por toda amizade e apoio.

Gostaria também de agradecer aos amigos do Interlab-Poli USP que me acolheram muitas vezes e também muito me ajudaram, em especial pelo coordenador do grupo, professor Dr. Romero Tori.

Gostaria de agradecer também ao Inpettecc pelo apoio a realização do experimento deste trabalho e também a seu diretor e grande amigo Elton Rodrigo de Souza pela parceria de longa data. 


\section{Resumo}

FARIA, Tulio Vitor Machado. Mindboard: sistema para colaboração durante a aula e fora dela. 2015. 188 f. Dissertação (Mestrado em Ciências) - Escola de Artes, Ciências e Humanidades, Universidade de São Paulo, São Paulo, 2015.

Atualmente, as crianças e jovens possuem cada vez mais acesso e contato com tecnologias digitais. Aliado a programas governamentais que fomentam a disponibilidade de dispositivos móveis e computadores aos alunos e professores de escolas públicas, e também aos estudantes levando seus próprios dispositivos para a sala de aula, um grande ecossistema propício ao uso de tecnologias antes, durante e depois da aula está sendo formado. Neste escopo, o objetivo deste trabalho é avaliar se um conjunto de funcionalidades propostas aliadas a metodologia pedagógica adequada favorecem a colaboração durante a aula e fora dela. Faz parte também dos objetivos deste trabalho projetar e desenvolver este sistema. Batizado como Mindboard, esse sistema teve um protótipo utilizado em um experimento com alunos em um curso de verão para avaliar o uso de suas funcionalidades em relação a colaboração e a tecnologia utilizada, além disso a relevância das funcionalidades foram avaliadas através de pesquisas com professores e alunos e também por meio de uma revisão exploratória da literatura. O experimento realizado mostrou de forma qualitativa o aumento das interações de maior qualidade na turma que utilizou o sistema Mindboard, uma vez que os alunos não precisavam interagir sobre problemas ao visualizar o que estava sendo projetado durante a aula. Além disso, nesta mesma turma houve uma inclusão de alunos introvertidos e de alunos que possuem problemas de visão. A tecnologia utilizada no desenvolvimento do protótipo também mostrou-se adequada ao desenvolvimento deste tipo de sistema e foi suficiente para o desenvolvimento de todos os requisitos funcionais e não-funcionais.

Palavras-chaves: educação. tecnologia. sistema. colaboração. durante aula. fora da aula. 


\begin{abstract}
FARIA, Tulio Vitor Machado. Mindboard: a collaboration system to be used during the class and beyond. 2015. 188 p. Dissertation (Master of Science) - School of Arts, Sciences and Humanities, University of São Paulo, São Paulo, 2015.

Currently, children and young people have more access and contact with digital technologies. Combined with government programs that promote the availability of mobile devices and computers to students and teachers in public schools, as well as students bringing more and more their own devices to the classroom, a large ecosystem to support the use of technologies during the class and after that being formed. In this scenario, the aim of this study is to validate a set of functionalities proposed in a system and design and develop it with these features that can enable collaboration in class and beyond. This system, named Mindboard, had a prototype used in an experiment with students in a summer course to evaluate the use of its functionality in relation to collaboration and the technology used. The relevance of the system's features were also assessed through surveys with teachers and students and also through an exploration of the literature. The experiment showed qualitatively the increase in higher quality interactions in the group that used the Mindboard system, since students did not have to interact about problems viewing what was being created during the class. Additionally, in this same group there was an inclusion of introverted students and students who have vision loss. The technology used in the development of the prototype also proved to be suitable for the development of such system and is sufficient for the development of all functional and non-functional requirements.
\end{abstract}

Keywords: education. collaboration. system. in-class. out-class. 


\section{Lista de figuras}

Figura 1 - Metodologia utiliza para a realização do trabalho . . . . . . . . . . . 30

Figura 2 - Laboratório 1 do INPETTECC, onde o curso foi lecionado. . . . . . . . 34

Figura 3 - Imagem destacando a posição da câmera e do computador utilizados para gravação das aulas. . . . . . . . . . . . . . . . . . . 35

Figura 4 - Modalidades pedagógicas . . . . . . . . . . . . . 56

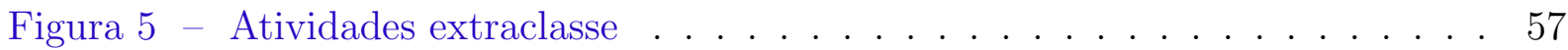

Figura 6 - Recursos utilizados . . . . . . . . . . . . 57

Figura 7 - Retorno dos alunos . . . . . . . . . . . . 58

Figura 8 - Inibição dos alunos em dar retorno ou fazer questionamento em aula . 58

Figura 9 - Uso de internet em sala de aula pelos alunos . . . . . . . . . . . . 59

Figura 10 - Quais metodologias pedagógicas os alunos aprendem mais . . . . . . . 60

Figura 11 - Quais os recursos seus professores utilizam . . . . . . . . . . . 60

Figura 12 - Inibição dos alunos ao fazer questionamentos ou dar um retorno sobre a aula aos professores. . . . . . . . . . . . . . 6 61

Figura 13 - Utilização de internet em sala de aula pelos alunos . . . . . . . . . . . 61

Figura 14 - Recursos computacionais utilizados por alunos e professores . . . . . . 62

Figura 15 - Quantidade de horas que alunos e professores utilizam por semana . . . 63

Figura 16 - Importância da ferramenta ser multiplataforma, comparação entre as respostas de professores e alunos . . . . . . . . . . . . . . 64

Figura 17 - Importância da ferramenta permitir que os alunos visualizem o conteúdo em tempo real, comparação entre as respostas de professores e alunos . 64

Figura 18 - Importância da ferramenta permitir que os alunos anotem sobre o conteúdo, comparação entre as respostas de professores e alunos . . . . 65

Figura 19 - Importância da ferramenta ser multiplataforma, comparação entre as respostas de professores e alunos . . . . . . . . . . . . 6 65

Figura 20 - Importância da ferramenta permitir um retorno anônimo dos alunos aos professores sobre as aulas (respostas de professores e alunos) . . . .

Figura 21 - As fases de um processo genérico relacionadas com as fases do Processo Unificado . . . . . . . . . . . . . . . . . . . 69

Figura 22 - Formas de iteração do Processo Unificado . . . . . . . . . . . . . . . . 69

Figura 23 - Diagrama de casos de uso - identificação e acesso a ferramenta . . . . . 74 
Figura 24 - Diagrama de casos de uso - acesso como professor . . . . . . . . . . 74

Figura 25 - Diagrama de casos de uso - acesso como aluno . . . . . . . . . . . . 74

Figura 26 - Diagrama de classes . . . . . . . . . . . . . . . 75

Figura 27 - Arquitetura de servidores do Mindboard . . . . . . . . . . . . . . . . 81

Figura 28 - Módulos do protótipo do sistema Mindboard . . . . . . . . . . . . . . . 84

Figura 29 - Tela de gerenciamento de aulas - telas maiores . . . . . . . . . . . . 86

Figura 30 - Tela de gerenciamento de aulas - telas com resolução menor . . . . . . 86

Figura 31 - Tela de aula projetando apresentação em uma tela com resolução maior 87

Figura 32 - Tela de aula projetando código-fonte em telas com resolução maior 87

Figura 33 - Tela de aula projetando apresentação em telas com resolução menor e barra de anotações oculta . . . . . . . . . . . . . . . . . . . . . 88

Figura 34 - Tela de aula projetando apresentação em telas com resolução menor e barra de anotações visível . . . . . . . . . . . . . . . . . . . . . . 89

Figura 35 - Tela de aula projetando um objeto de aprendizagem desenvolvido no grupo de pesquisas LInE . . . . . . . . . . . . . . . . . . 89

Figura 36 - Tela de um curso no Moodle e um exemplo de onde o usuário acessaria

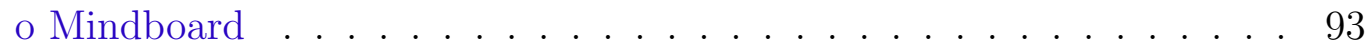

Figura 37 - Diagrama de sequência ilustrando a integração entre um block do Mindboard no Moodle e uma instalação do Mindboard . . . . . . . . . 93

Figura 38 - Aula do Minboard sendo visualizada dentro do Moodle . . . . . . . . . 94

Figura 39 - Visão geral do consumo de recursos no dia 19/01/2015 - Dia 1 de curso 180 Figura 40 - Visão geral do uso de disco rígido no dia 19/01/2015 - Dia 1 de curso . 181

Figura 41 - Visão geral do uso de rede no dia 19/01/2015 - Dia 1 de curso . . . . . 181 Figura 42 - Visão geral do uso de recursos pelos processos no dia 19/01/2015 - Dia 1 de curso . . . . . . . . . . . . . . . . . . . . . . . 182

Figura 43 - Visão geral do consumo de recursos no dia 20/01/2015 - Dia 2 de curso 182 Figura 44 - Visão geral do uso de disco rígido no dia 20/01/2015 - Dia 2 de curso . 183 Figura 45 - Visão geral do uso de rede no dia 20/01/2015 - Dia 2 de curso . . . . . 183 Figura 46 - Visão geral do uso de recursos pelos processos no dia 20/01/2015 - Dia 2 de curso . . . . . . . . . . . . . . . . . . . . . . . 184

Figura 47 - Visão geral do consumo de recursos no dia 21/01/2015 - Dia 3 de curso 184 Figura 48 - Visão geral do uso de disco rígido no dia 21/01/2015 - Dia 3 de curso . 185 Figura 49 - Visão geral do uso de rede no dia 21/01/2015 - Dia 3 de curso . . . . . 185 
Figura 50 - Visão geral do uso de recursos pelos processos no dia 21/01/2015 - Dia 3 de curso . . . . . . . . . . . . . . . . . . . . . 186

Figura 51 - Visão geral do consumo de recursos no dia 22/01/2015 - Dia 4 de curso 186 Figura 52 - Visão geral do uso de disco rígido no dia 22/01/2015 - Dia 4 de curso . 187 Figura 53 - Visão geral do uso de rede no dia 22/01/2015 - Dia 4 de curso . . . . . 187 Figura 54 - Visão geral do uso de recursos pelos processos no dia 22/01/2015 - Dia 4 de curso . . . . . . . . . . . . . . . . . . . . 188 


\section{Lista de tabelas}

Tabela 1 - Perguntas de pesquisa definidas para a revisão sistemática . . . . . . . 41

Tabela 2 - Strings de busca utilizadas em cada base . . . . . . . . . . . . . 42

Tabela 3 - Critérios de inclusão . . . . . . . . . . . . . . . . . . . 42

Tabela 4 - Critérios de exclusão . . . . . . . . . . . . . . . . . . 42

Tabela 5 - Importância de uma característica a ser ativada em um sistema de ensino a distância . . . . . . . . . . . . . . . 53

Tabela 6 - Distribuição geográfica . . . . . . . . . . . . . 56

Tabela 7 - Prioridade dos requisitos . . . . . . . . . . . . 72

Tabela 8 - Visualizações das atividades . . . . . . . . . . . . . 78

Tabela 9 - Questões de utilidade . . . . . . . . . . . . . . . . . 98

Tabela 10 - Questões de Facilidade de Uso . . . . . . . . . . . . . . . . . . . . 99

Tabela 11 - Questões de Satisfação . . . . . . . . . . . . . . . . . . . . 99 


\section{Sumário}

$1 \quad$ Introdução . . . . . . . . . . . . . . . 15

2 Fundamentação . . . . . . . . . . . . . . . 19

2.1 Evolução dos sistemas e ferramentas computacionais para educação . . . . . . . . . . . . . . . . . . . . 19

2.2 Sistemas cooperativos e sua utilização na educação . . 22

$2.3 \quad$ Modalidade pedagógica: ensino híbrido . . . . . . . . 25

$3 \quad$ Metodologia . . . . . . . . . . . . . . . . 29

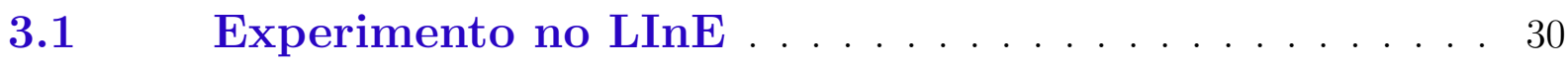

$3.2 \quad$ Pesquisa com alunos e professores . . . . . . . . . 32

$3.3 \quad$ Experimento em sala de aula . . . . . . . . . . . 33

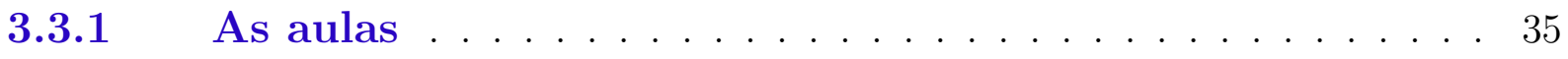

3.3.2 Colaborações . . . . . . . . . . . . . . . . 36

3.3.3 Avaliação do sistema Mindboard utilizada em conjunto com a metodologia sala de aula invertida . . . . . . . . . 37

3.3.4 Avaliação de usabilidade: questionário USE . . . . . . . . 38

3.3.5 Avaliação da ferramenta e levantamentos de interações e colaborações extraclasse . . . . . . . . . . . . . . . . . 39

4 Revisão da Bibliografia . . . . . . . . . . . . . . 40

4.1 Revisões relacionadas . . . . . . . . . . . . . . . 40

$4.2 \quad$ Metodologia . . . . . . . . . . . . . . . . . . . . 41

4.3 Resultados e discussão . . . . . . . . . . . . . . . . 43

4.4 Funcionalidades presentes em sistemas de aprendiza-

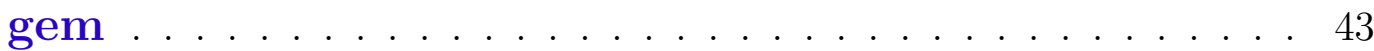

$5 \quad$ Resultados da pesquisa com professores e alunos . $\quad 55$

$5.1 \quad$ Análise dos resultados específicos a professores . . . . 55

5.2 Análise dos resultados específicos a alunos . . . . . . . . 59

5.3 Avaliação do uso de internet e tecnologias por professores e alunos . . . . . . . . . . . . . . . . 62 
5.4 Opinião dos professores e alunos quanto a uma futura ferramenta . . . . . . . . . . . . . . . . . 63

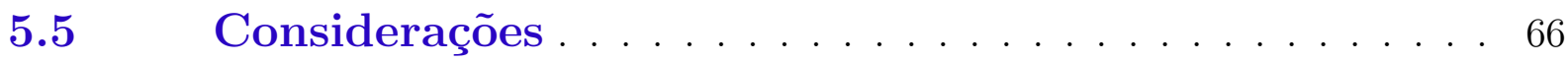

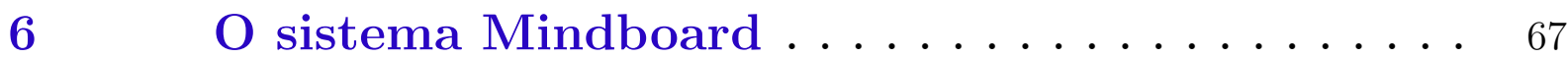

6.1 O Processo Unificado e suas customizações . . . . . . . . 67

6.2 Customizações do Processo Unificado . . . . . . . . . . . . 69

$6.3 \quad$ Iterações . . . . . . . . . . . . . . . . . . . 70

6.4 Captura de requisitos . . . . . . . . . . . . . . 71

6.4.1 Descrição dos atores . . . . . . . . . . . . . . . . . 72

6.4.2 Diagramas de casos de uso . . . . . . . . . . . . 73

6.4.3 Visão de dados . . . . . . . . . . . . . . . . . . . . 75

6.5 Tecnologias . . . . . . . . . . . . . . . . . 76

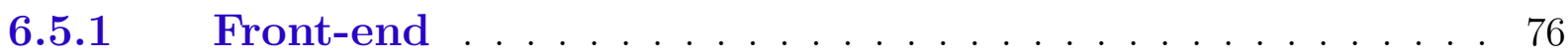

6.5.2 Back-end . . . . . . . . . . . . . . . . . . . . 79

6.5.3 Arquitetura . . . . . . . . . . . . . . . . 81

6.6 Implementação . . . . . . . . . . . . . . . . . . . . 82

6.6.1 Organização em módulos . . . . . . . . . . . . . . . 82

6.6.2 Interface gráfica . . . . . . . . . . . . . . . . . 85

6.6.3 Algoritmo de sincronização . . . . . . . . . . . . . . . . 9 90

6.6.4 Extensibilidade e integração com sistemas de terceiros . . 92

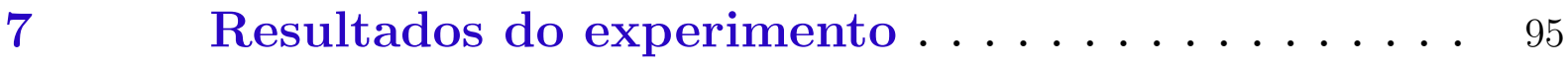

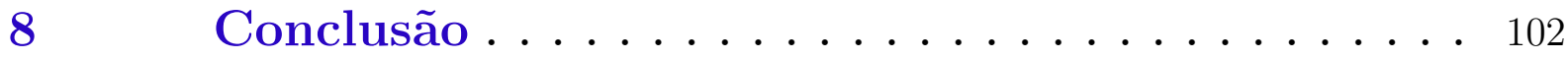

Referências $^{1} \ldots \ldots \ldots \ldots \ldots$. . . . . . . 106

Apêndice A-Formulário da pesquisa com professores ................. 116

Apêndice $\mathrm{B}$-Formulário da pesquisa com alunos 125

1 De acordo com a Associação Brasileira de Normas Técnicas. NBR 6023. 
Apêndice C-Projeto completo submetido ao Conselho de Ética pela Plataforma Brasil 132

Apêndice D-Termo livre e esclarecido do experimento prático .......... 138

Apêndice E-Parecer do Comitê de Ética em relação ao experimento . . . . . . . . 141

Apêndice F-Questionário de avaliação da sala de aula invertida - Turma 1 . . . . . 145

Apêndice G-Questionário de avaliação da sala de aula invertida - Turma 2 . . . . . 150

Apêndice H-Questionário USE . . . . . . . . 155

Apêndice I - Questionário utilizado ao final do curso - Turma $1 \ldots \ldots \ldots 163$

Apêndice J-Questionário utilizado ao final do curso - Turma 2 . . . . . . . . . . . 169

Apêndice K-Requisitos funcionais e não funcionais175 K.1 Requisitos funcionais . . . . . . . . . . . . . . . 175

K.1.1 RF 01 - Identificar professores e alunos . . . . . . . . 175

K.1.2 RF 02 - Gerenciar aulas . . . . . . . . . . . . 175

K.1.3 RF 03 - Acessar aulas . . . . . . . . . . . . . . 175

K.1.4 RF 04 - Projetar apresentações de slides em uma aula . 175

K.1.5 RF 05 - Anotações . . . . . . . . . . . . . . . 176

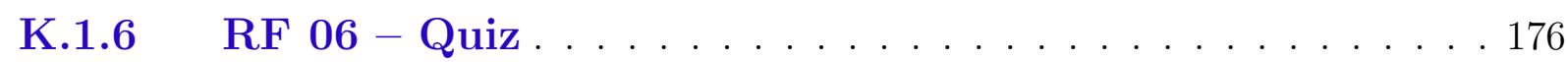

K.1.7 RF 07 - Coletar e sumarizar opiniões sobre a aula . . . 176

K.1.8 RF 08 - Coletar e sumarizar dúvidas durante e após a aula . . . . . . . . . . . . . . . . . . . . 176

K.1.9 RF 09 - Rever uma aula . . . . . . . . . . . . . . 177

K.1.10 RF 10 - Colaborar assincronamente em uma aula . . . 177 
K.1.11 RF 11 - Permitir o compartilhamento de código-fonte em tempo-real . . . . . . . . . . . . . . . . . . . . 177

K.1.12 RF 12 - Permitir integração com outros sistemas . . . . . 177

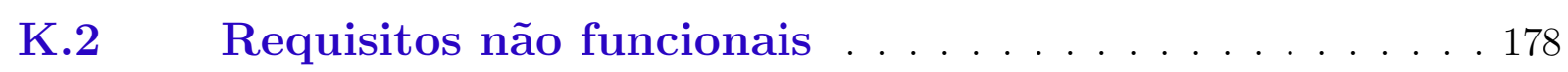

Apêndice $\mathrm{L}$-Relatórios de utilização de recursos computacionais do experimento . . . 180 


\section{Introdução}

Atualmente, as crianças e jovens no Brasil e no mundo possuem cada vez mais acesso e contato com tecnologias digitais. No Brasil, cerca de $75 \%$ dos jovens entre 10 e 18 anos afirmam navegar na internet, e 38,3\% afirmam que a utilizam para estudos e realização de tarefas escolares (PALOSCHI, 2012). Além disso, de acordo com o New Horizon Report (JOHnSON; ADAMS; CUMMINS, 2012), mundialmente, as instituições de ensino aumentam cada vez mais a disponibilidade e a qualidade de acesso à internet dentro de suas dependências.

Os estudantes também trazem cada vez mais seus próprios dispositivos para as salas de aula, em uma tendência conhecida como Bring Your Own Device (BYOD), como notebooks, tablets e smartphones, dispositivos estes que também são utilizados para seus estudos fora de sala de aula. Esses dispositivos poderiam enriquecer o aprendizado independente de lugar e momento, não se restringindo a somente as salas de aula (JOHNSON et al., 2014).

Além da presença de tecnologia em sala de aula ocorrer naturalmente por parte dos alunos, como visto anteriormente, existem ações públicas em diversos países que visam à inclusão de tecnologia tanto para alunos quanto para professores. O governo brasileiro, por exemplo, por meio do programa ProInfo fomenta o uso de tecnologia da informação e comunicação (TIC) na rede pública de ensino (PROINFO..., 2014). Essa presença de

infraestrutura favorece cada vez mais a utilização de sistemas computacionais para a educação.

Os sistemas para educação vem evoluindo juntamente com a computação, e tem como objetivo atuar como meio ou ferramenta a contribuir com objetivos pedagógicos (TCHOUNIKINE, 2011). Atualmente a utilização de sistemas computacionais podem ocorrer em todos os aspectos do ambiente educacional servindo assim vários propósitos e objetivos. Alguns propósitos utilizados atualmente incluem servir realmente como um meio de instrução, onde o aprendizado acontece completamente por meio de computadores (BARCELOS; TAROUCO; BERCHT, 2009), ou ainda no uso da gestão da educação, propiciando novos recursos para que professores e demais envolvidos no processo possuam dados e ferramentas para acompanhamento do progresso dos alunos (SZABO; FLESCHER, 2002) ou ainda com o enriquecimento da experiência de aprendizagem por meio de recursos computacionais (COTTON, 1991). A computação em sala de aula está abrindo novas possibilidades de 
utilização de metodologias pedagógicas que sem tecnologia eram impraticáveis ou inviáveis. Um exemplo de metodologia potencializada pela tecnologia é a Sala de Aula Invertida.

A Sala de Aula Invertida é uma metodologia onde lições teóricas são realizadas online por meio da internet e o tempo em sala de aula é utilizado para tirar dúvidas e para aplicação destas teorias em trabalhos práticos que podem envolver o trabalho conjunto entre os alunos (STAKER; HORN, 2012). A utilização de metodologias inovadoras em conjunto com atividades que envolvem dois ou mais alunos colaborando por um objetivo em comum aumentam e muito sua motivação.

A motivação e a participação são aspectos educacionais bastante pesquisados atualmente, principalmente pelos benefícios que podem trazer ao processo de ensinoaprendizagem. Estudos apontam que quando os alunos participam ativamente do processo, esta atividade acaba por aumentar o aprendizado e persistência do conhecimento, aumentam as notas ou ainda torna-os mais participativos (FELDER, 1992). Assim, torna-se relevante a pesquisa de sistemas computacionais que poderiam ser utilizados na educação para aproveitar o ambiente que já conta com dispositivos conectados à internet dos próprios alunos ou fornecidos pelas escolas, porém sua utilização poderia ser diferente da realizada atualmente, buscando aumentar a participação e a colaboração dos alunos. Atualmente, muitos sistemas educacionais são utilizados somente como meio de transferência de materiais de aula e tem funcionalidades relacionadas a colaboração subutilizadas (TAKEDA et al., 2013), principalmente no que se refere a seu uso durante o período de aula.

Neste contexto, foram elaboradas as seguintes perguntas de pesquisa para este trabalho:

Pergunta 1: quais seriam as funcionalidades que atendem a um possível sistema para fomentar a colaboração entre alunos e com o professor durante a aula e fora dela?

Pergunta 2: considerando estes requisitos, quais as tecnologias web poderiam ser utilizadas em seu desenvolvimento?

Como hipótese inicial a Pergunta de Pesquisa 1 temos o seguinte conjunto de funcionalidades, extraídas da análise de trabalhos e sistemas semelhantes:

Funcionalidade 1: permitir ao aluno visualizar conteúdo (apresentações, textos, vídeos, etc.) disponibilizado pelo professor, tanto durante a aula quanto fora dela;

Funcionalidade 2: possibilitar ao aluno informar anonimamente o professor, durante a aula, o quanto está compreendendo o assunto; 
Funcionalidade 3: possibilitar que o professor receba o retorno dado pelo aluno na funcionalidade anterior em tempo real, enquanto está dando aula, sobre o quanto os alunos julgam estar entendendo o conteúdo. Permitir também que o professor visualize o histórico destes retornos;

Funcionalidade 4: permitir que o aluno faça anotações no computador ou em dispositivos móveis diretamente sobre o material de aula que o professor disponibilizou;

Funcionalidade 5: permitir ao aluno compartilhar estas anotações (descritas na funcionalidade anterior) e dúvidas, respostas ou comentários com os demais alunos ou com o professor, durante a aula e depois dela;

Além destas funcionalidades, um requisito não funcional considerado importante é que o sistema possa ser executado apropriadamente e com boa usabilidade em diferentes plataformas de hardware e software, dados os diferentes dispositivos usados por alunos e professores durante a aula ou depois dela.

A validação dessa hipótese será realizada através de uma pesquisa com alunos e professores do ensino médio e superior, onde cada um destes grupo de usuários respondeu sobre a relevância destas funcionalidades a um futuro sistema a ser desenvolvido, a metodologia dessa pesquisa foi descrita na Seção 3.2. Outra análise também avaliará as funcionalidades presentes em sistemas educacionais comerciais e descritas em artigos científicos, estas funcionalidades foram levantadas e analisadas através da revisão da literatura descrita no Capítulo 4. Um protótipo do sistema desenvolvido contendo estas funcionalidades também será utilizado em um experimento para conhecer melhor sua relevância como um todo no processo de ensino e aprendizagem. O experimento é realizado conforme descrito na Seção 3.3 e seus resultados compõem o Capítulo 7.

Já as hipóteses iniciais para a segunda pergunta de pesquisa que envolve a definição das tecnologias web mais adequadas para o desenvolvimento incluem dois grupos de tecnologias para o front-end: uma onde a interface com o usuário utilizaria Java Applet e outra onde seria utilizado HTML5, JavaScript e CSS3. A validação de cada hipótese será realizada através de um experimento realizado no Laboratório de Informática na Educação (LInE), em que será possível coletar indícios de facilidade de execução pelo usuário final em cada uma delas. Serão utilizados também relatos e estudos de casos disponibilizados publicamente. A metodologia do experimento realizado no LInE é descrita na Seção 3.1 já seus resultados são descritos na Seção 6.5.1. Além disso, serão pesquisadas também as melhores alternativas para o desenvolvimento do back-end. 
Assim, o objetivo geral deste trabalho é verificar se esse conjunto de funcionalidades para um sistema a ser utilizado durante a aula e fora dela pode aumentar a colaboração entre alunos e com o professor; e definir quais tecnologias web são adequadas para implementá-las. Como objetivos secundários será desenvolvido um protótipo do sistema, avaliadas sua utilização e também sua usabilidade.

Neste Capítulo foram introduzidos a motivação e o contexto ao qual este trabalho está relacionado e definidas as perguntas de pesquisa e o objetivo do trabalho. No Capítulo 2 são apresentados os conceitos envolvidos no trabalho através da Fundamentação Teórica. Já o Capítulo 3 apresenta a metodologia aplicada no trabalho e em cada experimento realizado.

No Capítulo 4 é realizada a revisão da literatura para conhecer outros sistemas comerciais e acadêmicos que podem ser utilizados para a educação. O Capítulo 5 discute os resultados obtidos nas pesquisa com alunos e professores do ensino médio e superior e no Capítulo 6 é descrito como foi desenvolvido o sistema Mindboard, quais tecnologias foram utilizadas e todas as demais decisões técnicas. Neste capítulo também é discutido o resultado da pesquisa realizada no LInE, pois a mesma norteou uma decisão técnica no trabalho.

O Capítulo 7 mostra e discute os resultados do experimento onde foi utilizado o sistema Mindboard e o trabalho é concluído no Capítulo 8. 


\section{Fundamentação}

Para alcançar os objetivos descritos no Capítulo 1, este trabalho vai lidar com vários conceitos da área da educação, colaboração na educação e computação. Assim, neste capítulo serão descritos e discutidos os conceitos fundamentais ao desenvolvimento deste trabalho.

\subsection{Evolução dos sistemas e ferramentas computacionais para educação}

Este trabalho lida com sistemas computacionais para a educação, assim, faz-se necessário um conhecimento mais amplo desses tipos de sistemas, bem como sua evolução ao longo do tempo. Nesta seção faz-se uma análise dos tipos de sistemas empregados na educação visando uma desambiguação em suas definições.

Sistemas computacionais para educação são ferramentas que auxiliam em algum atividade no processo de ensino e aprendizagem (TCHOUNIKINE, 2011). O início da utilização de computadores na educação aconteceu em meados da década de 60 e 70 nas universidades de Ilinóis (ALPERT; BITZER, 1970), Flórida, Stanford e Dartmouth (CHAMBERS; SPRECHER, 1980).

Um dos primeiros relatos de utilização de sistemas computacionais na educação foi relacionado ao sistema Programmed Logic for Automatic Teaching Operations (PLATO). Desenvolvido na Universidade de Ilinóis, o PLATO tem como objetivo pesquisar a utilização de computadores na educação focando tornar viável técnica e financeiramente o uso em

larga escala de computadores modernos para a época na educação (ALPERT; BITZER, 1970).

Durante esse período, na Universidade da Flórida, surgiram os primeiros experimentos nos quais utilizou-se um computador interativo IBM 1500 em cursos de nivelamento de física e estatística e que possuía como forma de comunicação com o usuário a digitação de textos (CHAMBERS; SPRECHER, 1980). Uma outra perspectiva foi adicionada na mesma época com o desenvolvimento da linguagem BASIC na universidade de Dartmouth, onde os estudantes contavam com uma linguagem de programação simples que permitia a criação de pequenos programas com propósitos educacionais (CHAMBERS; SPRECHER, 1980).

Já na universidade de Stanford a aplicação foi feita de uma maneira um pouco diferente, focando uma utilização por alunos mais novos e com pouco conhecimento 
de programação, o objetivo era aumentar as habilidades de crianças e adolescentes em matemática e inglês, por meio de atividades teóricas e práticas (CHAMBERS; SPRECHER, 1980).

Durante esse período a utilização de recursos computacionais na educação era bastante restrita devido a seu alto custo e à grande necessidade de espaço físico, problema este que somente foi possível de ser reduzido com o surgimento dos computadores pessoais.

A evolução dos sistemas computacionais com objetivos educacionais continuou e na universidade de Ilinóis a plataforma PLATO foi melhorada, concentrando na automatização da assistência de resolução de problemas. Assim foi criada a possibilidade do aluno utilizar a estratégia top-down para a solução de problemas de programação, por meio de diálogos em linguagem natural (DANIELSON; NIEVERGELT, 1975). Já nos anos 80, os sistemas de tutoria inteligente começaram a ser explorados. Sistemas de tutoria inteligentes permitem um acompanhamento dos alunos de forma individualizada através de sistemas computacionais (BLOOM, 1984). Durante a utilização deste tipo de sistema o aluno é conduzido pelo conteúdo seguido de testes formais. Além disso são realizados outros testes e obtidos retornos dos alunos sobre o andamento para que possam ser executadas ações corretivas na tutoria (BLOOM, 1984).

Posteriormente, outros tipos de ferramentas computacionais começaram a surgir, como jogos educativos e sistemas de simulação. Jogos educativos compõem uma iniciativa de envolver a educação com uma motivação intrínseca: através de conquistas de níveis e promovendo a característica que o aluno pode superar um determinado nível, tornando a atividade de aprendizagem auto motivada e gratificante ao aluno (AMORY et al., 1999). Já os sistemas de simulação provêm aos alunos a oportunidade de aplicar seus conhecimentos para resolver problemas práticos e este convite a exploração pode levar a uma aceleração na aprendizagem, aumentar a retenção de conteúdo e obter altos níveis de motivação e interesse (DAM; BECKER; SIMPSON, 2007).

Mais recentemente tem sido pesquisados os Sistemas de Gerenciamento de Curso (SGC), de educação móvel e em redes sociais. SGC são sistemas que gerenciam todos os aspectos do processo de ensino e aprendizagem, servindo de infraestrutura para entrega e gerenciamento de conteúdo, identificação e acesso de informações individuais e organizacionais, objetivos pedagógicos, rastreia o progresso perante estes objetivos além de coletar dados para supervisionar a educação como um todo (SZABO; FLESCHER, 2002). 
Sistemas de Gestão de Aprendizagem (SGA) são sistemas computacionais baseados em ferramentas de armazenamento de dados e apresentação. Os SGAs gerenciam por completo o programa pedagógico e o progresso de cada aluno no que diz respeito às regras e competências definidas pela instituição (SZABO; FLESCHER, 2002). Outras características desses sistemas são herdadas de seus antecessores, os de Instrução Gerenciada por Computador, o qual identifica a performance em relação a alguns padrões e fornece recursos relevantes a este padrão (SZABO; FLESCHER, 2002). Além das vantagens que surgiram com os SGAs, a evolução dos sistemas computacionais com o surgimento e evolução dos smartphones e outros dispositivos móveis abriram novos horizontes à educação.

A educação móvel é uma aplicação de sistema computacional para educação onde a entrega de conteúdo ou gerenciamento da atividade de ensino e aprendizagem ocorre por meio do uso de dispositivos móveis. O uso desses dispositivos permite que o aluno aprenda em qualquer lugar e a qualquer tempo, tanto no ensino presencial quanto a distância (BARCELOS; TAROUCO; BERCHT, 2009).

Um movimento mais recente envolve o uso de outros tipos de sistemas computacionais para propósitos educacionais. Um desses movimentos busca formas de utilizar redes sociais para distribuição de conteúdo e colaboração entre alunos e entre alunos e professores. A grande motivação para a utilização de mídias sociais na educação vem de sua notória popularização entre os jovens em seu cotidiano, o que facilitaria a adição do uso para fins educacionais (DOTTA, 2011). Uma rede social bastante explorada atualmente é o Facebook que pode ser utilizado como ferramenta pedagógica importante, principalmente na promoção da colaboração no processo educativo, e ainda, permite a construção crítica e reflexiva de informação e conhecimento (FERNANDES, 2011).

$\mathrm{Na}$ área de sistemas computacionais aplicados à educação há uma taxonomia bastante diversificada para definir sistemas com características específicas e há também termos que definem sistemas com características muito semelhantes entre si. A seguir é organizado uma pequena parte destes termos e suas características.

Um dos primeiros termos a ser utilizado amplamente na área foi o Computer-Assisted Instruction (CAI). CAI é descrito como ferramentas computacionais ou baseadas em computador que fornecem exercícios e materiais de tutoria (KADIYALA; CRYNES, 1998). Uma outra característica do CAI é a possibilidade de ser ou utilizado como complemento às aulas convencionais ou para instruções totalmente realizadas por meio deste (COTTON, 1991). Sistemas com essas características também são definidos na literatura como Computer- 
Aided Instruction, Computer-Augmented-Instruction e Computer-Administered Instruction (KULIK; KULIK; BANGERT-DROWNS, 1985).

O termo Computer-based Education (CBE) também pode ser utilizado para conceitualizar sistemas com as características presentes no CAI, porém com algumas funcionalidades adicionais. O CBI pode ser utilizado de três maneiras: para exercícios, tutoria e em modo de diálogo. No modo exercícios, o professor leciona de maneira convencional e o computador provê exercícios (KADIYALA; CRYNES, 1998). Já no modo tutoria, o computador é responsável por apresentar os conceitos e seus exercícios. E no modo de diálogo, o computador apresenta as lições e exercícios, e o alunos podem tanto realizar questionamentos de modo irrestrito e controlar quase que por completo a sequência de aprendizado (KADIYALA; CRYNES, 1998). Alguns autores incluem nesta definição usos mais avançados de computação na educação, como simulações, programação, tutoriais, desenvolvimento de banco de dados, escrita em processadores de texto, entre outros (COTTON, 1991).

O termo Computer-managed instruction (CMI) refere-se a sistemas computacionais utilizados pelos funcionários da escola para organizar os dados dos alunos, ajudar na tomada de decisão instrucional, guiar os alunos para materiais instrucionais apropriados, avaliar os dados de performance de testes de alunos, ajudando a manter os registros de seus progressos (COTTON, 1991; KADIYALA; CRYNES, 1998). Ainda temos o termo Computer-enriched instruction (CEI) que é definido como atividades educativas onde o computador gera dados baseado nos pedidos dos alunos para ilustrar relacionamentos em modelos de realidade sociais e físicas, executar programas desenvolvidos pelos próprios alunos ou prover enriquecimento geral relativo a exercícios sem estruturas fixas criados para estimular e motivar os alunos (COTTON, 1991).

Esta seção buscou explorar parte da história do uso de sistemas computacionais para a educação e também apresentar um pouco da taxonomia presente na área. Na seção seguinte será apresentado sistemas computacionais envolvidos ou não com a educação e que possuem como principal característica a colaboração.

\subsection{Sistemas cooperativos e sua utilização na educação}

O objetivo principal deste trabalho envolve o projeto e desenvolvimento de um sistema colaborativo para ser utilizado dentro e fora de sala de aula. Assim, é relevante 
explorar as características de sistemas computacionais com esta finalidade e também sua aplicação na educação.

O termo Computer-Supported Colaborative Work (CSCW) surgiu em 1984 como uma identificação a um workshop interdisciplinar organizado por Greif e Cashman no MIT em Agosto daquele ano para pesquisadores convidados para discutir como o uso de computadores poderia favorecer as várias formas de trabalho. Um segundo workshop foi realizado e atraiu 300 pessoas (GREIF, 1988). Desde então, o evento é realizado a cada 2 anos, iniciando em 1988. A grande preocupação levantada na época é como dar suporte ao perfil descentralizado das corporações onde funcionários poderiam trabalhar em um mesmo objeto mesmo estando fisicamente distantes (REINHARD et al., 1994).

Essa nova área vem pautada de uma taxonomia específica que pode ser traduzida em fatores a serem levados em consideração quando um sistema ou ferramenta colaborativa é construída.

O CSCW é fortemente relacionado a área em que será utilizado, sendo assim muitas ferramentas são desenvolvidas pensando no domínio do problema a ser resolvido. Assim, pode ser que seja necessária a criação de ferramentas em que editores de texto, planilhas ou outros dados são compartilhados e colaborados entre usuários, porém, as funcionalidades continuam sendo muito relacionadas com o domínio (REINHARD et al., 1994).

Os sistemas que envolvem atividades colaborativas possuem requisitos de aplicação que são avaliados na maioria dos sistemas. O primeiro requisito avaliado em ferramentas colaborativas é a interação com o sistema.

A interação pode acontecer de forma síncrona ou assíncrona, dependendo do tipo da atividade. A interação síncrona acontece quando os usuários colaboram sobre uma mesma informação ao mesmo tempo. Já a interação assíncrona os usuários colaboram sobre a mesma informação em tempos distintos (REINHARD et al., 1994). A interação também pode ser classificada quanto a natureza da comunicação, em implícita e explícita. Na implícita a comunicação é realizada por meio de imagens, desenhos e textos, já na explícita por meio de gestos, áudio e/ou vídeo (SCHMIDT; BANNON, 1992).

A coordenação também é um requisito muito importante para sistemas colaborativos, e é a funcionalidade que define quando os participantes podem interagir. A coordenação é diretamente relacionada ao número de participantes e o tipo de atividade que será desenvolvida. Pequenos grupos necessitam de menos coordenação ou não precisam de uma coordenação centralizada, já grandes grupos precisam de uma forma de coordenação mais 
precisa para que possa haver a colaboração e comunicação. Em uma pequena reunião com três pessoas precisa-se de menos coordenação ao comparar-se a uma conferência com centenas de pessoas (REINHARD et al., 1994).

As ferramentas de colaboração também possuem pontos a serem considerados quanto a distribuição geográfica de seus usuários. Pois, uma colaboração explícita gerará a necessidade de mais canais de comunicação ou da utilização de mais recursos para a comunicação. Além desse quesito técnico, outros fatores podem influenciar, como o fuso horário, diferenças de linguagem e idioma, diferenças culturais, políticas entre outras (REINHARD et al., 1994).

Outra característica interessante ao CSCW é a percepção do usuário. Na colaboração transparente, o usuário não percebe e não possui um retorno por parte da aplicação de que mais de um usuário está usando a aplicação. Já quando há a colaboração consciente, a aplicação deixa claro que mais de um usuário está colaborando no mesmo ambiente e quais os papéis dos mesmos (REINHARD et al., 1994).

Em relação às informações trocadas e construídas em sistemas colaborativos, há dois fatores influentes: visualização e ocultamento de dados. A visualização diz respeito a como a aplicação mostra a colaboração aos usuários. Por exemplo, se cada usuário tem o cursor de uma cor, ou uma área de trabalho comum e compartilhada com a informação resultante da colaboração, mesmo que a colaboração seja feita por outras formas de interação (REINHARD et al., 1994).

Sobre o ocultamento de dados, também conhecido na literatura como visibilidade, é a capacidade do sistema em permitir que os usuários mantenham versões públicas e privadas de suas informações. O controle do que cada usuário pode ver também está relacionado a está característica. Esta política geralmente é aplicada em nível de usuários, grupos de usuários ou pelo papel do usuário (RAMANAU; GENG, 2009; REINHARD et al., 1994).

Quando o CSCW é aplicado na área da educação, o mesmo passa a ser denominado como Computer-Supported Collaborative Learning (CSCL). O CSCL é muito semelhante ao CSCW e adiciona características específicas provenientes da aprendizagem colaborativa.

A aprendizagem colaborativa é uma situação onde duas ou mais pessoas alcançam seus objetivos de aprendizagem em conjunto (CHUANG, 2015). Dentre as vantagens da aprendizagem colaborativa estão a melhoria nas notas de provas e a promoção do interesse dos alunos na aprendizagem (CALDWELL, 2007; POLLOCK, 2006). Além dessa modalidade 
pedagógica mover o ensino centrado no professor para uma forma de instrução centrada no aluno, inclui uma aprendizagem mais social, ativa e construtivista (KIRSCHNER, 2001).

A aprendizagem colaborativa utilizando computadores ou apoiada por computadores permite a utilização de algumas estratégias que podem ser aplicadas tanto no ensino presencial quanto no ensino à distância. Uma das estratégias bastante comuns é realizada por meio da escrita colaborativa. Nessa estratégia, os envolvidos podem construir a solução ou conhecimento por meio de interações contínuas (ONRUBIA; ENGEL, 2009). Uma outra abordagem bastante comum é a de realização de discussões como forma de construção de conhecimento. Neste formato os alunos podem utilizar fóruns de discussão online ou wikis para gerar novos conhecimentos e atingir o objetivo pedagógico proposto pelo professor e/ou tutor (RAMANAU; GENG, 2009).

Uma outra abordagem muito comum é relacionado ao trabalho em equipe para a solução de um problema, favorecendo a metodologia pedagógica da aprendizagem baseada em problemas. Em Baker e Lund (1997) o autor descreve o uso de um ambiente CSCL para a aprendizagem de Física, onde os envolvidos colaboram utilizando a internet. Nesse texto também há a divisão do trabalho em duas tarefas cognitivas: resolver o problema através da modelagem em Física e colaboração, sendo a segunda tarefa a atividade principal de comunicação entre os envolvidos para a solução e modelagem do problema. Esse tipo de abordagem, dependendo da área de conhecimento, pode exigir ferramentas específicas para a modelagem e construção da solução do problema.

\subsection{Modalidade pedagógica: ensino híbrido}

O sistema pesquisado, proposto e desenvolvido neste trabalho é aplicado à educação e pode ser utilizado dentro e fora de sala de aula. Assim, é relevante discutir algumas metodologias pedagógicas que possam ser mais beneficiadas por essas condições, inclusive porque uma ou mais dessas metodologias pode ser explorada futuramente em experimentos com o sistema.

Atualmente existem várias modalidades pedagógicas que podem ser utilizadas dentro e fora de sala de aula, e que são potencializadas pelo uso de tecnologia e meios

digitais. Mesmo existindo sem o uso de computadores, quando aliada ao mesmo, traz muitas vantagens aos utilizadores e as instituições de ensino, como o aumento do número de 
alunos que podem ser atendidos pela instituição sem aumentar o custo e uma flexibilidade de estudo por parte dos alunos.

Uma modalidade pedagógica muito em discussão atualmente é a blended-learning ou ensino híbrido. O ensino híbrido acontece toda vez que o aluno aprende pelo menos uma parte do conteúdo sob supervisão na escola e pelo menos uma parte do conteúdo é entregue de forma online com possibilidade do aluno controlar o tempo, lugar, ordem e/ou ritmo de estudo (HORN; STAKER, 2011).

De acordo com o Horizon Report (JOHNSON et al., 2015) o ensino híbrido é uma tendência para os próximos anos principalmente pela busca de professores e alunos a alternativas ao ensino presencial convencional para favorecer os resultados do processo de aprendizagem.

O ensino híbrido pode ser realizado segundo alguns modelos diferentes como o flexível, auto-aprendizagem, enriquecido virtualmente e o de rotação (STAKER; HORN, 2012).

O modelo flexível é um programa onde o conteúdo e instrução é entregue primariamente pela internet, e os alunos caminham por um conteúdo curricular individualizado, personalizado e com agenda flexível e contam ainda com o suporte presencial dos professores na escola (STAKER; HORN, 2012). Uma outra modalidade também comum ao ensino híbrido é o modelo de auto-aprendizagem, onde os alunos decidem por si mesmos complementar sua formação com cursos e lições realizados online (HORN; STAKER, 2011). Atualmente, sites como Khan Academy ${ }^{1}$, Coursera ${ }^{2}$ e edX ${ }^{3}$ favorecem este tipo de aprendizagem, oferecendo cursos online livres onde os alunos podem complementar seus conhecimentos.

O modelo enriquecido virtualmente é uma experiência aplicada a escola como um todo, onde cada curso/disciplina, os alunos dividem o tempo entre aulas presenciais na escola e a aprendizagem usando a entrega de conteúdo e instrução online. Esse modelo difere da sala de aula invertida, que será descrita a seguir, pois o aluno vai a escola presencialmente com menor frequência (STAKER; HORN, 2012).

O modelo de rotação é um programa onde em um curso ou conteúdo os alunos rotacionam a cada período de tempo ou de acordo com a decisão do professor entre 
modalidades onde pelo menos uma delas é realizada de forma online. As outras modalidades podem incluir aulas presenciais para pequenos grupos ou a sala de aula toda, projetos em grupo, tutoria individualizada e lições escritas (STAKER; HORN, 2012).

Cada implementação do modelo de rotação define o tamanho da turma, a frequência e o como a mesma é rotacionada. Na Rotação de Estação, em uma mesma sala de aula física, os alunos alternam entre modalidades pedagógicas a cada intervalo de tempo ou pela decisão do professor, e em pelo menos uma destas modalidades é incluído o uso de uma estação em sala de aula para aprendizagem online (STAKER; HORN, 2012).

A Rotação de Laboratório é um programa que o rotacionamento entre modalidades acontece a cada período de tempo ou pela decisão do professor, porém a turma toda troca de ambiente dentro da instituição de ensino, e em um destes o aluno receberá lições por meio online (STAKER; HORN, 2012). Já a Rotação Individual é uma outra forma de implementar o modelo de rotação. Nesta implementação os alunos rotacionam entre modalidades de forma individualizada baseada em uma agenda fixa, sendo que pelo menos uma destas modalidades é realizada de forma online (STAKER; HORN, 2012).

A Sala de Aula Invertida (flipped-classroom) é uma implementação onde os alunos alternam entre aulas presenciais na instituição de ensino e lições online com conteúdos teóricos assistidas em casa. As lições online formam a maneira primária do estudo de conceitos, sendo que posteriormente, estes são aplicados em sala de aula em projetos e atividades em grupo (STAKER; HORN, 2012). Uma das vantagens desta implementação está no melhor aproveitamento do tempo de aula. Os professores criam ou são curadores de conteúdos como vídeos, gravações de tela, gravações de áudios e textos, que os alunos estudam fora da sala de aula através de distribuição por meios digitais e online, e este estudo extraclasse respeita a individualidade de cada aluno, que pode determinar o ritmo e ordem do aprendizado. Já o valioso tempo em sala de aula física é utilizado para outras atividades mais envolventes, como projetos práticos, discussões e trabalhos em grupo (MILMAN, 2012).

Além da vantagem citada anteriormente, a Sala de Aula Invertida permite os professores atuarem mais próximos dos alunos em sala de aula, aumentar e melhorar as atitudes dos alunos e melhorar a habilidade dos alunos em resolver problemas (FULTON, 2012).

Pelo ponto de vista dos alunos, a aprendizagem no próprio ritmo e tempo é uma grande vantagem. Além do baixo nível de frustração e o favorecimento de alunos com 
diferentes estilos de aprendizagem, já que os alunos podem rever as aulas gravadas assistidas online e não precisam necessariamente aprender ouvindo/assistindo pela primeira vez como no ensino tradicional (FULTON, 2012).

As vantagens da Sala de Aula Invertida também pode tornar-se em alguns desvantagens. Como já descrito anteriormente, os alunos nesta modalidade podem aprender em seu próprio ritmo, porém esta atividade requer do aluno muita motivação (DU; FU; WANG, 2014). Além disso há outros desafios a serem superados como a avaliação da classe e manter todos os alunos em um mesmo assunto pode ser desafiador (DU; FU; WANG, 2014). 


\section{Metodologia}

Este capítulo apresenta a metodologia utilizada para a realização deste trabalho desde sua concepção à análise dos dados oriundos do experimento em sala de aula, com exceção da metodologia de desenvolvimento que será descrita com mais detalhes no Capítulo 6.

Este trabalho teve início com a exploração do tema informática na educação, devido ao interesse do autor e seu orientador pela área. Nesse contexto, foi realizada uma revisão exploratória da literatura. Durante a revisão foi possível elaborar questões de pesquisa relacionadas à informática na educação, e identificar possíveis contribuições. Durante esta atividade foi também projetado e desenvolvido a ferramenta computacional JustReview (FARIA; BERNARDES JUNIOR, 2014) que tem como objetivo auxiliar a atividade de revisão da literatura.

Para reforçar o conhecimento e contato com a área de informática na educação foi cursada a disciplina MAC5857 - Desenvolvimento de Sistemas Web para Apoio ao Ensino/Aprendizagem no Instituto de Matemática e Estatística (IME) da Universidade de São Paulo (USP), onde foi possível conhecer o professor Dr. Leônidas Brandão e também participar do LInE, onde o mesmo é o coordenador.

No grupo de pesquisas foram desenvolvidas provas de conceito de objetos de aprendizagem que foram utilizados em disciplinas relacionadas a matemática e que contribuíram muito para algumas decisões técnicas tomadas neste trabalho, como a escolha da tecnologia. No LInE foi realizado um experimento que permitiu comparar o ensino de programação a partir de uma abordagem visual e textual, e também comparar algumas alternativas de tecnologias. Na Seção 3.1 é mostrado como foi realizado o experimento e quais tipos de levantamentos foram relevantes a este trabalho.

Durante este trabalho também foi levantado por meio de uma pesquisa o perfil e opiniões de alunos e professores, que constituem o público alvo do trabalho. Na Seção 3.2 é descrito com mais detalhes como foi realizada esta pesquisa.

Neste trabalho também foi realizado um experimento em sala de aula para avaliar o uso do sistema dentro do contexto para qual foi desenvolvido. Este experimento com usuários finais é descrito com mais detalhes na Seção 3.3.

A Imagem 1 ilustra graficamente como foi a realização deste trabalho. É importante observar as atividades que foram realizadas em paralelo, como a participação no grupo de 
pesquisas LInE, a revisão da literatura e a pesquisa com alunos e professores do ensino médio e superior.

Figura 1 - Metodologia utiliza para a realização do trabalho

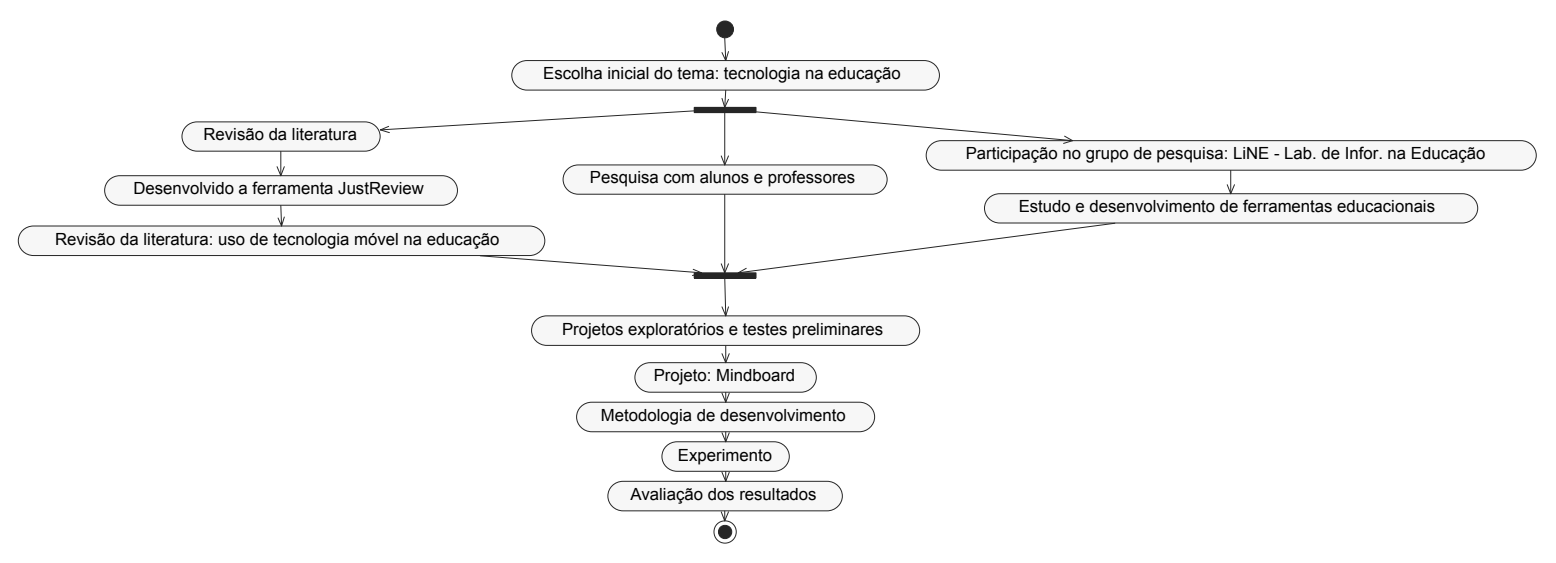

Fonte: Tulio Faria, 2015

\subsection{Experimento no LInE}

No grupo de pesquisa LInE, um dos trabalhos desenvolvidos foi um módulo de programação visual denominado IVProg, módulo este que faz parte da família de objetos interativos de aprendizagem do grupo de pesquisas.

O objetivo principal do IVProg é reduzir os problemas do início da aprendizagem de lógica de programação, onde problemas em decorrência de erros de sintaxe ou de configuração de ambientes de programação podem influenciar negativamente e desmotivar os alunos.

Para comparar os efeitos da abordagem de programação visual em relação a programação textual foi realizado um experimento que inferiu a carga de trabalho feito pelos alunos.

O experimento foi composto de um curso de Introdução à Programação desenvolvido no LInE sendo conduzido totalmente online e seus resultados podem ser encontrados em Ribeiro et al. (2014).

No contexto desta dissertação será avaliado o objetivo secundário do experimento, onde foram levantados indícios confrontando as ferramentas desenvolvidas em tecnologias diferentes. Esta análise é importante para verificar a influência da tecnologia no processo de aprendizagem. 
As inscrições para o curso eram livres, não havendo restrição documental nem mesmo por filiação a uma dada instituição. A divulgação aconteceu durante um pequeno intervalo de tempo (4 semanas). Algumas divulgações extras dos membros do grupo de pesquisa renderam mais inscrições de algumas unidades da USP, UNIP e também de escolas estaduais paulistas de ensino técnico.

Os principais meios de divulgação foram: apresentação oral de curta duração aos calouros que estavam matriculados em disciplinas de programação, cartazes afixados em algumas unidades da USP e redes sociais. As inscrições aconteceram online, bastando apenas ter um e-mail válido para poder finalizá-la.

Os inscritos foram divididos em 3 turmas: T1, T2 e T3. A primeira turma utilizava a ferramenta VPL, desenvolvida em Java Applet que permite a execução de códigos-fonte diretamente no servidor, sem necessitar que o aluno tenha um ambiente de desenvolvimento instalado. As turmas T2 e T3 utilizavam a ferramenta IVProg desenvolvida pelo LInE. A ferramenta IVProg permite a construção e execução de algoritmos de forma totalmente visual, reduzindo problemas dos alunos em relação a sintaxe. A turma T2 utilizou uma versão da ferramenta desenvolvida em Java Applet, já a turma T3 utilizou uma versão em HTML5 com funcionalidades idênticas à desenvolvida em Java Applet.

As turmas foram divididas seguindo um critério de balanceamento. Assim, cada turma teve o mesmo número de participantes com e sem experiência em programação e que estudavam na USP ou em outras instituições.

Foram analisados os dados de acesso $(l o g)$ de cada módulo de aprendizagem utilizado durante o experimento. Na análise, é possível descobrir quantas vezes cada módulo foi utilizado e visualizado, e como todos as turmas tem o mesmo tamanho e possuem perfis balanceados, estes dados poderão fornecer indícios a respeito das tecnologias de cada ambiente.

Além da análise dos dados de acesso foi realizada uma pesquisa ao final do experimento, onde foi enviado um e-mail a todos os inscritos para saber se tiveram acesso ao curso, algum problema e para que dessem suas opiniões. Os resultados dessa pesquisa relevantes a este trabalho são discutidos na Seção 6.5.1. 


\subsection{Pesquisa com alunos e professores}

A pesquisa com alunos e professores do ensino médio, superior e pós-graduação teve como objetivo obter informações de como os mesmos utilizam tecnologia dentro e fora de sala de aula, e também, avaliar a suas opiniões sobre a relevância de determinadas funcionalidades em um sistema integrado e multiplataforma com suporte a dispositivos móveis que poderia ser utilizado no processo de ensino e aprendizagem.

A obtenção dos dados da pesquisa com professores foi realizada durante 14 de Maio e 15 de Julho de 2013 e a pesquisa com alunos foi realizada no período de 13 de Novembro e 01 de Dezembro de 2014. Ambas as pesquisas foram realizadas por meio da ferramenta Google Forms ${ }^{1}$. A ferramenta permitiu que usuários visualizassem e respondessem ao questionário através da internet.

Durante cada período os formulários foram divulgados por meio de redes sociais dos autores deste trabalho, em grupos de discussão da área (Educação Sem Distância e Recursos Educacionais Abertos, que possuem um grande número de professores que responderam ou ajudaram a divulgar a seus alunos), em listas de e-mails de universidades e através de convites diretos. Esta divulgação resultou em 81 respostas de professores e 125 respostas de alunos, sendo que os resultados obtidos serão analisados no Capítulo 5.

O formulário preenchido pelos professores foi constituído de 37 questões e por 31 questões para os alunos. Em ambos os formulários haviam questões para o levantamento do perfil, sobre uso de tecnologia no cotidiano e em sala de aula e também relativas às funcionalidades presentes em um futuro sistema. O formulário permitia opcionalmente o preenchimento do campo nome e e-mail, caso fosse desejado receber os resultados da pesquisa. O questionário completo enviado aos professores pode ser visto no Apêndice A e o enviado aos alunos no Apêndice B.

No início dos formulários era comunicado sobre a finalidade da pesquisa, e garantia que todos estavam respondendo por livre e espontânea vontade e que poderiam abandonar o preenchimento a qualquer momento e por qualquer motivo, não havendo nenhuma obrigatoriedade em finalizar o mesmo.

Esta pesquisa possui um risco à sua validade devido ao fato que professores que não façam uso de internet não tiveram suas opiniões coletadas. O impacto deste risco é

1 http://docs.google.com 
reduzido por serem justamente os usuários pesquisados os potenciais usuários iniciais do sistema a ser desenvolvido.

\subsection{Experimento em sala de aula}

O experimento teve como principal objetivo avaliar o sistema Mindboard no contexto para o qual o mesmo foi concebido, assim, foi lecionado um curso de verão pelo autor deste trabalho para a utilização do sistema em sala de aula. O curso MEAN Stack na Prática foi realizado presencialmente no Instituto de Pesquisa e Tecnologia Computacional (INPETTECC) em Pouso Alegre, MG. O experimento foi aprovado pelo comitê de ética da EACH-USP e registrado na Plataforma Brasil ${ }^{2}$ com o número do Certificado de Apresentação para Apreciação Ética (CAAE) 39888114.0.0000.5390. No Apêndice C encontra-se o projeto submetido ao comitê de ética e no Apêndice E o parecer.

O curso foi lecionado em duas turmas distintas. O grupo de controle Turma 1 não fazia o uso do sistema Mindboard e o grupo experimental Turma 2 que fazia.

As inscrições para o curso foram realizadas pela internet por meio da divulgação em grupos de discussão de tecnologia do sul de Minas Gerais. O curso não teve fins lucrativos, foi cobrado apenas o suficiente para cobrir os custos com o café servido no intervalo do curso. As inscrições foram recebidas pelo sistema Eventioz ${ }^{3}$, o sistema gerenciou as inscrições para cada turma e fez o recebimento da contribuição para o café.

O curso foi realizado para a Turma 1 entre os dias 12 e 15 de Janeiro de 2015 e para a Turma 2 entre os dias 19 e 22 de Janeiro de 2015, ambos no período noturno. As aulas aconteceram no Laboratório de Informática I do INPETTECC (localizado a Av. Getulio Vargas, 138, Terceiro Andar, na cidade de Pouso Alegre/MG), e os alunos levaram seus próprios computadores para o curso, utilizando apenas a internet sem fio da instituição.

A Figura 2 mostra a configuração do laboratório para todas as turmas, onde é possível perceber que todos os alunos, apesar da disponibilidade do laboratório da instituição, trouxeram seus próprios computadores.

Todas as aulas foram gravadas em vídeo para avaliação de colaboração entre os alunos e entre os alunos e o professor. A Figura 3 mostra o projetor juntamente com a webcam utilizada para a gravação de todas as aulas presenciais. As gravações

2 Plataforma criada pelo Governo Federal para sistematizar o recebimento de pesquisas científicas que envolvam seres humanos. Disponível em: http://http://aplicacao.saude.gov.br/plataformabrasil/

3

http://www.eventioz.com.br 
Figura 2 - Laboratório 1 do INPETTECC, onde o curso foi lecionado.

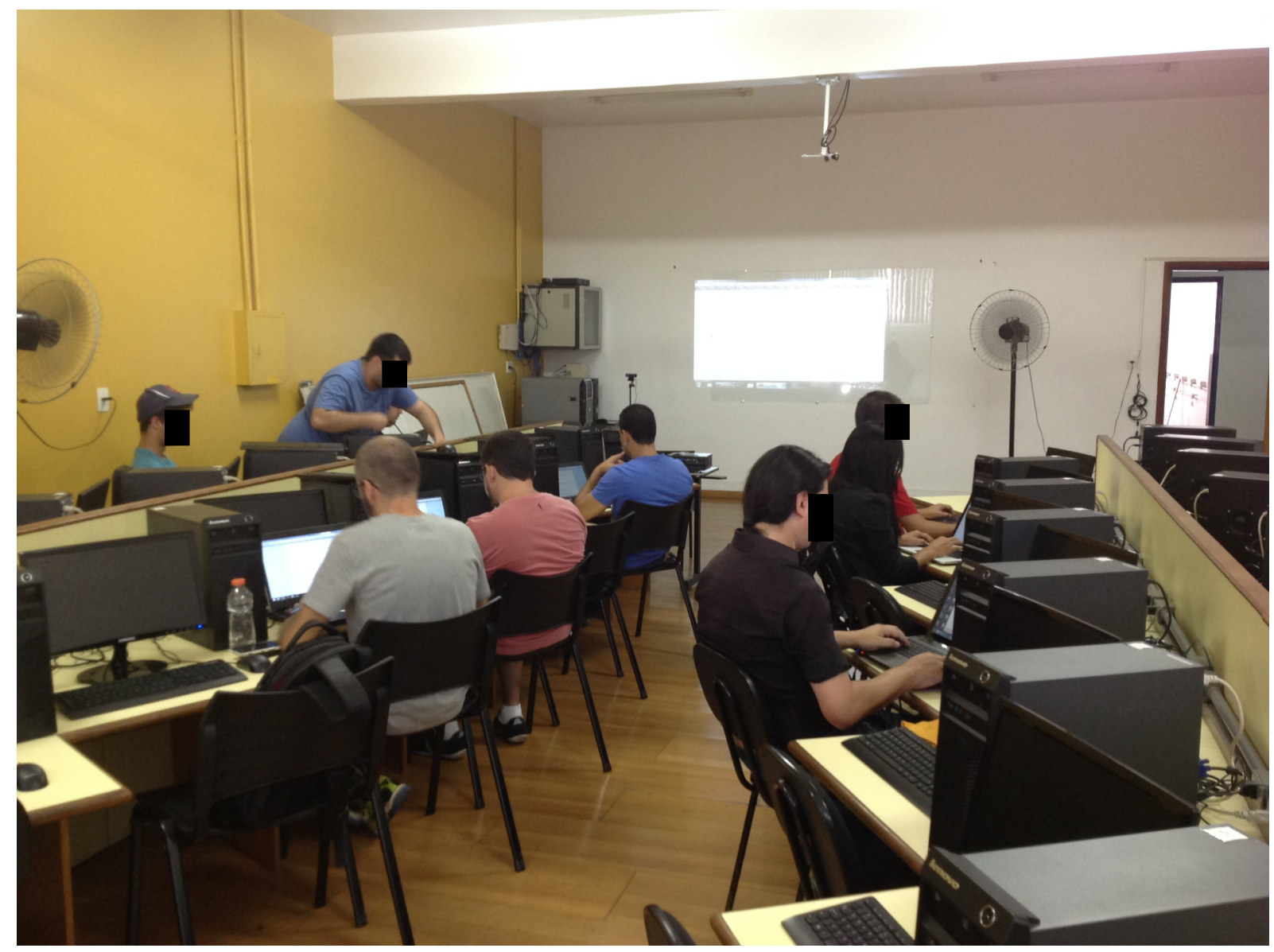

Fonte: Tulio Faria, 2015

foram realizadas utilizando a webcam Logitech C920 posicionada a frente do projetor e direcionada para os alunos, e as gravações foram feitas em qualidade HD ${ }^{4}$. As imagens eram armazenadas diretamente no disco rígido do computador em que a webcam estava conectada.

No início do curso foi apresentado o Termo de Consentimento Livre-Esclarecido, o qual dispunha todas as informações relevantes a pesquisa, seus riscos e como a possibilidade destes riscos ocorrerem eram reduzidos. Os termos foram preenchidos e assinados na primeira aula. No Apêndice D encontra-se o conteúdo completo do termo que foi assinado pelos alunos.

$\overline{4}$ Qualidade equivalente a 1220 por $720 \mathrm{px}$. 
Figura 3 - Imagem destacando a posição da câmera e do computador utilizados para gravação das aulas.

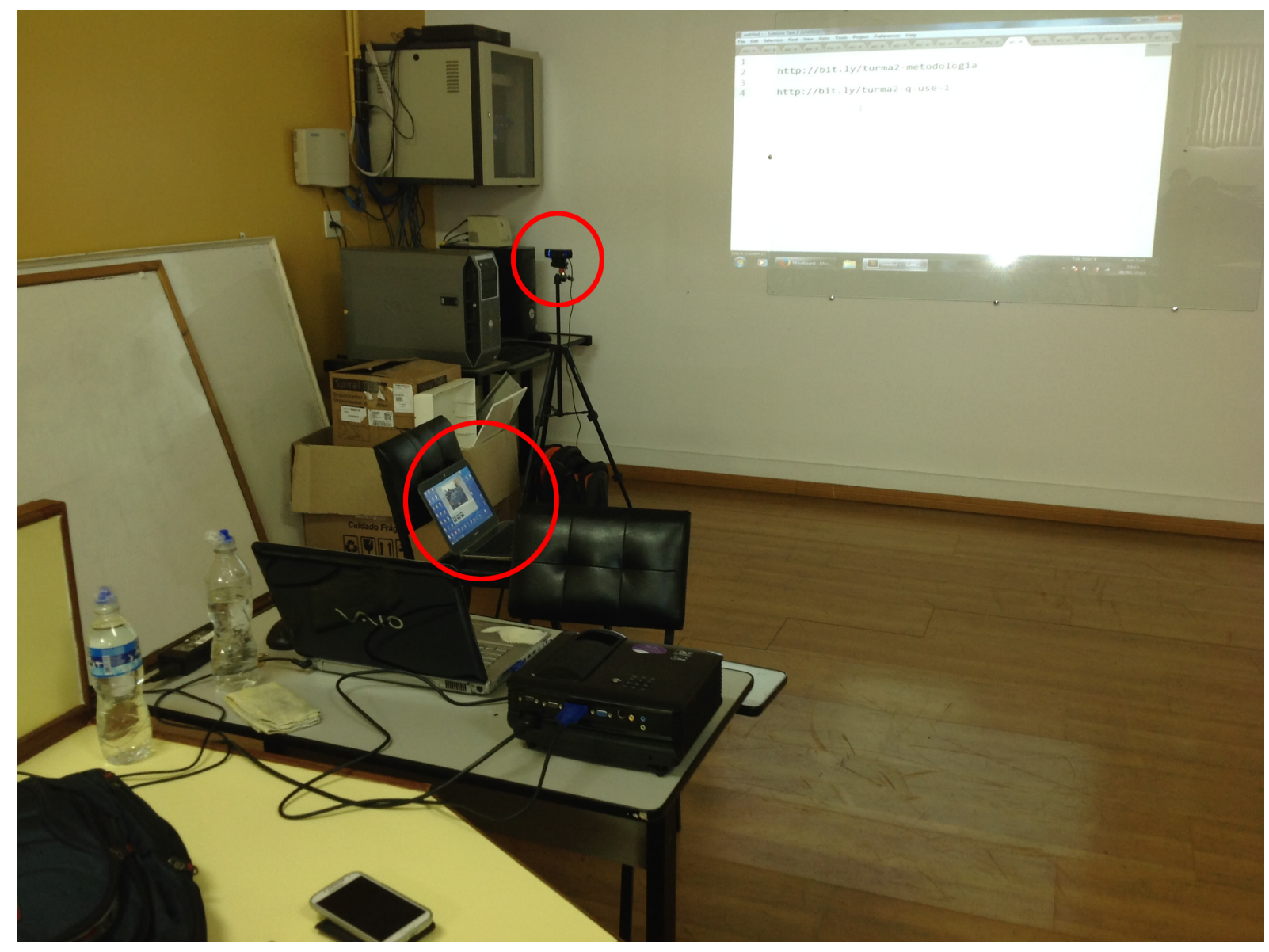

Fonte: Tulio Faria, 2015

\subsubsection{As aulas}

As aulas do curso foram realizadas por meio da explicação conceitual de cada tópico, e posteriormente era realizado um pequeno projeto prático utilizando-o. Os tópicos de aula seguiram a seguinte estrutura e ordem para ambas as turmas:

Dia 01 - Sobre MEAN: os alunos foram introduzidos ao conceito de $M E A N$ stack, onde foi explanado o significado de cada camada bem como cada uma de suas vantagens. A aula foi finalizada através da criação de um projeto inicial básico utilizando o controlador de dependências Node Package Manager (NPM).

Dia 01 - Organização em módulos: neste tópico os alunos foram apresentados ao conceito de organização de código no JavaScript por meio de módulos. Assim foi exemplificado como criar e importar seus módulos além de como importar módulos de terceiros. Além disso, foi criado dois exemplos de servidores web, um utilizando apenas os módulos padrão do NodeJS e um utilizando o módulo ExpressJS. 
Dia 02 - Conceito de closures: nesta aula realizada remotamente, foi introduzido o conceito de closures e a vantagem de sua utilização em JavaScript. Além disso foi criado 3 exemplos, um utilizando setInterval (função timer em JavaScript), um exemplo simulando o conceito de encapsulamento em orientação a objetos porém em JavaScript e o terceiro exemplo de closure com jQuery.

Dia 02 - Módulos: nesta aula remotamente, foi apresentado mais a fundo a questão de módulos em JavaScript. Os exemplos incluiram as várias formas de iniciar um módulo, como injetar dependências em módulos e como trabalhar a visibilidade de variáveis e funções em módulos.

Dia 02 - Controle de fluxo: nesta aula gravada, o objetivo principal era introduzir como controlar o fluxo de chamadas assíncronas. Assim, foi apresentado o conceito de promises e foi realizado alguns exemplos utilizando o módulo q, que facilita a criação de promises em JavaScript.

Dia 03 - Ligando o front-end e o back-end: esta aula foi uma aula mais densa do curso, pois foi posto em prática os conceitos aprendidos nas aulas anteriores e nas aulas feitas de forma remota. Esta aula prática foi criado uma aplicação simples utilizando AngularJS no front-end e criados os controllers e models no NodeJS. Ao final da aula, os alunos tinham um exemplo de como inserir, retornar, alterar e excluir dados armazenados no MongoDB.

\subsubsection{Colaborações}

Durante o curso, todas as aulas foram gravadas para que fosse possível contabilizar as interações ocorridas em ambas as turmas. Era contabilizado uma interação toda vez que um aluno interagia com outro e quando interagiam com o professor.

A interação era considerada finalizada quando todos os envolvidos interrompiam sua comunicação por 2 segundos. Em algumas situações um participante começava a interagir com o professor, e outro inicia a interação em conjunto poucos segundos depois. Enquanto estes dois participantes não parassem de interagir por 2 segundos, não era contabilizada uma nova interação.

No Mindboard foram contabilizadas as interações por meio da geração de logs de uso das funcionalidades Retorno sobre a aula, anotação sobre o material e comentário sobre a anotação. 


\subsubsection{Avaliação do sistema Mindboard utilizada em conjunto com a metodologia sala de aula invertida}

Para avaliar o uso do sistema Mindboard nos contextos para os quais o mesmo foi desenvolvido, o sistema deveria ser utilizado dentro de sala de aula e também deveria haver uma motivação para que os alunos o fizessem no horário extraclasse.

Conforme já descrito na Seção 3.3.3, as ferramentas computacionais impulsionaram e potencializaram a utilização de metodologias inovadoras na educação, como o ensino híbrido e sua implementação da sala de aula invertida. Nesta metodologia o aluno tem lições de conceitos fora da sala de aula de forma online e em salas de aula convencionais praticam estes conceitos em aulas mais dinâmicas e colaborativas. O conteúdo do curso lecionado durante o experimento envolve programação de projetos práticos que fazem uso de conceitos da linguagem Javascript.

Assim, para que fosse possível a utilização da sala de aula invertida, o curso foi projetado para possuir uma duração de 4 dias de aulas, porém o segundo dia era realizado totalmente online. Essa aula extraclasse foi planejada desta forma, por o curso ter sido realizado no período noturno, com a grande maioria dos participantes trabalhando em período integral, o que impossibilitaria a realização de seus estudos no horário comercial.

O conteúdo das aulas foram gravadas em 3 vídeos conceituais. Essas aulas foram distribuídas pelo YouTube, onde os links eram diretamente enviados aos alunos da Turma 1, e foram incorporados do próprio YouTube no Mindboard para a Turma 2.

Nas aulas seguintes ao estudo destes conceitos, os mesmos eram utilizados durante a realização de um projeto prático.

Ao final desta aula, foi enviado um questionário aos alunos para saber a opinião deles sobre a forma que o curso foi conduzido e se ela poderia aumentar o aproveitamento em um curso de programação. Para a Turma 1 foi questionado se seria interessante possuir um sistema além do YouTube para a visualização das aulas, e para a Turma 2 foi questionado se as funcionalidades presentes no Mindboard para este tipo de metodologia eram suficientes e se havia alguma sugestão.

O questionário aplicado a Turma 1 encontra-se no Apêndice F, já o aplicado a Turma 2 encontra-se no Apêndice G. 


\subsubsection{Avaliação de usabilidade: questionário USE}

A avaliação de usabilidade pode ser realizada de diversas maneiras como por meio de entrevistas, análises de uso e também através do preenchimento de questionários. Para simplificar o processo de coleta de dados durante o experimento prático, a avaliação de usabilidade do sistema Mindboard foi escolhido ser feito por meio de questionários. Além disso o questionário inferir de maneira objetiva os níveis de satisfação e facilidade de uso da ferramenta.

No processo de avaliação de usabilidade de ferramentas e sistemas computacionais há alguns questionários padrões que podem ser utilizados para essa atividade. A seguir, serão descritos sucintamente alguns deles.

O questionário Questionnarie for User Interaction Satisfaction (QUIS) é uma ferramenta criada por um time multidisciplinar do laboratório de interação humanocomputador da Universidade de Maryland (NORMAN; SHNEIDERMAN; HARPER, 1987), não foi utilizada neste trabalho por sua licença comercial.

O questionário Computer System Usability Questionnaire (CSUQ) foi projetado por Jim Lewis e sua licença é de domínio público. Possui uma grande confiabilidade mas não possui uma padronização (LEWIS, 1995). Este questionário não foi utilizado pois comparado ao questionário a seguir não resulta em um nível específico de satisfação e facilidade de uso.

O questionário Usefulness, Satisfaction and Ease of use (USE), criado por Arnie Lund, tem como objetivo avaliar e sintetizar a usabilidade de uma interface através de um modelo com três fatores: utilidade, satisfação e facilidade de uso (LUND, 2001). O questionário USE foi escolhido para os testes de usabilidade do Mindboard apesar de não possuir dados nem referências sobre suas avaliações. O fato do mesmo gerar os três fatores sintetizados e por ser de domínio público também favoreceram sua escolha.

O questionário USE foi aplicado no último dia de curso a Turma 2 utilizando o Google Forms. O questionário utiliza 27 questões com escala de sete pontos de Likert, onde o usuário responde questões dividas em 3 grupos: Utilidade, Satisfação e Facilidade de uso. Em cada uma destas questões há também um campo de texto livre onde pode-se realizar algum comentário. No fim do questionário é solicitado ao participante 3 pontos positivos e 3 pontos negativos que ele tenha encontrado no sistema. O Apêndice $\mathrm{H}$ mostra este questionário disponibilizado para preenchimento aos participantes da Turma 2. 


\subsubsection{Avaliação da ferramenta e levantamentos de interações e cola- borações extraclasse}

Ao fim do curso, em ambas as turmas foi realizado mais um questionário. Nele os participantes eram questionados se os mesmos haviam interagido com outros alunos durante o curso e por meio de qual mecanismo. Além disso, para a Turma 1 foi questionado a opinião dos alunos sobre um sistema com as funcionalidades semelhantes a do Mindboard ajudariam o curso a ser mais produtivo. Um exemplo de questionamento foi: Você acha que se visualizasse o código-fonte do professor na sua própria máquina, em tempo real, seria mais fácil acompanhar os passos da aula?. A Turma 2, além dos questionamentos sobre interações informais, que poderiam ter ocorrido extraclasse, foi questionada sobre as funcionalidades do sistema Mindboard, investigando se cada uma delas contribuíram na opinião do participante, para um melhor aproveitamento do curso.

O Apêndice I mostra o formulário utilizado para a Turma 1 e o Apêndice J o utilizado na Turma 2. 


\section{Revisão da Bibliografia}

Este capítulo descreve o trabalho de revisão da bibliografia realizado. Foram realizadas duas revisões exploratórias: uma exploratória livre e uma seguindo recomendações de Kitchenham (2004) porém com menos rigidez, ambas com o objetivo principal de estabelecer um conjunto de funcionalidades presentes em sistemas utilizadas em sala de aula no ensino médio e superior tanto em sala de aula quanto fora dela. São levantadas também informações sobre como é realizado seu uso através de dispositivos móveis. Além disso, foram pesquisadas também ferramentas comerciais que podem ser utilizadas com esses objetivos.

Assim, estas funcionalidades servem de base para a definição de um conjunto de funcionalidades que poderiam ser utilizadas em um único sistema integrado e também contribuiram para a definição dos requisitos funcionais do protótipo desenvolvido neste trabalho.

\subsection{Revisões relacionadas}

Há revisões sistemáticas publicadas que possuem objetivos bem próximos aos aqui almejados, porém extraindo informações diferentes da proposta por este.

Em Barbosa (2012) é realizada uma revisão sistemática da literatura com o objetivo de investigar e estabelecer um conjunto de características e requisitos para o domínio de sistemas computacionais de aprendizagem móveis, focando principalmente nas características e requisitos não funcionais.

No trabalho são descritos pontos relevantes a serem considerados em projetos de sistemas computacionais de aprendizagem convencionais e com suporte a dispositivos móveis. Segundo ainda o autor, um projeto de sistema deve atender aos requisitos básicos educacionais/pedagógicos, garantir um nível de serviço, segurança e desempenho mínimo, atentando-se também a usabilidade do mesmo.

A revisão realizada neste trabalho difere do exposto por Barbosa (2012) por levantar características e funcionalidades de sistemas convencionais que podem de alguma forma ou não possuírem suporte a dispositivos móveis, e também por almejar levantar as funcionalidades dos mesmos, não focando principalmente em requisitos não funcionais. 


\subsection{Metodologia}

Existem muitos motivos para se fazer uma revisão, dentre eles: conhecer de forma abrangente um determinado assunto, identificar possíveis oportunidades para futuras pesquisas ou ainda para ser utilizada como base a atividades de pesquisa (KITCHENHAM, 2004).

O planejamento desta revisão foi realizada segundo (KITCHENHAM, 2004), onde aconselha-se a definição das perguntas de pesquisa como a primeira tarefa após a definição do objetivo principal. As perguntas de pesquisa definidas para este trabalho estão descritas na Tabela 1.

Tabela 1 - Perguntas de pesquisa definidas para a revisão sistemática

Pergunta 1: Quais sistemas computacionais são utilizados em aula, online e/ou extra-classe?

Pergunta 2: Quais destes sistemas são multiplataforma, incluindo sistemas móveis?

Pergunta 3: Quais destes sistemas permitem interação em tempo-real?

Pergunta 4: Quais destes sistemas quantos permitem retorno/feedback do aluno em tempo-real?

Pergunta 5: Quais destes sistemas permitem ao aluno rever a aula posteriormente?

Pergunta 6: Se utilizado em sala de aula, quais os resultados obtidos baseados em métricas como desempenho acadêmico, motivação?

Fonte: Tulio Faria, 2015

Após a definição das perguntas de pesquisa, foi planejado uma estratégia de busca. Nesta atividade foram escolhidas quais bases de dados seriam utilizadas como fonte de artigos e quais seriam os critérios para incluir ou não um artigo de acordo com sua relevância ao objetivo da pesquisa. Assim sendo, foram escolhidas como fontes de artigos as seguintes bases: IEEE Xplore, ACM Digital Library e Revista Brasileira de Informática na Educação (RBIE).

Definidas as fontes onde seriam realizadas as buscas, a próxima etapa foi estabelecer como as buscas seriam realizadas através da construção de strings de busca. A Tabela 2 mostra as bases e suas respectivas strings. Como as strings de busca não foram padronizadas entre as fontes, para aumentar o número de artigos retornados, está revisão é considerada exploratória e não sistemática. 
Tabela 2 - Strings de busca utilizadas em cada base

\begin{tabular}{|l|l|}
\hline Base & String de busca \\
\hline IEEE Xplore & $\begin{array}{l}\text { ((teach OR learn OR education) AND ("computer as- } \\
\text { sisted"OR "computer aided"OR "computer supported") } \\
\text { AND mobile AND (web OR internet)) }\end{array}$ \\
\hline ACM & $\begin{array}{l}\text { (teach or learn or education) and ("computer assisted"or } \\
\text { "computer aided"or "computer supported") }\end{array}$ \\
\hline RBIE & colaboração \\
\hline RBIE & móvel \\
\hline
\end{tabular}

Fonte: Tulio Faria, 2015

As strings de busca foram construídas levando em consideração o tipo de base em que a busca seria feita. Por exemplo, a string conter termos informática e educação na RBIE não se fez explicitamente necessário, por a mesma tratar-se de uma revista específica sobre este assunto.

Na etapa subsequente, foram estabelecidos os critérios de inclusão e exclusão, os quais auxiliam na classificação de um artigo como relevante ou não a pesquisa. A Tabela 3 e 4 mostram os critérios de inclusão e de exclusão, respectivamente.

Tabela 3 - Critérios de inclusão

Publicados e disponíveis integralmente em bases de dados científicas

Trabalhos que utilizam tecnologia em educação, especificamente com utilização de tecnologias móveis

Fonte: Tulio Faria, 2015

Tabela 4 - Critérios de exclusão

Trabalhos que não são relacionados com tecnologia na educação.

Trabalhos como laboratórios virtuais ou ferramentas semelhantes voltadas a auxiliar o aprendizado de um único conteúdo ou conjunto de conteúdo específicos

Trabalhos que não são aplicados ao ensino médio e superior

Trabalhos que são estudos secundários

Fonte: Tulio Faria, 2015

Para a realização das buscas nas bases científicas, bem como gerenciar o processo de classificação dos artigos de acordo com os critérios de inclusão e exclusão, foi desenvolvido a ferramenta JustReview (FARIA; BERNARDES JUNIOR, 2014). A ferramenta salva os 
resultados obtidos através das buscas às bases de dados, e permite também uma forma eficiente de classificar os artigos confrontando o abstract com os critérios de inclusão e exclusão. Após realizado a primeira classificação dos artigos através do abstract, a ferramenta baixa as versões completas dos artigos classificados como relevantes para leitura.

A revisão exploratória buscou ainda ferramentas de mercado que geralmente não geraram publicações científicas, e portanto, não foram possíveis de serem analisadas na revisão em bases científicas. Foram buscadas ferramentas que podem ser utilizadas em sala de aula e no ensino a distância, e foi feita também a análise quando ao uso em plataforma móveis.

\subsection{Resultados e discussão}

A partir das buscas realizadas, foram retornados 751 artigos das 3 bases de dados utilizadas. Destes artigos, através da leitura dos abstracts e depois de aplicado os critérios de inclusão e exclusão, foram selecionados 80 artigos para leitura completa. Após a leitura completa, 42 artigos foram selecionados para a extração das informações referentes a esta revisão, onde os resultados são apresentados a seguir. Foram encontrados também 12 ferramentas comerciais que também foram selecionados baseados nos critérios de inclusão e exclusão.

\subsection{Funcionalidades presentes em sistemas de aprendizagem}

As funcionalidades presentes em sistemas de aprendizagem extraídas dos artigos lidos são listadas, descritas e analisadas a seguir. Relatos sobre a expansão de uma determinada funcionalidade, ou algum uso ainda mais específico, também é analisado. Ao final da descrição de cada funcionalidade são sumarizados os artigos que descrevem sistemas que possuem essa funcionalidade.

Quiz: permite que os alunos respondam a uma ou mais questões fechadas (TOKIWA; NONOBE; IWATSUKI, 2009; IJTIHADIE et al., 2010; SCHMIEDL; GRECHENIG; SCHMIEDL, 2010; COVIC; CINGER; IVKOVIC, 2010; SCHON; KOPF; EFFELSBERG, 2012), e o professor monitore as respostas das mesmas, gerando visualizações gráficas. O Clicker é uma aplicação especial de Quiz onde geralmente as respostas são enviadas através de hardwares específicos 
(TOKIWA; NONOBE; IWATSUKI, 2009). O Quiz pode ser utilizado também para aumentar a motivação em cursos presenciais e a distância, principalmente pela sua simplicidade e rapidez em ser aplicado (TOKIWA; NONOBE; IWATSUKI, 2009). Funcionalidade presente em:

- AuReS (JAGAR; PETROVIC; PALE, 2012)

- A Lightweight Mobile Quiz Application with Support for Multimedia Content (SCHON; KOPF; EFFELSBERG, 2012)

- Conducting Classroom Discussions in the Manner of an Orchestra Using a Mobile Phone Based Response Analyzing System (NAKAI; NAGAOKA, 2007)

- An Integrated e-Learning Platform for Use in Higher Education (FLOREA; FRUNZETE; STEFANESCU, 2011)

- Development of a system for mobile learning (COVIC; CINGER; IVKOVIC, 2010)

- Instructional m-Learning System Design Based on Learners: MprinceTool (FARDOUN et al., 2010)

- Offline web application and quiz synchronization for e-learning activity for mobile browser (IJTIHADIE et al., 2010)

- Web-based tools to sustain the motivation of students in distance education (TOKIWA; NONOBE; IWATSUKI, 2009)

- Implementing a Mobile Campus Using MLE Moodle (XHAFA et al., 2010) e Mobile enabling of virtual teams in school: an observational study on smart phone application in secondary education (SCHMIEDL; GRECHENIG; SCHMIEDL, 2010)

Presente também nos sistemas comerciais:

- TopHat (2014)

- PollEverywhere (2014)

- $\operatorname{SMSPoll~(2014)}$

- ClickerSchool (2014)

- Shakespeak (2014)

- Socrative (2014)

Anotações: permite que os alunos editem, salvem e compartilhem suas anotações de aula com outros alunos e professores (SINGH; DENOUE; DAS, 2004; RAWAT; RIDDICK; MOORE, 2008; GRIFFIOEN; SEALES; JR, 1998). Utilizado em sistemas para o ensino a distância (SINGH; DENOUE; DAS, 2004; RAWAT; RIDDICK; MOORE, 2008) e em presenciais (GRIFFIOEN; SEALES; JR, 1998). Funcionalidade presente em: 
- A Mobile Lecture Slide Organization Tool for Students (CHOW et al., 2006)

- Collaborative Note Taking (SINGH; DENOUE; DAS, 2004)

- How ECM can be used for distance learning content management ECM to LCM (DAOUDI, 2012)

- KLeOS: A personal, mobile, knowledge and learning organisation system (VAVOULA; SHARPLES, 2002)

- Work in progress-integrating mobile Tablet-PC technology and Classroom Management Software in undergraduate electronic engineering technology courses (RAWAT; RIDDICK; MOORE, 2008)

- Supporting Online Coordination of Learning Teams through Mobile Devices (ROIGTORRES; XHAFA; CABALLE, 2012) Teaching in realtime wireless classrooms (GRIFFIOEN; SEALES; JR, 1998).

Apresentação de slides: apresentações de slides são muito utilizados em sala de aula, e quando disponíveis em sistemas de aprendizagem computacionais estão relacionadas principalmente em disponibilizá-las de forma organizada aos alunos (CHOW et al., 2006) e permitir o compartilhamento de anotações sobre os slides entre alunos e entre alunos e professores em tempo-real (SINGH; DENOUE; DAS, 2004; GRIFFIOEN; SEALES; JR, 1998; RAWAT; RIDDICK; MOORE, 2008). É uma funcionalidade utilizada tanto em sala de aula quanto no ensino a distância. Esta presente ferramenta comercial: Shakespeak (2014) e também nos seguintes artigos:

- A Lightweight Mobile Quiz Application with Support for Multimedia Content (SCHON; KOPF; EFFELSBERG, 2012)

- A Mobile Lecture Slide Organization Tool for Students (CHOW et al., 2006)

- How ECM can be used for distance learning content management ECM to LCM (DAOUDI, 2012)

- A smil-based multimedia system for mobile education (DI et al., 2009)

- Distance-Learning and Converging Mobile Devices (HoGanson, 2009)

- Unibook SE: An innovative environment for life-long learning (CHIMOS et al., 2012)

- Unified content design for ubiquitous learning: The soldering seminar use case (RODRIGUEZ-ALSINA et al., 2010).

Mensagens em tempo-real: a troca de mensagens em tempo-real é uma funcionalidade utilizada em sala de aula através de sistemas não educacionais comerciais (YAO, 
2011), em sistemas de aprendizagem em aulas presenciais (GRIFFIOEN; SEALES; JR, 1998) e no ensino a distância (RODRIGUEZ-ALSINA et al., 2010). Pode ser utilizado na troca de mensagens entre alunos, alunos e professores, e professores e pais de alunos (HASHIM; AHMAD, 2012). Funcionalidade presente em:

- How ECM can be used for distance learning content management ECM to LCM (DAOUDI, 2012)

- Instructional m-Learning System Design Based on Learners: MprinceTool (FARDOUN et al., 2010)

- Mobile Learning Application Based On Hybrid Mobile Application Technology Running On Android Smartphone and Blackberry (SETIABUDI; TJAHYANA, 2013)

- Enhancing Classroom Education with Instant Messaging Tools (YAO, 2011)

- Unibook SE: An innovative environment for life-long learning (CHIMOS et al., 2012)

- Unified content design for ubiquitous learning: The soldering seminar use case (RODRIGUEZ-ALSINA et al., 2010)

- Implementing a Mobile Campus Using MLE Moodle (XHAFA et al., 2010)

- Supporting Online Coordination of Learning Teams through Mobile Devices (ROIGTORRES; XHAFA; CABALLE, 2012)

- The Development of New Conceptual Model for MobileSchool (HASHIM; AHMAD, 2012)

- Xtask-adaptable working environment (KETAMO, 2002)

Esta presente também nas ferramentas comerciais:

- MasteryConnect (2014)

- Edmodo (2014)

- Remind101 (2014)

Fórum de discussões: fórum de discussões é uma funcionalidade que permite alunos fazerem questionamentos, compartilhar e trocar ideias, aprender mais sobre os materiais de aula e sobre experiências (NGUYEN; GUGGISBERG; BURKHART, 2006). É uma funcionalidade também bastante presente em sistemas utilizados de ensino a distância, sendo nestes casos uma das formas de medição de participação (CHIMOS et al., 2012; SCHMIEDL; GRECHENIG; SCHMIEDL, 2010; KETAMO, 2002). Está presente na ferramenta comercial Edmodo (2014) e também presente nos artigos:

- Supporting Online Coordination of Learning Teams through Mobile Devices (ROIGTORRES; XHAFA; CABALLE, 2012) 
- CoMobile: Collaborative learning with mobile devices (NGUYEN; GUGGISBERG; BURKHART, 2006)

- How ECM can be used for distance learning content management ECM to LCM (DAOUDI, 2012)

- E-School: A web-service oriented resource based e-learning system (SULTANA; SULTANA, 2010)

- Mobile Learning Application Based On Hybrid Mobile Application Technology Running On Android Smartphone and Blackberry (SETIABUDI; TJAHYANA, 2013)

- Using cellular phones in higher education: mobile access to online course materials (MERMELSTEIN; TAL, 2005)

- Implementing a Mobile Campus Using MLE Moodle (XHAFA et al., 2010)

- The Development of New Conceptual Model for MobileSchool (HASHIM; AHMAD, 2012)

Áudio: é uma funcionalidade onde arquivos de áudio são disponibilizados para os alunos. Os arquivos podem conter livros narrados (MERMELSTEIN; TAL, 2005), conter a aula gravada ou outros conteúdos disponíveis para acesso antes ou depois da aula pelos alunos (BOYINBODE; BAGULA; NG'AMBI, 2012) ou no ensino a distância disponibilizando arquivos gravados ou transmissões ao vivo (HOGANSON, 2009; RODRIGUEZ-ALSINA et al., 2010). Funcionalidade presente em:

- A mobile learning application for delivering educational resources to mobile devices (BOYINBODE; BAGULA; NG'AMBI, 2012)

- How ECM can be used for distance learning content management ECM to LCM (DAOUDI, 2012)

- A smil-based multimedia system for mobile education (DI et al., 2009)

- E-School: A web-service oriented resource based e-learning system (SULTANA; SULTANA, 2010)

- Distance-Learning and Converging Mobile Devices (HOGAnson, 2009)

- Management of Multimedia Data for Streaming on a Distributed e-Learning System (HAYAKAWA et al., 2012)

- KLeOS: A personal, mobile, knowledge and learning organisation system (VAVOULA; SHARPLES, 2002) 
- On webcasting to mobile devices: reusing web \& video content for pervasive e-learning (TURRO et al., 2007)

- Unibook SE: An innovative environment for life-long learning (CHIMOS et al., 2012)

- Using cellular phones in higher education: mobile access to online course materials (MERMELSTEIN; TAL, 2005)

Vídeo: é uma funcionalidade onde arquivos de vídeo são disponibilizados para os alunos. Os arquivos podem conter a gravação das aulas presenciais (MERMELSTEIN; TAL, 2005), aulas do ensino a distância gravadas e ao vivo (HOGANSON, 2009; TURRO et al., 2007; CHIMOS et al., 2012; RODRIGUEZ-ALSINA et al., 2010). Pode ser utilizado também uma variação desta funcionalidade onde é possível transmitir a tela do computador e também fazer chamadas ou conferências em vídeo (CHIMOS et al., 2012). Está presente na ferramenta comercial Edmodo (2014) e presente também nos seguintes artigos:

- A mobile learning application for delivering educational resources to mobile devices (BOYINBODE; BAGULA; NG'AMBI, 2012)

- How ECM can be used for distance learning content management ECM to LCM (DAOUDI, 2012)

- A smil-based multimedia system for mobile education (DI et al., 2009)

- E-School: A web-service oriented resource based e-learning system (SULTANA; SULTANA, 2010)

- Distance-Learning and Converging Mobile Devices (HOGANSON, 2009)

- Management of Multimedia Data for Streaming on a Distributed e-Learning System (HAYAKAWA et al., 2012)

- KLeOS: A personal, mobile, knowledge and learning organisation system (VAVOULA; SHARPLES, 2002)

- On webcasting to mobile devices: reusing web \& video content for pervasive e-learning (TURRO et al., 2007)

- Unibook SE: An innovative environment for life-long learning (CHIMOS et al., 2012)

- Unified content design for ubiquitous learning: The soldering seminar use case (RODRIGUEZ-ALSINA et al., 2010) e Using cellular phones in higher education: mobile access to online course materials (MERMELSTEIN; TAL, 2005)

Tela compartilhada: permite que alunos colaborem em uma área compartilhada com a inserção de apresentações de slides, arquivos e textos (LIU et al., 2007), pode ainda ser 
utilizada como um quadro-branco interativo possibilitando ser desenhado sobre (CHIMOS et al., 2012; GRIFFIOEN; SEALES; JR, 1998). Está presente na ferramenta comercial ClassDojo (2014) e nos artigos:

- An Interaction Study of Learning with Handhelds and Large Shared-Displays in Technology-Enriched Collaborative Classroom (LIU et al., 2007)

- Unibook SE: An innovative environment for life-long learning (CHIMOS et al., 2012)

Materiais: a disponibilização e distribuição de materiais é uma tarefa recorrente em ambientes acadêmicos. Esta funcionalidade está presente em sistemas de ensino a distância Bonastre, Benavent e García (2005) e Sultana e Sultana (2010) e em sistemas utilizados em aulas presenciais (MERMELSTEIN; TAL, 2005). Está presente nas ferramentas comerciais: MasteryConnect (2014), Edmodo (2014) e TeacherKit (2014) e também nos artigos.

- Funcionalidade presente em: How ECM can be used for distance learning content management ECM to LCM (DAOUDI, 2012)

- E-dap: an e-learning tool for managing, distributing and capturing knowledge (BONASTRE; BENAVENT; GARCíA, 2005)

- E-School: A web-service oriented resource based e-learning system (SULTANA; SULTANA, 2010)

- Mobile Learning Application Based On Hybrid Mobile Application Technology Running On Android Smartphone and Blackberry (SETIABUDI; TJAHYANA, 2013)

- KLeOS: A personal, mobile, knowledge and learning organisation system (VAVOULA; SHARPLES, 2002)

- Using cellular phones in higher education: mobile access to online course materials (MERMELSTEIN; TAL, 2005)

- The Development of New Conceptual Model for MobileSchool (HASHIM; AHMAD, 2012)

- Xtask-adaptable working environment (KETAMO, 2002)

Avaliações: avaliar o conhecimento dos alunos através de testes é uma funcionalidade bastante utilizada em sistemas de aprendizagem utilizados em aulas presenciais (FARDOUN et al., 2010) e também em sistemas de ensino a distância (BONASTRE; BENAVENT; GARCíA, 2005). Há algumas funcionalidades adicionais que também podem estar presentes, 
como formas de gerar testes aleatórios através de bancos de testes e de questões (FARDOUN et al., 2010). Funcionalidade presente em:

- An Integrated e-Learning Platform for Use in Higher Education (FLOREA; FRUNZETE; STEFANESCU, 2011)

- E-School: A web-service oriented resource based e-learning system (SULTANA; SULTANA, 2010)

- Instructional m-Learning System Design Based on Learners: MprinceTool (FARDOUN et al., 2010)

- Design and Development of the Online Examination and Evaluation System Based on B/S Structure (LI; WU, 2007)

- Implementing a Mobile Campus Using MLE Moodle (XHAFA et al., 2010)

Está presente também nas ferramentas comerciais:

- MasteryConnect (2014)

- TeacherKit (2014)

- ClassDojo (2014)

- StickPick (2014)

- Socrative (2014)

Quadro de recados: servir como um canal de comunicação entre professores e alunos em ambiente acadêmico. Está bastante presente em sistemas de ensino a distância pela própria natureza do mesmo (SUlTANA; SUlTANA, 2010). Funcionalidade presente em: E-School: A web-service oriented resource based e-learning system (SULTANA; SULTANA, 2010) e Implementing a Mobile Campus Using MLE Moodle (XHAFA et al., 2010), e está presente também na ferramenta comercial ClickerSchool (2014).

Suporte a dispositivos móveis: todos os artigos selecionados na revisão sistemática possuiam algum tipo de suporte a dispositivos móveis. Funcionalidade presente em:

- AuReS (JAGAR; PETROVIC; PALE, 2012)

- A Lightweight Mobile Quiz Application with Support for Multimedia Content (SCHON; KOPF; EFFELSBERG, 2012)

- A Mobile Lecture Slide Organization Tool for Students (CHOW et al., 2006)

- Collaborative Note Taking (SINGH; DENOUE; DAS, 2004)

- Conducting Classroom Discussions in the Manner of an Orchestra Using a Mobile Phone Based Response Analyzing System (NAKAI; NAGAOKA, 2007) 
- Supporting Online Coordination of Learning Teams through Mobile Devices (ROIGTORRES; XHAFA; CABALLE, 2012)

- An Interaction Study of Learning with Handhelds and Large Shared-Displays in Technology-Enriched

- Collaborative Classroom (LIU et al., 2007)

- An Integrated e-Learning Platform for Use in Higher Education (FLOREA; FRUNZETE; STEFANESCU, 2011)

- CoMobile: Collaborative learning with mobile devices (NGUYEN; GUGGISBERG; BURKHART, 2006)

- A mobile learning application for delivering educational resources to mobile devices (BOYINBODE; BAGULA; NG'AMBI, 2012)

- Development of a system for mobile learning (COVIC; CINGER; IVKOVIC, 2010)

- How ECM can be used for distance learning content management ECM to LCM (DAOUDI, 2012)

- A smil-based multimedia system for mobile education (DI et al., 2009)

- E-dap: an e-learning tool for managing, distributing and capturing knowledge (BONASTRE; BENAVENT; GARCíA, 2005)

- E-School: A web-service oriented resource based e-learning system (SULTANA; SULTANA, 2010)

- Distance-Learning and Converging Mobile Devices (HOGAnson, 2009)

- Instructional m-Learning System Design Based on Learners: MprinceTool (FARDOUN et al., 2010)

- Management of Multimedia Data for Streaming on a Distributed e-Learning System (HAYAKAWA et al., 2012)

- Mobile Learning Application Based On Hybrid Mobile Application Technology Running On Android Smartphone and Blackberry (SETIABUDI; TJAHYANA, 2013)

- KLeOS: A personal, mobile, knowledge and learning organisation system (VAVOULA; SHARPLES, 2002)

- Offline web application and quiz synchronization for e-learning activity for mobile browser (IJTIHADIE et al., 2010)

- On webcasting to mobile devices: reusing web \& video content for pervasive e-learning (TURRO et al., 2007) 
- Design and Development of the Online Examination and Evaluation System Based on B/S Structure (LI; WU, 2007)

- Enhancing Classroom Education with Instant Messaging Tools (YAO, 2011)

- Unibook SE: An innovative environment for life-long learning (CHIMOS et al., 2012)

- Unified content design for ubiquitous learning: The soldering seminar use case (RODRIGUEZ-ALSINA et al., 2010)

- Using cellular phones in higher education: mobile access to online course materials (MERMELSTEIN; TAL, 2005)

- Web-based tools to sustain the motivation of students in distance education (TOKIWA; NONOBE; IWATSUKI, 2009)

- Work in progress-integrating mobile Tablet-PC technology and Classroom Management Software in undergraduate electronic engineering technology courses (RAWAT; RIDDICK; MOORE, 2008)

- Implementing a Mobile Campus Using MLE Moodle (XHAFA et al., 2010)

- Mobile enabling of virtual teams in school: an observational study on smart phone application in secondary education (SCHMIEDL; GRECHENIG; SCHMIEDL, 2010)

- Supporting Online Coordination of Learning Teams through Mobile Devices (ROIGTORRES; XHAFA; CABALLE, 2012)

- Teaching in realtime wireless classrooms (GRIFFIOEN; SEALES; JR, 1998)

- The Development of New Conceptual Model for MobileSchool (HASHIM; AHMAD, 2012)

- Xtask-adaptable working environment (KETAMO, 2002)

As ferramentas comericiais seguintes também possuem suporte a dispositivos móveis:

- PollEverywhere (2014)

- SMSPoll (2014)

- ClickerSchool (2014)

- Shakespeak (2014)

- MasteryConnect (2014)

- Edmodo (2014)

- TeacherKit (2014)

- ClassDojo (2014)

- Remind101 (2014) 
- StickPick (2014)

Na realização desta revisão exploratória foi encontrada também a pesquisa (PUSNIK; SUMAK; HERICKO, 2010) realizada com alunos do ensino superior onde categorias de funcionalidades foram confrontadas quanto o seu nível de importância para alunos em um sistema de ensino a distância a ser ativado. A Tabela 5 mostra o resultado desta pesquisa. Tabela 5 - Importância de uma característica a ser ativada em um sistema de ensino a distância

\begin{tabular}{|c|c|c|c|c|c|c|}
\hline $\begin{array}{l}\text { Conjunto de } \\
\text { funcionalidades }\end{array}$ & $\begin{array}{l}\text { Muito im- } \\
\text { portante }\end{array}$ & Importante & Indeciso & $\begin{array}{l}\text { Não } \\
\text { muito } \\
\text { impor- } \\
\text { tante }\end{array}$ & $\begin{array}{l}\text { Sem im- } \\
\text { portância }\end{array}$ & $\begin{array}{l}\text { Média / } \\
\text { Desvio }\end{array}$ \\
\hline $\begin{array}{l}\text { Trabalho colabora- } \\
\text { tivo com outros } \\
\text { alunos }\end{array}$ & $74(31,5 \%)$ & $103(43,8 \%)$ & $33(14 \%)$ & $21(8,9 \%)$ & $4(1,7 \%)$ & $\begin{array}{l}3,94 \\
0,983\end{array}$ \\
\hline $\begin{array}{l}\text { Comunicação com } \\
\text { outros alunos (sínc. } \\
\text { e assínc.) }\end{array}$ & $65(27,7 \%)$ & $100(42,6 \%)$ & $29(12,3 \%)$ & $35(14,9 \%)$ & $6(2,6 \%)$ & $\begin{array}{l}3,78 \\
1,087\end{array}$ \\
\hline $\begin{array}{l}\text { Comunicação com } \\
\text { professores (sínc. e } \\
\text { assínc.) }\end{array}$ & $116(49,4 \%)$ & $92(39,1 \%)$ & $16(6,8 \%)$ & $10(4,3 \%)$ & $1(0,4 \%)$ & $\begin{array}{l}4,33 \\
0,816\end{array}$ \\
\hline $\begin{array}{l}\text { Tecnologias } \\
2.0 \quad \text { web } \\
\text { RSS, etc.) }\end{array}$ & $49(20,9 \%)$ & $103(43,8 \%)$ & $44(18,7 \%)$ & $35(14,9 \%)$ & $4(1,7 \%)$ & $\begin{array}{l}3,67 \\
1,021\end{array}$ \\
\hline
\end{tabular}

Fonte: Tulio Faria, 2015

Nesta pesquisa, fica evidente a importância para os alunos que os sistemas de aprendizagem possam permitir a colaboração e uma maior comunicação entre os alunos e entre os alunos e professores, bem como uma maior proximidade com os sistemas e plataformas sociais de mercado.

Além disso, foi encontrado o sistema Quadro-Branco que tem como objetivo adicionar colaboração e interação para alunos com problemas cognitivos, sensoriais e físicos (SANTAROSA; CONFORTO; MACHADO, 2012). Esse sistema assemelha-se bastante ao Mindboard, e possui funcionalidades interessantes como a construção textual colaborativa e uma interface gráfica acessível a deficientes visuais.

Uma diferença entre o Mindboard e o Quadro-branco é no modo de colaboração, uma vez que no Mindboard é feita através de anotações sobre os conteúdos e no QuadroBranco é realizada através da produção textual em conjunto. Outra diferenciação é o público-alvo de cada sistema, o Quadro-Branco buscou atender usuários que possuem algum tipo de problema cognitivo, sensorial ou físico, enquanto o Mindboard objetivou 
alunos sem estas restrições. O sistema Quadro-Branco também possui uma funcionalidade que pode indicar seu uso mais apropriado para o ensino a distância que é a transmissão de áudio e vídeo.

Outra ferramenta encontrada que também possui objetivos bem semelhantes ao Mindboard é a apresentada em Singh, Denoue e Das (2004). Essa ferramenta tem como objetivo o compartilhamento de apresentações e de notas utilizando dispositivos móveis PDA, os antecessores dos smartphones. No estudo, os autores apresentam problemas de legibilidade por parte dos alunos e também algumas preocupações dos alunos quanto a privacidade das notas realizadas. Esta ferramenta difere-se do sistema Mindboard também pelo foco, pois o Mindboard pode ser utilizado tanta em computadores quanto em dispositivos móveis. Além disso, no Mindboard o sistema de anotações permitem uma maior colaboração entre os alunos, tornando-se uma funcionalidade de colaboração. Nos resultados desta ferramenta, os alunos disseram que ela é de grande valor ao processo de aprendizagem (SINGH; DENOUE; DAS, 2004), o que indica que ferramentas que seguem por esta linha podem contribuir muito para o processo.

Os artigos que apresentam seus resultados apenas o relatam como uma melhoria no processo de ensino e aprendizagem, mas não mostram como o resultado foi mensurado. Alguns artigos mostram a melhoria através da opinião dos alunos obtidos através de um questionário (RAWAT; RIDDICK; MOORE, 2008). Há artigos que apenas relatam que o uso da ferramenta ajudou a aumentar a motivação dos alunos em sala de aula e em cursos a distância (TOKIWA; NONOBE; IWATSUKI, 2009).

Esta seção apresentou as funcionalidades levantadas que estão presentes em sistemas de aprendizagem que podem ser utilizados em sala de aula ou no ensino a distância, e que podem ou não possuir suporte a dispositivos móveis, obtidos através da revisão exploratória.

As funcionalidades aqui apresentadas ajudaram a definir um conjunto de funcionalidades interessantes a um sistema a ser utilizado em sala de aula e fora dela, conhecendo um pouco mais o funcionamento de cada uma delas, além de também contribuir com informações de tecnologias que foram utilizadas para seu desenvolvimento. 


\section{Resultados da pesquisa com professores e alunos}

Conforme descrito no Capítulo 3, foram realizadas duas pesquisas envolvendo os usuários finais alvo do sistema Mindboard, sendo uma com os professores e uma com os alunos. A seguir são apresentados seus resultados.

\subsection{Análise dos resultados específicos a professores}

Esta seção analisa os dados específicos aos professores. Importante ressaltar que a forma de captação dos formulários adicionou um viés a pesquisa, uma vez que a divulgação do mesmo aconteceu massivamente através de meios digitais. Assim, os professores que responderam ao questionário já possuem uma tendência a utilizar tecnologia em seu cotidiano, principalmente redes sociais e e-mails, podendo assim, possuir uma tendência a usar mais tecnologia em sala de aula. Assim, não é possível descobrir o motivo pelos quais os demais professores não utilizariam tecnologia em suas aulas.

A média da idade dos professores que responderam ao questionário foi de 40 anos de idade, com desvio padrão de 8,25, e o tempo médio atuando como professor foi de 12 anos, com desvio padrão de 9,42. Desta última informação, pode-se deduzir que muitos professores durante suas formações não tiveram acesso à internet ou a tecnologia, o que poderia influenciar a não utilização nos dias atuais.

As respostas foram coletadas por meio da internet, o que permitiu obter respostas de 10 estados brasileiros diferentes. Os estados com mais respostas foram os estados de origem de cada autor deste estudo: São Paulo e Minas Gerais. A Tabela 6 mostra o total de respostas obtidas em cada estado.

Sobre o tipo de instituições em que os professores lecionam, 61 atuam em particulares, 31 em rede pública, sendo 14 no ensino médio e 70 no ensino superior, lembrando que alguns podem atuar em ambas.

A modalidade pedagógica mais utilizada pelos professores ainda é a aula expositiva que esteve presente em 79 respostas, seguidas por aulas dialogadas com 60, pesquisas com 61, BPL com 42, visitas com 19 e outros com 8 respostas. A Figura 4 mostra graficamente os resultados desta questão. 
Tabela 6 - Distribuição geográfica

\begin{tabular}{|l|l|l|}
\hline Estado: & Total de respostas & Porcentagem: \\
\hline BA & 2 & $2,47 \%$ \\
\hline CE & 1 & $1,23 \%$ \\
\hline GO & 1 & $1,23 \%$ \\
\hline MG & 32 & $39,51 \%$ \\
\hline MT & 1 & $1,23 \%$ \\
\hline PR & 1 & $1,23 \%$ \\
\hline RJ & 1 & $1,23 \%$ \\
\hline RS & 2 & $2,47 \%$ \\
\hline SP & 38 & $46,91 \%$ \\
\hline TO & 2 & $2,47 \%$ \\
\hline Total: & 81 & $100,00 \%$ \\
\hline
\end{tabular}

Fonte: Tulio Faria, 2015

Figura 4 - Modalidades pedagógicas

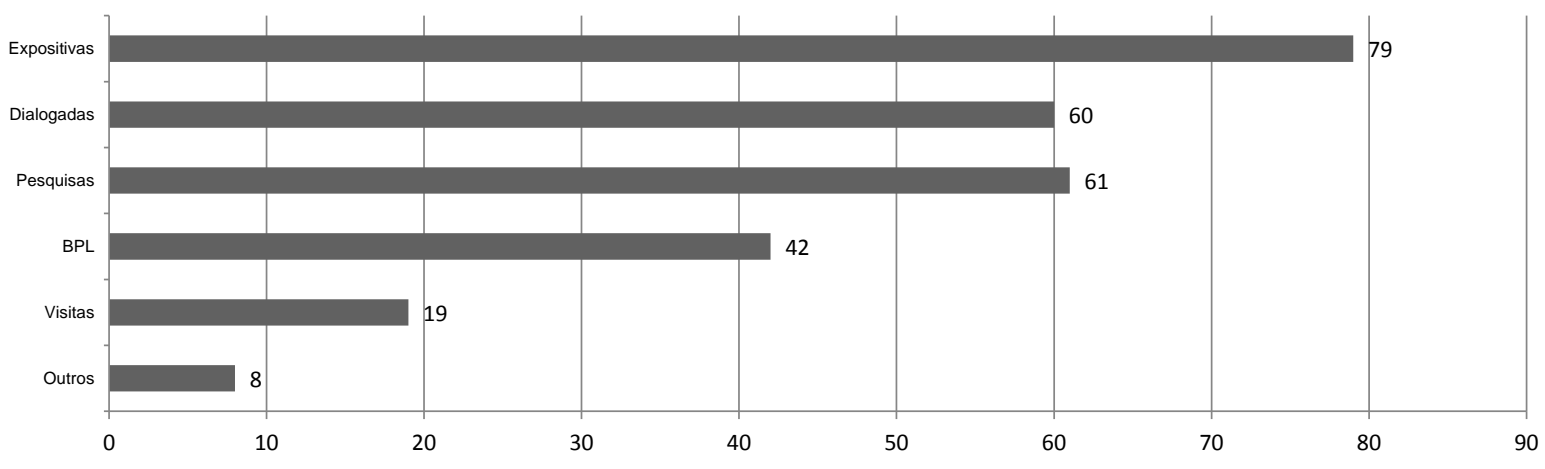

Fonte: Tulio Faria, 2015

Já quanto as atividades extraclasse os professores responderam que utilizam muito exercícios, trabalhos de pesquisa e trabalhos práticos. Os dois primeiros são utilizados por pelo menos 65 dos 81 pesquisados, e o último por 58 .

As atividades extraclasse que poderiam gerar algum tipo de colaboração, como é o caso do fórum de discussões, ainda são pouco utilizadas, sendo a opção de 18 professores. A Figura 5 ilustra graficamente as respostas a esta pergunta.

A pesquisa também abordou questões sobre quais recursos eram mais utilizados em aula pelos professores. As respostas foram bastante coerentes ao tipo de aulas mais utilizadas, sendo recursos mais comumente utilizados em aulas expositivas. Neste caso, o 
Figura 5 - Atividades extraclasse

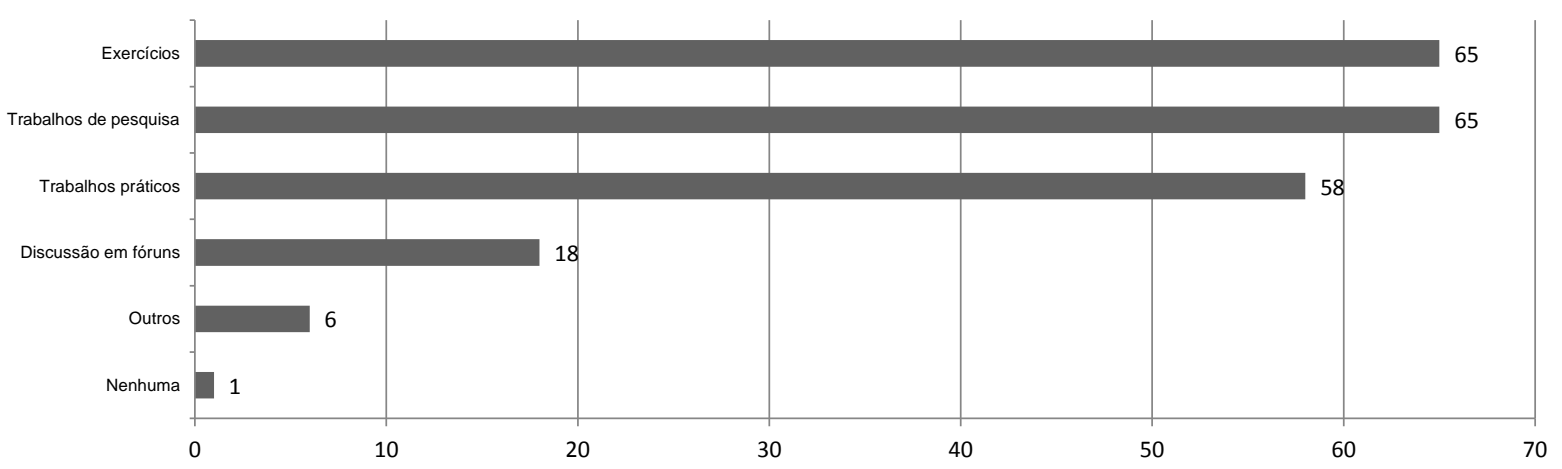

Fonte: Tulio Faria, 2015

Figura 6 - Recursos utilizados

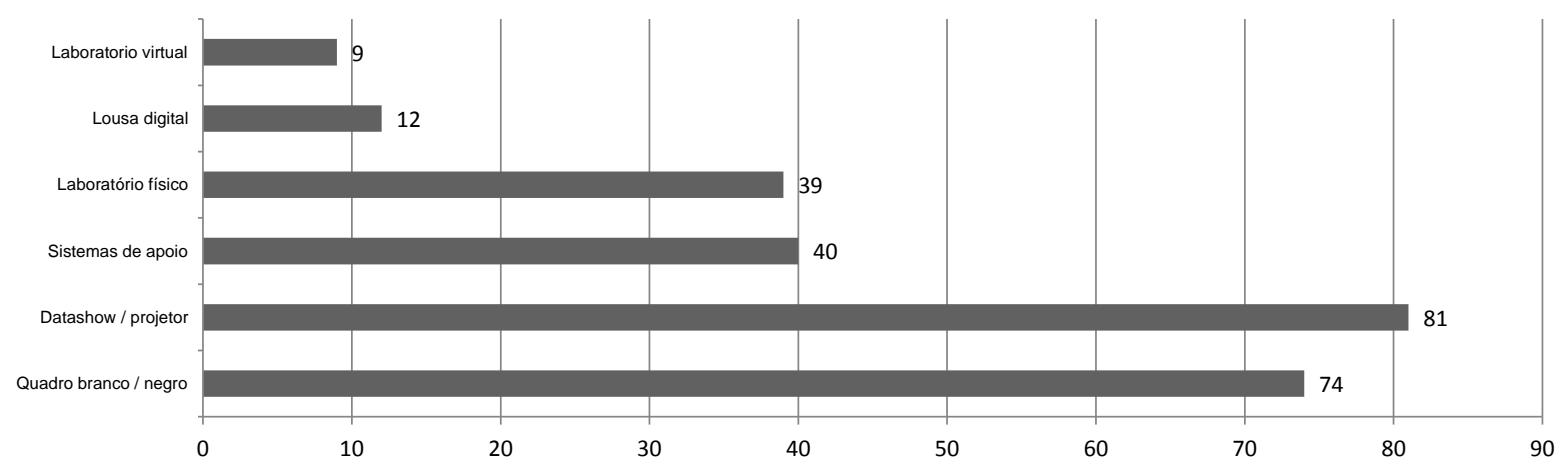

Fonte: Tulio Faria, 2015

datashow/projetor é utilizado por todos os professores que responderam a pesquisa, e o quadro branco/negro por 74 dos 81 professores. O terceiro recurso em uso são os sistemas de apoio como Moodle e Sakai que são utilizados por 40 pesquisados.

A Figura 14 mostra graficamente o total de respostas para cada tipo de recurso.

A pesquisa levantou também se as instituições oferecem sistemas para gerenciamento de conteúdo, como por exemplo, Moodle, Blackboard, Sakai, etc. A resposta de 57 professores é que a sua instituições oferecem, 22 deles disseram que a instituição não oferece e 5 deles que a instituição não oferece mas eles usam um por conta própria.

Foi perguntado também se os professores conseguem, de alguma forma, saber a opinião dos alunos sobre as aulas, mesmo sem obter um retorno direto dos alunos. Neste quesito, 45 professores dos 81 pesquisados responderam que conseguem saber deste andamento através do comportamento dos alunos e pelas atividades realizadas em aula. Uma parcela dos professores (18) conseguem também obter esta informação somente através de atividades realizadas em aula, e 16 deles somente através do comportamento dos alunos, e 4 deles não conseguem avaliar. 
Figura 7 - Retorno dos alunos

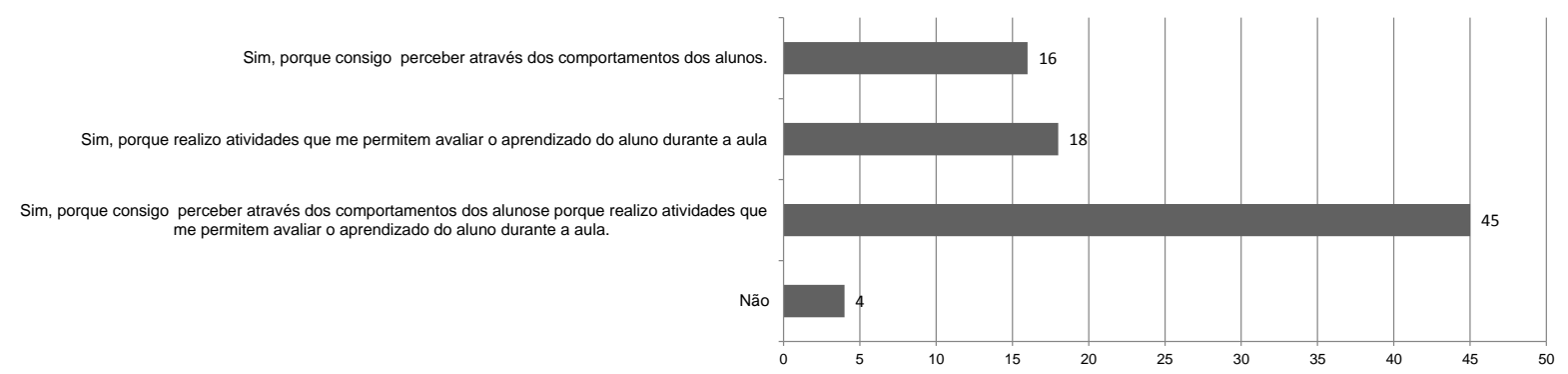

Fonte: Tulio Faria, 2015

Figura 8 - Inibição dos alunos em dar retorno ou fazer questionamento em aula

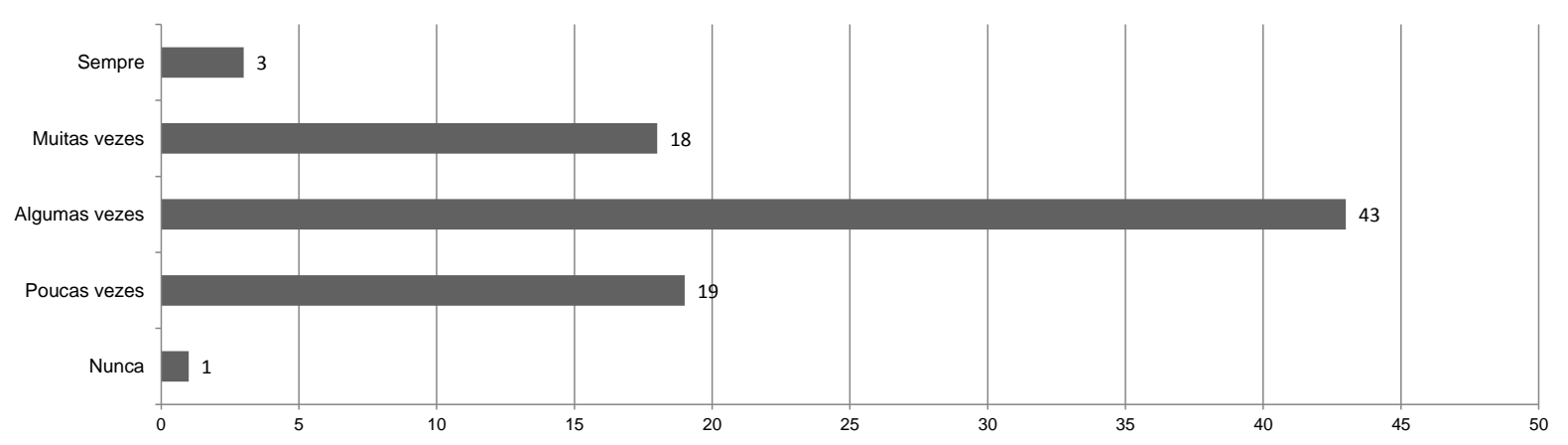

Fonte: Tulio Faria, 2015

A Figura 20 mostra graficamente estas respostas dos professores, que 37 pesquisados dizem obter esta informação com muita confiança e 34 com confiança média. Outra informação relevante que foi levantada é que 75 pesquisados gostariam de obter este retorno com mais frequência.

Ainda relacionado ao retorno dos alunos sobre a aula, a pesquisa ainda questionou se os professores percebem ou acham que seus alunos ainda se sentem inibidos em dar algum retorno sobre a aula ou realizar questionamentos. Um pouco mais da metade (43) dos pesquisados acham que algumas vezes sentem seus alunos inibidos, e 18 deles acham que isso acontece muitas vezes. A Figura 8 mostra graficamente estas respostas.

A pesquisa buscou também conhecer sobre a utilização de internet pelos alunos tanto dentro quanto fora da sala de aula. Assim sendo, 79 professores acham que seus alunos acessam a internet no dia-a-dia. Foi perguntado também se os professores sabem quantos de seus alunos usam a internet em seus dispositivos móveis durante a aula, sendo que 6 responderam Todos os alunos, 23 Muitos alunos, e 26 Alguns alunos. A Figura 9 mostra graficamente os dados completos. Importante notar também que dos professores 
Figura 9 - Uso de internet em sala de aula pelos alunos

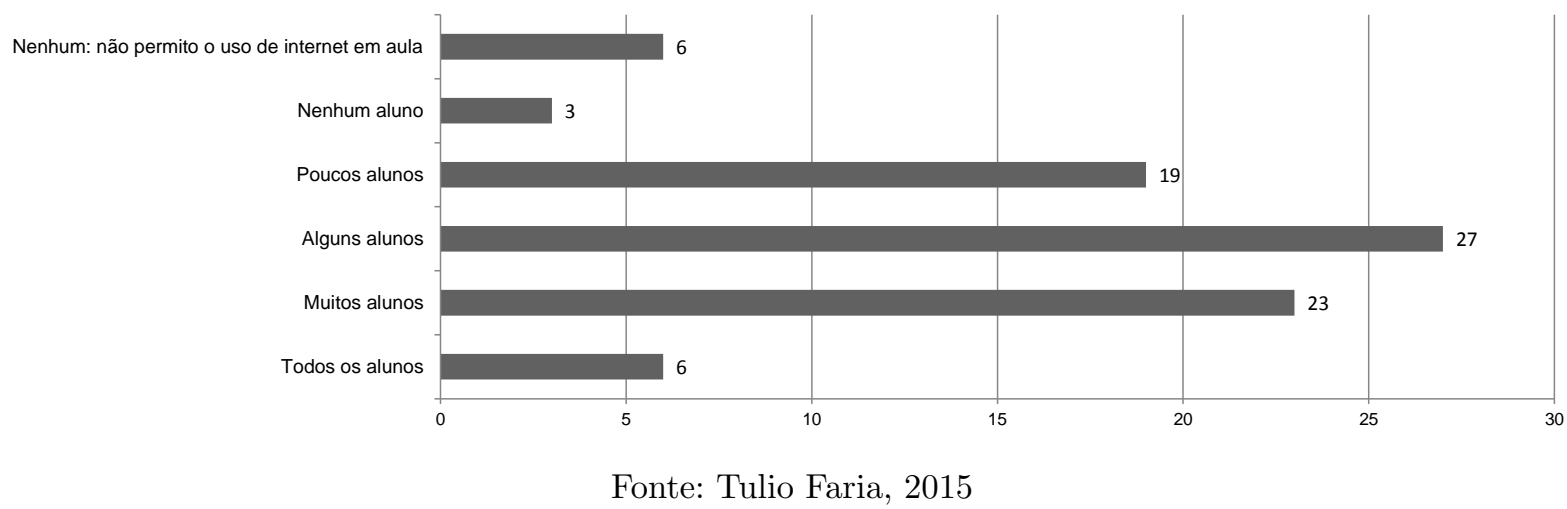

que responderam que seus alunos usam a internet em sala de aula, 25 deles acham que seus alunos utilizam com finalidade acadêmica e 46 acham que utilizam para fins pessoais.

Foi pesquisado também se os professores gostariam de saber quanto seus alunos estudam em casa e, 72 deles responderam que gostariam de conhecer esta informação, contra 9 que não desejariam.

\subsection{Análise dos resultados específicos a alunos}

O total de alunos que responderam ao questionário foi de 126, onde a média de idade dos respondentes foi de 24 anos de idade, informação que pode indicar que estes alunos desde a infância e/ou adolescência já possuem contato com tecnologias digitais. Sobre a localização destes alunos 75 são do estado de MG (59,52\%) e 43 (34,13\%) de SP, números justificados por ser os estados de origem dos autores. Sobre o tipo de instituição que cada aluno pertence, 39 (30,7\%) estudam em instituições públicas e 88 (69,3\%) em privadas. Outro fator levantado também foi que 7 alunos (5,5\%) estudam no ensino-médio e $120(94,5 \%)$ no ensino superior ou pós-graduação.

Os alunos responderam sobre quais modalidades pedagógicas eles aprendem melhor, e pelo ponto de vista dos mesmos, aulas dialogadas é a que mais obtém resultados. A Figura 10 compara graficamente o número de respostas de cada modalidade.

Os alunos responderam também sobre quais recursos o seu professor utiliza em salas de aula. O recurso de quadro negro ou branco e projetor foram as mais marcadas, com 107 e 121 respostas, respectivamente. A Figura 11 compara graficamente o número de respostas de cada recurso. 
Figura 10 - Quais metodologias pedagógicas os alunos aprendem mais

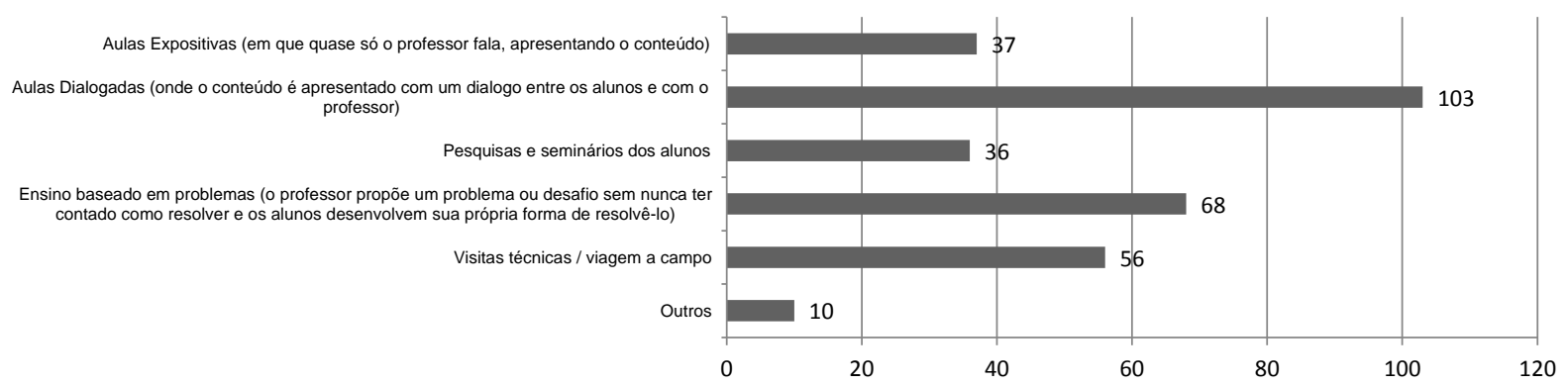

Fonte: Tulio Faria, 2015

Figura 11 - Quais os recursos seus professores utilizam

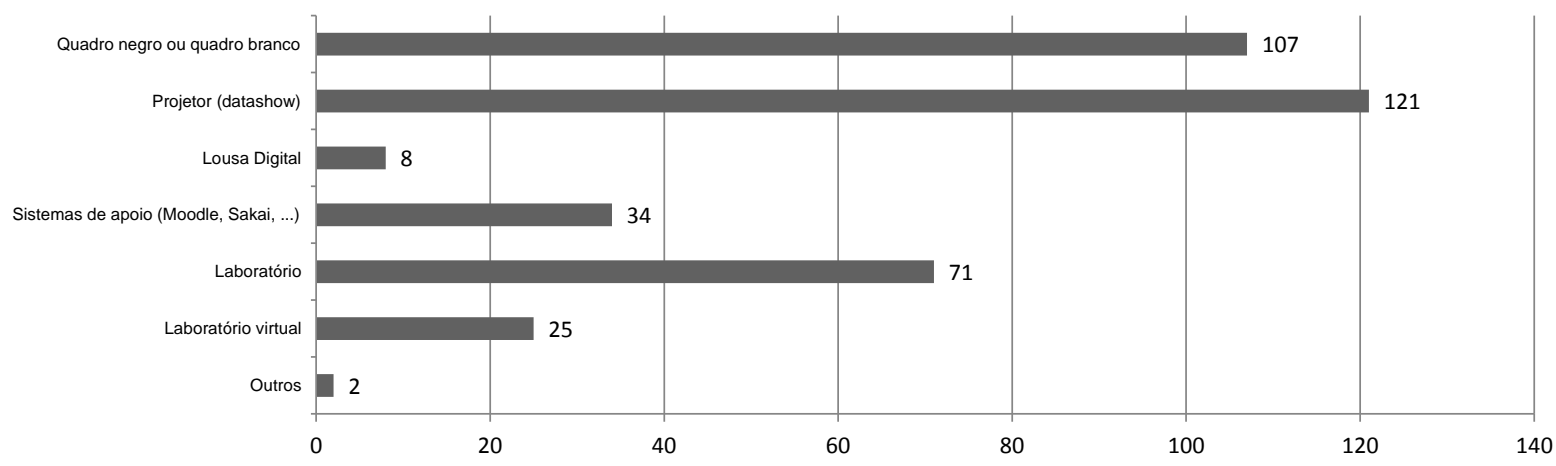

Fonte: Tulio Faria, 2015

Já sobre as atividades extraclasse muitos alunos acham que aprendem mais fazendo exercícios práticos, com 81,9\% (104).

Um fator explorado no questionário foi sobre a comunicação entre alunos e professores em sala de aula. Um exemplo deste tipo de informação é relacionada a se os alunos informam seu entendimento sobre as aulas aos professores, ou se os alunos ainda sentem-se inibidos ao realizar questionamentos. Em 17,3\% (22) das respostas dos alunos eles não informam ao professor sobre seu entendimento de aula, em 46,6\% (59) informam somente as vezes e em 36,2\% (46) informam sempre. A justificativa dos alunos para não informarem aos professores sobre o entendimento das aulas, de acordo com algumas justificativas recebidas estão relacionadas a inibição, falta de interesse por parte do aluno, falta de diálogo com os professores ou simplesmente porque o aluno não gosta de o fazer. Já as justificativas dos alunos que dão este retorno ao professor o fazem para obter um melhor entendimento da aula e para ajudar ao professor a mensurar seus resultados, como justificado por estes alunos: "Por que acho importante o feedback ao professor sobre a abordagem e conteúdos apresentados.", "Para que ele saiba que conseguiu atingir sua meta" e "Acho necessário que ele entenda como os alunos estão acompanhando o conteúdo". 
Figura 12 - Inibição dos alunos ao fazer questionamentos ou dar um retorno sobre a aula aos professores

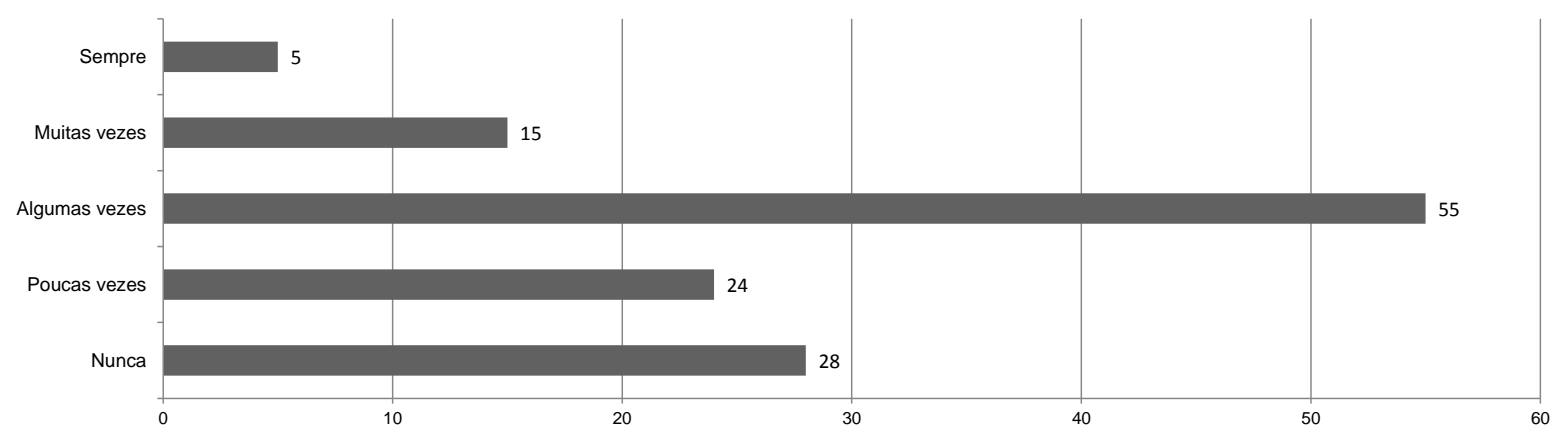

Fonte: Tulio Faria, 2015

Figura 13 - Utilização de internet em sala de aula pelos alunos

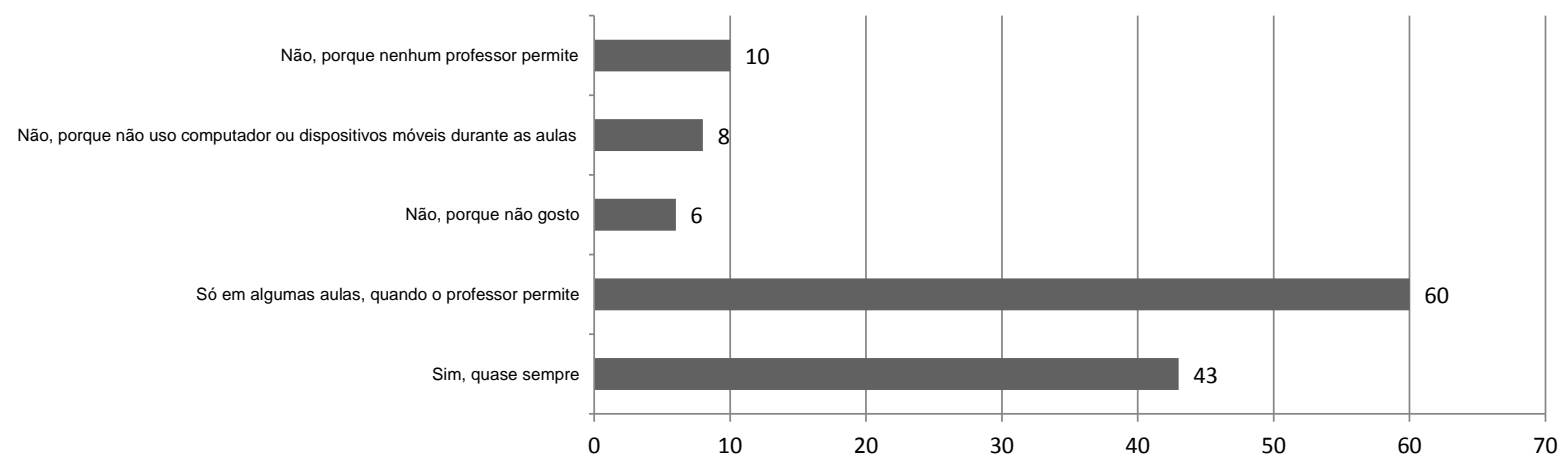

Fonte: Tulio Faria, 2015

Em $66,1 \%$ das respostas, os alunos gostariam de possuir uma forma de opinar sobre a aula aos professores de forma anônima, e na Figura 12 mostra graficamente o quanto os alunos ainda se sentem inibidos para dar algum retorno ao professor ou realizar questionamentos. Pode-se perceber que uma porcentagem pequena (22\%) (28) nunca sente-se inibido.

Sobre o uso de internet em sala de aula, 33,9\% (43) dos alunos responderam que utilizam quase sempre, e 47,2\% (60) responderam que utilizam quando o professor permite. O interessante desse levantamento é a quantidade de alunos que disseram que utilizam internet em sala de aula, mostrando o quanto a mesma já está presente no ambiente escolar seja com a aprovação do professor ou não. Dos alunos que disseram que utilizam internet em sala de aula, 90,3\% (93) disseram que utilizam para fins acadêmicos e $65 \%$ (67) para fins pessoais, lembrando que esta questão não era exclusiva e portanto o aluno poderia marcar que faz ambos os usos. Na Figura 13 compara-se graficamente a utilização de internet por alunos na sala de aula. 
Figura 14 - Recursos computacionais utilizados por alunos e professores

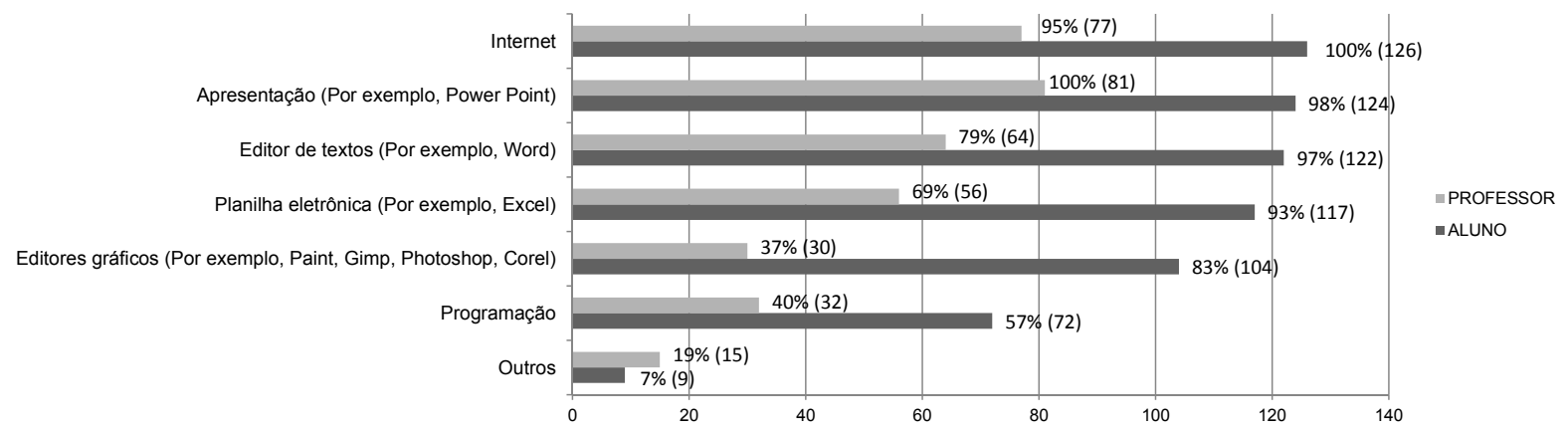

Fonte: Tulio Faria, 2015

\subsection{Avaliação do uso de internet e tecnologias por professores e alunos}

A pesquisa contém uma seção de questionamentos para conhecer um pouco do perfil de alunos e professores em relação ao uso de tecnologia e internet no seu dia-a-dia e em sala de aula.

$\mathrm{Na}$ análise de tipos de aplicativos e ferramentas que alunos e professores utilizam, um fato interessante é que os alunos possuem uma tendência a utilizar recursos computacionais que exigem um pouco mais de conhecimento, como por exemplo, Editores Gráficos são utilizados por 104 de 126 alunos e Planilha Eletrônica são utilizadas por 117 de 126 alunos. E recursos como Internet, Apresentações e Editor de Textos praticamente utilizados por todos os alunos. O fato dos alunos possuírem uma maior desenvoltura com tecnologia beneficia a utilização e a integração de tecnologia em sala de aula.

Já analisando a mesma questão para os professores, os recursos mais utilizados são Internet, Apresentações e Editor de Textos, o que pode indicar que muitos professores ainda utilizam apenas aplicativos mais básicos. A Figura 14 mostra graficamente os valores relacionados aos recursos tecnológicos e seus usos entre alunos e professores.

O uso de internet foi outra informação levantada através do questionário. Nesse item, foi levantado que $67,90 \%$ dos professores e $76 \%$ dos alunos utilizam mais que 20 horas internet por semana. Já o uso de até 5 horas semanais representou 3,17\% e 3,70\%, para alunos e professores, respectivamente. Estes números evidenciam que tanto alunos como professores estão cada vez mais conectados e que passam um boa quantidade de horas semanais utilizando internet. A Figura 15 mostra graficamente o uso de cada faixa de horas para alunos e professores. 
Figura 15 - Quantidade de horas que alunos e professores utilizam por semana

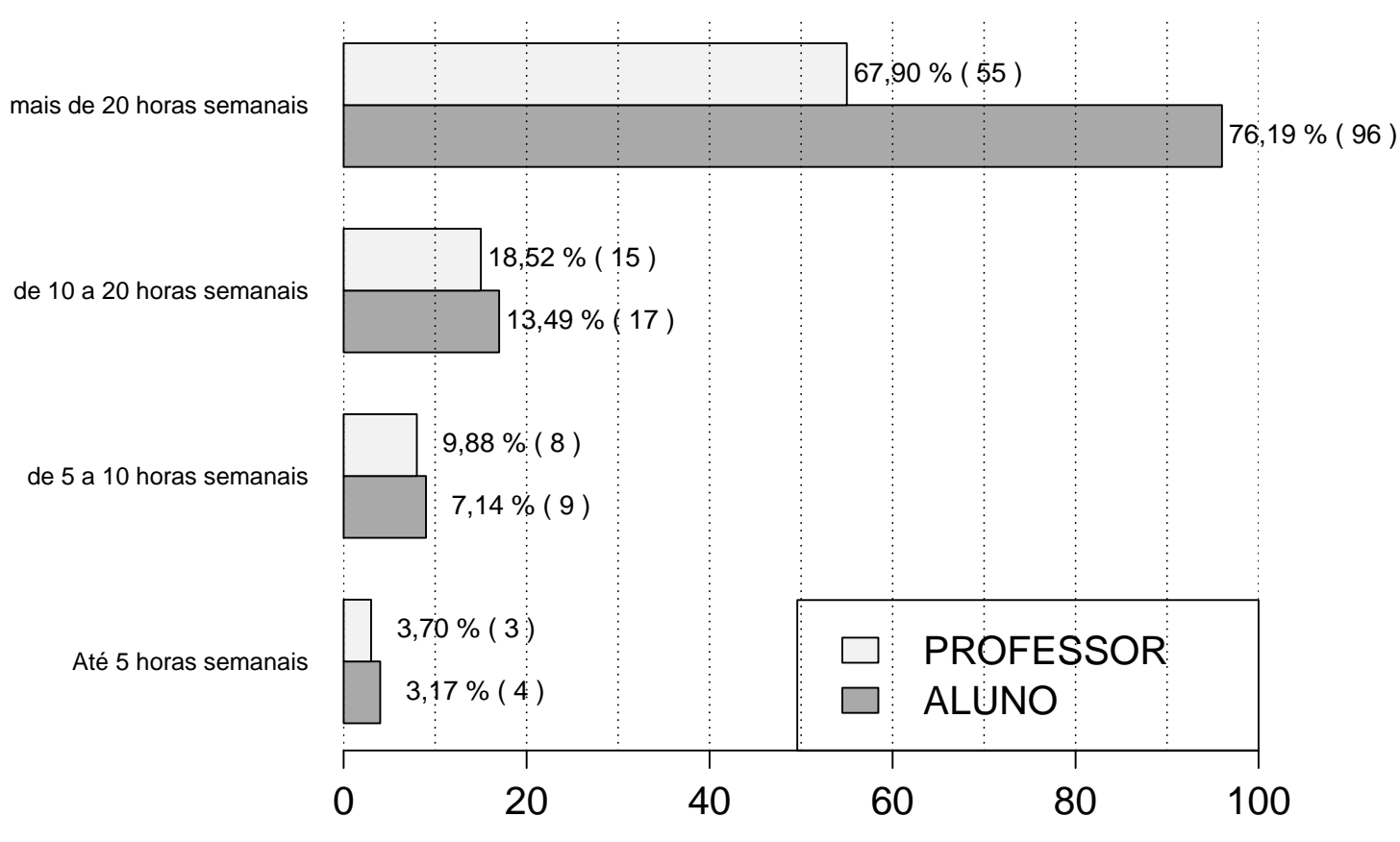

Fonte: Tulio Faria, 2015

\subsection{Opinião dos professores e alunos quanto a uma futura ferra- menta}

A pesquisa em sua segunda parte tem como objetivo saber a opinião dos alunos e professores em relação a uma futura ferramenta a ser utilizada dentro e fora de sala de aula. O primeiro questionamento foi exatamente saber o quão importante é esta ferramenta ser multiplataforma. Mais de metade (62) dos professores consideraram esta característica como muito importante (39) ou de total importância (23), já os alunos também definiram em grande parte como importante, sendo 58 como muito importante e 45 como de total importância . A Figura 16 compara as respostas de alunos e professores relativamente.

Sobre a possível funcionalidade onde os alunos pudessem visualizar o conteúdo de aula do professor em tempo real grande parte dos professores e alunos definiram como muito importante ou de total importância. A Figura 17.

Outra funcionalidade questionada na pesquisa é relacionada a possibilidade de alunos e professores adicionarem informações sobre o material de aula. Sobre esta característica em um futuro sistema a ser utilizado na educação, alunos e professores também marcaram como de total importância ou muito importante, somando 72,84\% e 65,88\% para professores 
Figura 16 - Importância da ferramenta ser multiplataforma, comparação entre as respostas de professores e alunos

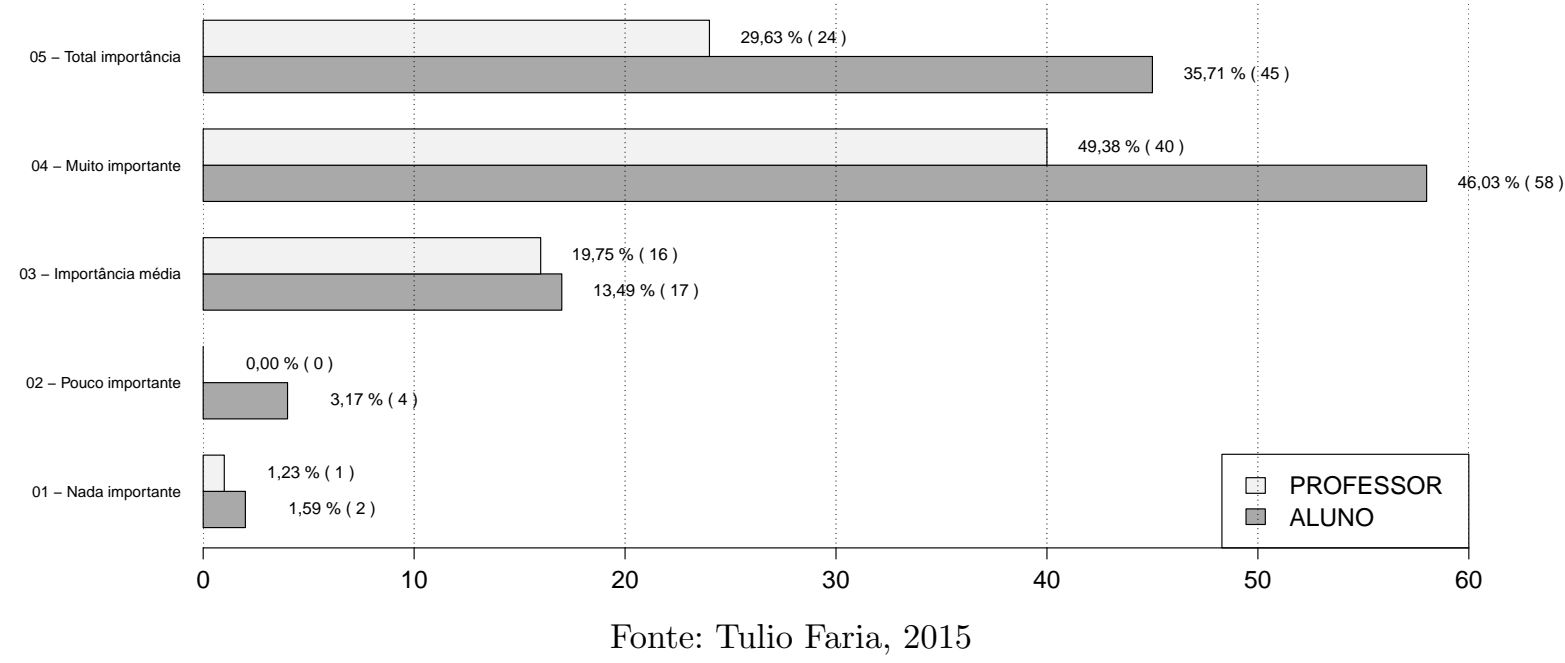

Figura 17 - Importância da ferramenta permitir que os alunos visualizem o conteúdo em tempo real, comparação entre as respostas de professores e alunos

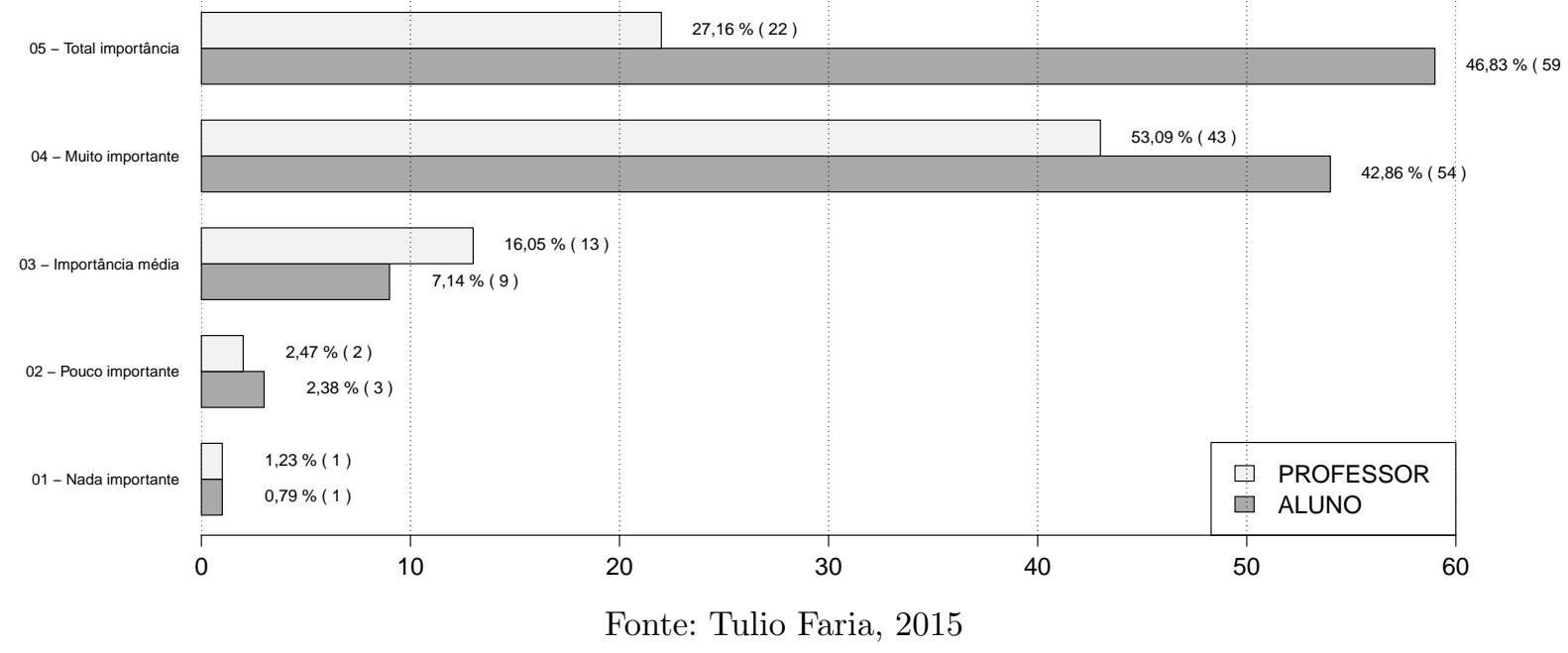

e alunos, respectivamente, indicando assim uma funcionalidade muito relevante ao escopo educacional. A Figura 18 compara graficamente as respostas de alunos e professores.

Ainda sobre esta funcionalidade foi questionado a opção destas informações adicionadas ao material de aula poderem ser compartilhadas opcionalmente entre os demais usuários, sendo que também grande parte das respostas marcaram como de total importância ou muito importante, somando $67,9 \%$ e $62,7 \%$ para professores e alunos, respectivamente. A Figura 19 compara graficamente estas respostas.

A funcionalidade da ferramenta permitir o retorno anônimo do aluno é uma nova forma de comunicação possível entre alunos e professores, e pode ser utilizada como 
Figura 18 - Importância da ferramenta permitir que os alunos anotem sobre o conteúdo, comparação entre as respostas de professores e alunos

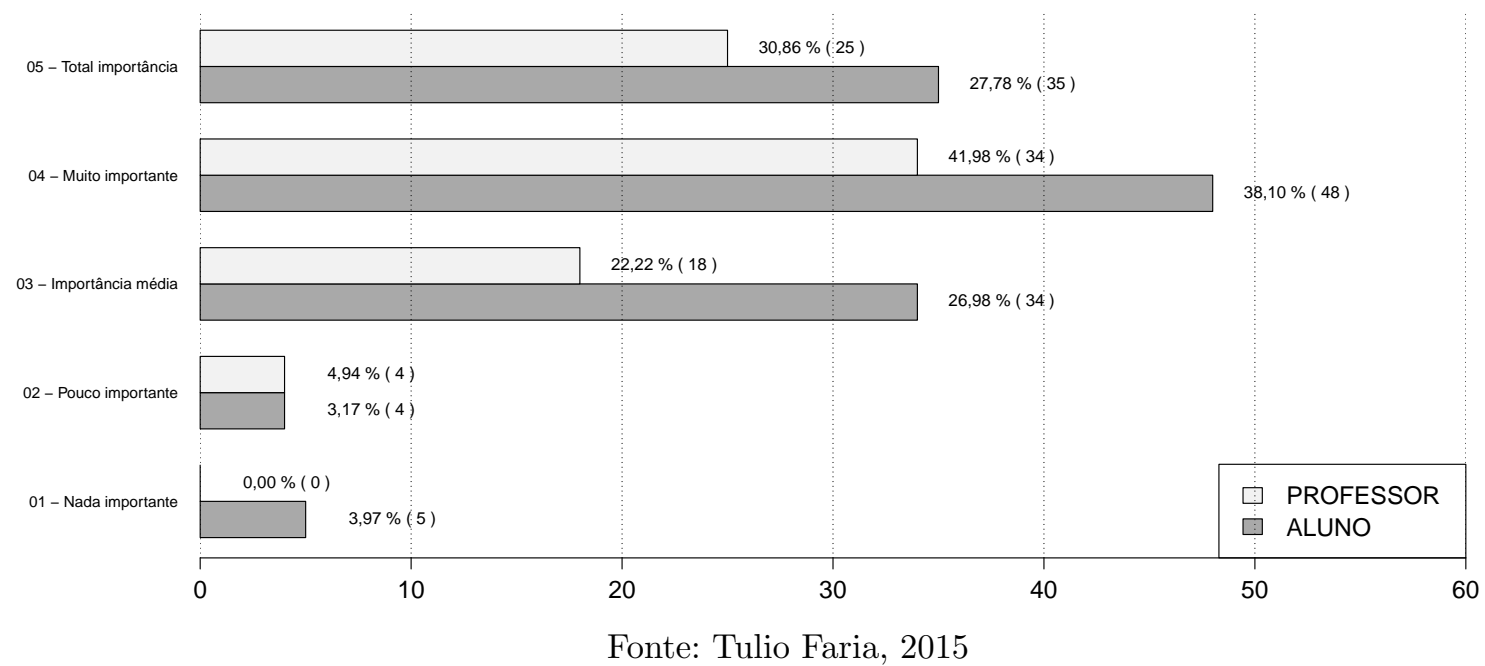

Figura 19 - Importância da ferramenta ser multiplataforma, comparação entre as respostas de professores e alunos

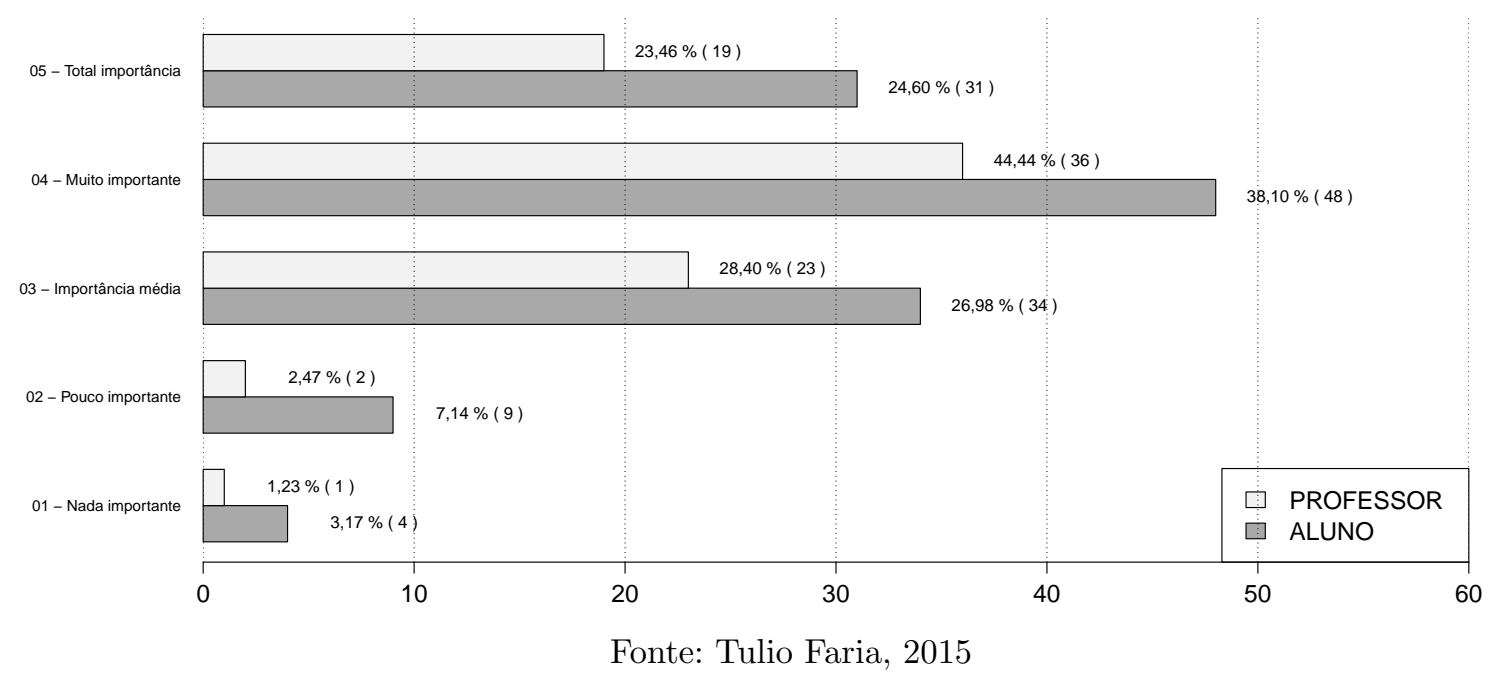

um termômetro em sala de aula permitindo ao professor possuir mais um indicador de motivação e/ou satisfação dos alunos, podendo adequar sua aula a medida que a mesma está acontecendo ou analisando estes dados posteriormente. Sobre esta funcionalidade, também grande parte das respostas de alunos e professores consideram-a como importante, somando $77,78 \%$ e $51,58 \%$, respectivamente, como de total importância e muito importante. A Figura 20 mostra graficamente estas respostas. 
Figura 20 - Importância da ferramenta permitir um retorno anônimo dos alunos aos professores sobre as aulas (respostas de professores e alunos)

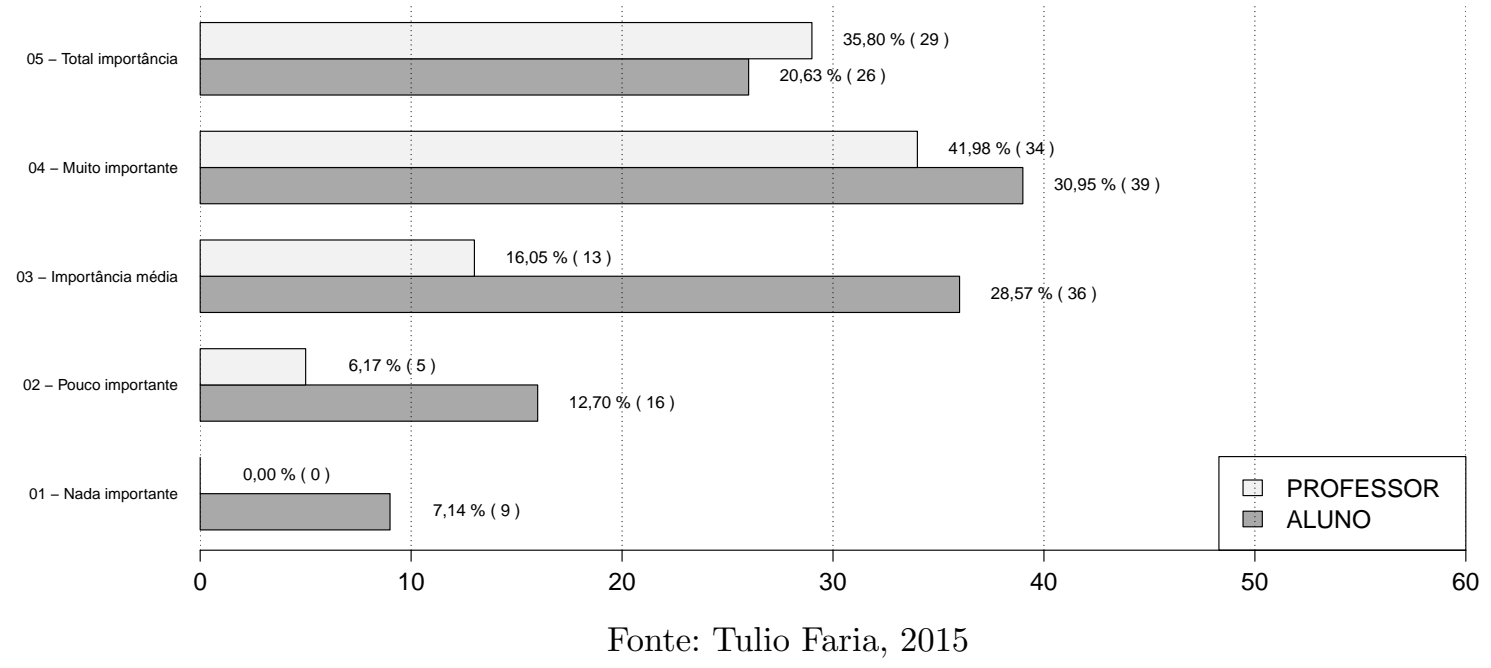

\subsection{Considerações}

A pesquisa possibilitou conhecer um pouco mais sobre uma parte do público deste trabalho. Também permitiu conhecer os recursos utilizados e perceber que estes são diretamente ligados ao tipo de metodologias e modalidades pedagógicas mais amplamente utilizadas.

Alguns professores fizeram considerações interessantes sobre uma ferramenta com as características propostas. Como por exemplo, um professor considera a possibilidade de permitir ao aluno pesquisar na internet durante a aula de extrema importância para demonstrar sua capacidade de raciocínio e consequentemente seu interesse na aula e no tema. Outro professor, acha que ao oferecer uma ferramenta como esta, a grande maioria dos alunos passariam a utilizar internet em aula com a finalidade acadêmica deixando assim de utilizar para fins pessoais.

Os resultados desta pesquisa foram também utilizados para nortear quais e como as funcionalidades da ferramenta deverão ser projetas e desenvolvidas, sendo um fator muito importante ao levantamento de requisitos descrito no Capítulo 6. 


\section{O sistema Mindboard}

Este capítulo tem como objetivo detalhar o projeto e desenvolvimento do sistema Mindboard. O desenvolvimento seguirá o processo unificado customizado de forma similar à proposta por Bernardes (2004).

\subsection{O Processo Unificado e suas customizações}

O Processo Unificado foi inicialmente discutido por Jacobson, Booch e Rumbaugh (1999) em sua busca por um processo de software guiado por casos de uso, centrado na arquitetura, iterativo e incremental. Segundo Pressman (2006) o Processo Unificado é uma tentativa de apoiar-se nos melhores recursos e características de modelos convencionais de processo de desenvolvimento de software reforçando pontos de desenvolvimento ágil.

Pressman (2006) descreve o processo unificado como um arcabouço de um processo genérico, onde o mesmo é composto pelas fases de Comunicação, Planejamento, Modelagem, Construção e Implantação. Na fase de Comunicação acontece toda a troca de informações com os interessados no projeto e clientes, e inclui o levantamento de requisitos e atividades relacionadas. A fase de Planejamento, define e estabelece as tarefas futuras a serem desenvolvidas, juntamente com os riscos, recursos necessários, produtos de trabalhos que serão gerados e um cronograma do trabalho. A fase de Modelagem é a atividade onde são desenvolvidos modelos que facilitam o entendimento pelos desenvolvedores e cliente dos requisitos e do projeto que irá satisfazer os mesmos. Na fase de Construção são desenvolvidas as atividades de geração de códigos fonte e de testá-los. E a fase de Implantação, que é a fase final, o software completo ou uma atualização do mesmo é entregue ao cliente (PRESSMAN, 2006). A Figura 21 ilustra a ordem em que estas fases acontecem.

O Processo Unificado é composto por ciclos que passam por atividades contidas nas fases genéricas de um processo descritas anteriormente por Pressman (2006), porém de uma maneira iterativa e incremental. As fases no Processo Unificado são nomeadas de forma diferente, sendo elas a Concepção, Elaboração, Construção, Transição e Produção.

A fase de Concepção abrange as atividades das fases de Comunicação e Planejamento do processo genérico descrito anteriormente. Durante a Concepção acontecem as atividades de comunicação com o cliente e usuários finais, é realizada a descrição dos requisitos, uma 
arquitetura é proposta, e um plano de trabalho para este ciclo/incremento é criado. Nesta fase são comumente utilizados diagramas que facilitem o entendimento e comunicação entre os interessados no projeto, como Diagramas de Casos de Uso e Diagramas de Classes (PRESSMAN, 2006). Nesta fase deve-se também avaliar o contexto onde o projeto será inserido verificando seu impacto e retorno. Caso o retorno seja mínimo ou não valha a pena, pode ser cancelado após esta fase (SOMMERVILLE, 2010).

Após a Concepção, a iteração passa para a fase de Elaboração incluindo as atividades das fases de Planejamento e Modelagem do processo genérico. A Elaboração expande os Casos de Usos e Diagramas de Classes gerados na fase anterior, permitindo uma visão mais específica e refinada sobre os requisitos (PRESSMAN, 2006). O objetivo principal desta fase é desenvolver uma visão sólida do domínio, estabelecer um arcabouço arquitetural, definir um planejamento e identificar os principais riscos (SOMMERVILLE, 2010).

A fase de Construção é idêntica a do processo genérico (PRESSMAN, 2006), envolvendo projetar, programar e testar o sistema, incluindo o desenvolvimento de testes unitários. Partes do sistema desenvolvidas em paralelo são integradas nesta fase. Ao final desta fase, deve-se gerar uma versão funcional do software e sua documentação relacionada pronta para entrega aos interessados (SOMMERVILLE, 2010).

Já na fase de Transição acontece a mudança do sistema/conjunto de funcionalidades do estado de desenvolvimento para produção (SOMMERVILLE, 2010). Quando relacionado ao processo genérico, esta fase abrange os últimos estágios de Construção e a primeira da Implantação, e nesta fase o cliente e usuários finais possuem contato com uma versão beta do software e é possível que eles deem retorno sobre o mesmo (PRESSMAN, 2006).

A Figura 21 ilustra as fases do Processo Unificado e seus relacionamentos ao processo genérico definido por Pressman (2006). Os itens delimitados por linhas pontilhadas são pertencentes ao Processo Unificado, e as de linhas contínuas, pertencem ao processo genérico de software.

O Processo Unificado permite escolher, de acordo com as características de cada projeto, a forma como as mesmas são percorridas, ou seja, são iteradas. As iterações podem acontecer de duas formas: a) cada fase pode ser conduzida de forma iterativa com os resultados desenvolvidos de forma incremental; b) todo o conjunto de fases podem ser conduzidas de forma incremental (SOMMERVILLE, 2010). 
Figura 21 - As fases de um processo genérico relacionadas com as fases do Processo Unificado

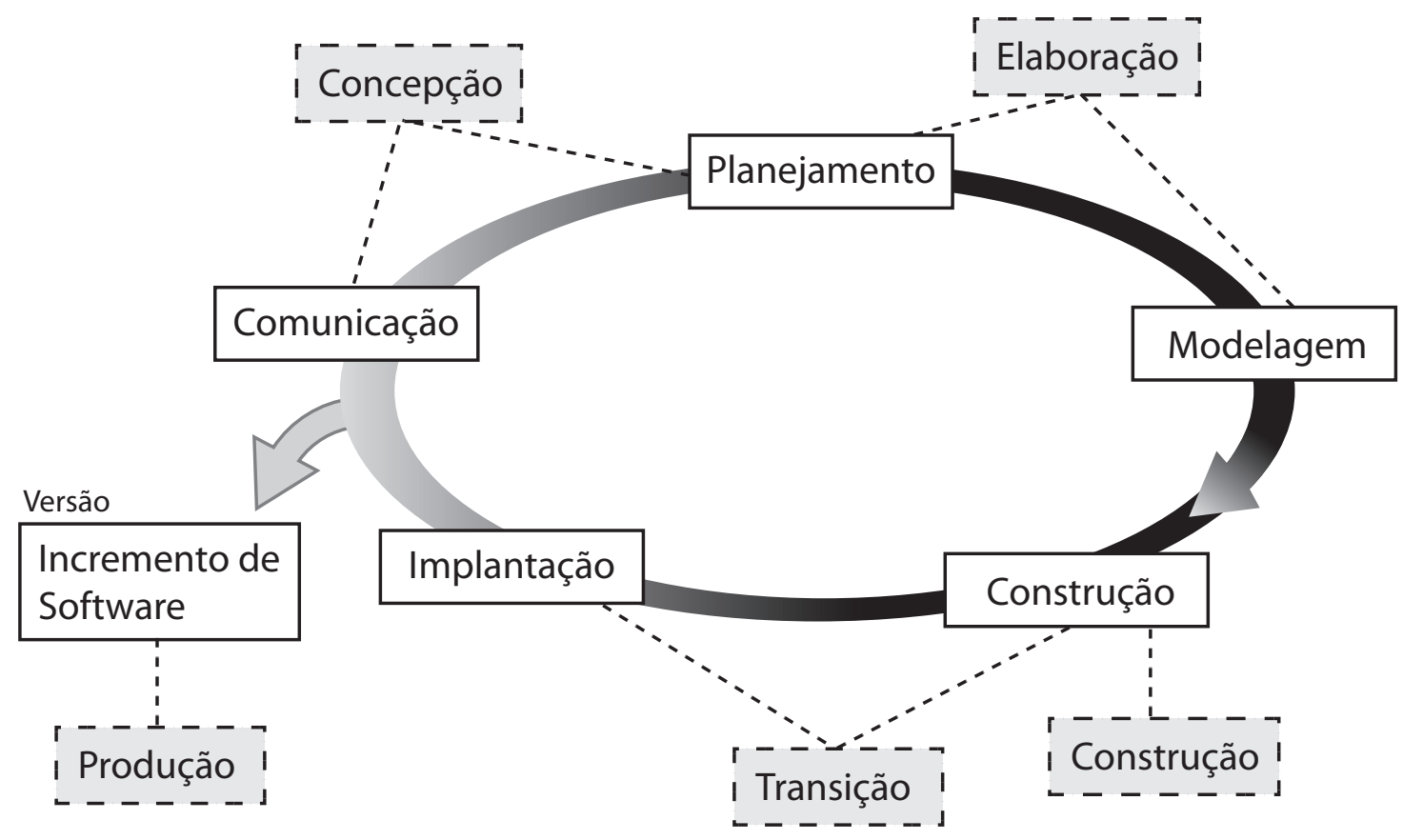

Fonte: Pressman (2006)

Na Figura 22 as setas menores indicam a possibilidade de seu comportamento incremental nas atividades daquela fase. Já a seta maior, indica o cenário onde todas as fases são percorridas incrementalmente.

Figura 22 - Formas de iteração do Processo Unificado

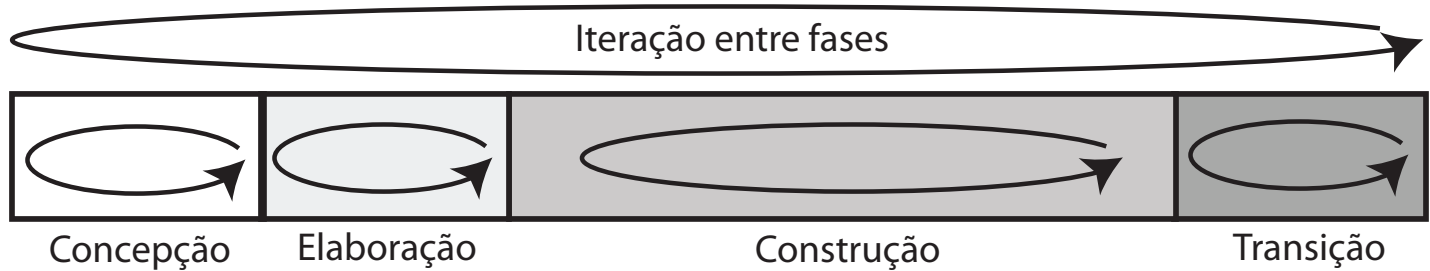

Fonte: Sommerville (2010)

\subsection{Customizações do Processo Unificado}

Neste trabalho, para o desenvolvimento do sistema será utilizado o Processo Unificado com as customizações propostas por Bernardes (2004), que propõe algumas simplificações no Processo Unificado convencional possíveis pelo baixo risco financeiro do projeto, 
pela pequena escala envolvendo um único desenvolvedor e para a redução do número de artefatos artefatos gerados.

De acordo com Smith (2001) em projetos com estas características as fases de Concepção e Elaboração podem ser reduzidas a uma rápida análise de viabilidade e com a definição de um cronograma de alto nível para as atividades do trabalho, que é refinado em cada etapa.

Este projeto terá documentado exclusivamente a fase de Construção, pois dentro desta fase, segundo Jacobson, Booch e Rumbaugh (1999), podem ser absorvidas as atividades de requerimento, projeto e implantação em projetos de pequeno porte, e portanto, não precisa ser realizada explicitamente.

A etapa de projeto é bastante estendida em projetos de pesquisa pois inclui o desenvolvimento de, experimentação com, protótipos. A última alteração no Processo Unificado proposto é em relação aos artefatos gerados. Embora tenha sido dividido em várias iterações. As etapas de cada iteração serão descritas de uma única vez e serão mantidos somente os artefatos gerados já resultantes de todas as iterações realizadas até cada momento.

\subsection{Iterações}

As iterações no Processo Unificado fundamentalmente seguem a ideia que problemas menores são mais fáceis de resolver que problemas maiores (ARLOW; NEUSTADT, 2002). Assim, o Processo Unificado divide um projeto em "projetos menores" que são mais fáceis de gerenciar e desenvolver. Cada "projeto menor" é uma iteração (ARLOW; NEUSTADT, 2002), e o grande ponto chave que cada iteração passa pelas mesmas fases descritas anteriormente.

O projeto e desenvolvimento do sistema Mindboard aconteceu em quatro iterações. A primeira iteração foi focada em determinar a arquitetura mais adequada aos requisitos de escalabilidade e extensibilidade. Nesta fase também foi estruturada como será realizada a comunicação entre os participantes de uma aula, desde a arquitetura bem como o protocolo utilizado. Foram codificadas nesta fase provas de conceitos para que estas funcionalidades fossem experimentadas.

A segunda iteração é focada em desenvolver as funcionalidades de envio de apresentações de slides, permitindo a anotação colaborativa sobre os mesmos, funcionalidade 
presente em alguns dos trabalhos analisados na revisão da literatura mas não disponível em nenhum dos sistemas comerciais. Nesta interação também são desenvolvidas a geração de enquetes e o recebimento de retorno dos alunos sobre o andamento das aulas e serão projetadas e codificadas as políticas de visibilidade de informação, de modo que cada usuário que contribuir com informações poderá definir quem poderá visualizar a mesma.

Na terceira iteração, a interface é desenvolvida com o objetivo principal de obter uma interface responsiva que se adapta em dispositivos com telas de tamanhos distintos. Nesta iteração todos os dados e informações geradas e trocadas durante uma aula terão sua persistência garantida através do uso de um banco de dados.

Já na quarta e última iteração, foi desenvolvida a funcionalidade de possibilitar rever uma aula, e também toda colaboração assíncrona da ferramenta. Foi adicionada também a funcionalidade de compartilhamento de código-fonte em tempo real, e o projeto foi disponibilizado para a realização do experimento prático.

Como relatado anteriormente, os artefatos que serão apresentados neste capítulo são o resultado de todas iterações executadas, e não as versões parciais desenvolvidas em cada uma delas.

\subsection{Captura de requisitos}

Os requisitos funcionais descrevem as funcionalidades que se espera que o sistema disponibilize, de uma forma completa e consistente. É aquilo que o usuário espera que o sistema ofereça, atendendo aos propósitos para qual o sistema está sendo desenvolvido (PáDUA, 2005).

Neste projeto os requisitos funcionais foram priorizados, adotando as seguintes denominações: essencial, importante e desejável. A Tabela 7 descreve o significado de cada uma delas.

Os requisitos funcionais da ferramenta Mindboard foram motivados pelas funcionalidades encontradas em ferramentas acadêmicas e de mercado através das revisões exploratórias descritas no Capítulo 4, pelas pesquisas conduzidas com professores e alunos do ensino médio e superior em que foi questionada a relevância da presença de determinadas funcionalidades em uma ferramenta multiplataforma para uso dentro e fora de sala de aula. A metodologia utilizada nestas pesquisas foi descrita na Seção 3.2 e seus resultados encontram-se no Capítulo 5. 
Tabela 7 - Prioridade dos requisitos

\begin{tabular}{|l|l|}
\hline Tipo & Descrição \\
\hline Essencial & $\begin{array}{l}\text { É o requisito sem o qual o sistema não entra em funci- } \\
\text { onamento. Requisitos essenciais são requisitos impres- } \\
\text { cindíveis, que têm que ser implementados. }\end{array}$ \\
\hline Importante & $\begin{array}{l}\text { É o requisito o qual o sistema entra em funcionamento, } \\
\text { mas de forma não satisfatória. Requisitos importantes } \\
\text { devem ser implementados, mas, se não forem, o sistema } \\
\text { pode ser implantado e usado mesmo assim, por exemplo, } \\
\text { sendo usado ainda durante o desenvolvimento, fornecendo } \\
\text { valor mesmo antes do término do projeto. }\end{array}$ \\
\hline Desejável & $\begin{array}{l}\text { É o requisito que não compromete as funcionalidades } \\
\text { básicas do sistema, isto é, o sistema pode funcionar de } \\
\text { forma satisfatória sem ele. Requisitos desejáveis são requi- } \\
\text { sitos que podem ser deixados para versões posteriores do } \\
\text { sistema caso não haja tempo hábil para implementá-los }\end{array}$ \\
\hline
\end{tabular}

Fonte: Tulio Faria, 2015

A publicação de Pusnik, Sumak e Hericko (2010) encontrada através da revisão sistemática mostra a relevância em um sistema de ensino a distância de algumas funcionalidades. Nesta pesquisa, a colaboração entre os alunos é citada como muito importante por $31,5 \%$ e como importante para $43,8 \%$ dos entrevistados. A comunicação com outros alunos também é relacionada como muito importante por $27,7 \%$ e como importante por 42,6\% dos entrevistados. A Tabela 5 mostra os resultados completos desta pesquisa.

Acredita-se que as características levantadas como relevantes em sistemas de ensino a distância também são relevantes ao ensino presencial, tanto para uso dentro como fora de sala de aula, uma vez que a comunicação e colaboração estão cada vez mais presentes em serviços online, e pela própria necessidade das gerações atuais em comunicar-se.

Os requisitos funcionais e não funcionais da ferramenta Mindboard são listadas e descritas no Apêndice K. Além disso, os requisitos funcionais estão nos diagramas de caso de uso mostrados adiante e o principal requisito não funcional refere-se à característica multiplataforma e com interface responsiva do sistema.

\subsubsection{Descrição dos atores}

Em um sistema, todos os elementos externos que de alguma forma interajam com o software é chamado de ator. Cada ator desempenha um papel no qual ele utiliza ou interage 
com os serviços e funções do sistema (GUEDES, 2009). Para a ferramenta Mindboard, os atores e seus devidos papéis são descritos a seguir.

\section{Ator 1 - Usuário}

Todos os usuários previamente cadastrados na ferramenta podem identificar-se no sistema através de um nome de usuário e senha.

\section{Ator 2 - Professor}

Usuários do tipo professor podem criar, gerenciar e conduzir aulas. Usuários Professores podem também gerenciar os usuários que podem acessar uma aula.

\section{Ator 3 - Aluno}

Usuários do tipo aluno podem acessar aulas já criadas pelos professores. Usuários do tipo aluno podem, dentro de uma aula, comentar sobre o material de aula e acompanhar o conteúdo antes, durante e depois da aula.

\section{Ator 4 - Outro sistema}

Outros sistemas podem interagir com o Mindboard para o gerenciamento de aulas, além de identificar e autenticar usuários.

\subsubsection{Diagramas de casos de uso}

Os diagramas de caso de uso visam exibir de uma maneira gráfica e rápida os casos de uso da ferramenta projetada. Para a ferramenta Mindboard, os diagramas de casos de uso foram agrupados de acordo com o tipo de usuário que a está utilizando.

A Figura 23 mostra o caso de uso de identificação de usuários. Todos os usuários deverão executar estes casos de uso antes de utilizar a ferramenta. No caso do ator ser outro sistema, a identificação do usuário bem como as credenciais de acesso são concedidas através de uma interface específica a integrações.

Os casos de uso da Figura 23 mostram o acesso de um usuário que está utilizando a ferramenta como professor. Nela o mesmo pode gerenciar aulas, e gerar todas as informações que são distribuídas a todos os demais usuários.

A Figura 25 mostra os casos de uso relacionados ao ator aluno. É formado por casos de uso que permitem ao usuário visualizar as informações geradas pelo professor e interagir através de perguntas e do compartilhamento das próprias anotações. 
Figura 23 - Diagrama de casos de uso - identificação e acesso a ferramenta

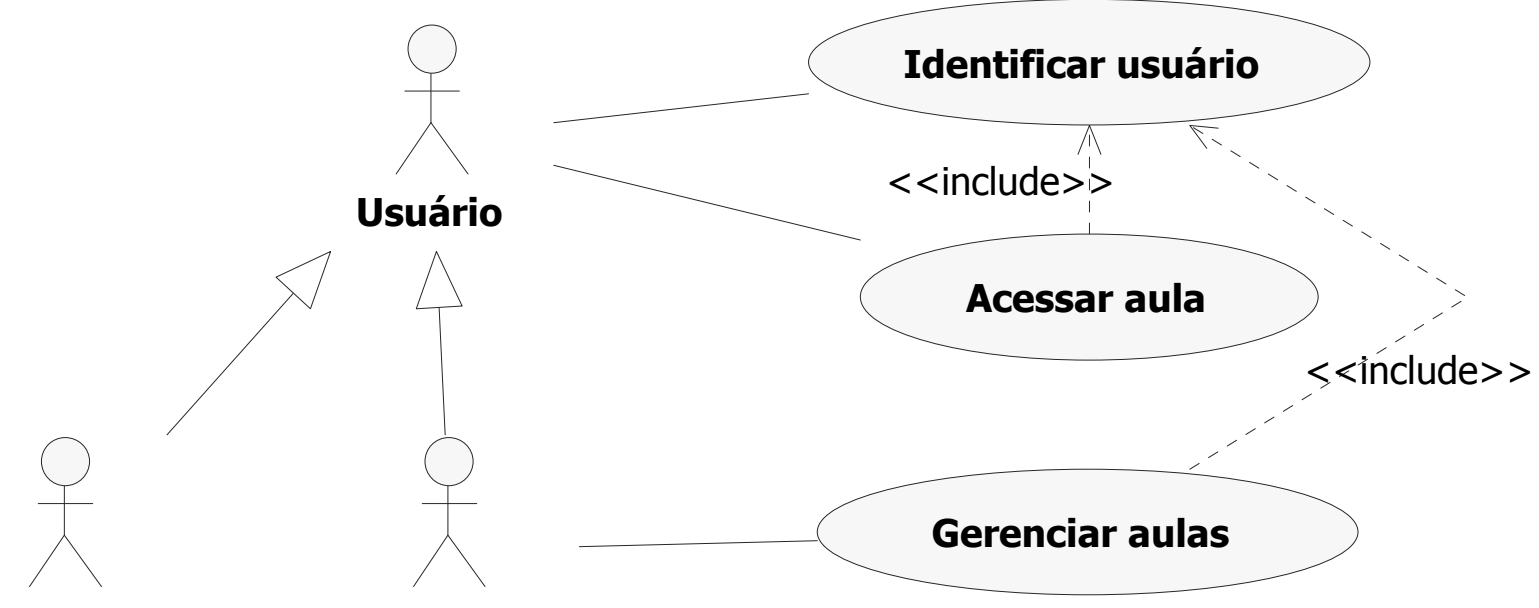

Aluno

Professor

Fonte: Tulio Faria, 2015

Figura 24 - Diagrama de casos de uso - acesso como professor

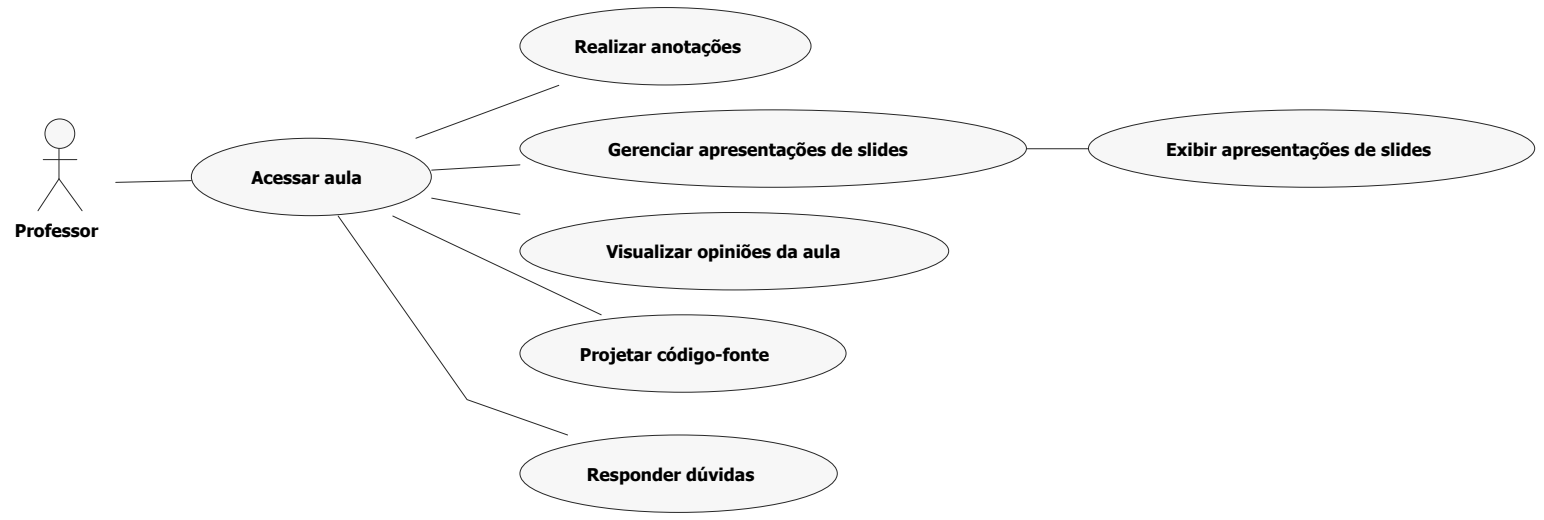

Fonte: Tulio Faria, 2015

Figura 25 - Diagrama de casos de uso - acesso como aluno

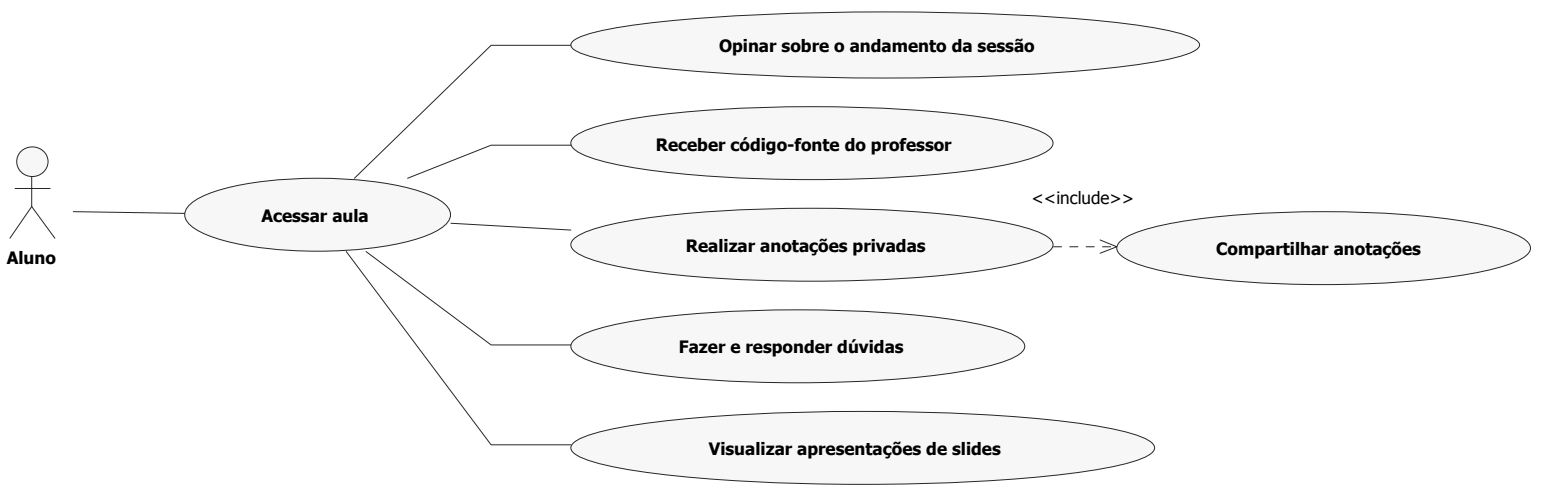

Fonte: Tulio Faria, 2015 


\subsubsection{Visão de dados}

O diagrama de classes permite a visualização das classes utilizadas pelo sistema e como estas relacionam, permitindo assim uma visão estática de como os dados utilizados na ferramenta são persistidos. O diagrama de classe do projeto é mostrado na Figura 26.

Figura 26 - Diagrama de classes

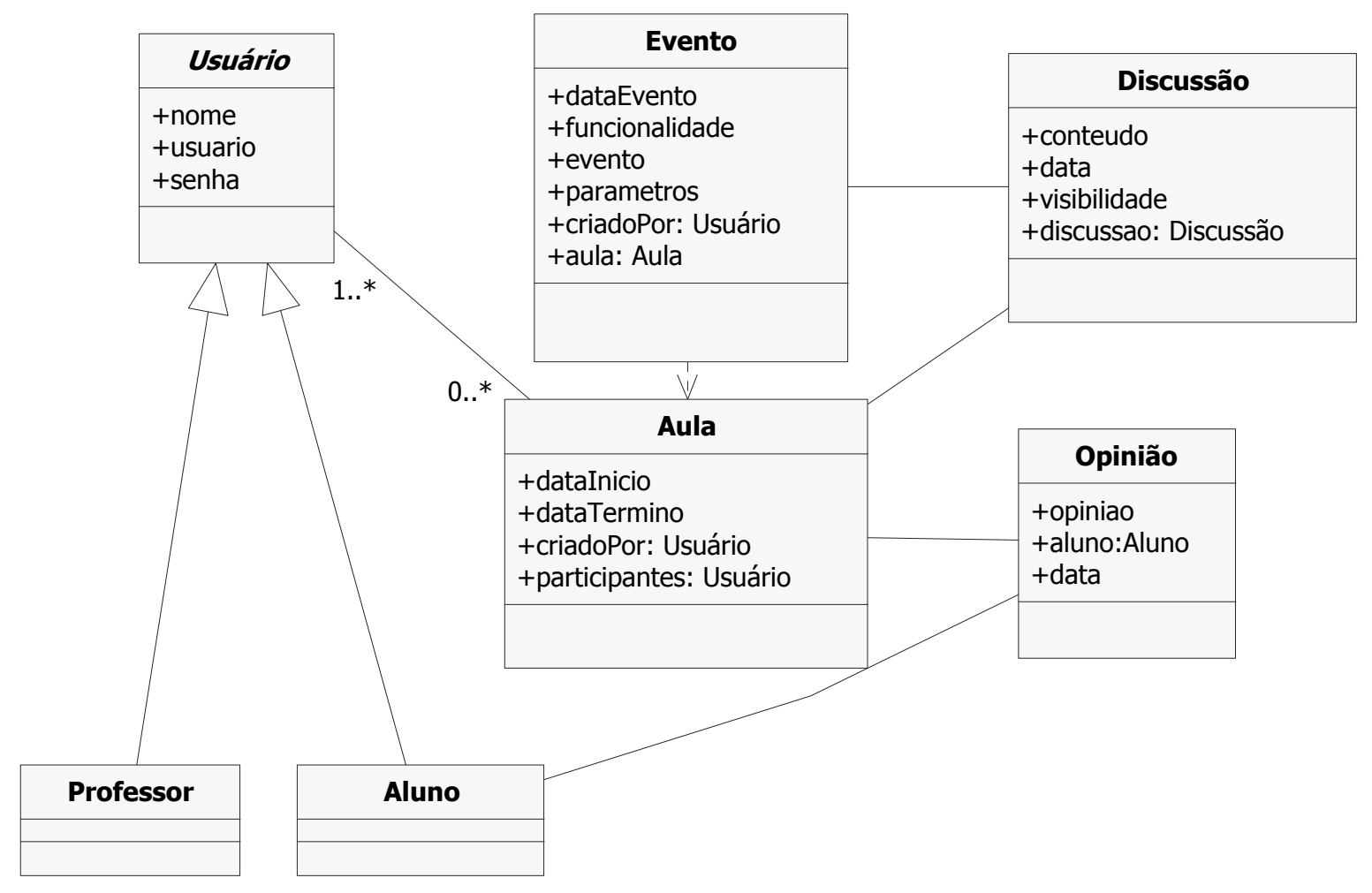

Fonte: Tulio Faria, 2015

A classe Usuário é abstrata e portanto só pode ser instanciada pela suas subclasses Aluno e Professor. Estas 3 classes que serão utilizadas para representar os dados dos usuários do sistema. A classe Aula é um período de utilização da ferramenta, ela pode ser criada por um Professor ou por um Outro Sistema através da interface de integração.

A classe Evento é relacionada a todo tipo de ação ou atividade realizada dentro de uma aula. Por exemplo, a troca de uma apresentação de slides por outra é um evento. A classe Discussão permite a vinculação das anotações em uma data aula, e também possibilita a criação de discussões e perguntas sobre o conteúdo. Já a classe Opinião é responsável pelo retorno dos alunos sobre uma dada aula. 


\subsection{Tecnologias}

O protótipo do Mindboard, de acordo com o especificado no objetivo deste trabalho, deve funcionar em mais de uma plataforma e de maneira simples. Neste sentido, o desenvolvimento foi norteado a um sistema web. As tecnologias envolvidas nessa arquitetura geralmente são classificadas em front-end e back-end, quando são executadas no navegador de internet e em servidores, respectivamente.

As tecnologias envolvidas no desenvolvimento do protótipo do sistema Mindboard foram definidas inicialmente baseado na participação no grupo de pesquisas LInE e pela experiência anterior do autor. Durante a participação no experimento do LInE foi possível projetar e desenvolver módulos de aprendizagem em duas linguagens: Java para a criação de Applets e JavaScript. Na Seção seguinte será discutido o papel destas linguagens para as decisões de projeto tomadas no desenvolvimento do protótipo.

\subsubsection{Front-end}

As tecnologias que são executadas nos navegadores de internet são denominadas tecnologias ou linguagens de front-end. Essas tecnologias formam a parte do ambiente web em que usuário vê e interage (LONG, 2012), e portanto, é o ponto fundamental para que um sistema web possa ser multiplataforma.

Durante a participação no grupo de pesquisas LInE, o autor desta pesquisa desenvolveu várias provas de conceitos e objetos de aprendizagem em tecnologias front-web como Java Applet e em JavaScript, HTML5 e CSS3. A linguagem Java quando utilizada para a criação de pequenos programas que executam nos navegadores de internet são conhecidos como Java Applet.

Já as linguagens JavaScript, HTML5 e CSS3 são linguagens comumente utilizadas em conjunto. JavaScript é uma linguagem de script e portanto interpretada em tempo de execução no navegador, sendo a responsável por adicionar interatividade ao HTML5 e ao CSS3.

A quinta versão da linguagem HTML adicionou novas funcionalidades, tais como a possibilidade de comunicação em tempo real e uma maior possibilidade de criação de aplicativos web (HTML5, 2015). A linguagem HTML é uma linguagem de marcação sendo 
responsável por descrever os dados e estruturas em um ambiente web. Já a linguagem CSS é uma linguagem utilizada para definir o layout e aparência dos elementos.

Para o desenvolvimento do protótipo do sistema Mindboard é necessário que as tecnologias de front-end possam comunicar-se em tempo real com o servidor de maneira a utilizar o mínimo de recursos computacionais possíveis e que permita criar uma interface gráfica que adequa-se ao tamanho de tela de cada dispositivo dispositivo.

A linguagem Java conta com suporte a Sockets, que é uma maneira de permitir a abertura de uma comunicação bidirecional para troca de dados entre computadores distintos (WHAT..., 2015a). Essa técnica pode ser utilizada em sua versão a ser executada no navegador. Já o HTML5 juntamente com o JavaScript pode utilizar-se de uma técnica chamada web-socket, que é muito semelhante ao Socket citado anteriormente, porém para ser utilizado na web e tem seu funcionamento sobre o protocolo Hyper-Text Transfer Protocol (HTTP), fato que evita que muitos antivírus e firewalls bloqueiem este tipo de comunicação (WHAT..., 2015b).

Outro requisito não funcional exigido pelo protótipo do sistema Mindboard é a possibilidade de adaptar-se a diferentes dispositivos e tamanhos de tela. Na tecnologia Java é possível utilizar gerenciadores de layout que utilizam posição relativa para atender a esta necessidade. Já em CSS3 é possível utilizar media-queries que é uma forma de exibir elementos de maneira diferente de acordo com as dimensões da tela ou pela especificação do dispositivo (CSS3..., 2015).

Dado que ambas as tecnologias atendem aos requisitos e objetivos deste trabalho, um primeiro experimento é necessário para levantar indícios de qual seria a melhor adoção para o protótipo do sistema Mindboard. Assim, foi realizado o experimento no grupo de pesquisas LInE, conforme descrito na Seção 3.1.

Durante o experimento foram gerados dados de acesso a cada vez que uma atividade era iniciada e visualizada na tela. Isso indicava que a interface gráfica estava totalmente funcional. Assim, foram somadas os totais em cada atividade do VPL (Java Applet), ivProg (Java Applet) e ivProg HTML5. A Tabela 8 mostra os totais em cada uma delas.

Importante notar que apesar do número de visualizações reduzir entre a semana 1 e 4 em todos os grupos, avaliando semana a semana, o com ivProg HTML5 obteve mais visualizações que os outros grupos, principalmente nas semanas iniciais, onde um problema técnico de impossibilidade de acessar a ferramenta poderia ocasionar no abandono do curso. Nas semanas subsequentes, uma possível causa a redução do número de visualizações de 
Tabela 8 - Visualizações das atividades

\begin{tabular}{|c|c|c|c|c|c|c|c|c|}
\hline Curso & $\begin{array}{c}\text { Semana } 1 \\
\text { (4 atividades) }\end{array}$ & $\begin{array}{l}\text { Visualizações } \\
\text { por atividade }\end{array}$ & $\begin{array}{c}\text { Semana } 2 \\
\text { (6 atividades) }\end{array}$ & $\begin{array}{l}\text { Visualizações } \\
\text { por atividade }\end{array}$ & $\begin{array}{c}\text { Semana } 3 \\
\text { (4 atividades) }\end{array}$ & $\begin{array}{l}\text { Visualizações } \\
\text { por atividade }\end{array}$ & $\underset{\text { (3 atividades) }}{\text { Semana } 4}$ & $\begin{array}{l}\text { Visualizações } \\
\text { por atividade }\end{array}$ \\
\hline $\begin{array}{l}\text { G1 } \\
\text { (VPL - Java Applet) }\end{array}$ & $517(17 \%)$ & 129 & $217(12 \%)$ & 36 & $80(20 \%)$ & 20,0 & $70(31 \%)$ & 23 \\
\hline $\begin{array}{l}\text { G2 } \\
\text { (IVProg - Java Applet) }\end{array}$ & $1182(39 \%)$ & 296 & $516(28 \%)$ & 86 & $140(34 \%)$ & 35,0 & $66(29 \%)$ & 22 \\
\hline $\begin{array}{l}\text { G3 } \\
\text { (IVProg - HTML5/CSS3/JS) }\end{array}$ & $1343(44 \%)$ & 336 & $1112(60 \%)$ & 185 & $187(46 \%)$ & 46,8 & $92(40 \%)$ & 31 \\
\hline Total & 3042 & & 1845 & & 407 & & 228 & \\
\hline
\end{tabular}

Fonte: Tulio Faria, 2015

modo geral a medida que o curso era conduzido pode ser compreendido como um maior compreendimento dos alunos sobre os assuntos ou até mesmo pelo abadono do curso pelos mesmos.

Durante o período do curso foram realizados vários atendimentos de suporte aos alunos guiando-os a instalar e configurar de forma apropriada suas máquinas para que fosse possível utilizar o VPL e o iVProg versão Java Applet, mesmo assim, para alguns alunos este entrave tecnológico representou uma barreira a utilização do curso e ainda há aqueles alunos que simplesmente desistiram e não avisaram. Um exemplo do que um aluno com problemas enviou "Eu tive dificuldades (e ainda estou tendo) em realizar os algoritmos em C (este aluno pertence a G1 e refere-se ao VPL construído em Java Applet), diretamente pela ferramenta, pois apesar de ter a versão atualizada do Java em minha máquina eu não consigo pois o sistema informa que minhas configurações de segurança estão bloqueando a aplicação. Gostaria de uma ajuda dos Srs. para resolver isso.".

A tecnologia Java Applet possui um outro problema o qual vem ocorrendo nas últimas versões do navegador Google Chrome. Esse navegador está removendo progressivamente o suporte a tecnologia que permite que o Java Applet seja executado (HOW..., 2015). Assim, como mais de $60 \%$ dos usuários atualmente utilizam esse navegador (BROWSER..., 2015), uma grande parcela dos usuários não poderiam utilizar uma ferramenta feita com essa tecnologia.

Já a tecnologia HTML5, JavaScript e CSS3 é suportada de maneira mais ampla a cada nova atualização dos navegadores, e funciona muito bem em todas as versões mais atuais de todos os navegadores, inclusive os disponíveis em dispositivos móveis. Assim, a tecnologia escolhida para a criação do protótipo do Mindboard é a HTML5, com JavaScript 
e CSS3. Esta decisão também levou à escolha do JavaScript como linguagem back-end, conforme será descrito na Seção 6.5.2.

Foram também adotados 2 frameworks para auxiliar no desenvolvimento e organização do código-fonte no front-end: o AngularJS (ANGULARJS..., 2015) e o Bootstrap (BOOTSTRAP..., 2015). O AngularJS é um framework Javascript mantido pelo Google que permite a organização em camadas do código-fonte, a reutilização facilitada de código e principalmente uma redução de código para manipular o HTML5 através de um recurso chamado databinding (DATA..., 2015), que permite a sincronização entre a camada de dados e de visualização. A camada de visualização torna-se uma projeção da camada de dados, quando os dados mudam, a camada de visualização reflete estas mudanças, e vice-versa.

O framework Bootstrap é um framework HTML, CSS e JavaScript muito popular para o desenvolvimento de sites e sistemas web. Este framework traz uma série de soluções para que uma mesma interface gráfica funcione em diferentes dispositivos com diferentes tamanhos de tela sem a necessidade de codificação para cada um deles. Além disso, conta com uma série de implementações de componentes que não existem nativamente em HTML, como abas, janelas modais, etc.

\subsubsection{Back-end}

Linguagens ou tecnologias back-end são executadas em servidores e é onde um sistema web pode ser escalável para atender uma demanda maior de usuários. Todas as informações relevantes às regras de negócio do sistema ficam armazenados nessa parte da aplicação.

Conforme descrito anteriormente, depois de definido a linguagem JavaScript para ser utilizada no front-end, pesquisou-se também utilizá-la no lado do servidor e em toda a aplicação. Assim, foi utilizado o NodeJS para executá-la em servidores.

A tecnologia NodeJS é um ambiente que possibilita a execução de códigos JavaScript no servidor utilizando a mesma tecnologia por trás do navegador Google Chrome, a engine V8 (TILKOV; VINOSKI, 2010). Uma característica muito importante da linguagem JavaScript e que torna o NodeJS muito interessante para sistemas que possuem comunicação em tempo real é o fato do código ser assíncrono. Assim, todas as operações de entrada e saída que são por natureza lentas podem ser executadas de maneira eficiente (TILKOV; VINOSKI, 
2010). Foi utilizado também a ferramenta gerenciadora de módulos do NodeJS, o Node Package Manager (NPM), para gerenciar todos as depêndencias a módulos de terceiros. Outro ponto que também faz parte das tecnologias back-end é o armazenamento de dados, que neste caso foi escolhido o banco de dados MongoDB.

O MongoDB é um banco de dados não-relacional, ou seja, o armazenamento de dados é feito em estruturas não tabulares. Seu armazenamento de dados é feito em documentos onde a estrutura é composta por pares chave-valor. Os valores armazenados podem conter além de dados de tipos simples, outros documentos e vetores (INTRODUCTION..., 2014). Internamente o MongoDB armazena os documentos no formato BSON que é a forma binária de serialização do JavaScript Object Notation (JSON) (BSON, 2014). Assim, internamente o MongoDB armazena objetos JavaScript, o que facilita bastante as operações quando realizadas pelo NodeJS, já que não é necessário conversões de dados.

O MongoDB é muito eficiente no armazenamento de grandes volumes de dados, e de acordo com Boicea, Radulescu e Agapin (2012) o tempo para inserir grandes quantidades de informação chega a ser 15 vezes inferior que a mesma inserção em um banco de dados Oracle. O tempo para a realização de outras operações no MongoDB também são bem inferiores se comparado ao Oracle (BOICEA; RADUlESCU; AGAPIN, 2012). Pela facilidade da interoperabilidade entre o NodeJS e o MongoDB e por sua eficiência, ele é utilizado no armazenamento dos dados do protótipo do sistema Mindboard.

Outro componente também utilizado no back-end foi o banco em memória Redis, um banco key-value que possui uma excelente performance e eficiência por manter os dados em memória. Sua utilização mais comum é feita para cache de dados de banco de dados, porém sua funcionalidade pubsub também é muito indicada para sistemas com comunicação em tempo real como o Mindboard.

A funcionalidade pubsub (REDIS..., 2014) permite que sejam criados canais de dados entre instâncias de servidores de aplicações distintos. Um canal de dados é criado, e os usuários que precisam ser notificados de atualizações de informações naquele canal o fazem através do subscribe. Toda vez que uma nova informação é gerada através da operação publish, todos que fizeram subscribe no canal receberão essa informação. Na próxima seção será discutido como estes componentes podem ser organizados para que o sistema Mindboard possa ser escalável atendendo cada vez um número de usuários maior. 


\subsubsection{Arquitetura}

Os requisitos não funcionais do sistema Mindboard sugerem que o mesmo possua uma arquitetura que possa ser escalável e de fácil manutenção. Assim, para atingir este requisito foram pesquisados formas de disposição de servidores que permitissem a adição de recursos computacionais de forma simples sem a necessidade de reescrever todo o sistema. Foram encontrados alguns estudos de caso e relatos de sistemas comerciais que possuem um grande número de usuários ativos que descreve como foi definida sua arquitetura para suportar o número crescente de usuários.

Sendo assim, a arquitetura proposta para o sistema Mindboard foi baseada em relatos e estudos de caso dos sistemas Box.com (ZAKAS, 2014), Trello (KIEFER, 2014) e Boo-Box (GOMES, 2009). A Figura 27 ilustra esta arquitetura.

Figura 27 - Arquitetura de servidores do Mindboard

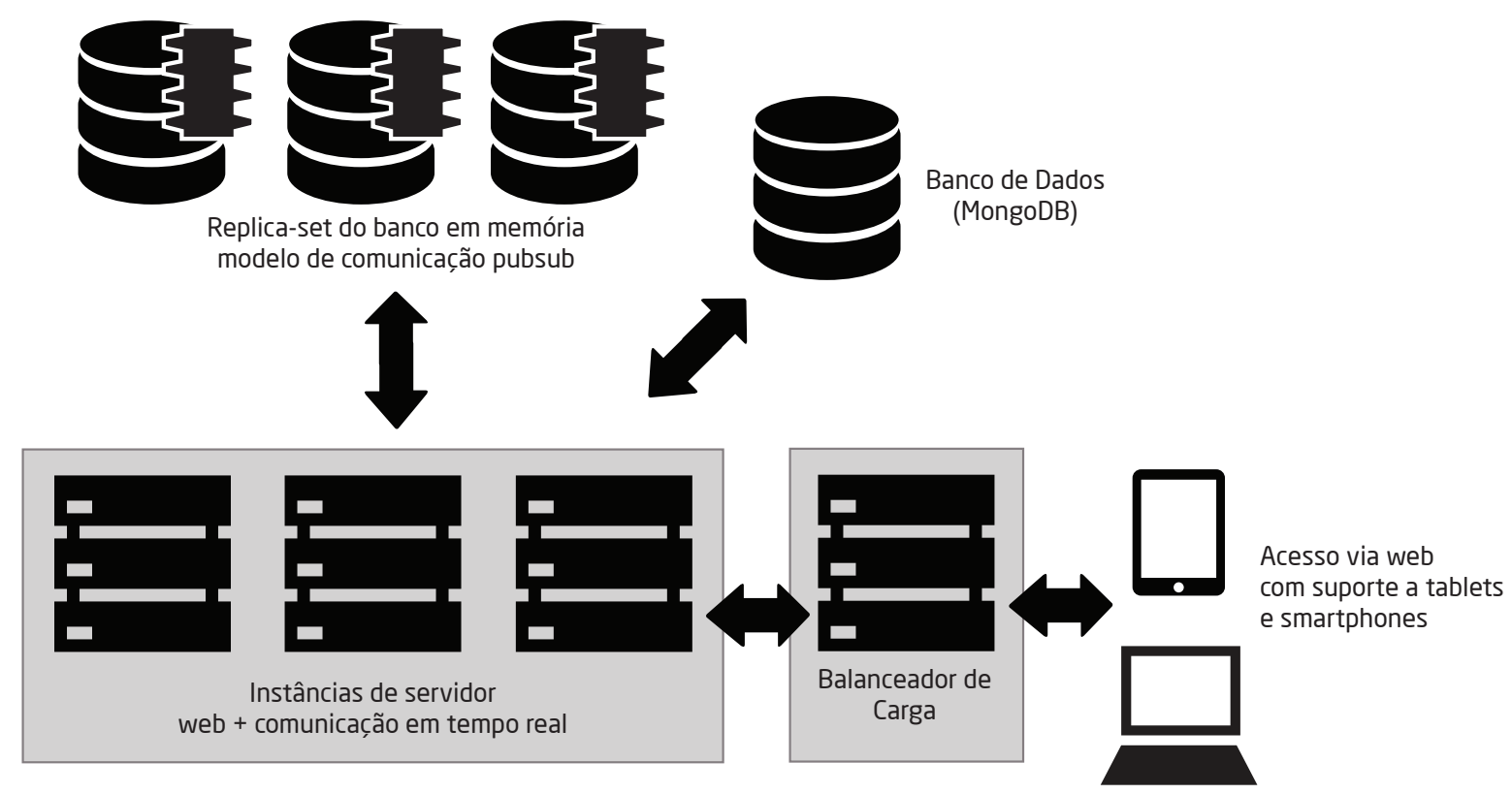

Fonte: Tulio Faria, 2015

Uma solicitação do usuário do sistema chega através do balanceador de carga. Este componente é composto por um ou mais servidores que recebem todas as requisições de usuários e as redistribui para cada servidor de aplicação. Esta redistribuição tem como objetivo manter a carga distribuída entre eles. O balanceador de carga também é 
responsável pelo isolamento dos demais componentes pertencentes a esta arquitetura de conexões provenientes da internet, sendo uma peça importante para a segurança de todo sistema.

A camada de servidores de aplicação, desenvolvida em JavaScript e executada no NodeJS, é responsável por receber as requisições do balanceador de carga e processar de forma completa a requisição do usuário. Nas requisições em que é necessário ler e persistir dados, a aplicação faz esta operação em um dos servidores de banco de dados.

O banco de dados MongoDB é configurado como um replica-set, ou seja, vários servidores espelhados e que em cada instância da aplicação pode conectar-se e realizar operações. Nesta configuração há a garantia de disponibilidade de dados e também o aumento da performance.

No caso do sistema Mindboard pode acontecer a situação onde usuários conectados a servidores de aplicação distintos precisem trocar dados entre si, como por exemplo, no momento de acesso a uma aula. Nessa situação, a comunicação entre servidores é realizada utilizando o banco de dados em memória Redis e sua funcionalidade pubsub.

A camada de comunicação entre servidores é composta por instâncias de servidores em memória também configurados como um replica-set, ou seja, os estes servidores também possuem uma alta disponibilidade e performance. Essa camada permite a comunicação em tempo real entre os servidores de forma rápida e eficiente, pois os dados não são persistidos em disco ficando apenas em memória.

\subsection{Implementação}

Após definida as tecnologias que serão utilizadas e como as mesmas estão dispostas, este Seção descreve como estas foram utilizadas no desenvolvimento do protótipo do sistema Mindboard. A seguir é apresentado como o sistema foi organizado.

\subsubsection{Organização em módulos}

Os módulos no NodeJS representam uma forma de organização de código-fonte e são compostos por um arquivo ou conjunto de arquivos fonte correlacionados, e podem ser de 3 tipos: internos, de terceiros ou disponíveis localmente. Os módulos internos são módulos com as funcionalidades já disponíveis nativamente no NodeJS, como por exemplo 
o $f s$ para gerenciamento de arquivos e diretórios físicos (Modules, 2015), e no caso de sua inclusão para uso é realizado utilizando a seguinte instrução require('fs').

Por meio de módulos de terceiros, os números de desenvolvedores aumentam e colaboram entre si, fortalecendo a comunidade NodeJS. Esses módulos geralmente são distribuídos através do repositório principal: NPM ${ }^{1}$ e também pode ser utilizado repositórios de código GIT. Estes módulos são colocados em um diretório node_modules no próprio diretório do projeto ou nos diretórios precedentes ao diretório principal. A inclusão destes módulos acontecem também por meio da instrução require, como por exemplo: require('nomeMódulo').

Já os módulos disponíveis localmente são compostos por arquivos simples ou diretórios. Quando disponibilizados em arquivos simples, eles são incluídos como require('·arquivo.js'). Já quando é colocado em um diretório, este diretório deverá possuir o arquivo package.json, o qual descreve e indica o ponto de entrada do módulo. A inclusão do módulo disponíveis em diretório também acontecem com require, como por exemplo, require('./nomeDoDiretório').

Para representar graficamente os módulos utilizados e os construídos no protótipo do sistema Mindboard será utilizado o diagrama de pacotes da UML. Esse diagrama representa partes do sistema divididos em agrupamentos lógicos entre eles. O diagrama da Figura 28 representa a organização de módulos do protótipo do sistema Mindboard.

O pacote node_modules representa os módulos de terceiros utilizados. Cada subpacote representa o módulo de terceiro em si. O módulo socket.io é responsável pela comunicação em tempo real utilizando web-sockets. O módulo mongoose é utilizado para a conexão e manipulação de dados no banco MongoDB, Passport é utilizado para a autenticação de usuários. Já o expressjs foi utilizado como framework web basicamente trabalhando como um mapeador entre a solicitação e resposta do usuário. O módulo async é utilizado para organizar o fluxo de código assíncrono, e o html-linkfy é utilizado para transformar endereços presentes em textos em links clicáveis. O módulo redis é utilizado para conexão com o banco em memória Redis, o módulo connect-busboy é utilizado para o gerenciamento de envio de arquivos. Já o módulo node-uiid é utilizado para gerar identificadores únicos. O cookie-parser é utilizado para o gerenciamento de cookies e o body-parser para tratar requisições onde os dados são enviados no corpo das solicitações.

1 http://npmjs.org 
Figura 28 - Módulos do protótipo do sistema Mindboard

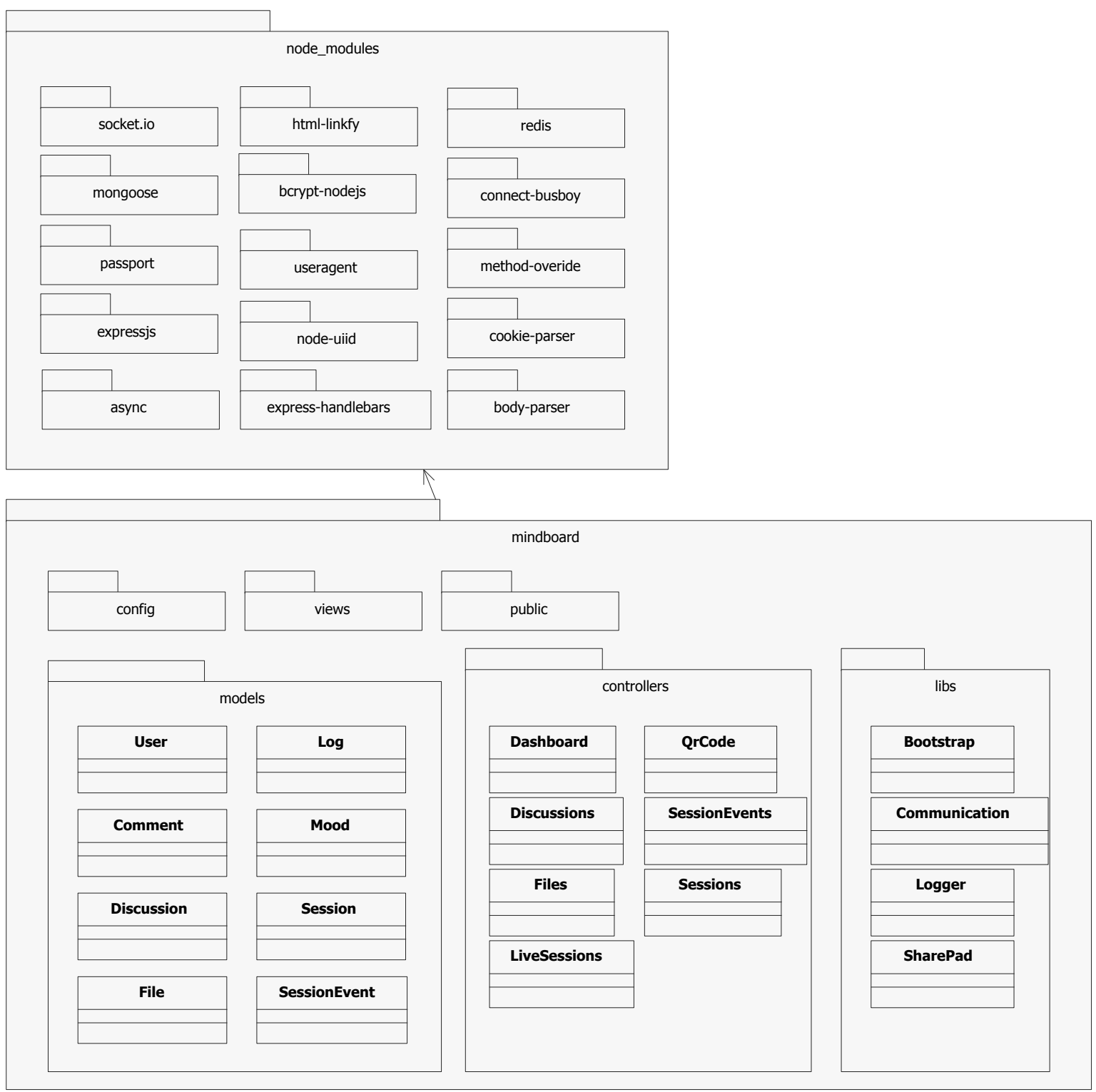

Fonte: Tulio Faria, 2015

O bcrypt-nodejs é utilizado para criptografar senhas e o express-handlebars para gerar templates dinâmicos utilizando a linguagem Handlebars.

Já o pacote config representa o diretório onde ficam todos os arquivos de configurações do sistema, tais como configurações de portas, de conexão com o MongoDB e configuração de rotas. Já o pacote views representa o diretório onde os templates escritos em Handlebars são armazenados, estes templates geram respostas em HTML dinamicamente. O pacote public representa o diretório que será acessado publicamente no sistema, e é onde estão localizados arquivos CSS, JavaScript e as imagens. 
O pacote models representa o diretório onde ficam os módulos que gerenciam como os dados são lidos e escritos no banco de dados MongoDB. Dentro deste diretório, o módulo User gerencia os dados de usuários, Comment gerencia os comentários das anotações, Discussion gerencia as anotações, File gerencia os arquivos, Log gerencia os dados de acesso, Mood representa o retorno do aluno em cada aula, Session gerencia cada aula no Mindboard e SessionEvent gerencia os eventos que ocorreram em cada Session.

O pacote controllers representa o diretório onde ficam os módulos responsáveis por receber uma requisição e retornar uma resposta em JSON. O pacote libs representa o diretório onde estão localizados os módulos Communication, Bootstrap, Logger e SharePad. O módulo Communication é um utilitário para comunicação em tempo real, o módulo Bootstrap é o utilitário por iniciar a aplicação toda, o módulo Logger é responsável por gerar todos os logs de utilização e o módulo SharePad por gerenciar as operações em tempo real em dados. Já o módulo $\operatorname{QrCode} e^{2}$ é responsável por gerar um código de leitura rápida para cada aula facilitando o acesso principalmente por meio de dispositivos móveis.

O controller Files utiliza a suíte de aplicativos Libre Office para a conversão e preparação do arquivos. Assim, quando o professor envia um arquivo em formato PDF ou PPT, este arquivo é automaticamente preparado através de sua conversão para imagens que podem ser visualizadas em qualquer dispositivo. A versão instalada do Libre Office é conhecida como versão headless pois não possui interface gráfica.

\subsubsection{Interface gráfica}

A interface gráfica do protótipo do sistema Mindboard, como descrito anteriormente, foi desenvolvido utilizando HTML5 e CSS3, e com suas interações feitas em JavaScript. A disposição dos elementos foi feita de maneira mais simples e objetiva, com objetivo de facilitar a utilização.

As telas foram divididas em 2 categorias, baseado nos momentos em que elas são utilizadas: as telas de gerenciamento e a tela de acesso a aula. As telas de gerenciamento, são telas onde é possível enviar arquivos e criar novas aulas. A Figura 29 mostra a tela com a listagem de aulas e com a possibilidade de criação de uma nova aula visualizada em resolução maior, simulando assim, a visualização a partir de um computador convencional.

2 Quick Response Code (QrCode) é uma forma de representação gráfica de dados que são possíveis de serem lidas rapidamente por máquinas. 
Figura 29 - Tela de gerenciamento de aulas - telas maiores

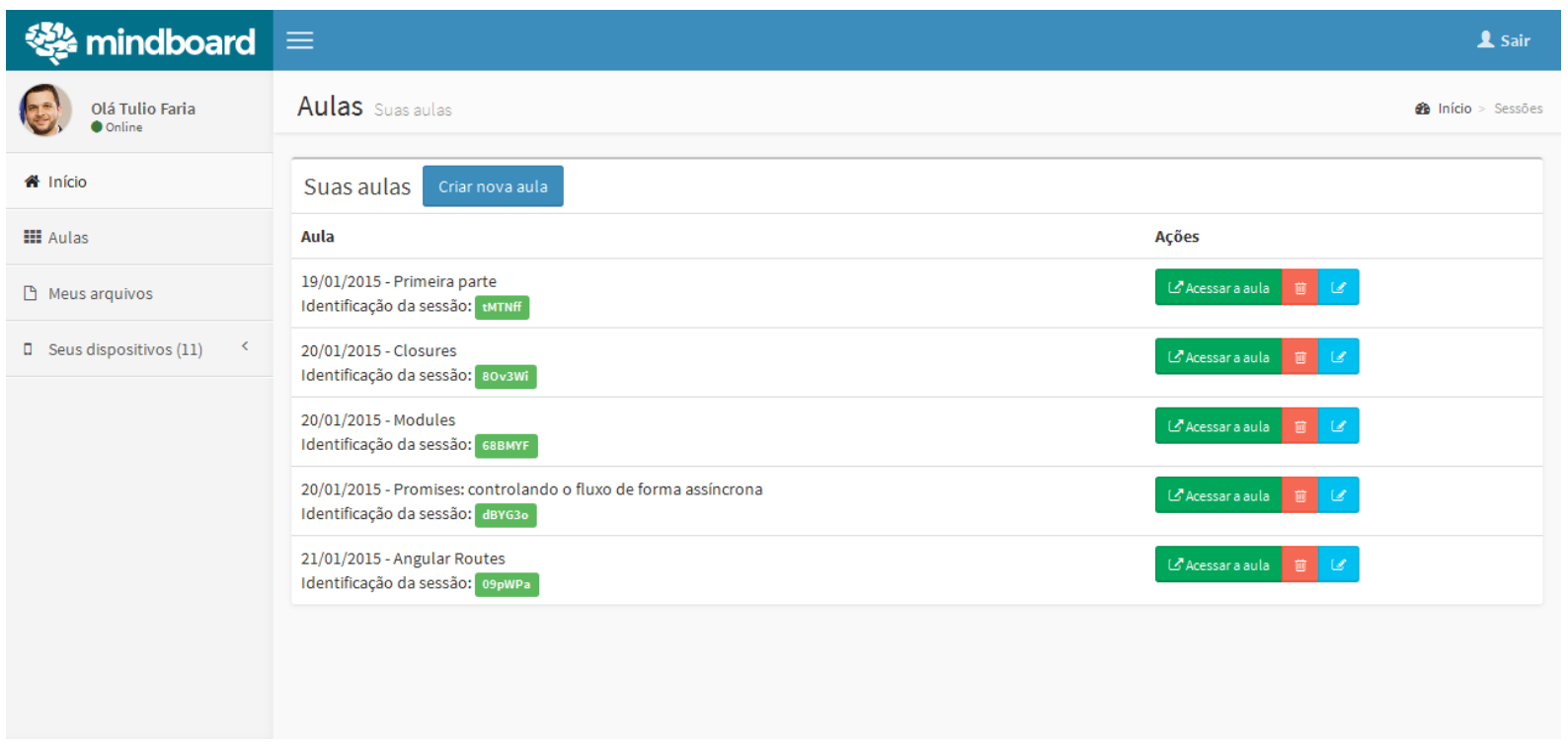

Fonte: Tulio Faria, 2015

Figura 30 - Tela de gerenciamento de aulas - telas com resolução menor

\section{zesces mindboard

\section{Aulas suas aulas \\ Início Sessōes}

\section{Suas aulas Criar nova aula}

\section{Aula}

19/01/2015 - Primeira parte

Identificação da sessão: tMTNiff

\section{Ações}

\section{$\checkmark$ Acessara aula III}

$\mathscr{6}$

Fonte: Tulio Faria, 2015

A mesma tela quando visualizada em um dispositivo com resolução de tela menor, por meio da utilização de media-queries, fica ligeiramente diferente. A Figura 30 mostra essa visualização. É interessante notar que o menu de navegação fica oculto até que o ícone ao lado do logo do sistema seja clicado, poupando assim espaço na tela.

Ao usuário entrar em Acessar a aula, é aberta uma nova janela com todo o conteúdo de aula. A Figura 31 mostra esta tela sendo aberta para uma aula presencial. Essa tela 
Figura 31 - Tela de aula projetando apresentação em uma tela com resolução maior

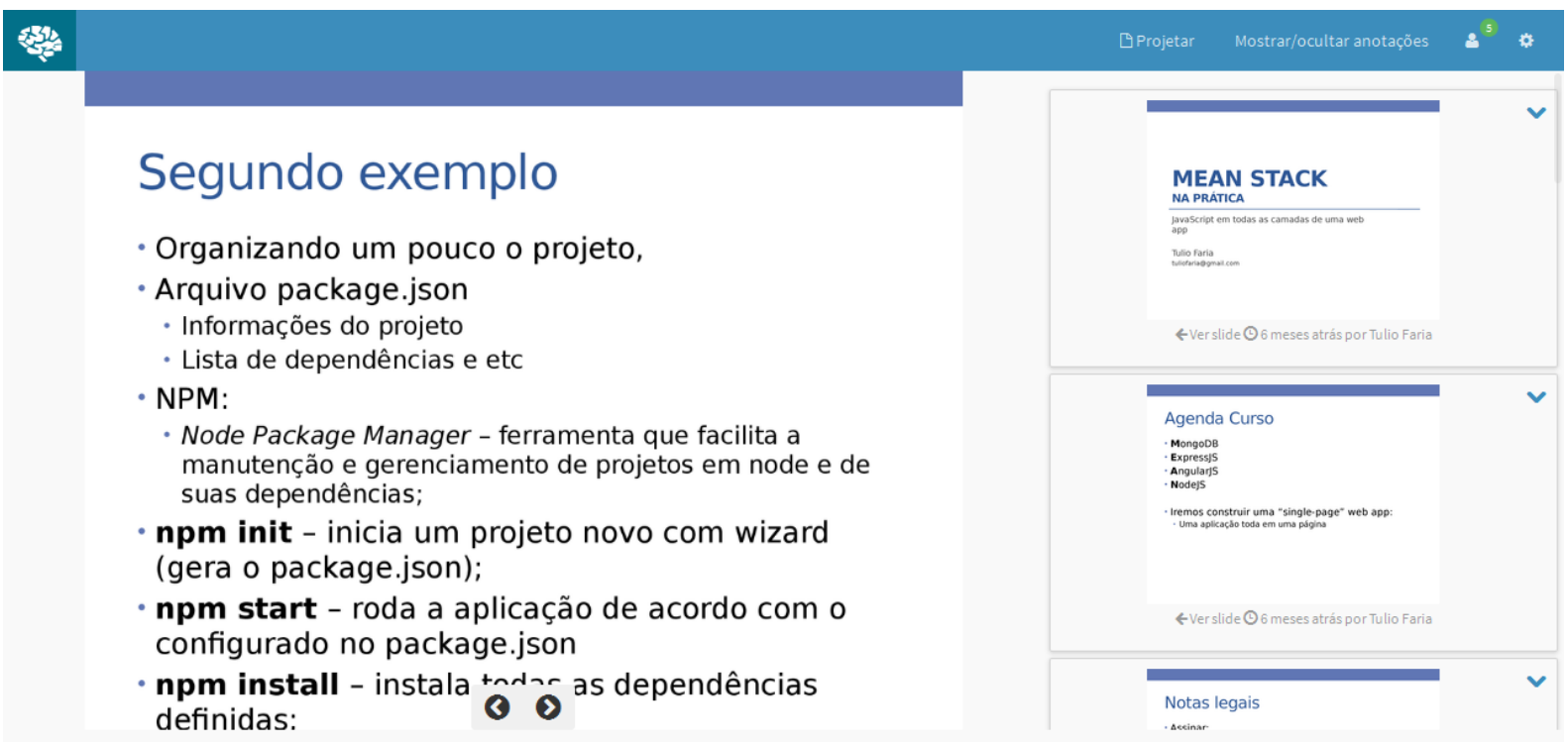

Fonte: Tulio Faria, 2015

Figura 32 - Tela de aula projetando código-fonte em telas com resolução maior

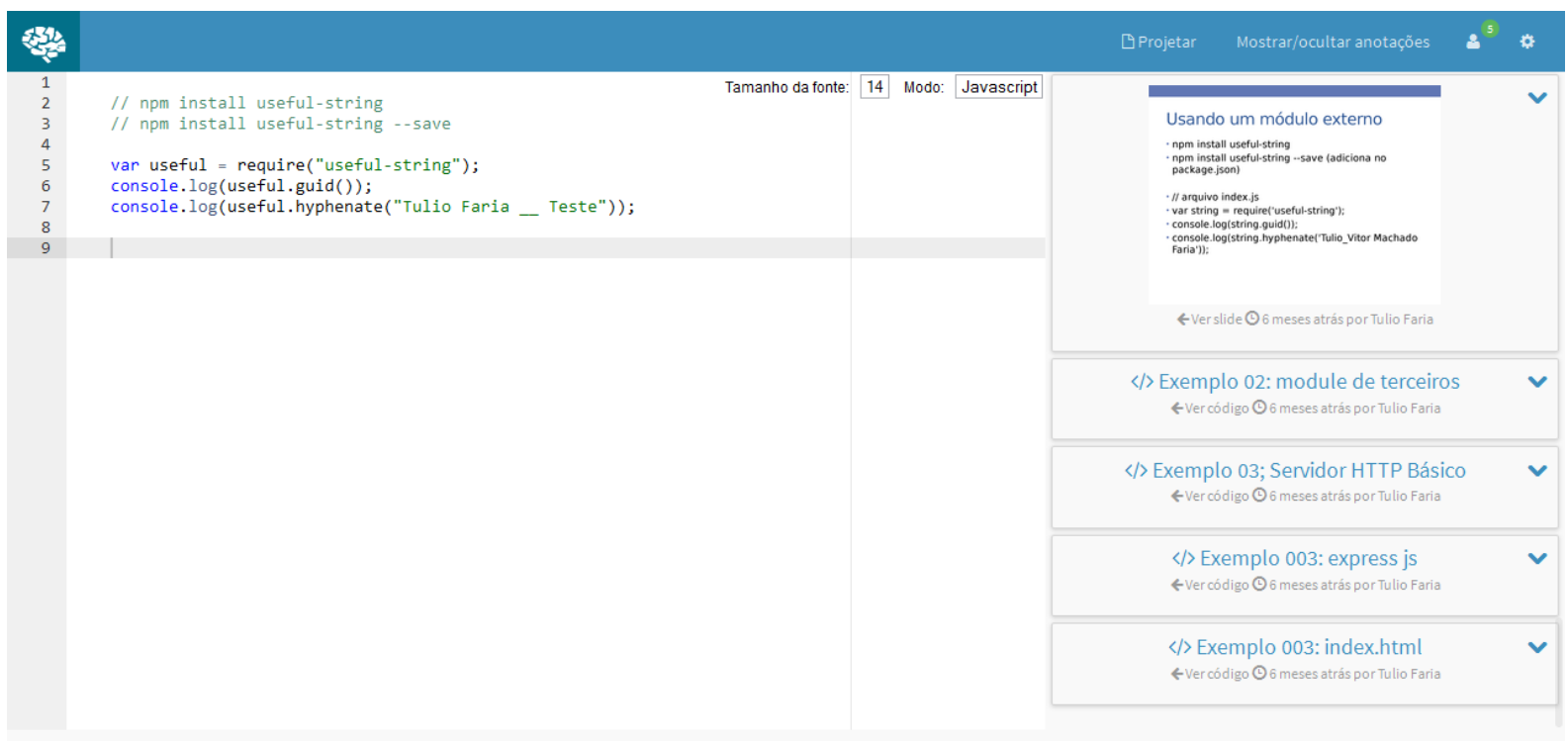

Fonte: Tulio Faria, 2015

mostra também, que atualmente na aula, é projetado uma apresentação de slides para todos os alunos, e é possível, através dos botões em formato de setas mostrar o próximo slide ou o anterior. Nessa tela é possível ver também o histórico do lado direito, e caso o aluno queira ele pode clicar sobre cada slide e revê-los.

Ao clicar no botão Projetar, além de uma apresentação de slides, pode-se escolher projetar código-fonte, e assim, tudo que é digitado nesta área pelo professor é sincronizado automaticamente com todos os alunos. A Figura 32 mostra a tela onde está sendo projetado código-fonte aos alunos. 
Figura 33 - Tela de aula projetando apresentação em telas com resolução menor e barra de anotações oculta

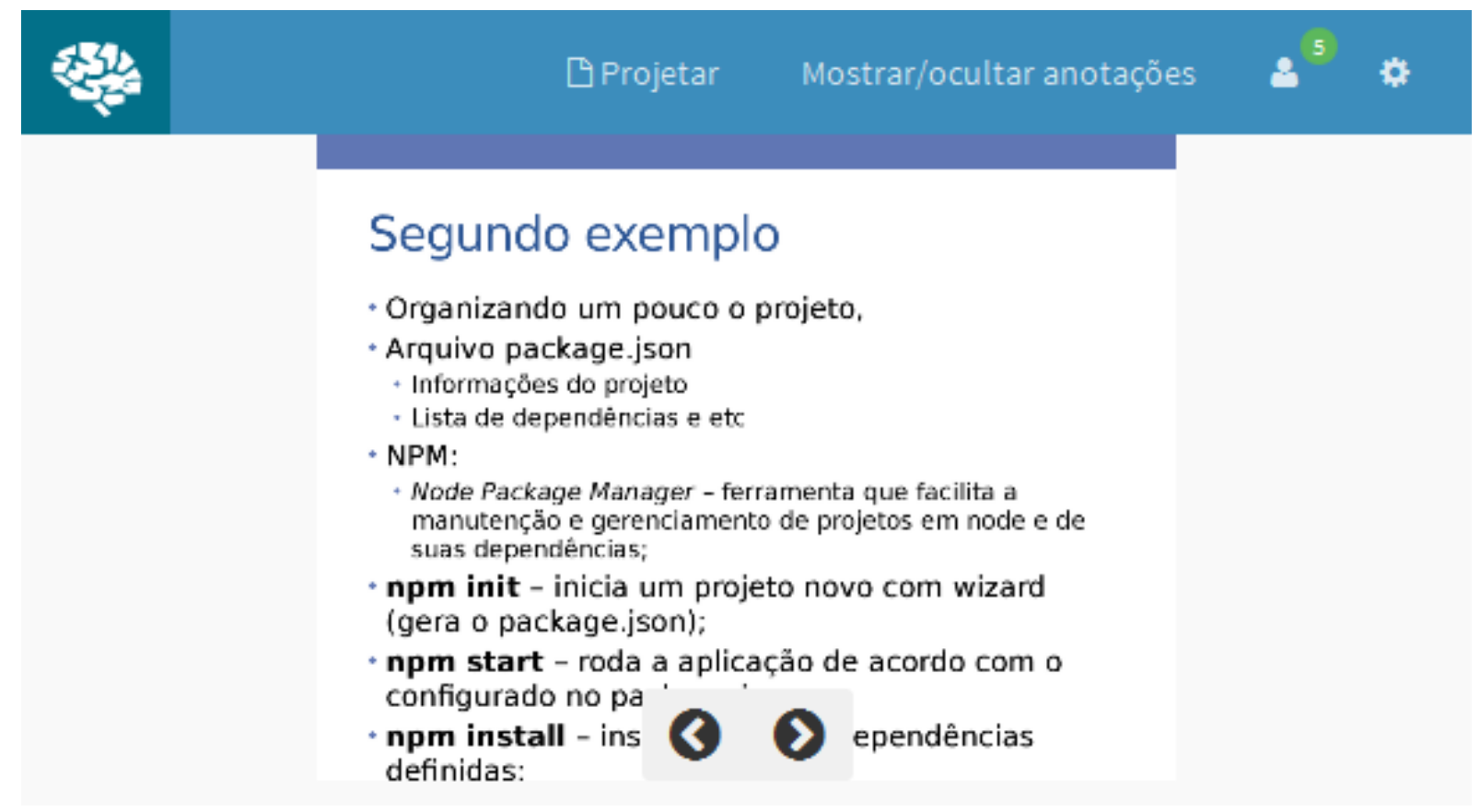

Fonte: Tulio Faria, 2015

É interessante ressaltar que ambas as telas das Figuras 31 e 32 podem ser utilizadas sendo projetadas aos alunos também pelo projetor da sala de aula. Facilitando também a indicação de algum item de forma convencional.

A tela de aula ao ser visualizada em dispositivos móveis ou com baixa resolução, também tem sua forma adaptada. Neste caso, pode-se ainda melhorar ainda mais a visualização mostrando e ocultando o item de anotações. A Figura 33 mostra a tela sendo visualizada em uma resolução menor com a barra de anotações/histórico ativa e a Figura 34 mostra a mesma tela com esta barra oculta.

A tela da Imagem 35 mostra a projeção de objetos e conteúdos de terceiros, mostrando assim a extensibilidade da ferramenta. Nesta tela está integrado um objeto de aprendizado desenvolvido pelo autor deste trabalho no grupo de pesquisa LInE. Esta funcionalidade também permite que os objetos de aprendizado utilizem o armazenamento de informações no Mindboard e também os componentes de comunicação em tempo-real. A utilização deste tipo de extensibilidade necessita que o objeto a ser integrado deva ser compatível com navegadores atuais e também devem ser responsivos. 
Figura 34 - Tela de aula projetando apresentação em telas com resolução menor e barra de anotações visível

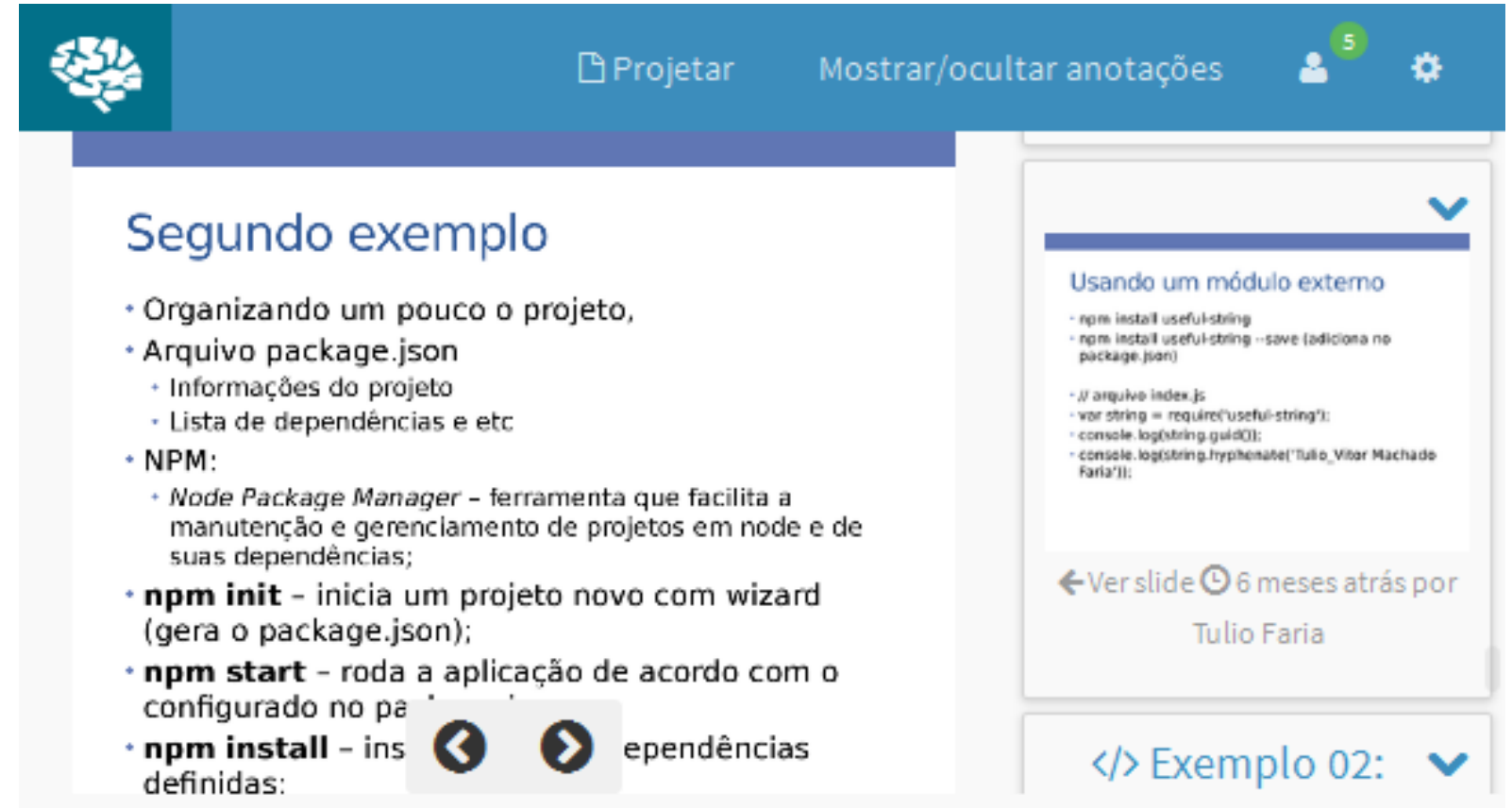

Fonte: Tulio Faria, 2015

Figura 35 - Tela de aula projetando um objeto de aprendizagem desenvolvido no grupo de pesquisas LInE

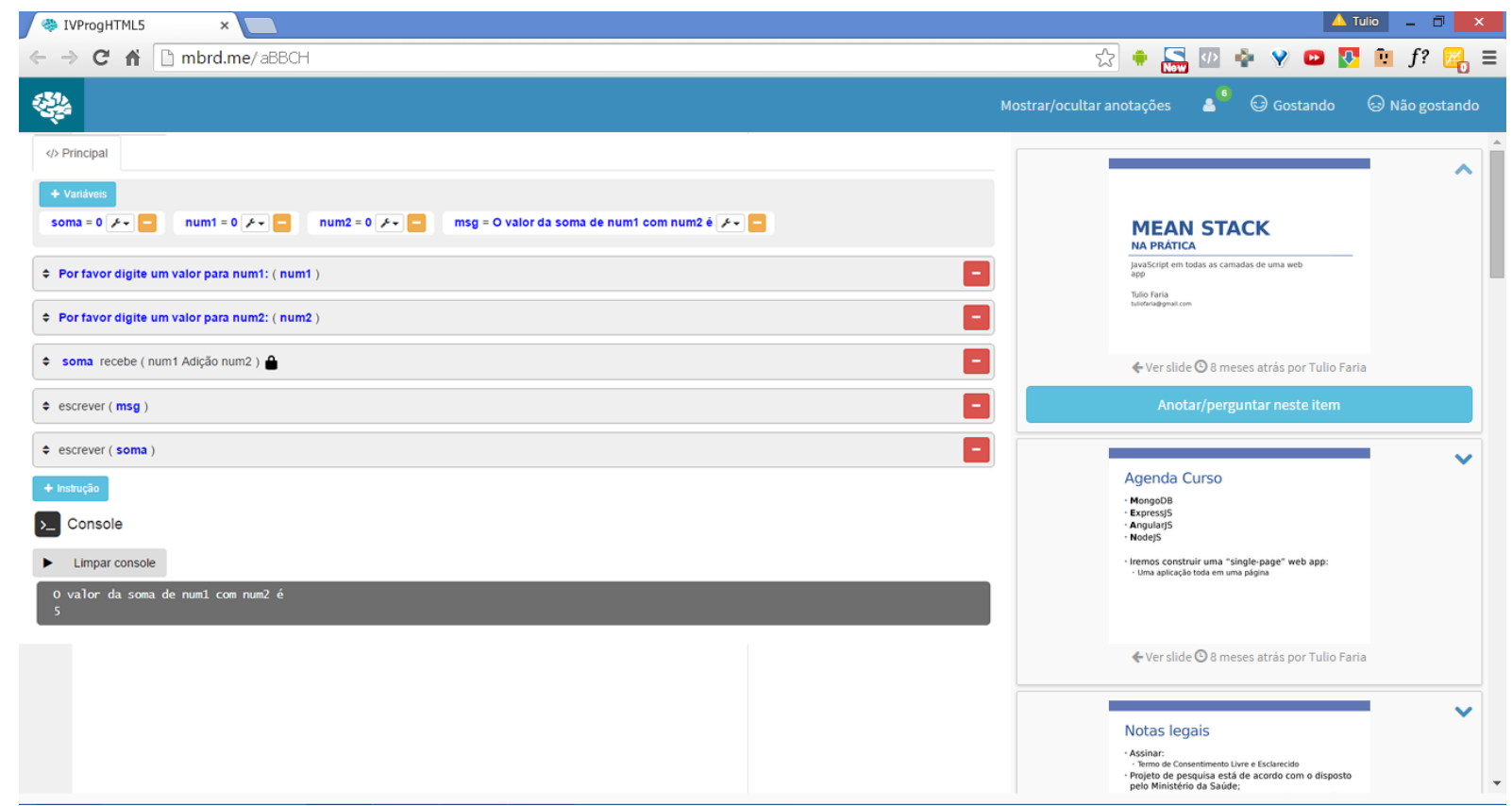

Fonte: Tulio Faria, 2015 


\subsubsection{Algoritmo de sincronização}

O sistema Mindboard compartilha informações entre professores e alunos, e este compartilhamento, precisa acontecer de forma a consumir menos recursos possíveis bem como garantir que todos os usuários estejam visualizando o mesmo estado da informação. Assim, é necessário conhecer formas de otimizar este processo de troca de informações.

A abordagem necessária para a troca de informações no projeto Mindboard precisa permitir que além das informações sejam trocadas de forma eficiente, em uma próxima versão do sistema, os usuários possam trabalhar sobre a informação de forma concorrente, e neste sentido, surge a necessidade de um algoritmo que permita o controle desta concorrência, e no desenvolvimento do protótipo do sistema Mindboard foi utilizado o Operational-Transformation (OT).

OT é um algoritmo utilizado em sistemas com troca de informações em tempo real para controle de concorrência e para garantir a consistência dos dados, principalmente, em atividades em grupo fortemente acopladas (ELLIS; GIBBS, 1989). Um exemplo de uma atividade fortemente acoplada é a edição de um texto simultaneamente por 4 usuários de locais distintos.

A funcionalidade de compartilhamento de código-fonte em tempo real do sistema Mindboard foi projetado para que, em futuras versões do sistema, permita também ao aluno editar o código junto ao professor. Este tipo de atividade acrescenta uma especificidade ao sistema, relacionado em como tratar edições concorrentes a um mesmo dado. Algumas abordagens inspiradas por funcionalidades semelhantes em sistemas gerenciadores de banco de dados não são adequadas a este cenário, abordagens como o lock do banco de dados ou a utilização de transactions (ELLIS; GIBBS, 1989). O principal motivo pelo qual estas abordagens não serem adequadas estão relacionadas a intensa troca de informações, como por exemplo, em uma digitação de texto, o banco de dados ficar em um estado de lock por muito tempo. Ou ainda, o banco de dados ficar neste estado por alguma lentidão na troca de informações. Ainda assim, após manter o estado atualizado no servidor, os dados alterados precisam ser enviados de volta a todos os usuários.

A ideia central em torno da utilização de OT pode ser ilustrada em um editor de textos compartilhado. Para ilustrar vamos imaginar que o texto inicial é "abc" e que este texto está replicado para 2 usuários. Estes 2 usuários realizam as seguintes operações simultaneamente: 
- Operação 1: usuário 1 insere o caractere " $x$ " na posição 0

- Operação 2: usuário 2 apaga o caractere "c" da posição 2

Caso sejam realizadas as operações 2 e 1, nesta ordem, na máquina do usuário 2, temos após a execução da primeira operação o texto "ab", e após a execução da operação 2: "xab". Nesta situação temos o estado correto.

Agora caso a ordem das operações seja 1 e 2, executadas na máquina do usuário 1, teremos após a execução da primeira operação: "xabc" e no momento que a segunda operação seria executada, temos o problema que a posição 2 não é mais o caractere "c", e se for excluído este caractere o estado atual do texto não é o almejado pelos usuários. Neste caso, a operação 2 deve ser transformada antes de ser aplicada e então ser realizada na posição correta, neste caso na posição 3.

O principal objetivo do algoritmo OT é transformar ou ajustar operações concorrentes de acordo com as executadas para que seja possível obter o resultado correto e mantido a consistência do documento (ELLIS; GIBBS, 1989).

As implementações de OT diferenciam-se entre si baseado na função de transformação que cada uma delas utiliza. Assim, temos exemplos como dOPT utilizado pelo sistema GROVE (ELLIS; GIBBS, 1989) e o Google Wave OT utilizado pelo Google Wave (LEUNG, 2013).

No desenvolvimento deste trabalho foi utilizado a implementação Google Wave OT através da sua implementação em JavaScript no projeto de código-livre ShareJS (GENTLE, 2011). Esta implementação pode ser integrada ao ambiente que já era utilizado no back-end do projeto Mindboard e também ao protocolo de comunicação. Este módulo é composto também por uma versão front-end para que as operações transferidas possam ser aplicadas na máquina de cada usuário.

Apesar de ainda não ser possível editar colaborativamente códigos-fonte no Mindboard, a utilização de OT trouxe muitos benefícios a comunicação, principalmente por serem transferidas apenas as operações sobre os dados e não mais o estado todo. $\mathrm{Ou}$ seja, em um arquivo fonte sendo compartilhado com os alunos, por exemplo, que possua 20.000 bytes, caso o professor altere 2 caracteres, não é necessário mais que 20 bytes para transferir esta operação aos demais pontos e que estes pontos visualizem o mesmo estado em suas máquinas. Uma quantidade de dados transmitidos bem inferior se comparado a transferência do estado completo, que neste caso seria os 20.000 bytes. Além dessa economia de banda, a mesma funcionalidade atualmente usada para o caso específico de 
colaboração em código fonte pode ser utilizada em versões futuras do sistema também para a criação e edição de textos ou outros conteúdos de forma colaborativa.

\subsubsection{Extensibilidade e integração com sistemas de terceiros}

As funcionalidades do sistema Mindboard podem ser ampliadas através da extensibilidade de funcionalidades internas, pela inclusão de novos tipos de conteúdos e através da integração com outros sistemas.

A arquitetura definida para o sistema permite que novas funcionalidades sejam desenvolvidas através de módulos. Os módulos podem utilizar todos os recursos de comunicação em tempo-real e de persistência de dados do sistema. Por exemplo, ao criar um novo módulo bastaria incluí-lo no script principal do sistema e injetar a dependência do módulo de comunicação. No caso da persistência, seria necessário criar um módulo model correspondente ao dado a ser persistente e importá-lo no módulo adicional que a persistência já seria realizada adequadamente.

A inclusão de novos tipos de conteúdos, como o mostrado na Imagem 35 dependem da criação de um novo módulo para este tipo de conteúdo. E neste caso, é realizado por meio do método descrito anteriormente. Uma outra maneira de ampliar as funcionalidades do sistema Mindboard também pode ser feita por meio de sistemas de terceiros.

A integração com sistemas de terceiros pode ser realizada utilizando API de integração em REST. Este tipo de integração utiliza requisições HTTP, que são os tipos de requisições realizadas entre os navegadores de internet e os servidores web, para a comunicação entre dois sistemas remotos. Assim, ainda será desenvolvido uma interface no Mindboard que permita este tipo de integração principalmente para que ele possa ser integrado a sistemas já utilizados dentro das instituições de ensino.

Um exemplo possível para este tipo de integração seria através da criação de um block do Moodle. O Moodle é um sistema muito utilizado atualmente nas instituições de ensino como plataforma para comunicação entre alunos e professores. A Imagem 36 ilustra a tela de um curso no Moodle, e o item destacado seria o criado pelo block do Mindboard.

Ao usuário entrar no item destacado na Imagem 36, o block de integração realiza uma série de atividades, como verificar se este usuário já está cadastrado no Mindboard e cadastrá-lo em caso negativo. Além disso, autentica este usuário no Mindboard e o 
Figura 36 - Tela de um curso no Moodle e um exemplo de onde o usuário acessaria o Mindboard

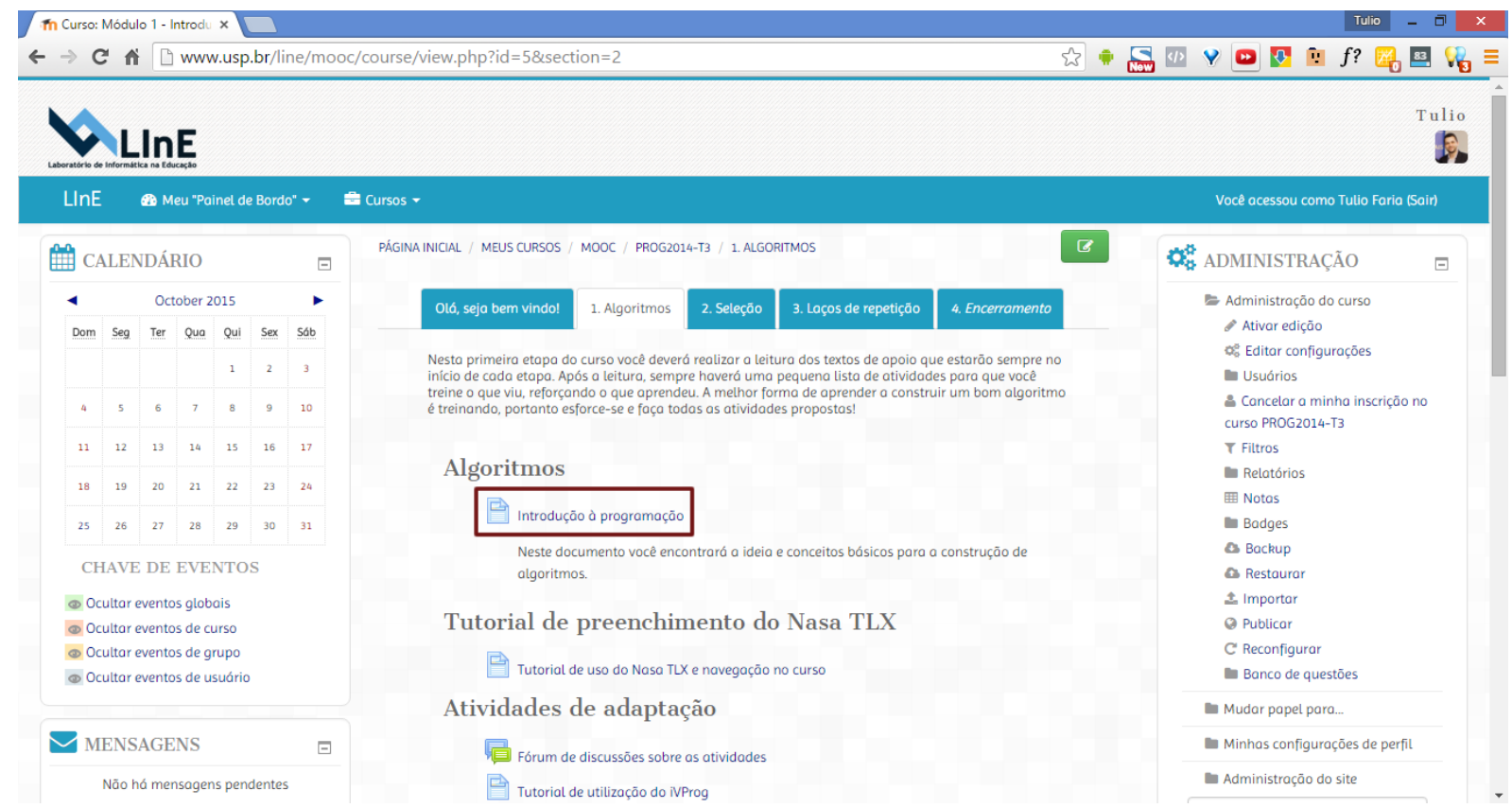

Fonte: Tulio Faria, 2015

Figura 37 - Diagrama de sequência ilustrando a integração entre um block do Mindboard no Moodle e uma instalação do Mindboard

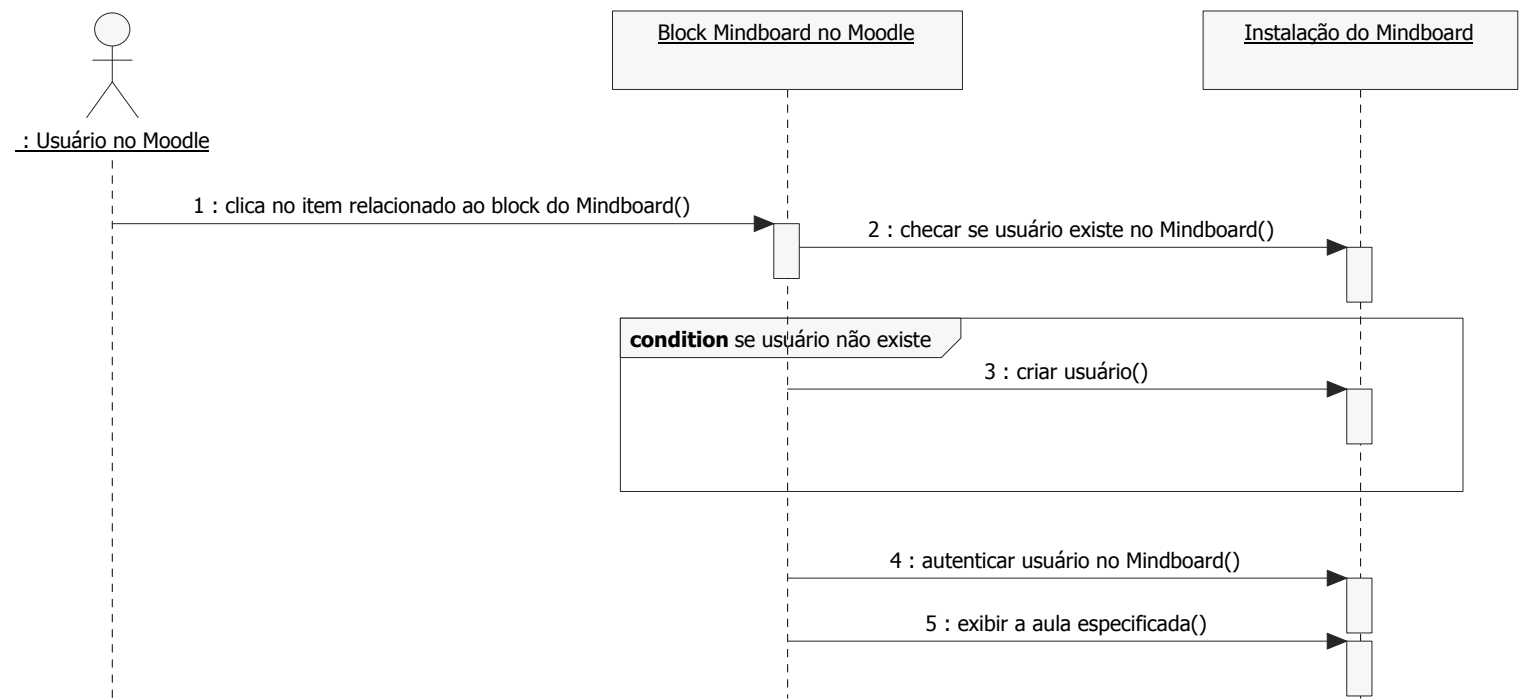

Fonte: Tulio Faria, 2015

leva para a visualização da aula em específico. Este processo é ilustrado através de um diagrama de sequência na Imagem 37.

A última atividade descrita no diagrama da Imagem 37 é a visualização da aula do Mindboard dentro do Moodle. A Imagem 38 ilustra uma simulação de como seria esta visualização. 
Figura 38 - Aula do Minboard sendo visualizada dentro do Moodle

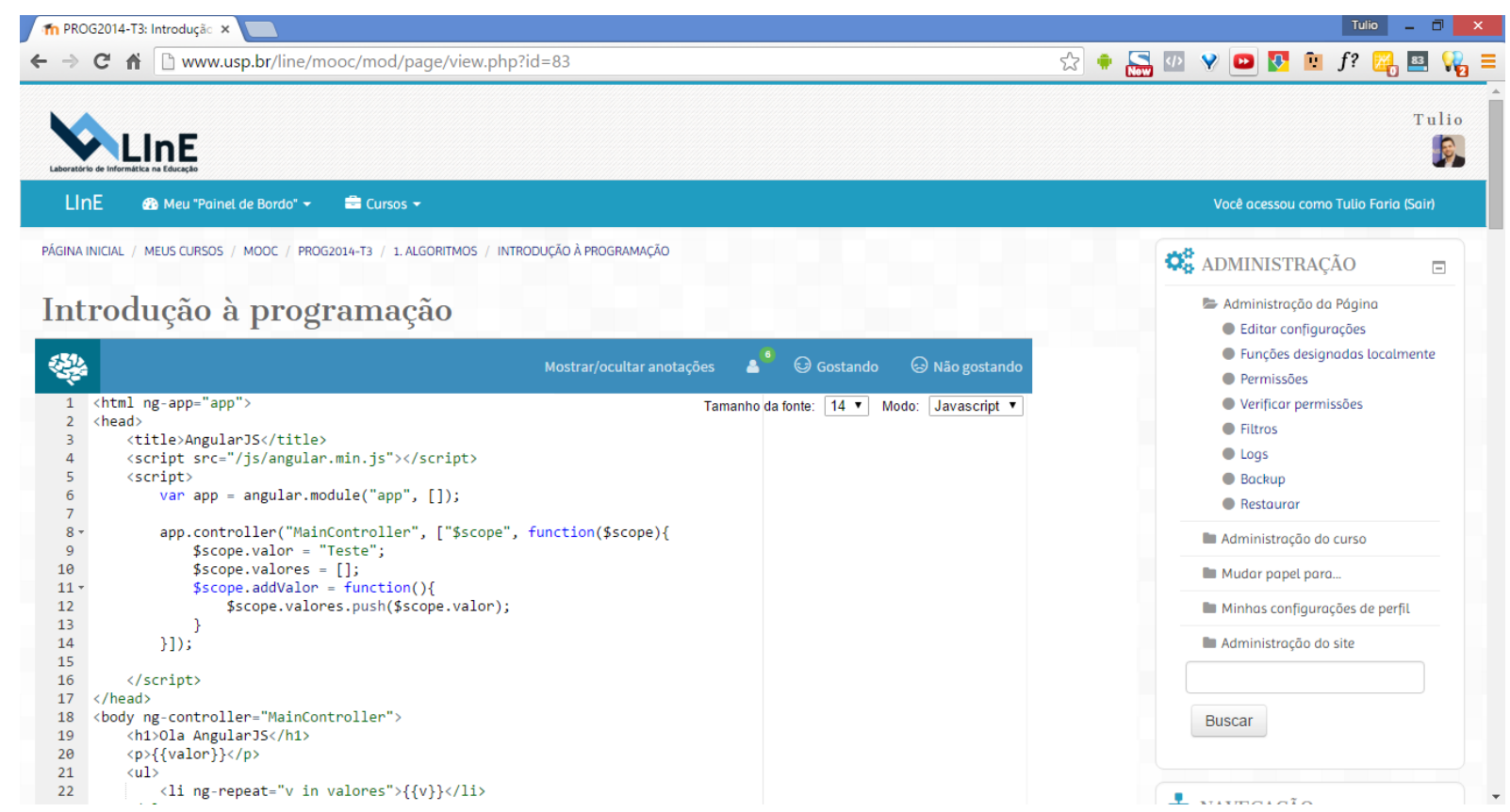

Fonte: Tulio Faria, 2015

É sugerido esta forma de integração para não haver a necessidade de manter dois cadastros redundantes em dois sistemas distintos, assim, o único cadastro necessário de ser atualizado é o mantido no Moodle. Outra vantagem é o usuário final não precisar acessar ou ter dados de acesso em mais de um sistema. 


\section{Resultados do experimento}

Além dos resultados obtidos no experimento no grupo de pesquisas LInE e das pesquisas com alunos e professores do ensino médio e superior, descritas na Capítulos 5 e 6 respectivamente, foram realizados também testes funcionais no protótipo do sistema Mindboard. Durante estes testes foi verificado que todos os requisitos funcionais e nãofuncionais foram implementados e estavam funcionando de acordo com o especificado.

Após verificado o funcionamento do sistema e suas funcionalidades através do teste citado anteriormente, foi realizado o experimento em um curso de verão, conforme descrito na Seção 3.3. Durante a execução deste experimento foram detectados alguns pontos que podem ser melhor trabalhados em um futuro experimento.

O principal empecilho durante o experimento foi a geração de poucos dados. Eram esperados 40 alunos no total, sendo 20 em cada turma. Porém, inscreveram-se 16 alunos no total, sendo uma turma com 7 e outra com 9 alunos. Aliado a este número reduzido de alunos, o curso de verão também teve uma duração curta, com 4 aulas de 4 horas, sendo 3 presenciais e 1 online.

Um outro fator que influenciou no experimento era o fato de grupos de alunos já se conhecerem, que aliado ao tamanho reduzido das turmas, facilitava e deixava a comunicação entre eles bem mais natural.

A contagem das interações foi realizada através da captura do áudio e vídeo e durante o experimento foi descoberto que o áudio tornou-se praticamente indecifrável. Já com o vídeo, por ter realizado a gravação em uma câmera apenas, várias vezes ocorreu a oclusão visual quando um aluno ou o professor passava em frente a câmera.

Devido a esses fatos, os dados coletados em relação a colaboração através de áudio, vídeo e logs de uso na ferramenta não mostraram ter muita significância estatística, por isso, neste capítulo será realizada principalmente uma análise qualitativa baseada nos comentários deixado nos questionários e presencialmente pelos alunos.

Apesar de ambas as turmas, a que utilizou e a que não utilizou o Mindboard, tiverem praticamente o mesmo número de interações por aluno, foi possível perceber que no grupo que não utilizou o Mindboard, entre 20 e 30\% das interações eram realizadas por problemas na leitura do conteúdo que era projetado, ou seja, não era relacionado ao conteúdo de aula em si. Este problema já não aconteceu com a turma que utilizou o Mindboard pois o conteúdo projetado em aula era exibido por meio da ferramenta em 
tempo real para os alunos, o que torna as interações realizadas na turma que utilizou o Mindboard de maior qualidade e relevância à aula.

Outra situação que gerou muitas interações de pouca qualidade na turma que não utilizou o Mindboard ocorreu quando alternava-se o arquivo fonte projetado para os alunos. Uma vez que se algum aluno não havia conseguido entender ou visualizar o arquivo anterior, ele solicitava que voltasse a visualização. Na turma que utilizou o Mindboard isso não aconteceu pois os alunos tinham acesso ao código de cada arquivo em tempo real em suas máquinas, e eles podiam visualizar qualquer arquivo compartilhado no momento que quisessem em seu estado mais atual. Em um dos questionários realizados após a utilização do sistema, um aluno comentou: "Essa funcionalidade facilitou muito o acompanhamento principalmente trechos de códigos anteriores para verificação.".

Além disso, na turma que utilizou o Mindboard, segundo relato dos próprios alunos, com o compartilhamento de conteúdo em tempo real nas próprias máquinas, os alunos poderiam focar e manter suas atenções na explicação do professor e realizar anotações apenas nos pontos que eles se interessavam. Sobre essa funcionalidade um aluno reportou: "A funcionalidade de poder ver o código que está sendo digitado na sua própria máquina é muito boa pois o aluno não se perde, se o professor explicar com detalhes o que está sendo feito o aproveitamento é muito grande.". Outros alunos também opinaram de forma semelhante: "Esta funcionalidade tem a vantagem de dar a oportunidade do aluno analisar o código e não simplesmente ficar focado em digitá-lo para não perder o exemplo, essa ferramenta diminui os erros de todos." e "Essa funcionalidade ajudou muito no acompanhamento pois não precisava ficar virado olhando para o datashow.".

Esse recurso do sistema Mindboard também favoreceu na acessibilidade por alunos que possuem alguns tipos de problemas de visão, já que eles tinham o conteúdo nas próprias máquinas e poderiam inclusive alterar o tamanho da fonte. Esta funcionalidade seria muito interessante à turma que não utilizou o Mindboard, conforme a opinião de um aluno: "Eu tenho hipermetropia e tinha dificuldade de enxergar alguns trechos do código no datashow.".

Apesar de muitas escolas contarem com lousas digitais que inclusive permitem ao aluno acompanhar em sua própria máquina, este recurso não é muito eficiente em aulas de programação, uma vez que todo o conteúdo é ainda transferido como desenhos. Isso também torna ineficiente a digitação para o professor. Assim, em aplicações onde 
é relevante o compartilhamento de textos, a forma que foi desenvolvida no Mindboard favorece o compartilhamento mais rico.

Na turma que utilizou o Mindboard havia um aluno que não tinha um relacionamento anterior com os demais alunos e durante o curso estava bem introvertido. Através do sistema, ele foi o que mais interagiu e deu feedbacks sugerindo que a ferramenta o ajudou a interagir.

Assim, a turma que utilizou o Mindboard teve mais interações de qualidade quando foi reduzido o número de interações espúrias. Ela ajudou muito os alunos a manterem o foco no conteúdo e não se preocuparem em copiar códigos, também ajudou na acessibilidade e inclusão, uma vez que alunos com problemas para enxergar o conteúdo projetado poderiam acompanhar de suas próprias máquinas e alunos tímidos poderiam interagir pelo sistema.

Além disso, os alunos fizeram sugestões sobre algumas funcionalidades que poderiam estar presentes no Mindboard, como por exemplo, alguns alunos disseram que faltou um bate-papo integrado no sistema. A intenção é que esta funcionalidade seja integrada ao SGC utilizado pela instituição, evitando assim funcionalidades replicadas. Durante o experimento, o sistema Mindboard não foi integrado a nenhum SGC. A funcionalidade de repositório de arquivos também não está presente no Mindboard pelo mesmo motivo.

Outros alunos também disseram ser interessante a integração do compartilhamento de código em tempo real com ferramentas integradas de desenvolvimento, esta sugestão é interessante e será avaliada para futuras versões do sistema.

Após o experimento, os alunos que utilizaram o Mindboard também preencheram o formulário de avaliação de usabilidade USE, conforme descrito na Seção 3.3.4. Os resultados obtidos são apresentados e discutidos a seguir.

O questionário USE avalia a usabilidade de um sistema baseado em 3 pontos de vista: utilidade, facilidade de uso e satisfação. O primeiro grupo de questões que são avaliadas a seguir pertencem ao grupo utilidade.

As duas primeiras questões pedem para o aluno escolher um grau de 1 a 7 o quanto a ferramenta os torna mais efetivos e o quanto ela os torna mais produtivos. As duas questões tiveram média 5,5 e 5,4 (acima da média da escala que é 4), respectivamente. Reforçando alguns itens já discutidos anteriormente, que o sistema Mindboard favorece o aluno a ter interações de mais qualidade e aumentar o foco na aula, tornando-os mais efetivos e produtivos durante a aula. 
Tabela 9 - Questões de utilidade

\begin{tabular}{|l|c|}
\hline Questões de Utilidade: & Média: \\
\hline O sistema me ajuda a ser mais efetivo & 5,5 \\
\hline O sistema me ajuda a ser mais produtivo & 5,4 \\
\hline O sistema é útil & 6,3 \\
\hline O sistema me permite controlar/acompanhar minhas aulas & 6,5 \\
\hline O sistema permite que o que desejo fazer possa ser feito mais facilmente & 5,4 \\
\hline O sistema me poupa tempo quando a utilizo & 5,3 \\
\hline O sistema faz tudo que eu esperava que ela fizesse Nível de utilidade: & 5,8 \\
\hline
\end{tabular}

Fonte: Tulio Faria, 2015

Todas as questões de utilidade são mostradas com suas respectivas médias na Tabela 11. A média das questões de utilidade foi 5,6, o que indica na opinião dos alunos que a ferramenta tem um bom nível de utilidade para os mesmos. Uma questão que teve uma média um pouco mais baixo diz respeito a se a ferramenta faz tudo que o aluno esperava que ela fizesse, que obteve uma média 4,8. Este valor um pouco mais baixo pode ter acontecido por muitos alunos desejarem algumas funcionalidades muito específicas, como a integração a um ambiente de desenvolvimento. A maior média ficou com a questão que pergunta se o sistema permite controlar/acompanhar as aulas, com média 6,5.

Já as questões de facilidade de uso levantam indícios de como foi a experiência dos alunos quanto a utilização do sistema. Neste quesito o sistema Mindboard também obteve uma média boa, com 5,76. A Tabela 11 mostra todas as questões e suas respectivas médias. Nesta análise, é interessante notar que a maior nota diz respeito a utilizar o sistema sem instruções escritas, com 6,2, que para um sistema a ser utilizado na educação é muito interessante, uma vez que não é desejado o aluno além de ter que aprender um novo conteúdo de aula, ter também que aprender a usar um sistema. Neste grupo de questões, a que dizia respeito a se o usuário poderia se recuperar facilmente de um erro foi a mais baixa, com 5,3 de média.

As questões relacionadas a satisfação do usuário perante o sistema também obtiveram uma média de avaliação boa, com 5,7. A questão com maior média foi relacionada a se o usuário consegue lembrar facilmente de como utilizar o sistema, com média de 6,7. Novamente analisando que o sistema é aplicado a educação, este é um ponto muito interessante, pois como como já avaliado no grupo anterior, se o sistema pode ser utilizado sem instruções escritas e o que o usuário já aprendeu a usar do sistema pode ser facilmente utilizado, ele tem uma menor possibilidade de problemas de utilização pelos alunos. 
Tabela 10 - Questões de Facilidade de Uso

\begin{tabular}{|c|c|}
\hline Questões de Facilidade de Uso: & Média: \\
\hline O sistema é fácil de usar & 5,8 \\
\hline O sistema é simples de usar & 6,1 \\
\hline O sistema é amigável & 5,8 \\
\hline O sistema necessita de poucos passos para fazer o que desejo & 5,8 \\
\hline O sistema é flexível & 5,4 \\
\hline Posso usar o sistema sem instruções escritas & 6,2 \\
\hline Eu não notei nenhuma inconsistência enquanto o utilizava & 5,2 \\
\hline Tanto usuários regulares quando ocasionais irão gostar do sistema & 6,0 \\
\hline Posso me recuperar de erros de forma fácil e simples & 5,3 \\
\hline Eu posso utilizar o sistema com sucesso a todo momento & 6,0 \\
\hline Nível de Facilidade de Uso: & 5,76 \\
\hline
\end{tabular}

Fonte: Tulio Faria, 2015

Tabela 11 - Questões de Satisfação

\begin{tabular}{|l|c|}
\hline Questões de Satisfação: & Média: \\
\hline Eu aprendi a usar o sistema rapidamente & 6,3 \\
\hline Eu facilmente me lembro como utilizar o sistema & 6,7 \\
\hline É fácil aprender a usar o sistema & 6,6 \\
\hline Eu rapidamente me tornei habilidoso com o sistema & 6,2 \\
\hline Eu estou satisfeito com o sistema & 6,0 \\
\hline Eu recomendaria o sistema para um amigo & 6,3 \\
\hline O sistema é divertido de usar & 5,7 \\
\hline O sistema funciona da maneira que eu gostaria de funcionasse & 5,3 \\
\hline O sistema é maravilhoso & 5,1 \\
\hline Eu sinto que eu tenho que ter o sistema & 5,4 \\
\hline O sistema dá prazer em utilizar & 5,3 \\
\hline \multicolumn{1}{|c|}{ Nível de Satisfação: } & 5,9 \\
\hline
\end{tabular}

Fonte: Tulio Faria, 2015

Além das questões onde os usuários poderiam responder um grau de 1 a 7 se ele concorda fracamente ou fortemente com cada afirmação, o questionário USE também pede para os usuários listarem 3 pontos mais positivos e 3 pontos mais negativos do sistema.

Os pontos positivos que mais foram citados foram facilidade de utilização, interface gráfica amigável, intuitiva e funcional para seu objetivo. Outros pontos levantados destacam as funcionalidades da ferramenta como sendo pontos positivos, como o acompanhamento em tempo real do que o professor está escrevendo, a integração com vídeos gravados e anotações.

Já como pontos negativos, alguns alunos citaram a demora no carregamento inicial e eles mesmos já justificaram que a internet estava com a velocidade um pouco comprometida nos dias de aula. Outros pontos colocados pelos alunos estão relacionados a uma integração 
com ambientes de desenvolvimento e a falta de comunicação através de um bate-papo pelo sistema. Os retornos negativos são relevantes para a definição de melhoria que estarão presentes nos próximos passos do sistema.

Além do questionário da usabilidade, durante o curso foi avaliado também o consumo de recursos computacionais do servidor em que o protótipo do sistema Mindboard estava sendo executado. Para o experimento, dado o número restrito de alunos, foi possível deixar todos os serviços em uma única máquina. O experimento todo foi executado em uma máquina virtual adquirida no fornecedor DigitalOcean ${ }^{1}$. A máquina contratada tinha a configuração composta por 2GB de memória RAM, 2 CPUs e 30GB de espaço em disco.

Para a mensuração do uso dos recursos computacionais, foi utilizado o sistema comercial NewRelic Servers ${ }^{2}$ em seu plano gratuito. Esse plano, permite a visualização de 6 horas de histórico de uso de memória, processamento, disco, transferência de rede da máquina, e também a avaliação de cada processo no quesito uso de processador e de memória. Os relatórios utilizados nas avaliações aqui realizadas foram gerados todos os 4 dias de curso, próximo ao fim da noite. Assim, os dados refletem a janela de uso de aproximadamente entre 18:00 e 00:00.

Avaliando os relatórios, é possível notar que os índices de utilização dos recursos como um todo foram bastante baixos. Em média os processos chegaram a utilizar um pouco mais de 200MB de memória e $0.4 \%$ de CPU. Os picos de utilização também ocorreram em horários bem próximos, às 19:30 de cada dia. Isso se deu pelo início das aulas coincidir com este horário, ou seja, no carregamento inicial do sistema, há um consumo um pouco maior de recursos. Neste pico, em média, a utilização em memória pelos processos relevantes chega em 235MB de uso de RAM e $0.6 \%$ de uso de CPU.

Um dos motivos de ter ocorrido estes picos de utilização de recursos pode estar ligado às validações realizadas quando os usuários conectam-se. Uma suspeita adicional diz respeito a utilização em uma conexão de internet com velocidade reduzida, que pode aumentar a necessidade do servidor reenviar os dados, uma informação que pode reafirmar esta suspeita é o fato do envio de dados no período das 19:30 também é maior, podendo indicar a transferência inicial de toda interface do sistema ou simplesmente o reenvio

1 DigitalOcean é uma provedora de servidores em nuvem, e que possui um ótimo preço para servidores virtuais.

2 http://newrelic.com/server-monitoring 
constante. No Apêndice L constam os relatórios de todos os dias de curso, onde é possível verificar os padrões de utilização de recursos. 


\section{Conclusão}

Conforme foi visto inicialmente, as crianças e adolescentes possuem cada vez mais contato com tecnologias digitais, além de usarem a internet com frequência. Além disso, programas de incentivo governamentais fomentam este uso cada vez mais comum dentro das dependências das escolas. Neste escopo, o objetivo geral deste trabalho foi verificar se um conjunto de funcionalidades para um sistema a ser utilizado durante a aula e fora dela pode, em conjunto com uma metodologia pedagógica adequada, aumentar a colaboração entre alunos e com o professor; e definir quais tecnologias web são adequadas para implementá-las. Como objetivos secundários será desenvolvido um protótipo do sistema, avaliadas sua utilização e também sua usabilidade.

O sistema Mindboard também mostrou-se interessante a ser utilizado no ensino a distância, como um meio de distribuição de conteúdo, e também na visualização de vídeos com dados contextuais relacionados. Além disso, mostrou-se interessante também para a utilização com outros tipos de objetos de aprendizagem, como o IVProg desenvolvido no grupo de pesquisas LInE.

Durante a execução deste trabalho, foi realizado uma revisão exploratória para a definição destas funcionalidades e também pesquisas para validar as tecnologias web mais adequadas e quais as opiniões de alunos e professores sobre uma futura ferramenta. Logo após, foi iniciado o projeto do protótipo do sistema Mindboard, e definidos todos os itens necessários a sua implementação. Após implementado, foi realizado um experimento onde foi possível descobrir pontos que precisam ser melhorados, pontos acertados e novas etapas que podem exploradas.

O experimento realizado com a finalidade de utilizar o sistema Mindboard dentro e fora de sala de aula foi realizado com sucesso, porém, alguns itens podem ser trabalhados para que seja possível levantar mais dados a respeito da colaboração. As dificuldades encontradas durante o experimento, sugerem a realização de um novo melhorando alguns pontos. Este novo experimento não foi realizado durante este trabalho de mestrado por falta de tempo hábil de aprovar o experimento no Comitê de Ética em Pesquisa e realizá-lo. Para um futuro experimento, alguns pontos podem ser melhorados, principalmente em relação a quantidade de dados gerados.

Este novo experimento, idealmente, deverá possuir 2 grupos entre 40 a 60 alunos, que é geralmente o tamanho das turmas de graduação de Sistemas de Informação na 
EACH. Um cuidado extra que deverá ser tomado é em relação aos alunos menores de idade, uma vez que eles apenas podem participar de experimentos com a autorização dos responsáveis.

Também visando o aumento do quantidade de dados gerados, propõe-se o aumento do tempo do experimento, onde a duração mínima deva ser de 2 meses, com aulas 2 vezes na semana com duração de 2 horas cada. Para este novo experimento, não será utilizado o áudio para a contagem das interações, pois, durante o experimento realizado neste trabalho não foi possível distinguir o som por ruídos e pela própria distância entre os alunos. Será utilizado também mais de uma câmera para que possa ser evitada a oclusão visual, que aconteceu com muita frequência neste experimento.

Outro ponto deste novo experimento é a utilização do sistema em aulas com um mesmo professor, porém sem que ele seja o autor deste trabalho. E também, a ferramenta ser utilizada em um curso que tenha uma quantidade maior de conteúdos teóricos, já que o curso do experimento deste trabalho teve mais conteúdo prático.

Apesar dos problemas já relatados no experimento, e das propostas de melhorias citadas anteriormente, os resultados obtidos neste trabalho foram muito interessantes, pois foi possível responder a cada uma das perguntas de pesquisa com a validação de cada hipótese.

A primeira hipótese era de que o seguinte conjunto de funcionalidades poderiam fomentar a colaboração entre os alunos em aula e fora dela:

Funcionalidade 1: permitir ao aluno visualizar conteúdo (apresentações, textos, vídeos, etc) disponibilizado pelo professor, tanto durante a aula quanto depois dela;

Resultado: essa funcionalidade foi ampliada com o compartilhamento de códigosfonte em tempo real, e obteve um alto grau de satisfação dos alunos pela facilidade de obtenção dos conteúdos de aula em tempo real, e também, por um benefício que até então, durante a elaboração das hipóteses, não havia sido considerado, que é a acessibilidade. Alunos com problemas de visão ou até mesmo que estão localizados em sala de aula um pouco mais afastados do projetor podem ter uma experiência em aula muito melhor, pois bastaria acompanhar o conteúdo de seus próprios computadores e dispositivos. O que evitaria uma perda no foco de aula por não enxergar corretamente o conteúdo exposto pelo professor.

O compartilhamento de conteúdo com código-fonte também teve uma relevância alta no curso realizado no experimento, uma vez que o aluno pode focar sua atenção na 
explicação do professor ao invés de preocupar-se em copiar os conteúdos, reduzindo assim o número de interações espúrias relacionadas a não visualização de um dado conteúdo.

Funcionalidade 2: possibilitar ao aluno informar anonimamente o professor, durante a aula, o quanto está compreendendo o assunto;

Funcionalidade 3: possibilitar que o professor receba o retorno dado pelo aluno na funcionalidade anterior em tempo real, enquanto está dando aula, sobre o quanto os alunos julgam estar entendendo o conteúdo. Permitir também que o professor visualize o histórico destes retornos;

Funcionalidade 4: permitir que o aluno faça anotações no computador ou em dispositivos móveis diretamente sobre o material de aula que o professor disponibilizou;

Funcionalidade 5: permitir ao aluno compartilhar estas anotações (descritas na funcionalidade anterior) e dúvidas, respostas ou comentários com os demais alunos, durante a aula e depois dela;

Resultado: as 4 funcionalidades anteriores durante o experimento permitiram que alunos mais tímidos ou que não estavam na turma junto com outros conhecidos pudessem participar da aula, mesmo que de forma anônima (que foi levantado por meio de questionários e por comentários em aula). Além disso, a funcionalidade é muito relevante ao professor para controle de qualidade de suas próprias aulas como também pôde ser visto na análise da respostas das pesquisas feita com professores e alunos neste trabalho. As anotações sobre o material de aula também mostraram-se muito relevantes, pois os alunos não precisam utilizar outros sistemas para fazer isso, e como no Mindboard as anotações podem ser questionamentos, é uma funcionalidade que gera bastante interação de qualidade em cima do conteúdo exposto em aula.

A segunda Pergunta de Pesquisa era dados estes requisitos, quais as tecnologias web poderiam ser utilizadas em seu desenvolvimento? E como Hipótese foram definidas as tecnologias Java Applet e HTML5, CSS3 e JavaScript.

Durante o experimento realizado no grupo de pesquisas LInE, foi possível levantar indícios que a tecnologia Java Applet possui muitas barreiras para ser utilizada hoje em dia, principalmente em sistemas para a educação, por suas dificuldades de funcionamento. Assim, devido às vantagens das tecnologias HTML5, CSS3 e JavaScript explicitadas no experimento, o protótipo do sistema Mindboard foi construído utilizando-as. A fim de manter uma uniformidade de tecnologias, foi escolhida também a linguagem JavaScript para construir todo o back-end do sistema. 
As tecnologias de front-end HTML5, CSS3 e JavaScript durante o experimento mostraram-se compatíveis com todos os navegadores utilizados pelos alunos, pois todos os alunos conseguirem utilizar a ferramenta. Já as tecnologias escolhidas para o back-end também mostraram-se adequadas e pelos resultados dos relatórios de utilização de recursos do servidor, consome poucos recursos computacionais por alunos e pode ser escalada para atender um número maior de alunos sem a necessidade de reescrita de códigos.

Como a arquitetura definida no sistema Mindboard é escalável e facilmente expansível, abre-se novas possibilidades para novos trabalhos, tais como:

Integração com um SGC: integrar o sistema Mindboard a SGCs conhecidos e muito utilizados no mercado, para facilitar ainda mais sua utilização, não necessitando gerenciar cadastros de informações de alunos e materiais de forma redundante.

Integração com ambientes de programação: para a utilização em aulas de programação, ampliar a integração da ferramenta para trocar código-fonte com ferramentas integradas de desenvolvimento, facilitando ainda mais a colaboração sobre código-fonte.

Permitir criar anotações também como desenhos: para facilitar ainda mais a anotação, permitir que alunos e professores anotem sobre o conteúdo utilizando desenhos, simplificando assim a utilização em conjunto com lousas digitais.

Além de possibilidades funcionais, é interessante explorar a utilização do sistema em outras situações, tais como:

Realizar mais experimentos com outras metodologias pedagógicas: explorar o uso do sistema em aulas onde são utilizadas metodologias pedagógicas diferentes da utilizada no experimento deste trabalho;

Realizar mais experimentos em outras áreas do conhecimento: explorar a utilização do sistema em outras áreas do conhecimento, como humanas e biológicas, e avaliar a ferramenta nessas condições;

Assim, este trabalho cumpriu seu objetivo de verificar o ganho em colaboração em sala de aula através da utilização de um sistema computacional. Além disso, foi possível utilizá-la e perceber novas facilidades e vantagens que não eram esperadas inicialmente e que provam que cada vez mais a tecnologia ao ser utilizada em sala de aula podem incluir alunos tímidos, aumentar a acessibilidade ao conteúdo de aula e potencializa a colaboração e motivação em aula. E que as tecnologias para a construção de um sistema com estas características estão disponíveis e podem ser utilizadas muito bem para a área da educação. 


\section{Referências $^{1}$}

ALPERT, D.; BITZER, D. L. Advances in computer-based education. Science, v. 167, p. 1582-1590, 1970. Citado na página 19.

AMORY, A. et al. The use of computer games as an educational tool: identification of appropriate game types and game elements. British Journal of Educational Technology, v. 30, n. 4, p. 311-321, 1999. Citado na página 20.

ANGULARJS: Superheroic JavaScript MVW Framework. 2015. Disponível em: $<$ https://angularjs.org/>. Citado na página 79 .

ARLOW, J.; NEUSTADT, I. Uml and the Unified Process: Practical Object-Oriented Analysis and Design. 1st. ed. Boston, MA, USA: Addison-Wesley Longman Publishing Co., Inc., 2002. ISBN 0201770601. Citado na página 70.

BAKER, M.; LUND, K. Promoting reflective interactions in a CSCL environment. Journal of computer assisted learning, v. 13, n. 3, p. 175-193, 1997. Disponível em: <http://onlinelibrary.wiley.com/doi/10.1046/j.1365-2729.1997.00019.x/abstract>. Citado na página 25.

BARBOSA, E. F. Estudo e definição de um conjunto de características e requisitos para ambientes de aprendizagem móvel. In: Anais do Simpósio Brasileiro de Informática na Educação. [S.l.: s.n.], 2012. v. 23. Citado na página 40.

BARCELOS, R.; TAROUCO, L.; BERCHT, M. O uso de mobile learning no ensino de algoritmos. RENOTE, v. 7, n. 3, p. 327-337, 2009. Disponível em: <http://www.seer.ufrgs.br/renote/article/download/13573/14076>. Citado 2 vezes nas páginas 15 e 21.

BERNARDES, J. J. L. Desenvolvimento de um ambiente para visualização tridimensional da dinâmica de risers. Dissertação (Mestrado) - Escola Politécnica, Universidade de São Paulo, São Paulo, 2004. Disponível em: <http://www.teses.usp.br/teses/disponiveis/3/3132/tde-22092005-202846/pt-br.php>. Acesso em: 24.07.2014. Citado 2 vezes nas páginas 67 e 69.

BLOOM, B. S. The 2 Sigma Problem: The Search for Methods of Group Instruction as Effective as One-to-One Tutoring. Educational Researcher, v. 13, n. 6, p. 4-16, jun. 1984. ISSN 0013-189X. Disponível em: <http://edr.sagepub.com/cgi/doi/10.3102/0013189X013006004>. Citado na página 20.

BOICEA, A.; RADULESCU, F.; AGAPIN, L. I. MongoDB vs oracle - database comparison. In: . IEEE, 2012. p. 330-335. ISBN 978-1-4673-1986-7, 978-0-7695-4734-3. Disponível em: $<$ http://ieeexplore.ieee.org/lpdocs/epic03/wrapper.htm?arnumber $=6354766>$. Citado na página 80.

BONASTRE, O. M.; BENAVENT, A. P.; GARCíA, M. A. O. E-dap: an e-learning tool for managing, distributing and capturing knowledge. In: Information Technology Based Higher Education and Training, 2005. ITHET 2005. 6th International Conference on. [S.l.: s.n.], 2005. p. S3B-11. Citado 2 vezes nas páginas 49 e 51.

$\overline{1}$ De acordo com a Associação Brasileira de Normas Técnicas. NBR 6023. 
BOOTSTRAP: The world's most popular mobile-first and responsive front-end framework. 2015. Disponível em: <http://getbootstrap.com/>. Citado na página 79.

BOYINBODE, O.; BAGULA, A.; NG'AMBI, D. A mobile learning application for delivering educational resources to mobile devices. In: Information Society (i-Society), 2012 International Conference on. [s.n.], 2012. p. 120-125. Disponível em: $<$ http://ieeexplore.ieee.org/xpls/abs $\backslash \_a l l . j s p ?$ arnumber $=6285060>$. Citado 3 vezes nas páginas 47, 48 e 51.

BROWSER Statistics. 2015. Disponível em: <http://www.w3schools.com/browsers/browsers_stats.asp $>$. Citado na página 78.

BSON. 2014. Disponível em: <http://bsonspec.org/>. Acesso em: 28.07.2014. Citado na página 80.

CALDWELL, J. E. Clickers in the large classroom: Current research and best-practice tips. CBE-Life Sciences Education, v. 6, n. 1, p. 9-20, 2007. Disponível em: $<$ http://www.lifescied.org/content/6/1/9.short>. Citado na página 24.

CHAMBERS, J. A.; SPRECHER, J. W. Computer assisted instruction: current trends and critical issues. Communications of the ACM, ACM, v. 23, n. 6, p. 332-342, 1980. Citado 2 vezes nas páginas 19 e 20.

CHIMOS, K. et al. Unibook SE: an innovative environment for life-long learning. In: Interactive Collaborative Learning (ICL), 2012 15th International Conference on. [S.1.: s.n.], 2012. p. 1-4. Citado 5 vezes nas páginas 45, 46, 48, 49 e 52.

CHOW, K. O. et al. A mobile lecture slide organization tool for students. In: Pervasive Computing and Applications, 2006 1st International Symposium on. [s.n.], 2006. p. 354-357. Disponível em: <http://ieeexplore.ieee.org/xpls/abs\_all.jsp?arnumber $=4079168>$. Citado 2 vezes nas páginas 45 e 50.

CHUANG, Y.-T. SSCLS: A Smartphone-Supported Collaborative Learning System. Telematics and Informatics, v. 32, n. 3, p. 463-474, ago. 2015. ISSN 07365853. Disponível em: < http://linkinghub.elsevier.com/retrieve/pii/S0736585314000720>. Citado na página 24.

CLASSDOJO. 2014. Disponível em: <http://www.classdojo.com>. Acesso em: 24.07.2014. Citado 3 vezes nas páginas 49, 50 e 52 .

CLICKERSCHOOL. 2014. Disponível em: <www.clickerschool.com>. Acesso em: 24.07.2014. Citado 3 vezes nas páginas 44, 50 e 52.

COTTON, K. Computer-assisted instruction. School improvement research series, 1991. Citado 3 vezes nas páginas 15, 21 e 22.

COVIC, Z.; CINGER, N. v. H.; IVKOVIC, M. Development of a system for mobile learning. In: Intelligent Systems and Informatics (SISY), 2010 8th International Symposium on. [s.n.], 2010. p. 189-191. Disponível em: <http://ieeexplore.ieee.org $/$ xpls $/$ abs $\backslash$ all.jsp?arnumber $=5647286>$. Citado 3 vezes nas páginas 43,44 e 51.

CSS3 @media Rule. 2015. Disponível em: <http://www.w3schools.com/cssref/css3_pr_mediaquery.asp $>$. Citado na página 77. 
DAM, A. V.; BECKER, S.; SIMPSON, R. M. Next-generation educational software: why we need it and a research agenda for getting it. In: ACM SIGGRAPH 2007 courses. ACM, 2007. p. 32. Disponível em: <http://dl.acm.org/citation.cfm?id=1281543>. Citado na página 20.

DANIELSON, R. L.; NIEVERGELT, J. An automatic tutor for introductory programming students. SIGCSE Bull., ACM, New York, NY, USA, v. 7, n. 1, p. 47-50, jan. 1975. ISSN 0097-8418. Disponível em: <http://doi.acm.org/10.1145/953064.811129>. Citado na página 20.

DAOUDI, N. How ECM can be used for distance learning content management ECM to LCM. In: Interactive Mobile and Computer Aided Learning (IMCL), 2012 International Conference on. [s.n.], 2012. p. 1-6. Disponível em: <http://ieeexplore.ieee.org/xpls/abs \_all.jsp?arnumber $=6396441>$. Citado 6 vezes nas páginas 45, 46, 47, 48, 49 e 51.

DATA Binding. 2015. Disponível em: < https://docs.angularjs.org/guide/databinding > Citado na página 79.

DI, J. et al. A smil-based multimedia system for mobile education. In: Broadband Network 83 Multimedia Technology, 2009. IC-BNMT'09. 2nd IEEE International Conference on. [s.n.], 2009. p. 724-728. Disponível em: <http://ieeexplore.ieee.org/xpls/abs \_all.jsp?arnumber $=5347777>$. Citado 4 vezes nas páginas 45, 47, 48 e 51 .

DOTTA, S. Uso de uma mídia social como ambiente virtual de aprendizagem. Anais do XXII Simpósio Brasileiro de Informática na Educação. Citado na pág, v. 1, 2011. Disponível em: <http://www.lbd.dcc.ufmg.br/colecoes/sbie/2011/0077.pdf>. Citado na página 21.

DU, S.-C.; FU, Z.-T.; WANG, Y. The Flipped Classroom-Advantages and Challenges. 2014. Disponível em: <http://www.atlantis-press.com/php/download_paper.php?id=11721>. Citado na página 28.

EDMODO. 2014. Disponível em: <https://www.edmodo.com/>. Acesso em: 24.07.2014. Citado 4 vezes nas páginas 46, 48, 49 e 52.

ELLIS, C. A.; GIBBS, S. J. Concurrency control in groupware systems. In: Acm Sigmod Record. ACM, 1989. v. 18, p. 399-407. Disponível em: <http://dl.acm.org/citation.cfm?id=66963>. Citado 2 vezes nas páginas 90 e 91.

FARDOUN, H. M. et al. Instructional m-learning system design based on learners: MPrinceTool. In: . IEEE, 2010. p. 220-225. ISBN 978-1-4244-8068-5. Disponível em: $<$ http://ieeexplore.ieee.org/lpdocs/epic03/wrapper.htm?arnumber $=5628909>$. Citado 5 vezes nas páginas 44, 46, 49, 50 e 51 .

FARIA, T. V. M.; BERNARDES JUNIOR, J. L. JustReview: Uma ferramenta para otimizar o processo de revisão sistemática da literatura. I, n. Trilhas Técnicas, p. 207-218, maio 2014. ISSN 2177-885X. Citado 2 vezes nas páginas 29 e 42.

FELDER, R. How about a quick one. Chemical Engineering Education, v. 26, n. 1, p. 18-19, 1992. Citado na página 16. 
FERNANDES, L. Redes sociais online e educação: Contributo do facebook no contexto das comunidades virtuais de aprendentes. 2011. [Online; acessado 31 de Maio de 2015]. Disponível em: < http://www.trmef.lfernandes.info/ensaio_TRMEF.pdf $>$. Citado na página 21.

FLOREA, B. C.; FRUNZETE, M.; STEFANESCU, V. An integrated e-learning platform for use in higher education. In: Design and Technology in Electronic Packaging (SIITME), 2011 IEEE 17th International Symposium for. [s.n.], 2011. p. 369-372. Disponível em: $<$ http://ieeexplore.ieee.org/xpls/abs $\backslash$ _all.jsp?arnumber $=6102754>$. Citado 3 vezes nas páginas 44, 50 e 51.

FULTON, K. P. 10 Reasons to Flip: A Southern Minnesota School District Flipped Its Math Classrooms and Raised Achievement and Student Engagement. Phi Delta Kappan, v. 94, n. 2, p. 20, 2012. Disponível em: <http://www.questia.com/library/journal/1G1309459584/10-reasons-to-flip-a-southern-minnesota-school-district>. Citado 2 vezes nas páginas 27 e 28.

GENTLE, J. ShareJS. 2011. Disponível em: <http://sharejs.org/>. Citado na página 91.

GOMES, M. A Infraaestrutura de servidores web do sistema Boo-Box. 2009. Disponível em: <http://blog.boo-box.com/br/2009/a-infraestrutura-de-servidores-web-do-sistemaboo-box/>. Acesso em: 28.07.2014. Citado na página 81.

GREIF, I. (Ed.). Computer-supported Cooperative Work: A Book of Readings. San Francisco, CA, USA: Morgan Kaufmann Publishers Inc., 1988. ISBN 0-934613-57-5. Citado na página 23.

GRIFFIOEN, J.; SEALES, W. B.; JR, J. E. L. Teaching in realtime wireless classrooms. In: Frontiers in Education Conference, 1998. FIE'98. 28th Annual. [s.n.], 1998. v. 2, p. 748-753. Disponível em: <http://ieeexplore.ieee.org/xpls/abs \_all.jsp?arnumber=738791>. Citado 5 vezes nas páginas 44, 45, 46, 49 e 52.

GUEDES, G. T. Uml 2. Uma Abordagem Prática”, São Paulo, Novatec, 2009. Citado na página 73.

HASHIM, A. S.; AHMAD, W. F. W. The development of new conceptual model for MobileSchool. In: . IEEE, 2012. p. 517-522. ISBN 978-1-4673-4977-2, 978-0-7695-4926-2. Disponível em: <http://ieeexplore.ieee.org/lpdocs/epic03/wrapper. htm?arnumber $=6410203>$. Citado 4 vezes nas páginas 46, 47, 49 e 52.

HAYAKAWA, T. et al. Management of multimedia data for streaming on a distributed e-learning system. In: . IEEE, 2012. p. 1282-1285. ISBN 978-1-4673-0867-0, 978-0-7695-4652-0. Disponível em: <http://ieeexplore.ieee.org/lpdocs/epic03/wrapper.htm?arnumber $=6185426>$. Citado 3 vezes nas páginas 47, 48 e 51.

HOGANSON, K. E. Distance-learning and converging mobile devices. In: . [S.l.]: IEEE, 2009. p. 1114-1119. ISBN 978-1-4244-3770-2. Citado 4 vezes nas páginas 45, 47, 48 e 51.

HORN, M. B.; STAKER, H. The rise of K-12 blended learning. Innosight Institute. Retrieved on September, v. 7, 2011. Disponível em: <http://www.leadcommission.org/sites/default/files/The\%20Rise\%20of\%20K-12\%20Blended\%20Learning_0.pdf>. Citado na página 26. 
HOW do I use Java with the Google Chrome browser? 2015. Disponível em: $<$ https://java.com/en/download/faq/chrome.xml>. Citado na página 78.

HTML5. 2015. Disponível em: <http://www.w3.org/TR/2012/CR-html5-20121217/introduction.html\#introduction>. Citado na página 76.

IJTIHADIE, R. M. et al. Offline web application and quiz synchronization for e-learning activity for mobile browser. In: TENCON 2010-2010 IEEE Region 10 Conference. [s.n.], 2010. p. 2402-2405. Disponível em: <http://ieeexplore.iee. org $/ \mathrm{xpls} / \mathrm{abs} \backslash \_$all.jsp? arnumber $=5685899>$. Citado 3 vezes nas páginas 43, 44 e 51.

INTRODUCTION to MongoDB. 2014. Disponível em: <http://docs.mongodb.org/manual/core/introduction/>. Acesso em: 28.07.2014. Citado na página 80 .

JACOBSON, I.; BOOCH, G.; RUMBAUGH, J. The Unified Software Development Process. [S.l.]: Addison-Wesley, 1999. Citado 2 vezes nas páginas 67 e 70.

JAGAR, M.; PETROVIC, J.; PALE, P. AuResS: the audience response system. In: ELMAR, 2012 Proceedings. [s.n.], 2012. p. 171-174. Disponível em: <http://ieeexplore.ieee.org $/$ xpls $/$ abs $\backslash$ all.jsp?arnumber $=6338498>$. Citado 2 vezes nas páginas 44 e 50.

JOHNSON, L.; ADAMS, S.; CUMMINS, M. The NMC Horizon Report: 2012 Higher Education Edition. Austin Texas, 2012. Citado na página 15.

JOHnSON, L. et al. The NMC Horizon Report: 2014 K-12 Edition. Austin Texas, 2014. Citado na página 15.

JOHNSON, L. et al. New Media Consortium Horizon Report: 2015 Higher Education Edition. Austin Texas: The New Media Consortium, 2015. Citado na página 26.

KADIYALA, M.; CRYNES, B. L. Where's the proof? A review of literature on effectiveness of information technology in education. In: Frontiers in Education Conference, 1998. FIE'98. 28th Annual. IEEE, 1998. v. 1, p. 33-37. Disponível em: $<$ http://ieeexplore.ieee.org/xpls/abs_all.jsp?arnumber $=736797>$. Citado 2 vezes nas páginas 21 e 22.

KETAMO, H. xTask-adaptable working environment. In: Wireless and Mobile Technologies in Education, 2002. Proceedings. IEEE International Workshop on. [S.l.: s.n.], 2002. p. 55-62. Citado 3 vezes nas páginas 46, 49 e 52.

KIEFER, B. The Trello Tech Stack. 2014. Disponível em: <http://blog.fogcreek.com/thetrello-tech-stack/>. Acesso em: 28.07.2014. Citado na página 81.

KIRSCHNER, P. A. Using integrated electronic environments for collaborative teaching/learning. Learning and Instruction, v. 10, p. 1-9, 2001. Disponível em: <http://www.sciencedirect.com/science/article/pii/S0959475200000219>. Citado na página 25.

KITCHENHAM, B. Procedures for performing systematic reviews. Keele, UK, Keele University, v. 33, p. 2004, 2004. Citado 2 vezes nas páginas 40 e 41. 
KULIK, J. A.; KULIK, C.-L. C.; BANGERT-DROWNS, R. L. Effectiveness of Computer-Based Education in Elementary Schools. In: Computers in Human Behavior. [S.l.]: Pergamon Press Inc., 1985. v. 1, p. 59-74. Citado na página 22.

LEUNG, C. Operational transformation in cooperative software systems. McGill Science Undergraduate Research Journal, v. 8, n. 1, 2013. Disponível em: <http://msurj.mcgill.ca/vol8/iss1/Leung2013.pdf>. Citado na página 91.

LEWIS, J. R. Ibm computer usability satisfaction questionnaires: Psychometric evaluation and instructions for use. International Journal of Human-Computer Interaction, v. 7, n. 1, p. 57-78, 1995. Citado na página 38.

LI, X.; WU, Y. Design and development of the online examination and evaluation system based on B/S structure. In: Wireless Communications, Networking and Mobile Computing, 200\%. WiCom 200\%. International Conference on. [s.n.], 2007. p. 6223-6225. Disponível em: <http://ieeexplore.ieee.org/xpls/abs $\backslash$ _all.jsp?arnumber $=4341300>$. Citado 2 vezes nas páginas 50 e 52 .

LIU, C.-C. et al. An interaction study of learning with handhelds and large shared-displays in technology-enriched collaborative classroom. In: Advanced Learning Technologies, 200\%. ICALT 200\%. Seventh IEEE International Conference on. [s.n.], 2007. p. 217-221. Disponível em: <http://ieeexplore.ieee.org/xpls/abs \_all.jsp?arnumber $=4280995>$. Citado 3 vezes nas páginas 48, 49 e 51 .

LONG, J. I Don't Speak Your Language: Frontend vs. Backend. 2012. Disponível em: $<$ http://blog.teamtreehouse.com/i-dont-speak-your-language-frontend-vs-backend $>$. Citado na página 76.

LUND, A. M. Measuring Usability with the USE Questionnaire. 2001. www.stcsig. org/usability/newsletter/0110_measuring_with_use.html. [Online; acessado 01 de Janeiro de 2015 a versão em cache de 2001]. Citado na página 38.

MASTERYCONNECT. 2014. Disponível em: < https://www.masteryconnect.com/>. Acesso em: 24.07.2014. Citado 4 vezes nas páginas 46, 49, 50 e 52.

MERMELSTEIN, B.; TAL, E. Using cellular phones in higher education: mobile access to online course materials. In: Wireless and Mobile Technologies in Education, 2005. WMTE 2005. IEEE International Workshop on. [S.1.: s.n.], 2005. p. 3-pp. Citado 4 vezes nas páginas 47, 48, 49 e 52.

MILMAN, N. B. The Flipped Classroom Strategy: What is it and how can it best be used? Ends and Means, v. 9, n. 3, p. 85-87, 2012. Citado na página 27.

Modules. 2015. Disponível em: <https://nodejs.org/api/modules.html>. Acesso em: 01.01.2015. Citado na página 83.

NAKAI, R.; NAGAOKA, K. Conducting classroom discussions in the manner of an orchestra using a mobile phone based response analyzing system. In: Advanced Learning Technologies, 200\%. ICALT 200\%. Seventh IEEE International Conference on. [s.n.], 2007. p. 340-341. Disponível em: <http://ieeexplore.ieee.org/xpls/abs \_all.jsp?arnumber $=4281029>$. Citado 2 vezes nas páginas 44 e 50. 
NGUYEN, D. P.; GUGGISBERG, M.; BURKHART, H. CoMobile: collaborative learning with mobile devices. In: Advanced Learning Technologies, 2006. Sixth International Conference on. [s.n.], 2006. p. 355-359. Disponível em: <http://ieeexplore.ieee.org/xpls/abs \_all.jsp?arnumber $=1652443>$. Citado 3 vezes nas páginas 46, 47 e 51.

NORMAN, K.; SHNEIDERMAN, B.; HARPER, B. QUIS: The Questionnaire for User Interaction Satisfaction. 1987. www.cs.umd.edu/hcil/quis/. [Online; acessado 01 de Dezembro de 2014]. Citado na página 38.

ONRUBIA, J.; ENGEL, A. Strategies for collaborative writing and phases of knowledge construction in CSCL environments. Computers \& Education, v. 53, n. 4, p. 1256-1265, dez. 2009. ISSN 03601315. Disponível em: <http://linkinghub.elsevier.com/retrieve/pii/S0360131509001559>. Citado na página 25.

PALOSCHI, L. C. Gerações Interativas Brasil - Crianças e adolescentes diante das telas. [S.l.], 2012. Citado na página 15.

PáDUA, W. d. P. Engenharia de software: fundamentos, métodos e padrões. 2. ed. ed. Rio de Janeiro: LTC, 2005. Citado 2 vezes nas páginas 71 e 178.

POLLEVERYWHERE. 2014. Disponível em: <http://www.polleverywhere.com/>. Acesso em: 24.07.2014. Citado 2 vezes nas páginas 44 e 52.

POLLOCK, S. J. Transferring transformations: learning gains, student attitudes, and the impacts of multiple instructors in large lecture courses. In: 2005 Physics Education Research Conference. [s.n.], 2006. v. 818, p. 141-144. Disponível em: <http://extras.springer.com/2006/978-0-7354-0311-6/cdr_pdfs/indexed/stage4_copyr/141_1.pdf>. Citado na página 24.

PRESSMAN, R. S. Engenharia de Software. Sexta edição. São Paulo, SP: McGraw-Hill, 2006. Citado 3 vezes nas páginas 67, 68 e 69.

PROINFO - Programa Nacional de Tecnologia Educacional. 2014. Disponível em: <http://www.fnde.gov.br/programas/programa-nacional-de-tecnologia-educacional-proinfo > . Acesso em: 24.07.2014. Citado na página 15.

PUSNIK, M.; SUMAK, B.; HERICKO, M. Investigation of virtual learning environment in the context of web 2.0. In: Mobile, Hybrid, and On-Line Learning, 2010. ELML'10. Second International Conference on. [s.n.], 2010. p. 1-6. Disponível em: <http://ieeexplore.ieee.org/xpls/abs_all.jsp?arnumber $=5430018>$. Citado 2 vezes nas páginas 53 e 72 .

RAMANAU, R.; GENG, F. Researching the use of Wiki's to facilitate group work. Procedia - Social and Behavioral Sciences, v. 1, n. 1, p. 2620-2626, 2009. ISSN 18770428. Disponível em: <http://linkinghub.elsevier.com/retrieve/pii/S1877042809004650>. Citado 2 vezes nas páginas 24 e 25.

RAWAT, K. S.; RIDDICK, G. B.; MOORE, L. J. Work in progress-integrating mobile tablet-PC technology and classroom management software in undergraduate electronic engineering technology courses. In: Frontiers in Education Conference, 2008. FIE 2008. 38th Annual. [S.l.: s.n.], 2008. p. S4D-23. Citado 4 vezes nas páginas 44, 45, 52 e 54. 
REDIS - Pubsub. 2014. Disponível em: <http://redis.io/topics/pubsub>. Acesso em: 28.07.2014. Citado na página 80.

REINHARD, W. et al. CSCW tools: concepts and architectures. Computer, v. 27, n. 5, p. 2836, 1994. Disponível em: <http://ieeexplore.ieee.org/xpls/abs_all.jsp?arnumber $=291293>$. Citado 2 vezes nas páginas 23 e 24.

REMIND101. 2014. Disponível em: <https://www.remind101.com>. Acesso em: 24.07.2014. Citado 2 vezes nas páginas 46 e 52.

RIBEIRO, R. et al. Programming web-course analysis: how to introduce computer programming? In: IEEE. 2014 Frontiers in Education Conference (FIE 2014). Madrid, Spain, 2014. p. 1-8. Citado na página 30.

RODRIGUEZ-ALSINA, A. et al. Unified content design for ubiquitous learning: The soldering seminar use case. In: E-Learning in Industrial Electronics (ICELIE), 2010 4th IEEE International Conference on. [S.1.: s.n.], 2010. p. 79-83. Citado 5 vezes nas páginas $45,46,47,48$ e 52 .

ROIG-TORRES, J.; XHAFA, F.; CABALLE, S. Supporting online coordination of learning teams through mobile devices. In: . IEEE, 2012. p. 941-946. ISBN 978-1-4673-1233-2, 978-0-7695-4687-2. Disponível em: <http://ieeexplore.ieee.org/lpdocs/epic03/wrapper.htm?arnumber $=6245714>$. Citado 4 vezes nas páginas 45, 46, 51 e 52 .

SANTAROSA, L.; CONFORTO, D.; MACHADO, R. P. Sincronismo, colaboração e acessibilidade na web 2.0. In: Anais do Simpósio Brasileiro de Informática na Educação. [s.n.], 2012. v. 23. Disponível em: <http://ceie-sbc.educacao.ws/pub/index.php/sbie/article/view/1770>. Citado na página 53.

SCHMIDT, K.; BANNON, L. Taking CSCW seriously. Computer Supported Cooperative Work $(C S C W)$, v. 1, n. 1-2, p. 7-40, 1992. Disponível em: <http://link.springer.com/article/10.1007/BF00752449>. Citado na página 23.

SCHMIEDL, G.; GRECHENIG, T.; SCHMIEDL, B. Mobile enabling of virtual teams in school: an observational study on smart phone application in secondary education. In: Education Technology and Computer (ICETC), 2010 2nd International Conference on. [s.n.], 2010. v. 2, p. V2-74. Disponível em: <http://ieeexplore.ieee. .org/xpls/abs $\backslash \_a l l . j s p ?$ arnumber $=5529432>$. Citado 4 vezes nas páginas 43, 44, 46 e 52 .

SCHON, D.; KOPF, S.; EFFELSBERG, W. A lightweight mobile quiz application with support for multimedia content. In: e-Learning and e-Technologies in Education (ICEEE), 2012 International Conference on. [s.n.], 2012. p. 134-139. Disponível em: $<$ http://ieeexplore.ieee.org/xpls/abs \_all.jsp?arnumber $=6333407>$. Citado 4 vezes nas páginas 43, 44, 45 e 50.

SETIABUDI, D. H.; TJAHYANA, L. J. Mobile Learning Application Based On Hybrid Mobile Application Technology Running On Android Smartphone and Blackberry. Tese (Doutorado) - Petra Christian University, 2013. Disponível em: $<$ http://repository.petra.ac.id/id/eprint/16082>. Citado 4 vezes nas páginas 46, 47, 49 e 51. 
SHAKESPEAK. 2014. Disponível em: <http://www.shakespeak.com>. Acesso em: 24.07.2014. Citado 3 vezes nas páginas 44, 45 e 52.

SINGH, G.; DENOUE, L.; DAS, A. Collaborative note taking. In: Wireless and Mobile Technologies in Education, 2004. Proceedings. The 2nd IEEE International Workshop on. [s.n.], 2004. p. 163-167. Disponível em: <http://ieeexplore.ieee.org/xpls/abs \_all.jsp?arnumber $=1281375>$. Citado 4 vezes nas páginas 44, 45, 50 e 54 .

SMITH, J. A comparison of rup and xp. Rational Software White Paper, p. 1-21, 2001. Citado na página 70 .

SMSPOLL. 2014. Disponível em: <http://www.smspoll.net/>. Acesso em: 24.07.2014. Citado 2 vezes nas páginas 44 e 52.

SOCRATIVE. 2014. Disponível em: <http://www.socrative.com>. Acesso em: 24.07.2014. Citado 2 vezes nas páginas 44 e 50.

SOMMERVILLE, I. Software Engineering. 9th. ed. [S.1.]: Addison-Wesley, 2010. Citado 2 vezes nas páginas 68 e 69 .

STAKER, H.; HORN, M. B. Classifying K-12 Blended Learning. Innosight Institute, 2012. Disponível em: <http://eric.ed.gov/?id=ED535180>. Citado 3 vezes nas páginas 16, 26 e 27.

STICKPICK. 2014. Disponível em: <http://stickpickapp.blogvspot.com.br>. Acesso em: 24.07.2014. Citado 2 vezes nas páginas 50 e 53.

SULTANA, A.; SULTANA, I. E-school: A web-service oriented resource based e-learning system. In: Networking and Information Technology (ICNIT), 2010 International Conference on. [s.n.], 2010. p. 415-419. Disponível em: <http://ieexplore.ieee.org/xpls/abs $\backslash \_a l l . j s p ?$ arnumber $=5508481>$. Citado 5 vezes nas páginas 47, 48, 49, 50 e 51.

SZABO, M.; FLESCHER, K. Cmi theory and practice: Historical roots of learning managment systems. In: World Conference on E-Learning in Corporate, Government, Healthcare, and Higher Education. [s.n.], 2002. v. 2002, p. 929-936. Disponível em: <http://www.editlib.org/p/15322/>. Citado 3 vezes nas páginas 15, 20 e 21.

TAKEDA, R. A. et al. Percepção dos alunos do curso de engenharia civil da ufscar sobre o uso do ava moodle como ferramenta de apoio ao ensino presencial. 2013. Disponível em: $<$ http://www.fadep.br/engenharia-eletrica/congresso/pdf/118031 \_1.pdf $>$. Citado na página 16.

TCHOUNIKINE, P. Computer Science and Educational Software Design. Berlin, Heidelberg: Springer Berlin Heidelberg, 2011. ISBN 978-3-642-20002-1, 978-3-642-20003-8. Disponível em: <http://link.springer.com/10.1007/978-3-642-20003-8>. Citado 2 vezes nas páginas 15 e 19.

TEACHERKIT. 2014. Disponível em: <http://www.teacherkit.net>. Acesso em: 24.07.2014. Citado 3 vezes nas páginas 49, 50 e 52. 
TILKOV, S.; VINOSKI, S. Node. js: Using JavaScript to build high-performance network programs. IEEE Internet Computing, v. 14, n. 6, 2010. Citado 2 vezes nas páginas 79 e 80.

TOKIWA, Y.; NONOBE, K.; IWATSUKI, M. Web-based tools to sustain the motivation of students in distance education. In: Frontiers in Education Conference, 2009. FIE'09. 39th IEEE. [S.l.: s.n.], 2009. p. 1-5. Citado 4 vezes nas páginas 43, 44, 52 e 54.

TOPHAT. 2014. Disponível em: <https://tophat.com>. Acesso em: 24.07.2014. Citado na página 44.

TURRO, C. et al. On webcasting to mobile devices: reusing web \& video content for pervasive e-learning. In: Pervasive Computing and Communications Workshops, 200\%. PerCom Workshops' 0\%. Fifth Annual IEEE International Conference on. [s.n.], 2007. p. 149-152. Disponível em: <http://ieeexplore.ieee.org/xpls/abs \_all.jsp?arnumber $=4144815>$. Citado 2 vezes nas páginas 48 e 51.

VAVOULA, G. N.; SHARPLES, M. KLeOS: a personal, mobile, knowledge and learning organisation system. In: Wireless and Mobile Technologies in Education, 2002. Proceedings. IEEE International Workshop on. [s.n.], 2002. p. 152-156. Disponível em: $<$ http://ieeexplore.ieee.org/xpls/abs \_all.jsp?arnumber $=1039239>$. Citado 5 vezes nas páginas 45, 47, 48, 49 e 51.

WHAT Is a Socket? 2015. Disponível em: <https://docs.oracle.com/javase/tutorial/networking/sockets/definition.html>. Citado na página 77.

WHAT is WebSocket? 2015. Disponível em: <https://www.websocket.org/>. Citado na página 77.

XHAFA, F. et al. Implementing a mobile campus using MLE moodle. In: . IEEE, 2010. p. 207-214. ISBN 978-1-4244-8538-3. Disponível em: < http://ieeexplore.ieee.org/lpdocs/epic03/wrapper.htm?arnumber $=5662787>$. Citado 5 vezes nas páginas 44, 46, 47, 50 e 52 .

YAO, X. Enhancing classroom education with instant messaging tools. In: . IEEE, 2011. p. 82-85. ISBN 978-1-4577-1561-7. Disponível em: <http://ieeexplore.ieee.org/lpdocs/epic03/wrapper.htm?arnumber $=6063198>$. Citado 2 vezes nas páginas 46 e 52 .

ZAKAS, N. Node.js High Availability at Box. 2014. Disponível em: <http://tech.blog.box.com/2014/06/node-js-high-availability-at-box/>. Acesso em: 28.07.2014. Citado na página 81. 
Apêndice A - Formulário da pesquisa com professores 


\section{Pesquisa}

Esta pesquisa tem como objetivo coletar dados sobre algumas facetas da utilização de tecnologia e internet no ensino/aprendizado nos ensinos médio e superior no Brasil. Tem também como objetivo verificar possíveis funcionalidades de uma ferramenta computacional para esta área.

Os dados pessoais e de contato aqui coletados serão utilizados com o propósito de comunicar os participantes sobre os resultados da pesquisa. É assegurada total privacidade sobre as informações pessoais e de contato coletadas.

Agradecemos a sua participação.

João Luiz Bernardes Junior

jlbernardes@usp.br

Tulio Vitor Machado Faria

tuliofaria@usp.br

*Obrigatório

\section{Dados básicos}

1. Nome: *

2. E-mail: *

O resultado da pesquisa será retornado para

todos por e-mail.

3. Idade:

4. Tempo de docência (aproximadamente), em anos:

5. Instituição de ensino ou escolas em que leciona:

6. Disciplinas lecionadas:

7. Cidade / estado: 
8. Marque abaixo todos os recursos computacionais que você utilizou durante o seu ensino superior ou depois, por exemplo, em uma pós-graduação, curso de especialização e/ou atualização (pode marcar mais de uma alternativa): *

Marque todas que se aplicam.

Internet

Apresentação (Por exemplo, Power Point)

Editor de textos

Planilha eletrônica

Editores gráficos (Por exemplo, Paint, Gimp, Photoshop, Corel)

D Programação

$\square$ Outro:

9. Quanto você utiliza a internet por semana? *

Marcar apenas uma oval.

Nada

Até 5 horas semanais

de 5 a 10 horas semanais

de 10 a 20 horas semanais

mais de 20 horas semanais

10. Tipo de instituição de ensino ou escola (pode marcar mais de uma alternativa): * Marque todas que se aplicam.

Pública

Privada

11. Nível (pode marcar mais de uma alternativa): *

Marque todas que se aplicam.

Ensino médio

Ensino superior e/ou pós-graduação

12. Selecione os modalidades pedagógicas/estratégias de ensino que você utiliza com frequência (pode marcar mais de uma alternativa): *

Marque todas que se aplicam.

Expositivas

Dialogadas

Pesquisas e seminários dos alunos

Ensino baseado em problemas (BPL)

Visitas técnicas / viagem a campo

Outro: 
13. Quais atividade extra-classes você utiliza em suas disciplinas (pode marcar mais de uma alternativa)? *

Marque todas que se aplicam.

Nenhuma

\section{Exercícios}

Trabalhos de pesquisa

Trabalhos práticos

Discussão em fóruns

Outro:

14. Quais dos recursos a seguir você utiliza em suas disciplinas (marque mais de um)? * Marque todas que se aplicam.

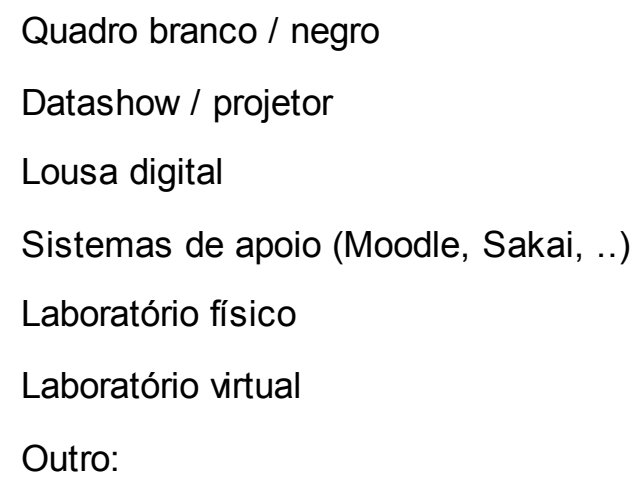

15. Sua instituição oferece sistemas para gerenciamento de conteúdo e compartilhamento de dados (por exemplo, Moodle, Blackboard, Sakai, Teleduc, TIDIA-Ae, COL, ...)? * Marcar apenas uma oval.
A) Sim.
B) Não, mas eu uso um por conta própria.
C) Não, eu não uso.

16. Caso você tenha marcado A ou B na questão anterior, informe qual sistema:

17. Você consegue ter algum retorno durante suas aulas sobre o aprendizado dos alunos? * Marcar apenas uma oval.

A) Sim, porque consigo perceber através dos comportamentos dos alunos.

B) Sim, porque realizo atividades que me permitem avaliar o aprendizado do aluno durante a aula.

C) Sim, porque consigo perceber através dos comportamentos dos alunos e porque realizo atividades que me permitem avaliar o aprendizado do aluno durante a aula.

D) Não 
18. Caso você tenha marcado B ou C na questão anterior, informe quais atividades:

19. Qual a confiança que você tem neste retorno? (por exemplo, quando você acha que os alunos estão compreendendo a matéria, quanto você confia que eles realmente estão?)

Marcar apenas uma oval.

Nenhuma confiança

Pouca confiança

Confiança média

Muita confiança

$\bigcirc$ Total confiança

20. Você gostaria de ter este retorno com mais frequência? *

Marcar apenas uma oval.

$\operatorname{Sim}$

Não

21. Você acha que os alunos ainda se sentem inibidos em dar este retorno ou realizar outros questionamentos? *

Marcar apenas uma oval.

Nunca

Poucas vezes

$\bigcirc$ Algumas vezes

Muitas vezes

Sempre

22. Você acha que seus alunos fazem uso frequente da internet em seu dia-a-dia? * Marcar apenas uma oval.

$\operatorname{Sim}$

Não

Não sei 
23. Quantos de seus alunos fazem uso da internet com dispositivos móveis durante suas aulas? *

Marcar apenas uma oval.
A) Nenhum: não permito o uso de internet em aula
B) Nenhum aluno
C) Poucos alunos
D) Alguns alunos
E) Muitos alunos
F) Todos os alunos

24. Caso você não tenha respondido $A$ ou $B$ na questão anterior, você acha que esta utilização de internet em sala de aula pelo alunos é feita para assuntos (pode marcar mais de uma alternativa):

Marque todas que se aplicam.

Acadêmicos: para pesquisar e estudar sobre o assunto da aula

Pessoais/não acadêmicos: para conversar com amigos, acessar redes sociais, etc.

25. Você gostaria de ter uma medida de quanto seus alunos estudam em casa? * Marcar apenas uma oval.

$\operatorname{Sim}$

Não

\section{Sobre a ferramenta}

Considerando um sistema Web de apoio didático (tanto em sala de aula ou laboratório quanto em atividades extra-classe), qual a importância que atribuiria as seguintes características na sua opinião:

26. Uma ferramenta multiplataforma (por exemplo, capaz de funcionar em desktop, notebook, smartphones, tablets, e sistemas operacionais diversos (Windows, Linux, Android, iOS, Windows Phone, etc...): *

Marcar apenas uma oval.

Nada importante

Pouco importante

Importância média

Muito importante

Total importância 
27. Você gostaria de fazer alguma observação sobre esta característica de multiplataforma:

28. Uma ferramenta que possibilite que o aluno visualize conteúdo (apresentações, textos, vídeos, etc) disponibilizado pelo professor, tanto em tempo real quanto após a aula: *

Marcar apenas uma oval.

Nada importante

Pouco importante

Importância média

Muito importante

Total importância

29. Você gostaria de fazer alguma observação sobre esta visualização de conteúdo:

30. Possibilitar que o professor tenha um retorno em tempo real, enquanto está dando aula, sobre o quanto os alunos julgam estar entendendo o conteúdo é: *

Marcar apenas uma oval.

Nada importante

Pouco importante

Importância média

Muito importante

Total importância

31. Você gostaria de fazer alguma observação sobre este retorno em tempo real: 
32. Poder visualizar o histórico deste retorno como descrito na pergunta anterior: * Marcar apenas uma oval.

Nada importante

Pouco importante

Importância média

Muito importante

Total importância

33. Você gostaria de fazer alguma observação sobre poder visualizar o histórico dos retornos dos alunos:

34. Permitir que os alunos façam anotações diretamente sobre o material de aula que você disponibilizou: *

Marcar apenas uma oval.

Nada importante

Pouco importante

Importância média

Muito importante

Total importância

35. Você gostaria de fazer alguma observação sobre essas anotações:

36. Permitir, quando o professor quiser, que os alunos compartilhem essas anotações (descritas na pergunta anterior), dúvidas e respostas, comentários, durante e após a aula: *

Marcar apenas uma oval.

Nada importante

Pouco importante

Importância média

Muito importante

Total importância 
37. Você gostaria de fazer alguma observação sobre este compartilhamento:

Google Forms 
Apêndice B - Formulário da pesquisa com alunos 


\section{Pesquisa com alunos do ensino médio, superior e pós-graduação}

Esta pesquisa tem como objetivo coletar dados sobre algumas facetas da utilização de tecnologia e internet no ensino/aprendizado nos ensinos médio e superior no Brasil. Tem também como objetivo verificar possíveis funcionalidades de uma ferramenta computacional para esta área.

Os dados pessoais e de contato aqui coletados serão utilizados com o propósito de comunicar os participantes sobre os resultados da pesquisa. É assegurada total privacidade sobre as informações pessoais e de contato coletadas.

Agradecemos a sua participação.

João Luiz Bernardes Junior

¡lbernardes@usp.br

Tulio Vitor Machado Faria

tuliofaria@usp.br

*Obrigatório

\section{Dados básicos}

Nome: *

E-mail: *

O resultado da pesquisa será retornado para todos por e-mail.

Idade:

Instituição de ensino:

Cidade / estado:

Marque abaixo todos os recursos computacionais que você já utilizou ou utiliza: *

Internet

Apresentação (Por exemplo, Power Point)

$\checkmark$ Editor de textos (Por exemplo, Word)

$\checkmark$ Planilha eletrônica (Por exemplo, Excel)

Editores gráficos (Por exemplo, Paint, Gimp, Photoshop, Corel)

Programação 
Outro:

\section{Quanto você utiliza a internet por semana? *}

Nada

Até 5 horas semanais

de 5 a 10 horas semanais

$\bigcirc$ de 10 a 20 horas semanais

mais de 20 horas semanais

Tipo de instituição de ensino ou escola: *

Pública

Privada

\section{Nível: *}

Ensino médio

Ensino superior e/ou pós-graduação

\section{Selecione com quais tipos que você acha que aprende melhor: *}

Aulas Expositivas (em que quase só o professor fala, apresentando o conteúdo)

Aulas Dialogadas (onde o conteúdo é apresentado com um dialogo entre os alunos e com o professor)

Pesquisas e seminários dos alunos

Ensino baseado em problemas (o professor propõe um problema ou desafio sem nunca ter contado como resolver e os alunos desenvolvem sua própria forma de resolvê-lo)

Visitas técnicas / viagem a campo

Outro:

Quais atividades fora de sala de aula você acha que melhoram seu entendimento (pode marcar mais de uma alternativa)? *

\section{Nenhuma}

$\square$ Exercícios

Trabalhos de pesquisa

Trabalhos práticos

Discussão em fóruns

Outro:

Quais dos recursos a seguir seu professor utiliza nas disciplinas (marque mais de um)? *

Quadro negro ou quadro branco

Projetor (Datashow)

Lousa digital

Sistemas de apoio (Moodle, Sakai, ..)

Laboratório

Laboratório virtual

Outro:

Sua instituição oferece sistemas para gerenciamento de conteúdo e compartilhamento de dados 
(por exemplo, Moodle, Blackboard, Sakai, Teleduc, TIDIA-Ae, COL, ...)? *

A) Sim.

B) Sim, mas não uso.

C) Não sei.

D) Não, a instituição não fornece.

Outro:

Caso você tenha marcado A ou B na questão anterior, informe qual sistema:

Você informa seu professor sobre seu entendimento do conteúdo da aula? *

A) Sim, sempre que preciso.

B) Só de vez em quando.

C) Não

\section{Por quê?}

Você gostaria de opinar ao professor sobre o andamento da aula de forma anônima? *
Sim
Não

Você se sente inibido em dar este retorno ou realizar questionamentos durante a aula? *

Nunca

Poucas vezes

Algumas vezes

Muitas vezes

Sempre

\section{Você faz uso da Internet durante as aulas? *}

A) Não, porque nenhum professor permite

B) Não, porque não uso computador ou dispositivos móveis durante as aulas

C) Não, porque não gosto

D) Só em algumas aulas, quando o professor permite

E) Sim, quase sempre

Caso você tenha respondido D ou E na questão anterior, você utiliza Internet em sala para assuntos (pode marcar mais de uma alternativa):

Acadêmicos: para pesquisar e estudar sobre o assunto da aula

Pessoais/não acadêmicos: para conversar com amigos, acessar redes sociais, etc.

\section{Sobre a ferramenta}


Uma ferramenta multiplataforma (por exemplo, capaz de funcionar em desktop, notebook, smartphones, tablets, e sistemas operacionais diversos (Windows, Linux, Android, iOS, Windows Phone, etc...): *

Nada importante

Pouco importante

Importância média

Muito importante

Total importância

Você gostaria de fazer alguma observação sobre esta característica de multiplataforma:

Uma ferramenta que possibilite que você, o aluno, visualize conteúdo (apresentações, textos, vídeos, etc) disponibilizado pelo professor, tanto durante a aula quanto depois dela: *

Nada importante

Pouco importante

Importância média

Muito importante

Total importância

Você gostaria de fazer alguma observação sobre esta visualização de conteúdo:

Possibilitar informar anonimamente o professor, durante a aula, o quanto você está compreendendo 0 assunto: *

Nada importante

Pouco importante

Importância média

Muito importante

Total importância

Você gostaria de fazer alguma observação sobre este retorno em tempo real: 
Permitir que você faça anotações no computador ou em dispositivos móveis diretamente sobre o material de aula que o professor disponibilizou: *

Nada importante

Pouco importante

Importância média

Muito importante

Total importância

Você gostaria de fazer alguma observação sobre essas anotações:

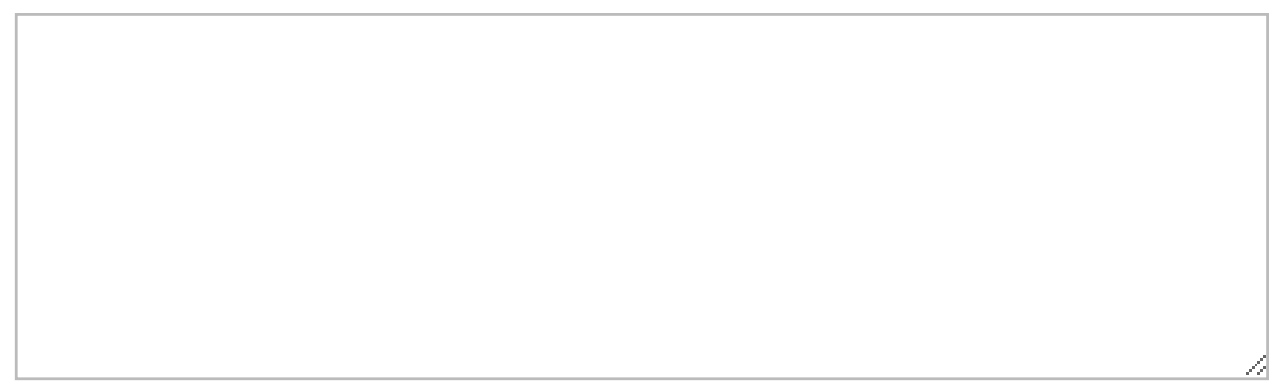

Compartilhar estas anotações (descritas na pergunta anterior) e dúvidas, respostas ou comentários com os demais alunos, durante a aula e depois dela: *

Nada importante

Pouco importante

Importância média

Muito importante

Total importância

Você gostaria de fazer alguma observação sobre este compartilhamento:

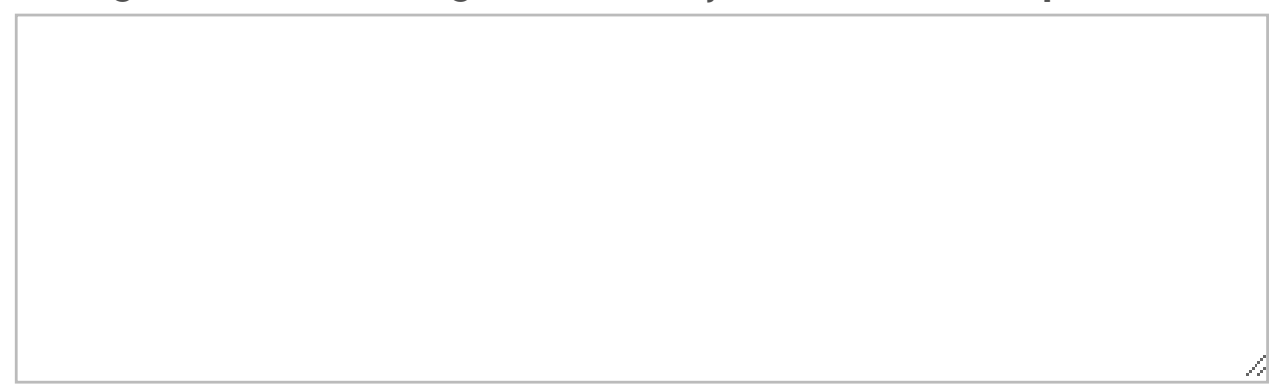


Apêndice C - Projeto completo submetido ao Conselho de Ética pela Plataforma Brasil 
Plotoforma MINISTÉRIO DA SAÚDE - Conselho Nacional de Saúde - Comissão Nacional de Ética em Pesquisa - CONEP

PROJETO DE PESQUISA ENVOLVENDO SERES HUMANOS

Projeto de Pesquisa: Interação e colaboração na atividade de ensino e aprendizagem.

Informações Preliminares

Responsável Principal

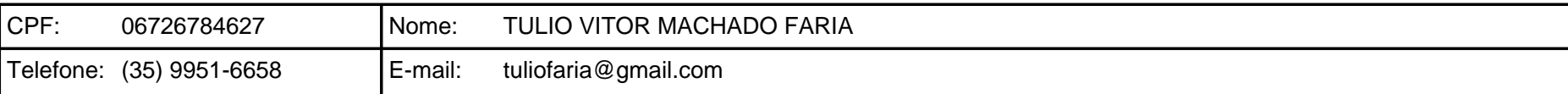

\section{Instituição Proponente}

\begin{tabular}{|l|l|}
\hline CNPJ: $63.025 .530 / 0062-26$ & Nome da Instituição: $\quad$ UNIVERSIDADE DE SAO PAULO \\
\hline
\end{tabular}

\section{É um estudo internacional? Não}

Assistentes

\begin{tabular}{|c|l|}
\hline CPF & \multicolumn{1}{|c|}{ Nome } \\
\hline $005.711 .659-82$ & João Bernardes \\
\hline
\end{tabular}

\section{Área de Estudo}

Grandes Áreas do Conhecimento (CNPq)

- Grande Área 1. Ciências Exatas e da Terra

Título Público da Pesquisa: Interação e colaboração na atividade de ensino e aprendizagem.

\section{Contato Público}

\begin{tabular}{|c|l|l|l|}
\hline CPF & \multicolumn{1}{|c|}{ Nome } & Telefone & E-mail \\
\hline 06726784627 & TULIO VITOR MACHADO FARIA & (35) 9951-6658 & tuliofaria@gmail.com \\
\hline
\end{tabular}




\section{Desenho:}

A pesquisa tem como objetivo principal avaliar a hipótese de que o uso de uma ferramenta computacional específica (Mindboard), para ser utilizada dentro e fora de sala de aula, favorece a colaboração e a interatividade entre os alunos e entre eles e professores. Para realizar testar esta hipótese, será oferecido um curso presencial de verão com 40 alunos divididos em 2 turmas de 20 alunos. Uma das turmas usará a ferramenta Mindboard e a outra não. A interações e colaborações serão contadas em ambos os casos, através da avaliação de logs (registro de um evento na ferramenta) da ferramenta Mindboard, na turma que fizer seu uso e, para ambas as turmas, através da análise dos eventos de aula (para isso as aulas serão gravadas em vídeo). A interação e colaboração serão também avaliadas através de questionários quantitativos, qualitativos e entrevistas. Esta avaliação inclui saber se os alunos interagiram e/ou colaboraram fora de sala de aula, utilizando outros meios (como conversas informais ou outras ferramentas, como e-mail). Os métodos estatísticos a serem utilizados para a análise dos dados ainda não foram definidos, pois dependerão da natureza destes dados (por exemplo, se seguem ou não uma distribuição normal), mas terão como objetivo comparar a colaboração e interação entre os participantes do curso com e sem o uso da ferramenta.

Apoio Financeiro

\begin{tabular}{|c|c|c|c|c|}
\hline CNPJ & Nome & E-mail & Telefone & Tipo \\
\hline & & & & $\begin{array}{l}\text { Financiamento } \\
\text { Próprio }\end{array}$ \\
\hline
\end{tabular}

\section{Palavra Chave}

\begin{tabular}{|l|l|}
\hline & Palavra-chave \\
\hline educação & \\
\hline colaboração
\end{tabular}

Detalhamento do Estudo

\section{Resumo:}

Atualmente, a tecnologia está cada vez mais presente em sala de aula. Os alunos com mais frequência estão levando seus próprios dispositivos para a sala e, além disso, há iniciativas de fundações e orgãos públicos para fomentar a disponibilidade de cada vez mais equipamentos para alunos e professores, e também ampliando a conectividade a Internet em sala de aula. A disponibilidade destas tecnologias em sala de aula potencializa a colaboração e interação entre alunos e entre alunos e professores durante e após a aula. Neste contexto, o objetivo deste experimento é analisar se com o uso de uma ferramenta computacional dentro e fora de sala de aula o número de colaborações e interações aumentam quando comparado com cursos em que não foram utilizadas uma ferramenta com esta finalidade. Também é objetivo deste experimento verificar a usabilidade da ferramenta levantando informações sobre a sua facilidade ou não de uso. Espera-se com este experimento avaliar se a ferramenta pode beneficiar alunos e professores através de uma maior colaboração e interação em sala de aula. Espera-se também que a usabilidade da ferramenta seja considera de fácil utilização.

\section{Introdução:}

Atualmente, as crianças e jovens brasileiros possuem cada vez mais acesso e contato com tecnologias digitais. Cerca de $75 \%$ dos jovens entre 10 e 18 anos afirmam navegar na internet, e destes 38,3\% afirmam utilizar este acesso para estudos e realização de tarefas escolares (Paloschi, 2012). Além disso, de acordo com o Horizon Report (Johnson; Adams; Cummins, 2012), mundialmente, as instituições de ensino aumentam cada vez mais a disponibilidade e a qualidade de acesso a Internet dentro de suas dependências. Os estudantes também trazem cada vez mais seus próprios dispositivos para as salas de aula (tendência conhecida como "Bring Your Own Device", ou BYOD), como notebooks, tablets e smartphones, dispositivos estes que também utilizam para seus estudos fora de sala de aula. Dessa forma, esses dispositivos podem enriquecer o aprendizado em diversos lugares e momentos, e não somente nas salas de aula (Johnson et al., 2014). Neste contexto, foi projetada e desenvolvida uma ferramenta capaz de potencializar a interatividade e colaboração durante o processo de ensino/aprendizado e permitindo o uso dessa grande variedade de dispositivos, de forma que a tecnologia já presente hoje dentro e fora de sala de aula possa de fato ser usada em benefício do ensinoaprendizado. O objetivo desse experimento é avaliar a eficácia desta ferramenta para fomentar a interação e colaboração entre os participantes dentro e fora de sala de aula. Além da presença de tecnologia em sala de aula estar acontecendo naturalmente por parte dos alunos como descrito anteriormente, existem ações públicas em diversos países que visam à inclusão de tecnologia tanto para alunos quanto para professores. O governo brasileiro, por exemplo, através do programa Prolnfo fomenta o uso de tecnologia da informação e comunicação (TIC) na rede pública de ensino (Prolnfo, 2014). Fazem parte desta iniciativa o PROUCA - Programa Um Computador por Aluno que permite a rede municipal de escolas públicas adquirirem computadores a seus alunos (Prouca, 2014), o PBLE, ou Programa Banda Larga nas Escolas que visa a democratização do acesso a Internet por banda larga em escolas públicas (PBLE, 2014) e o programa do Tablet Educacional, através do qual o Ministério da Educação distribuiu a professores tablets para serem utilizados em sala de aula (Tablet,2014). Mas como este ecossistema tecnológico melhora ou poderia melhorar a atividade de ensino-aprendizagem? Este cenário tecnológico pode ser usado para aumentar, por exemplo: a interação e colaboração entre alunos e entre eles e os professores; o interesse dos alunos; a possibilidade de uso de metodologias pedagógicas inovadoras como Blended Learning (HoicBozic; Mornar; Boticki, 2009); a velocidade de disponibilização de conteúdo para os participantes das aulas; o uso de recursos multimídia; a facilidade de se obter novas informações durante as aulas, por exemplo com consultas na Internet etc. Esse é o contexto que motivou a criação da ferramenta já mencionada, chamada Mindboard, e sua avaliação nessa pesquisa.

\section{Hipótese:}

A pesquisa tem como objetivo principal avaliar a hipótese de que o uso de uma ferramenta computacional específica (Mindboard), para ser utilizada dentro e fora de sala de aula, favorece a colaboração e a interatividade entre os alunos e entre eles e professores.

\section{Objetivo Primário:}

O objetivo primário da pesquisa é medir se uma ferramenta computacional a ser utilizada em um curso livre presencial, de forma síncrona, impacta na quantidade de colaborações e de interações realizadas entre alunos e entre alunos e professores comparado quando não é utilizada ferramenta com este fim.

\section{Objetivo Secundário:}

O objetivo secundário da pesquisa é avaliar a interface gráfica da ferramenta computacional Mindboard, determinando pontos em que os usuários acreditam poder serem melhorados, além de realizar a avaliação da mesma utilizando formulários de pesquisa padrão.

\section{Metodologia Proposta:}

A pesquisa será realizada em um curso livre proposto pelo proponente deste projeto. $\mathrm{O}$ curso será composto de 3 dias com 4 horas de duração em cada dia, sendo o mesmo oferecido gratuitamente aos participantes. A amostra será dividida em dois grupos. No grupo de controle, o curso realizado sem uma ferramenta de comunicação síncrona durante o curso. Já o outro grupo fará uso da ferramenta computacional Mindboard, desenvolvida pelo proponente deste experimento. Durante a realização do curso, em ambos os grupos, será 
realizada a gravação em vídeo da sala de aula. Esta gravação permitirá a contagem posterior do número de colaborações e interações, principalmente no grupo de controle. No grupo experimental, além do vídeo, serão registrados dados de log na ferramenta com este propósito. Ao final do curso serão realizadas entrevistas com os participantes para saber se a opinião dos mesmos sobre a utilização de uma ferramenta computacional durante o curso. Para o grupo de controle, as entrevistas serão utilizadas para descobrir se uma ferramenta poderia melhorar 0 aprendizado, a colaboração e a interatividade no curso.

\section{Critério de Exclusão:}

Serão excluídos do experimento pessoas com menos de 18 anos de idade ou sem experiência prévia em programação, visto que este será um prérequisito para o curso que será dado no decorrer do experimento.

\section{Riscos:}

O principal risco do experimento está relacionado a privacidade dos dados colhidos durante a pesquisa. Serão tomadas algumas ações com o objetivo de minimizar este problema. O primeiro é reduzir a quantidade de dados pessoais que possam ser colhidos durante o experimento, todos os logs serão armazenados de forma que não seja possível identificar o autor do dado, e as filmagens terão imagens restritas somente para a contabilização do número de colaborações e interações, além de outras análises qualitativas. Depois de extraídos os dados, as imagens serão destruídas. A pesquisa também possui um viés pelo instrutor do curso a ser testado é o próprio pesquisador. Este risco será mitigado através do auto-policiamento máximo para a não intervenção nos resultados do experimento. Existe o risco também da falta de objetividade durante as perguntas e respostas das entrevistas e questionários, para reduzir este risco, serão adotados formulários padronizados (para pesquisa de usabilidade e colaboração, onde estes riscos já foram reduzidos) e serão realizadas perguntas na entrevista que permitem respostas mais diretas.

\section{Benefícios:}

O principal benefício esperado desta pesquisa é a avaliação de uma ferramenta como a Mindboard que pode vir a aumentar a colaboração e interação entre alunos e entre eles e professores, tanto dentro como fora da sala de aula, o que, espera-se, pode trazer aumento no aproveitamento acadêmico dos alunos (esse possível aumento de rendimento não será medido neste experimento, mas talvez em experimentos futuros).

\section{Metodologia de Análise de Dados:}

Serão comparados a quantidade de interações e colaborações totais entre o grupo de controle e o grupo de testes. Será realizado também a análise qualitativa das entrevistas e dos questionários provenientes de ambos os grupos. Os métodos estatísticos a serem utilizados para à análise dos dados ainda não foram definidos, pois dependerão da natureza destes dados (por exemplo, se seguem ou não uma distribuição normal).

\section{Desfecho Primário:}

Estima-se que a pesquisa contribuirá com uma avaliação do uso desta tecnologia em sala de aula (e talvez possa ter resultados generalizáveis para outras tecnologias) e como a colaboração e interação gerada por ela pode ser ampliada com o uso de uma ferramenta computacional.

\section{Desfecho Secundário:}

O desfecho secundário será uma avaliação de usabilidade de uma ferramenta colaborativa para ser utilizada em sala de aula, gerando indícios de quais funcionalidades precisam de melhorias em como ser utilizadas.

Tamanho da Amostra no Brasil: 40

\section{Países de Recrutamento}

\begin{tabular}{|c|l|c|}
\hline País de Origem do Estudo & \multicolumn{1}{|c|}{ País } & № de participantes da pesquisa \\
\hline Sim & BRASIL & 40 \\
\hline
\end{tabular}


Haverá uso de fontes secundárias de dados (prontuários, dados demográficos, etc)?

Não

Informe o número de indivíduos abordados pessoalmente, recrutados, ou que sofrerão algum tipo de intervenção neste centro de pesquisa:

40

Grupos em que serão divididos os participantes da pesquisa neste centro

\begin{tabular}{|c|c|c|}
\hline ID Grupo & № de Indivíduos & Intervenções a serem relizadas \\
\hline Controle & 20 & $\begin{array}{l}\text { Entrevistas, respostas a formulários qualitativos sobre colaboração durante } \\
\text { as aulas, análise de interações durante a aula }\end{array}$ \\
\hline Experimental & 20 & $\begin{array}{l}\text { Entrevistas, respostas a formulários qualitativos sobre colaboração durante } \\
\text { as aulas, análise de interações durante a aula, avaliação dos logs gerados } \\
\text { pela ferramenta Mindboard }\end{array}$ \\
\hline
\end{tabular}

O Estudo é Multicêntrico no Brasil?

Não

Centros Coparticipantes

\begin{tabular}{|c|l|l|c|c|}
\hline CNPJ & Nome da Instituição Co-participante & Nome do Responsável & $\begin{array}{c}\text { Nome do Comitê de } \\
\text { Ética }\end{array}$ & $\begin{array}{c}\text { Instituição Selecionada Via } \\
\text { Plataforma Brasil }\end{array}$ \\
\hline 03044459000185 & $\begin{array}{l}\text { Inpettecc - Instituto de Pesquisa e } \\
\text { Treinamento em Tecnologia } \\
\text { Computac }\end{array}$ & Elton Rodrigo de Souza & & Não \\
\hline
\end{tabular}

Propõe dispensa do TCLE?

Não

Haverá retenção de amostras para armazenamento em banco?

Não

\section{Cronograma de Execução}

\begin{tabular}{|l|l|l|}
\hline \multicolumn{1}{|c|}{ Identificação da Etapa } & \multicolumn{1}{c|}{ Início (DD/MM/AAAA) } & \multicolumn{1}{c|}{ Término (DD/MM/AAAA) } \\
\hline Curso de verão com grupo experimental & $19 / 01 / 2015$ & $22 / 01 / 2015$ \\
\hline Curso de verão com grupo controle & $12 / 01 / 2015$ & $15 / 01 / 2015$ \\
\hline
\end{tabular}

Orçamento Financeiro

\begin{tabular}{|l|l|r|}
\hline \multicolumn{1}{|c|}{ Identificação de Orçamento } & \multicolumn{1}{c|}{ Tipo } & Valor em Reais (R\$) \\
\hline Uso do laboratório & Outros & $\mathrm{R} \$ 2.000,00$ \\
\hline
\end{tabular}

Total em R\$

$\mathrm{R} \$ 2.000,00$

\section{Bibliografia:}

FREIRE, P. Pedagogia do Oprimido. 17. ed. Rio de Janeiro: Paz e Terra, 1970. HOIC-BOZIC, N.; MORNAR, V.; BOTICKI, I. A blended learning approach to course design and implementation. IEEE Transactions on Education, v. 52, n. 1, p. 19, fev. 2009. ISSN 0018-9359. Disponível em: /ieeexplore.ieee.org/lpdocs/epic03/wrapper.htm?arnumber=4544803>. JOHNSON, L.; ADAMS, S.; CUMMINS, M. NMC horizon report: 2012 higher education edition. 2012. Disponível em: /www.editlib.org/p/48964/>. JOHNSON, L. et al. Horizon Report: 2014 K-12 Edition. [S.I.], 2014. KINASH, S.; WOOD, K.; KNIGHT, D. Digital immigrant teachers and digital native students: What happens to teaching? 2013. Disponível em:

/epublications.bond.edu.au/tls/50/>. KHAN Academy. 2014. Disponível em: /www.khanacademy.org>. Acesso em: 24.07.2014. PALOSCHI, L. C. Gerações Interativas Brasil - Crianças e adolescentes diante das telas. [S.I.], 2012. PBLE - Programa Banda Larga nas Escolas. 2014. Disponível em: /www.fnde.gov.br/programas/programa-nacional-de-tecnologia-educacionalproinfo/proinfo-programa-banda-larga-nas-escolas-pble $>$. Acesso em: 24.07.2014. PROINFO - Programa Nacional de Tecnologia Educacional. 2014. Disponível em: /www.fnde.gov.br/programas/programa-nacionalde-tecnologia-educacionalproinfo>. Acesso em: 24.07.2014. PROUCA - Programa um computador por Aluno. 2014. Disponível em:

/www.fnde.gov.br/programas/programa-nacional-de-tecnologia-educacionalproinfo/ proinfo-programa-um-computador-por-aluno-prouca $>$. Acesso em: 24.07.2014. TABLET. 2014. Disponível em: /www.fnde.gov.br/programas/programanacional-de-tecnologia-educacional-proinfo/proinfo-tablets>. Acesso em: 24.07.2014. TAKEDA, R. A. et al. Percepção dos alunos do curso de engenharia civil da ufscar sobre o uso do ava moodle como ferramenta de apoio ao ensino presencial. 2013. Disponível em: /www.fadep.br/engenharia-eletrica/congresso/pdf/118031 1.pdf>. TOKIWA, Y.; NONOBE, K.; IWATSUKI, M. Web-based tools to sustain the motivation of students in distance education. In: Frontiers in Education Conference, 2009. FIE'09. 39th IEEE. [S.I.: s.n.], 2009. p. 1-5.

\section{Upload de Documentos}

Arquivo Anexos:

\begin{tabular}{|l|l|}
\hline \multicolumn{1}{|c|}{ Tipo Arquivo } \\
\hline Folha de Rosto & \multicolumn{1}{|c|}{ Arquivo - Comite de Etica CEP.pdf } \\
\hline
\end{tabular}


TCLE - Modelo de Termo de Consentimento Livre e termo livre esclarecido.docx Esclarecido

Vínculo Instituições Participantes

Autorização cep.pdf

Projeto Detalhado

experimento.pdf

Finalizar

Manter sigilo da integra do projeto de pesquisa:

Não 
Apêndice D - Termo livre e esclarecido do experimento prático 
$\mathrm{Eu}$,

estou sendo convidado a participar de um estudo denominado Interação e colaboração na atividade de ensino e aprendizagem, cujos objetivo é avaliar a interação e colaboração em sala de aula, utilizando e não utilizando ferramentas computacionais, e também de avaliar a usabilidade de uma posssível ferramenta com esta finalidade. Este experimento é importante para avaliar o impacto na colaboração, interação e no aprendizado que o uso de tecnologia pode fazer.

A minha participação no referido estudo será no sentido de participar como aluno de um curso presencial e utilizar ferramentas computacionais específicas, que serão apresentadas durante o mesmo.

Fui alertado de que, da pesquisa a se realizar, posso esperar benefícios, tais como: o aprendizado de novas tecnologias e contribuição para a medição de colaboração dentro e fora de sala de aula, e que estes resultados serão a mim reportados ao fim da pesquisa.

Recebi, por outro lado, os esclarecimentos necessários sobre os possíveis desconfortos e riscos decorrentes do estudo, levando-se em conta que é uma pesquisa, e os resultados positivos ou negativos somente serão obtidos após a sua realização. Assim, estou ciente dos seguintes riscos e as ações que os pesquisadores realizarão para mitigá-los:

- Desconforto físico: os pesquisadores verificarão a disposição dos equipamentos (computadores), bem como a alturas das cadeiras e mesas de forma que gere o menor desconforto físico possível aos participantes;

- Sentimento de obrigação a participação: estou ciente e me inscrevi para fazer o curso e a qualquer momento, e sem necessidade de justificativa, poderei desistir de participar;

- Constrangimento pela violação de anonimato: estou ciente que serão gerados vídeos durante o curso do andamento das aulas e que os mesmos serão armazenados apenas pelo período de apuração dos dados e serão acessados apenas pelos pesquisadores. Serão geradas algumas imagens dos vídeos para obter informações de como aconteceram o experimento, neste caso, caso os pesquisadores se comprometem a impossibilitar o reconhecimento dos rostos dos participantes que possam aparecer e que nenhuma imagem será utilizada ou mantida fora deste contexto. Já os dados gerados através de logs de acesso, entrevistas e questionários não conterão a identificação nominal do usuário, para que não possa ser possível identificar posteriormente o gerador daquela 
informação, reduzindo a possibilidade de constrangimento por violação de privacidade;

- Constrangimento pelo enfrentamento de situação inesperada: quando for realizado a utilização de algum programa de computador ou ferramenta ainda desconhecida para o pesquisado, será mostrado como a mesma funciona, para evitar que o mesmo possa sentir-se constrangido pelo não conhecimento;

Estou ciente também que para maior aproveitamento do curso, devo possuir conhecimentos e noções básicas de programação. Além disso, estou ciente de que minha privacidade será respeitada, ou seja, meu nome ou qualquer outro dado ou elemento que possa, de qualquer forma, me identificar, será mantido em sigilo.

Também fui informado de que posso me recusar a participar do estudo, ou retirar meu consentimento a qualquer momento, sem precisar justificar, e de, por desejar sair da pesquisa, não sofrerei qualquer prejuízo financeiro.

Os pesquisadores envolvidos com o referido projeto são Tulio Vitor Machado Faria e João Luiz Bernardes Junior, ambos da EACH-USP e pertencentes ao PPGSi (programa de pós graduação em sistemas de informação) e com eles poderei manter contato pelos telefones (35) 9951-6658 (Tulio) e (11) 9-8456-4007 (João).

É assegurada a assistência durante toda pesquisa, bem como me é garantido o livre acesso a todas as informações e esclarecimentos adicionais sobre o estudo e suas conseqüências, enfim, tudo o que eu queira saber antes, durante e depois da minha participação.

Enfim, tendo sido orientado quanto ao teor de todo o aqui mencionado e compreendido a natureza e o objetivo do já referido estudo, manifesto meu livre consentimento em participar, estando totalmente ciente de que não há nenhum valor econômico, a receber, por minha participação.

De igual maneira, caso ocorra algum dano decorrente da minha participação no estudo, serei devidamente indenizado, conforme determina a lei.

Em caso de reclamação ou qualquer tipo de denúncia sobre este estudo devo ligar para o CEP EACH (11) 3091-1046 ou mandar um email para cep_each@usp.br

Pouso Alegre, 12 de Janeiro de 2015.

Tulio Vitor Machado Faria

Pesquisador 
Apêndice E - Parecer do Comitê de Ética em relação ao experimento 


\section{ESCOLA DE ARTES, CIÊNCIAS OPlotoforma E HUMANIDADES - EACH/USP Brasil}

\section{PARECER CONSUBSTANCIADO DO CEP}

\section{DADOS DO PROJETO DE PESQUISA}

Título da Pesquisa: Interação e colaboração na atividade de ensino e aprendizagem.

Pesquisador: TULIO VITOR MACHADO FARIA

Área Temática:

Versão: 1

CAAE: 39888114.0 .0000 .5390

Instituição Proponente: UNIVERSIDADE DE SAO PAULO

Patrocinador Principal: Financiamento Próprio

\section{DADOS DO PARECER}

Número do Parecer: 930.025

Data da Relatoria: $14 / 12 / 2014$

\section{Apresentação do Projeto:}

O pesquisador responsável afirma que a pesquisa tem como objetivo principal avaliar a hipótese de que o uso de uma ferramenta computacional específica (Mindboard), para ser utilizada dentro e fora de sala de aula, favorece a colaboração e a interatividade entre os alunos e entre eles e professores. Para realizar testar esta hipótese,

Para tanto, o pesquisador oferecerá um curso presencial de verão com 40 alunos divididos em 2 turmas de 20 alunos. Uma das turmas usará a ferramenta Mindboard e a outra não.

A interações e colaborações serão contadas em ambos os casos, através da avaliação de logs (registro de um evento na ferramenta) da ferramenta Mindboard, na turma que fizer seu uso e, para ambas as turmas, através da análise dos eventos de aula (para isso as aulas serão gravadas em vídeo).

A interação e colaboração serão também avaliadas através de questionários quantitativos, qualitativos e entrevistas. Esta avaliação inclui saber se os alunos interagiram e/ou colaboraram fora de sala de aula, utilizando outros meios (como conversas informais ou outras ferramentas, como e-mail).

Os métodos estatísticos a serem utilizados para a análise dos dados ainda não foram definidos, pois dependerão da natureza destes dados (por exemplo, se seguem ou não uma distribuição normal), mas terão como objetivo comparar a colaboração e interação entre os participantes do

Endereço: Av. Arlindo Béttio, № 1000

Bairro: Ermelino Matarazzo

CEP: $\quad 03.828-000$

UF: SP Município: SAO PAULO

Telefone: (11)3091-1046

E-mail: cep-each@usp.br 


\section{ESCOLA DE ARTES, CIÊNCIAS OPlotoforma E HUMANIDADES - EACH/USP Rrasil}

Continuação do Parecer: 930.025

curso com e sem o uso da ferramenta

\section{Objetivo da Pesquisa:}

O objetivo primário da pesquisa é medir se uma ferramenta computacional a ser utilizada em um curso livre presencial, de forma síncrona, impacta na quantidade de colaborações e de interações realizadas entre alunos e entre alunos e professores comparado quando não é utilizada ferramenta com este fim.

Objetivo Secundário:

O objetivo secundário da pesquisa é avaliar a interface gráfica da ferramenta computacional Mindboard, determinando pontos em que os usuários acreditam poder serem melhorados, além de realizar a avaliação da mesma utilizando formulários de pesquisa padrão.

\section{Avaliação dos Riscos e Benefícios:}

O pesquisador responsável indica os riscos da pesquisa como sendo:

O principal risco do experimento está relacionado a privacidade dos dados colhidos durante a pesquisa. Serão tomadas algumas ações com o objetivo de minimizar este problema.

O primeiro é reduzir a quantidade de dados pessoais que possam ser colhidos durante o experimento, todos os

logs serão armazenados de forma que não seja possível identificar o autor do dado, e as filmagens terão imagens restritas somente para a contabilização do número de colaborações e interações, além de outras análises qualitativas. Depois de extraídos os dados, as imagens serão destruídas. A pesquisa também possui um viés pelo instrutor do curso a ser testado é o próprio pesquisador. Este risco será mitigado através do auto-policiamento máximo para a não intervenção nos resultados do experimento. Existe o risco também da falta de objetividade durante as perguntas e respostas das entrevistas e questionários, para reduzir este risco, serão adotados formulários padronizados (para pesquisa de usabilidade e colaboração, onde estes riscos já foram reduzidos) e serão realizadas perguntas na entrevista que permitem respostas mais diretas.

Os benefícios anunciados pelo pesquisador são:

O principal benefício esperado desta pesquisa é a avaliação de uma ferramenta como a Mindboard que pode vir a aumentar a colaboração e interação entre alunos e entre eles e professores, tanto dentro como fora da sala de aula, o que, espera-se, pode trazer aumento no aproveitamento acadêmico dos alunos (esse possível aumento de rendimento não será medido neste experimento, mas talvez em experimentos futuros).

Endereço: Av. Arlindo Béttio, № 1000

Bairro: Ermelino Matarazzo

CEP: $03.828-000$

UF: SP Município: SAO PAULO

Telefone: (11)3091-1046

E-mail: cep-each@usp.br 


\section{ESCOLA DE ARTES, CIÊNCIAS E HUMANIDADES - EACH/USP}

Continuação do Parecer: 930.025

\section{Comentários e Considerações sobre a Pesquisa:}

Pesquisa bem estruturada, contendo os documentos necessários e recomendados para análise da ética da pesquisa com seres humanos.

Considerações sobre os Termos de apresentação obrigatória:

O TCLE é apresentado de forma adequada às necessidades.

\section{Recomendações:}

Não há recomendações.

Conclusões ou Pendências e Lista de Inadequações:

Este parecer aprova a pesquisa na sua dimensão ética.

Situação do Parecer:

Aprovado

Necessita Apreciação da CONEP:

Não

Considerações Finais a critério do CEP:

SAO PAULO, 08 de Janeiro de 2015

Assinado por:

Rosa Yuka Sato Chubaci

(Coordenador)

Endereço: Av. Arlindo Béttio, no 1000

Bairro: Ermelino Matarazzo

CEP: $\quad 03.828-000$

UF: SP

Município: SAO PAULO

Telefone: (11)3091-1046

E-mail: cep-each@usp.br 
Apêndice $\mathbf{F}$ - Questionário de avaliação da sala de aula invertida - Turma 1 


\section{Questionário}

Questionário sobre o estudo de conceitos em casa (de forma remota) e da aplicação prática em sala de aula

*Obrigatório

1. Você conseguiu acessar as lições em casa? *

Marcar apenas uma oval.

$\bigcirc \operatorname{sim}$

$\bigcirc$ Não

2. Você gostaria de fazer alguma observação sobre o item anterior?

3. Foi possível compreender os conceitos expostos nas lições? *

Marcar apenas uma oval.

$\Longrightarrow \operatorname{Sim}$

Não

4. Você gostaria de fazer alguma observação sobre o item anterior?

5. Você discutiu com algum colega do curso sobre as lições? *

Marcar apenas uma oval.

$\bigcirc \operatorname{sim}$

Não

6. Você gostaria de fazer alguma observação sobre o item anterior? 
7. Como foi feita esta discussão?

Marque todas que se aplicam.

E-mail

$\square$ Facebook

Skype

Pessoalmente

Outro:

8. Você acha que o estudo de conceitos fora da sala de aula favorece a um melhor aproveitamento do curso? *

Marcar apenas uma oval.

Sim

Não

9. Você gostaria de fazer alguma observação sobre o item anterior?

10. Você participare de um curso que utilizasse massivamente esta técnica? *

(Estudo de conceitos em casa e a prática em sala de aula)

Marcar apenas uma oval.

$\operatorname{Sim}$

Não

11. Você gostaria de fazer alguma observação sobre o item anterior?

12. Você recomendaria a um amigo/parente um curso que utiliza está técnica? *

Marcar apenas uma oval.

$\operatorname{Sim}$

Não 
13. Você gostaria de fazer alguma observação sobre o item anterior?

14. Você acha que o uso desta técnica pode ser considerado um diferencial em um curso? * Marcar apenas uma oval.
Sim
Não

15. Você gostaria de fazer alguma observação sobre o item anterior?

16. Você acha que esta técnica favorece o ensino de linguagens de programação (como é o caso deste curso)?

Marcar apenas uma oval.

Sim

Não

17. Você gostaria de fazer alguma observação sobre o item anterior?

18. Você acha que a ferramenta utilizada para aplicar esta técnica poderia ter mais funcionalidades?

Foi utilizado o Youtube, você acha que poderia ter algo a mais no youtube para facilitar esta técnica. 
19. Você gostaria de fazer qualquer obervação sobre esta técnica?

Powered by

国 Google Forms 
Apêndice G - Questionário de avaliação da sala de aula invertida - Turma 2 


\section{Questionário}

Questionário sobre o estudo de conceitos em casa (de forma remota) e da aplicação prática em sala de aula

*Obrigatório

1. Você conseguiu acessar as lições em casa? *

Marcar apenas uma oval.

$\bigcirc \operatorname{sim}$

$\bigcirc$ Não

2. Você gostaria de fazer alguma observação sobre o item anterior?

3. Foi possível compreender os conceitos expostos nas lições? *

Marcar apenas uma oval.

$\Longrightarrow \operatorname{Sim}$

Não

4. Você gostaria de fazer alguma observação sobre o item anterior?

5. Você discutiu com algum colega do curso sobre as lições? *

Marcar apenas uma oval.

$\bigcirc \operatorname{sim}$

Não

6. Você gostaria de fazer alguma observação sobre o item anterior? 
7. Como foi feita esta discussão?

Marque todas que se aplicam.

Minboard

E-mail

Facebook

Skype

Pessoalmente

Outro:

8. Você acha que o estudo de conceitos fora da sala de aula favorece a um melhor aproveitamento do curso? *

Marcar apenas uma oval.

$\operatorname{Sim}$

Não

9. Você gostaria de fazer alguma observação sobre o item anterior?

10. Você participaria de um curso que utilizasse massivamente esta técnica? *

(Estudo de conceitos em casa e a prática em sala de aula)

Marcar apenas uma oval.

$\operatorname{Sim}$

Não

11. Você gostaria de fazer alguma observação sobre o item anterior?

12. Você recomendaria a um amigo/parente um curso que utiliza está técnica? * Marcar apenas uma oval.

$\operatorname{Sim}$

Não 
13. Você gostaria de fazer alguma observação sobre o item anterior?

14. Você acha que o uso desta técnica pode ser considerado um diferencial em um curso? * Marcar apenas uma oval.
Sim
Não

15. Você gostaria de fazer alguma observação sobre o item anterior?

16. Você acha que esta técnica favorece o ensino de linguagens de programação (como é o caso deste curso)?

Marcar apenas uma oval.

Sim

Não

17. Você gostaria de fazer alguma observação sobre o item anterior?

18. Você acha que uma ferramenta como o Mindboard (que permite a colaboração entre os alunos e professores) auxilia na utilização desta técnica?

Marcar apenas uma oval.

$\operatorname{Sim}$

Não

19. Você gostaria de fazer alguma observação sobre a pergunta anterior? 
20. Você acha que a ferramenta utilizada para aplicar esta técnica poderia ter mais funcionalidades?

Foi utilizado o Mindboard, você acha que poderia ter algo a mais no Mindboard para facilitar esta técnica.

21. Você gostaria de fazer qualquer obervação sobre esta técnica?

Powered by

国 Google Forms 
Apêndice H - Questionário USE 


\section{Questionário USE}

*Obrigatório

\section{Utilidade}

Para cada questão marque 1 para "Discordo fortemente" e 7 para "Concordo fortemente"

1. A ferramenta me ajuda a ser mais efetivo *

Marcar apenas uma oval.

$\begin{array}{lllllll}1 & 2 & 3 & 4 & 5 & 6 & 7\end{array}$

Discordo fortemente $\square \square \square \square$ Concordo fortemente

2. Comentário sobre o item anterior

3. A ferramenta me ajuda a ser mais produtivo *

Marcar apenas uma oval.

$\begin{array}{lllllll}1 & 2 & 3 & 4 & 5 & 6 & 7\end{array}$

Discordo fortemente $\square \longrightarrow \square(0 \times C$ Concordo fortemente

4. Comentário sobre o item anterior

5. A ferramenta é útil *

Marcar apenas uma oval.

$\begin{array}{lllllll}1 & 2 & 3 & 4 & 5 & 6 & 7\end{array}$

Discordo fortemente $\square \square \square \square$ Concordo fortemente

6. Comentário sobre o item anterior

7. A ferramenta me permite controlar/acomapnhar minhas aulas *

Marcar apenas uma oval.

Discordo fortemente $\square \longrightarrow C$ Concordo fortemente

8. Comentário sobre o item anterior 
9. A ferramenta permite que o que desejo fazer possa ser feito mais facilmente *

Marcar apenas uma oval.

Discordo fortemente

10. Comentário sobre o item anterior

11. A ferramente me poupa tempo quando a utilizo *

Marcar apenas uma oval.

Discordo fortemente

12. Comentário sobre o item anterior

13. A ferramenta faz tudo que eu esperava que ela fizesse *

Marcar apenas uma oval.

$\begin{array}{lllllll}1 & 2 & 3 & 4 & 5 & 6 & 7\end{array}$

Discordo fortemente

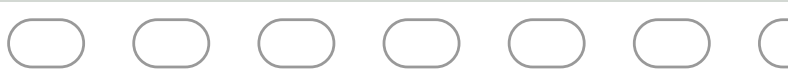

Concordo fortemente

14. Comentário sobre o item anterior

\section{Facilidade de uso}

15. A ferramenta é fácil de usar *

Marcar apenas uma oval.

Discordo fortemente

16. Comentário sobre o item anterior

17. A ferramenta é simples de usar *

Marcar apenas uma oval.

$\begin{array}{lllllll}1 & 2 & 3 & 4 & 5 & 6 & 7\end{array}$

Discordo fortemente

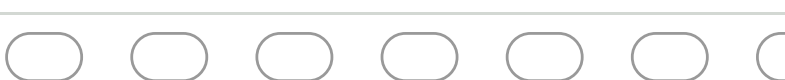


18. Comentário sobre o item anterior

19. A ferramenta é amigável *

Marcar apenas uma oval.

$\begin{array}{lllllll}1 & 2 & 3 & 4 & 5 & 6 & 7\end{array}$

Discordo fortemente $\square \square \square \square$ Concordo fortemente

20. Comentário sobre o item anterior

21. A ferramenta necessita de poucos passos para fazer o que desejo *

Marcar apenas uma oval.

Discordo fortemente

22. Comentário sobre o item anterior

23. A ferramenta é flexível *

Marcar apenas uma oval.

Discordo fortemente

24. Comentário sobre o item anterior

25. Posso usar a ferramenta sem instruções escritas *

Marcar apenas uma oval.

Discordo fortemente

26. Comentário sobre o item anterior

27. Eu não notei nenhuma inconsistência enquanto a utilizava *

Marcar apenas uma oval.

$\begin{array}{lllllll}1 & 2 & 3 & 4 & 5 & 6 & 7\end{array}$

Discordo fortemente

$\square \bigcirc \bigcirc \bigcirc \bigcirc$ Concordo fortemente 
28. Comentário sobre o item anterior

29. Tanto usuários regulares quando ocasionais irão gostar da ferramenta * Marcar apenas uma oval.

$\begin{array}{lllllll}1 & 2 & 3 & 4 & 5 & 6 & 7\end{array}$

Discordo fortemente

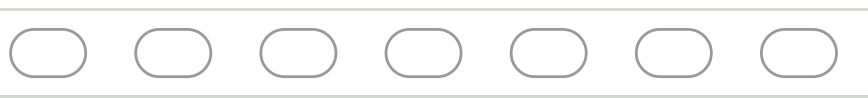

Concordo fortemente

30. Comentário sobre o item anterior

31. Posso me recuperar de erros de forma fácil e simples *

Marcar apenas uma oval.

Discordo fortemente

32. Comentário sobre o item anterior

33. Eu posso utilizar a ferramenta com sucesso a todo momento *

Marcar apenas uma oval.

Discordo fortemente

34. Comentário sobre o item anterior

\section{Facilidade de aprender}

35. Eu aprendi a usar a ferramenta rapidamente *

Marcar apenas uma oval.

Discordo fortemente $\square \longrightarrow C$

36. Comentário sobre o item anterior 
37. Eu facilmente me lembro como utilizar a ferramenta *

Marcar apenas uma oval.

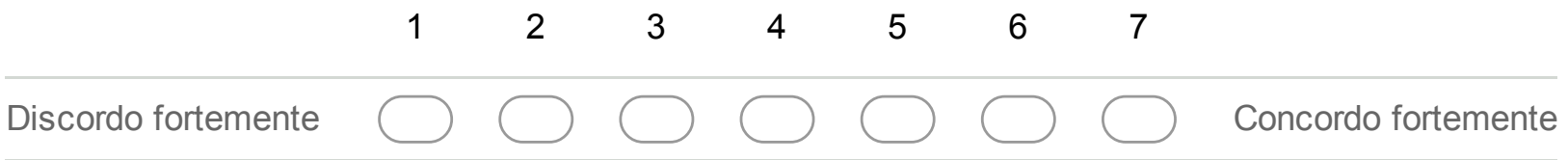

38. Comentário sobre o item anterior

39. É fácil aprender a usar a ferramenta *

Marcar apenas uma oval.

Discordo fortemente $\bigcirc \longrightarrow C$ Concordo fortemente

40. Comentário sobre o item anterior

41. Eu rapidamente me tornei habilidoso com a ferramenta *

Marcar apenas uma oval.

$\begin{array}{lllllll}1 & 2 & 3 & 4 & 5 & 6 & 7\end{array}$

Discordo fortemente $\square \longrightarrow \square C O C$ Concordo fortemente

42. Comentário sobre o item anterior

\section{Satisfação}

43. Eu estou satisfeito com a ferramenta *

Marcar apenas uma oval.

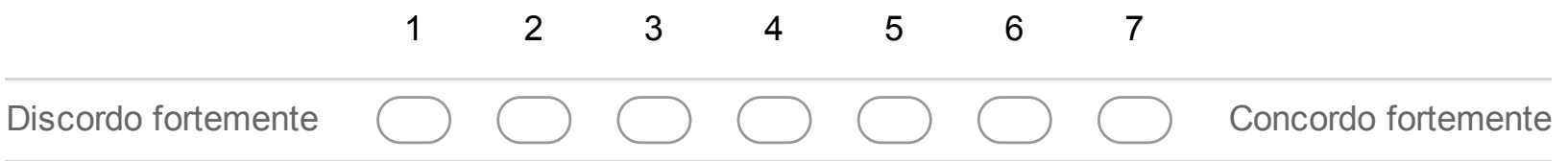

44. Comentário sobre o item anterior

45. Eu recomendaria a ferramenta para um amigo *

Marcar apenas uma oval.

$\begin{array}{lllllll}1 & 2 & 3 & 4 & 5 & 6 & 7\end{array}$

Discordo fortemente

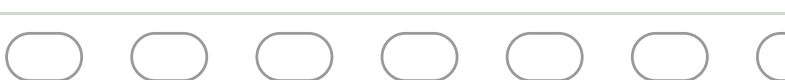

Concordo fortemente 
46. Comentário sobre o item anterior

47. A ferramenta é divertida de usar *

Marcar apenas uma oval.

$\begin{array}{lllllll}1 & 2 & 3 & 4 & 5 & 6 & 7\end{array}$

Discordo fortemente $\square \square \square \square$ Concordo fortemente

48. Comentário sobre o item anterior

49. A ferramenta funciona da maneira que eu gostaria de funcionasse *

Marcar apenas uma oval.

Discordo fortemente

50. Comentário sobre o item anterior

51. A ferramenta é maravilhosa *

Marcar apenas uma oval.

$\begin{array}{lllllll}1 & 2 & 3 & 4 & 5 & 6 & 7\end{array}$

Discordo fortemente $\square \longrightarrow \bigcirc \bigcirc \bigcirc+C$ Concordo fortemente

52. Comentário sobre o item anterior

53. Eu sinto que eu tenho que ter a ferramenta *

Marcar apenas uma oval.

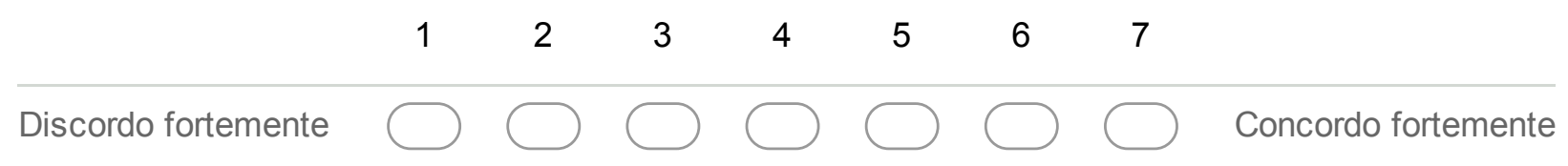

54. Comentário sobre o item anterior

55. A ferramenta dá prazer em utilizar *

Marcar apenas uma oval.

$\begin{array}{lllllll}1 & 2 & 3 & 4 & 5 & 6 & 7\end{array}$

Discordo fortemente

$\square \bigcirc \square \bigcirc \square 0$ Concordo fortemente


56. Comentário sobre o item anterior

57. Liste 3 aspectos mais negativos na ferramenta *

58. Liste 3 aspectos mais positivos da ferramenta *

Powered by

国 Google Forms 
Apêndice I - Questionário utilizado ao final do curso Turma 1 


\section{Avaliação de interação e colaboração (Turma 1)}

*Obrigatório

1. Você interagiu com outros alunos durante o curso? *

Marcar apenas uma oval.

$\bigoplus_{\text {Não }}$

2. Como aconteceu esta sua interação com outros alunos? *

Marque todas que se aplicam.

$\square$ E-mail

Facebook

$\square$ Pessoalmente

$\square$ Skype

$\square$ Outro:

3. Você acha que esta interação ajudou você a aprender mais? *

Marcar apenas uma oval.

$\bigcirc \operatorname{sim}$

Não

4. Você colaborou com outros alunos e com o professor durante o curso?

Colaborar seria trabalhar em conjunto com os demais com o objetivo de aprender ou desenvolver o aprendizado.

Marcar apenas uma oval.

$\operatorname{Sim}$

Não

5. Como aconteceu esta colaboração? *

Marque todas que se aplicam.

$\square$ E-mail

Facebook

$\square$ Pessoalmente

$\square$ Skype

Outro:

6. Você acha que a interação/colaboração permite uma maior eficiência no processo de ensino e aprendizagem? *

Marcar apenas uma oval.

$\operatorname{Sim}$

Não 
7. Você consegue acompanhar o professor construindo o código-fonte em tempo-real no datashow?

Marcar apenas uma oval.

$\int \operatorname{Sim}$

Não

8. Você consegue construir sua própria versão do código-fonte em sua máquina? (acompanhando os passos do professor no datashow) *

Marcar apenas uma oval.

$\operatorname{Sim}$

Não

9. Você gostaria de fazer uma observação sobre este último item?

10. Você acha que se visualizasse o código-fonte do professor na sua própria máquina, em tempo-real, seria mais fácil acompanhar os passos da aula? *

Sem ser pelo datashow, visualizando o código-fonte na própria máquina do aluno.

Marcar apenas uma oval.

Sim

$\bigcirc$ Não

11. Você gostaria de fazer uma observação sobre este último item?

12. Você acha conseguiria construir sua própria versão do código-fonte em sua máquina se acompanhando os passos do professor em sua própria máquina? *

Sem ser pelo datashow, visualizando o código-fonte na própria máquina do aluno.

Marcar apenas uma oval.

Sim

Não

13. Você gostaria de fazer uma observação sobre este último item? 
14. Você acha que os alunos poderem acompanhar/visualizar em casa (depois do horário da classe) os códigos-fontes e todo material criado pelo professor, ajudaria na aprendizagem e estudo extra-classe? *

Marcar apenas uma oval.

$\operatorname{Sim}$

Não

15. Você gostaria de fazer uma observação sobre este último item?

16. Você gostaria de poder perguntar e/ou anotar sobre o material de aula (slides, códigos-fonte, etc)?

Marcar apenas uma oval.

Sim

Não

17. Você gostaria de fazer uma observação sobre o último item?

18. Você acha que uma ferramenta com está funcionalidade facilitaria seu estudo extra-classe? * (seus estudos fora da sala de aula)

Marcar apenas uma oval.

$\bigcirc_{\text {Não }}$ Sim

19. Você gostaria de fazer uma observação sobre o último item?

20. Você acha que uma ferramenta com está funcionalidade facilitaria seu aprendizado sobre o assunto? *

Marcar apenas uma oval.

Sim

Não 
21. Você acha que uma ferramenta que permita você informar ao professor sua opinião (anonimamente) sobre o andamento da aula é importante? *

Exemplo: gostando ou não gostando

Marcar apenas uma oval.

$\operatorname{Sim}$

Não

22. Você gostaria de fazer uma observação sobre o último item?

23. Você gostaria de fazer uma observação qualquer?

Powered by

国 Google Forms 

Apêndice J - Questionário utilizado ao final do curso Turma 2 


\section{Avaliação de interação e colaboração (Turma 2)}

*Obrigatório

1. Você interagiu com outros alunos durante o curso? *

Marcar apenas uma oval.

$\bigoplus_{\text {Não }}$

2. Como aconteceu esta sua interação com outros alunos? *

Marque todas que se aplicam.

$\square$ Mindboard

$\square$ E-mail

Facebook

Pessoalmente

Skype

Outro:

3. Você acha que esta interação ajudou você a aprender mais? *

Marcar apenas uma oval.

$\bigcirc \operatorname{Sim}$

Não

4. Você colaborou com outros alunos e com o professor durante o curso?

Colaborar seria trabalhar em conjunto com os demais com o objetivo de aprender ou desenvolver o aprendizado.

Marcar apenas uma oval.

$\int \operatorname{sim}$

Não

5. Como aconteceu esta colaboração? *

Marque todas que se aplicam.

Mindboard

E-mail

- Facebook

$\square$ Pessoalmente

Skype

Outro: 
6. Você acha que a interação/colaboração permite uma maior eficiência no processo de ensino e aprendizagem? *

Marcar apenas uma oval.

S Sim

Não

7. Você consegue acompanhar o professor construindo o código-fonte em tempo-real no datashow?

Marcar apenas uma oval.

$\operatorname{Sim}$

Não

8. Você consegue construir sua própria versão do código-fonte em sua máquina? (acompanhando os passos do professor no datashow) *

Marcar apenas uma oval.

$\bigcirc \operatorname{Sim}$

Não

9. Você gostaria de fazer uma observação sobre este último item?

10. Você gostou de poder visualizar o código-fonte do professor na sua própria máquina, em tempo-real? *

Sem ser pelo datashow, visualizando o código-fonte na própria máquina do aluno.

Marcar apenas uma oval.

$\bigcirc \operatorname{sim}$

Não

11. Você utilizou a visualização do código-fonte do professor na sua própria máquina, em temporeal? *

Marcar apenas uma oval.

$\operatorname{Sim}$

Não

12. Esta funcionalidade facilitou o acompanhamento dos passos da aula? *

Marcar apenas uma oval.

$\operatorname{Sim}$

Não 
13. Você gostaria de fazer uma observação sobre esta funcionalidade (compartilhamento em tempo-real de código-fonte)?

14. Você conseguiu construir sua própria versão do código-fonte em sua máquina acompanhando os passos do professor através desta funcionalidade do Mindboard? *

Marcar apenas uma oval.

$\operatorname{Sim}$

Não

15. Você gostaria de fazer uma observação sobre este último item?

16. Você acha que os alunos poderem acompanhar/visualizar em casa (depois do horário da classe) os códigos-fontes e todo material criado/utilizado pelo professor, ajuda na aprendizagem e estudo extra-classe? *

Marcar apenas uma oval.

$\operatorname{Sim}$

Não

17. Você reviu os materiais de aula em casa (depois do horário da classe) os códigos-fontes e todo material criado/utilizado pelo professor? *

Marcar apenas uma oval.

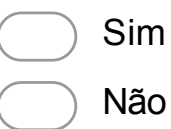

18. Você gostaria de fazer uma observação sobre este último item?

19. Você utilizou a funcionalidade de perguntar e/ou anotar sobre o material de aula (slides, códigos-fonte, etc) no Mindboard? *

Marcar apenas uma oval.

Sim

Não 
20. Você gostaria de fazer uma observação sobre o último item?

21. Você acha que esta funcionalidade facilitou seu estudo extra-classe? *

(seus estudos fora da sala de aula)

Marcar apenas uma oval.

22. Você gostaria de fazer uma observação sobre o último item?

23. Você acha que você informar ao professor sua opinião (anonimamente) sobre o andamento da aula é importante?

Exemplo: gostando ou não gostando

Marcar apenas uma oval.

$\operatorname{Sim}$

Não

24. Você utilizou este recurso no Mindboard? *

Marcar apenas uma oval.

$\operatorname{Sim}$

Não

25. Você gostaria de fazer uma observação sobre os dois últimos itens? 
26. Você gostaria de fazer uma observação qualquer?

Powered by

国 Google Forms 


\section{Apêndice $K$ - Requisitos funcionais e não funcionais}

\section{K.1 Requisitos funcionais}

\section{K.1.1 RF 01 - Identificar professores e alunos}

Descrição: a ferramenta deve permitir a identificação e autenticação de usuários professores e alunos, bem como gerenciar permissões específicas a cada um deles. Além disso, a forma de autenticação deverá exigir o preenchimento mínimo de informações.

Prioridade: essencial.

\section{K.1.2 RF 02 - Gerenciar aulas}

Descrição: a ferramenta deve permitir que professores iniciem novas aulas. Aulas são definidas como um conjunto de ações durante um período de tempo. Estão ações totalizam em conteúdo gerado.

Uma aula poderá ser identificada de forma única e simples, e poderá ser removida ou alterada pelos professores autores.

Prioridade: essencial.

\section{K.1.3 RF 03 - Acessar aulas}

Descrição: a ferramenta deve permitir que alunos e professores acessem aulas já iniciadas. Quando acessado como aluno, as ações realizadas são apenas visíveis ao próprio aluno, já quando acesso como professor, as ações realizadas serão distribuídas entre todos os participantes da aula.

Um único usuário poderá acessar uma mesma aula em mais de um dispositivo diferente. Permitindo, por exemplo, que professores acessem uma versão para projeção e outra gerenciar o conteúdo. Ou mesmo um aluno, acesse ao mesmo tempo de um tablet e notebook.

Prioridade: essencial.

\section{K.1.4 RF 04 - Projetar apresentações de slides em uma aula}

Descrição: a ferramenta deve permitir que professores insiram e projetem apresentações de slides dentro de uma aula. Uma vez inserido e gerenciado a apresentação de slides (por exemplo, alterar do slide 1 para o slide 2), todos os participantes receberão e visualizarão o mesmo slide. 
Prioridade: essencial.

\section{K.1.5 RF 05 - Anotações}

Descrição: a ferramenta deve permitir que alunos e professores anotem o conteúdo através de ferramentas de desenho. As anotações feitas por professores serão distribuídas a todos os alunos, já as realizadas pelos alunos serão disponíveis apenas para os que as criaram.

Prioridade: essencial.

\section{K.1.6 RF 06 - Quiz}

Descrição: a ferramenta deve permitir que professores realizem pequenas enquetes durante uma sessão. As respostas destas questões deverão serem totalizadas em tempo real ao professor, que pode escolher se quer exibir os resultados a todos os participantes.

Prioridade: desejado.

\section{K.1.7 RF 07 - Coletar e sumarizar opiniões sobre a aula}

Descrição: durante uma aula, os alunos poderão indicar seus relativos níveis de satisfação imediato ao professor. Este nível de satisfação é exibido em tempo real ao professor, e permite uma análise imediata do andamento de uma aula. Os níveis de satisfação coletados serão: positivo, neutro e negativo. Esta informação será armazenada também para posterior análise pelo professor.

Prioridade: essencial.

\section{K.1.8 RF 08 - Coletar e sumarizar dúvidas durante e após a aula}

Descrição: permitir que alunos façam perguntas durante e após as aula. No momento de realizar uma pergunta, o aluno pode informar se é apenas para o professor ou se pode ser respondida por um outro aluno. Ambos, professores e alunos, podem continuar colaborando sobre a dúvida postada.

A dúvida também pode ser contextualizada sendo indicado o momento em que ela ocorreu dentro da aula. Em sua resposta, podem ser citados momentos específicos da aula (atual ou outras aulas).

Prioridade: essencial. 


\section{K.1.9 RF 09 - Rever uma aula}

Descrição: após o fim de uma aula, todos os usuários poderão rever o conteúdo construído, podendo controlar o fluxo através de uma linha do tempo.

Prioridade: essencial.

\section{K.1.10 RF 10 - Colaborar assincronamente em uma aula}

Descrição: após o fim de uma aula, todos os usuários poderão rever a mesma e colaborar adicionando anotações. Exibindo para o usuário uma linha do tempo com as ações que ocorreram durante a aula.

Prioridade: essencial.

\section{K.1.11 RF 11 - Permitir o compartilhamento de código-fonte em tempo-real}

Descrição: permitir que o professor construa códigos de linguagens de programação e que estes códigos sejam compartilhados em tempo-real com os alunos.

Prioridade: essencial.

\section{K.1.12 RF 12 - Permitir integração com outros sistemas}

Descrição: permitir que outros sistemas interajam programaticamente com o Mindboard e realize as seguintes operações:

- Identificar e autenticar usuários;

- Gerenciar aulas e permitir que as mesmas sejam acessadas diretamente do outro sistema;

Prioridade: desejado.

O requisito $\mathbf{R F} \mathbf{0 6}$ teve sua prioridade alterada de essencial para desejado para que houvesse tempo hábil de trocar o requisito RF 11 para essencial. Esta troca foi necessária pois o compartilhamente de código-fonte é essencial ao curso de verão que foi realizado no experimento, e também foi possível, pois haveria outras formas de colaboração como as anotações (RF 10) e também por esta funcionalidade estar disponíveis em SGC que podem ser integrados no Mindboard no futuro. 


\section{K.2 Requisitos não funcionais}

Os requisitos não funcionais incluem os requisitos de desempenho e outros atributos de qualidade do produto, como usabilidade, padrões de codificação e implementação (PáDUA, 2005). Os requisitos não funcionais esperados para a ferramenta Mindboard são descritos a seguir.

RNF 1 - A ferramenta Mindboard deve possuir uma arquitetura facilmente extensível, permitindo futuras funcionalidades de serem acrescentadas sem que seja necessário remodelar toda a ferramenta.

Este requisito não funcional será atingido definindo uma arquitetura em módulos e através do padrão de projetos Model, View e Controller (MVC). Com esta organização do código será possível adicionar novas funcionalidades ao sistema sem a necessidade de refazer partes de códigos já funcionais.

Além disso, uma outra forma de extensibilidade será projetada, onde o sistema Mindboard terá os tipos de conteúdos e mídias disponíveis em uma aula extensíveis, como por exemplo, a integração de um objeto de aprendizado desenvolvido no grupo de pesquisas LInE. Para atingir esta forma de extensibilidade, o sistema Mindboard permitirá que o professor projete outros tipos de conteúdos (além de apresentações de slides e código-fonte) e que estes objetos projetados possam utilizar sua comunicação em tempo-real para troca de informações com os alunos e seu armazenamento de dados.

RNF 2 - A ferramenta Mindboard deve possuir suporte a computadores e dispositivos móveis, possuindo uma interface gráfica adaptável a plataforma utilizada.

Este requisito não funcional será obtido através do desenvolvimento de interfaces responsivas utilizando HTML, CSS e JavaScript.

RNF 3 - A ferramenta Mindboard deve possuir uma forma de acesso simplificada, reduzindo assim barreiras de utilização.

Para atender este requisito serão permitidas duas formas de acesso. A primeira através de um endereço curto, e uma segunda maneira, através da representação gráfica em um QR-Code deste endereço curto. Assim, será possível a digitação rápida do endereço ou a leitura direta por dispositivos móveis (no caso do QR-Code).

RNF 4 - A ferramenta Mindboard deve permitir que um mesmo usuário acesse de dispositivos diferentes dentro de uma mesma sessão.

A ferramenta deverá, para atender este requisito, não distinguir e não restringir o número de acessos por um mesmo usuário.

RNF 5 - A ferramenta Mindboard deve ser escalável, permitindo atender um grande número de usuários simultâneos apenas aumentando os recursos da infraestrutura, como por exemplo, aumentando o número de servidores, ou ampliando a quantidade de memória e processamento. Para permitir a escalabilidade, a arquitetura da ferramenta será definida utilizando balanceadores de carga, servidores redundantes de aplicação, servidores 
redundantes de bancos de dados e servidores replicados de banco de dados em memória. A arquitetura escalável é mostrada na Seção 6.5. 


\section{Apêndice L - Relatórios de utilização de recursos computacionais do experimento}

Figura 39 - Visão geral do consumo de recursos no dia 19/01/2015 - Dia 1 de curso

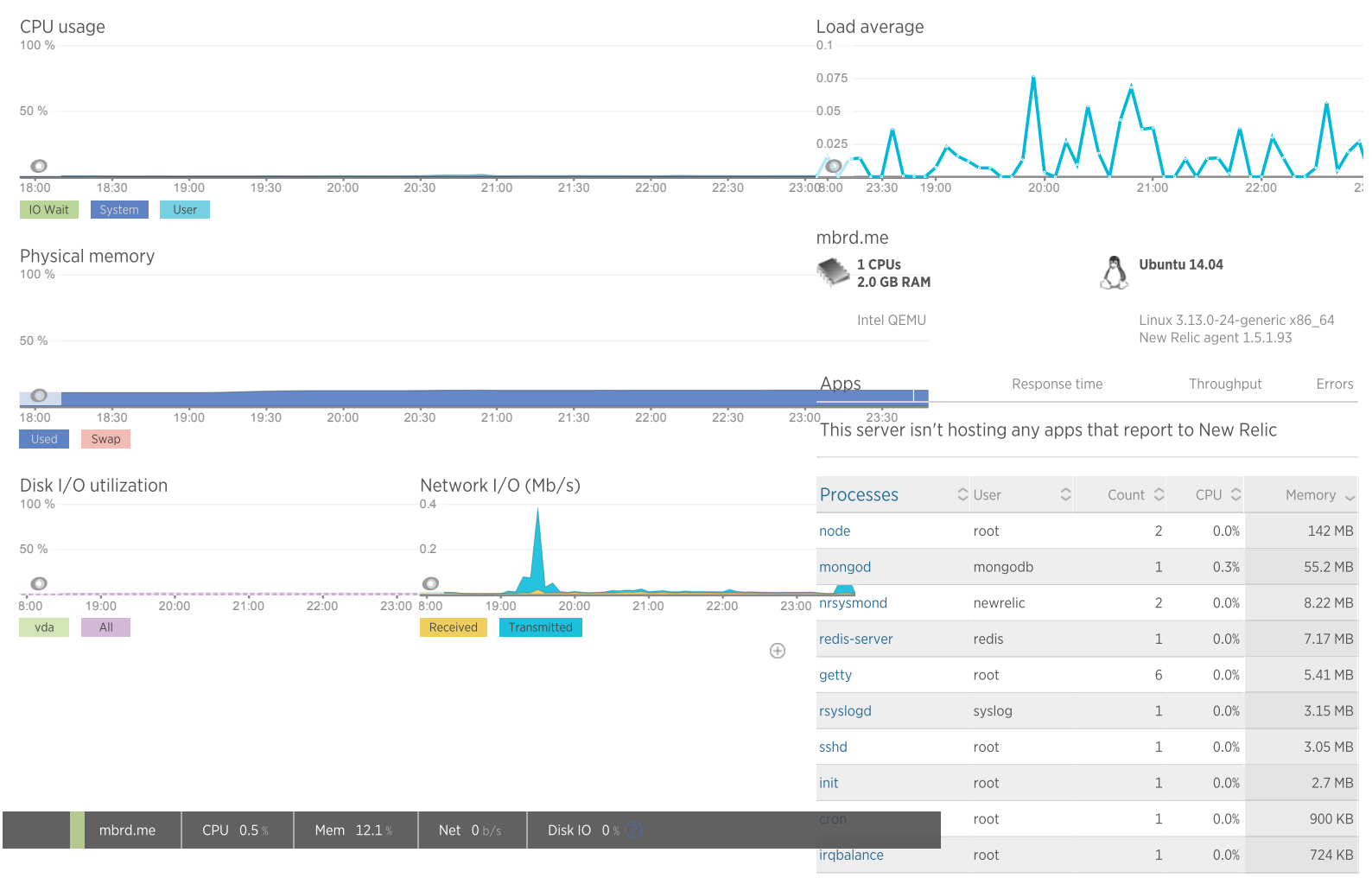

Fonte: Tulio Faria, 2015 
Figura 40 - Visão geral do uso de disco rígido no dia 19/01/2015 - Dia 1 de curso

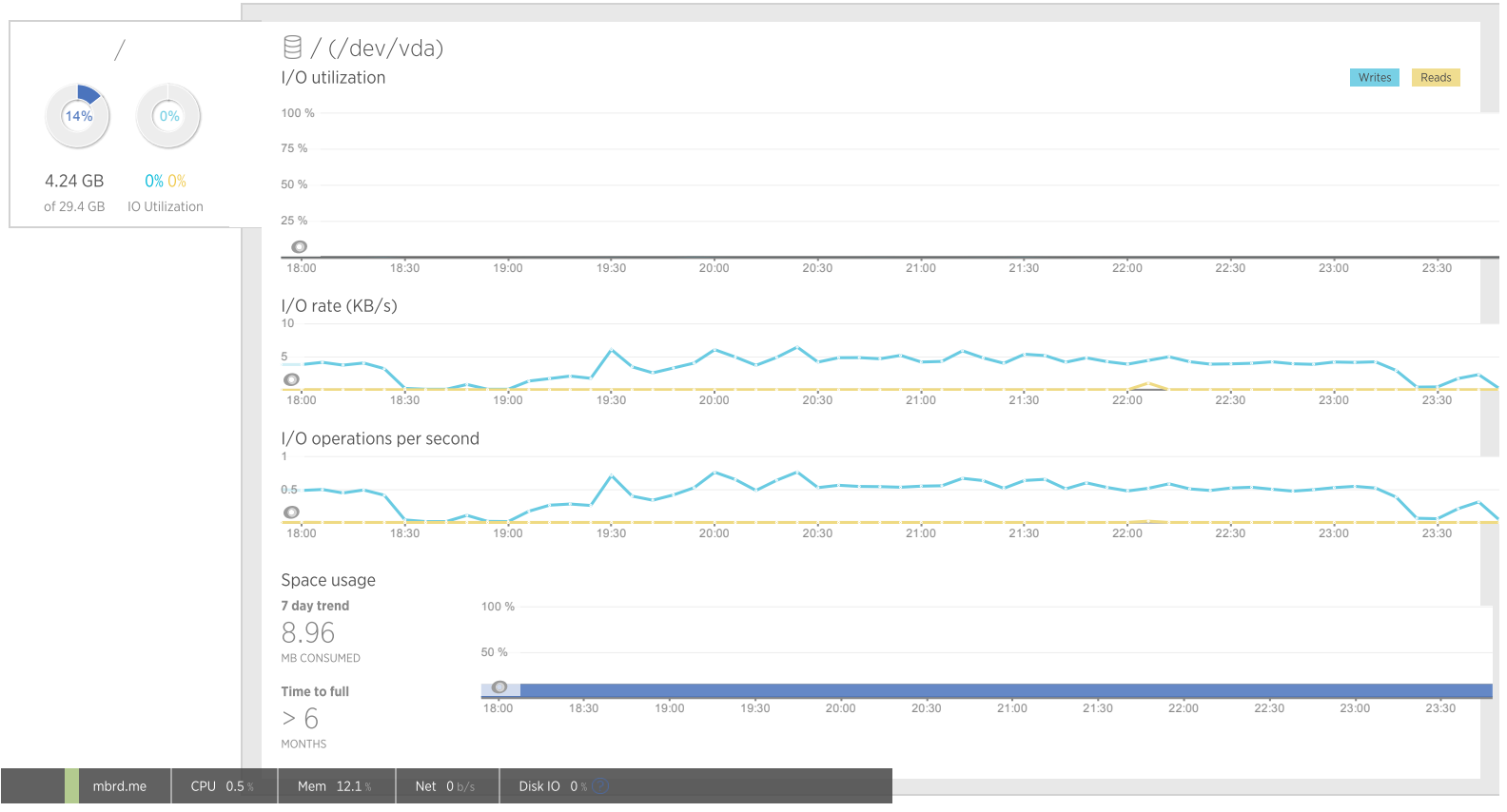

Fonte: Tulio Faria, 2015

Figura 41 - Visão geral do uso de rede no dia 19/01/2015 - Dia 1 de curso

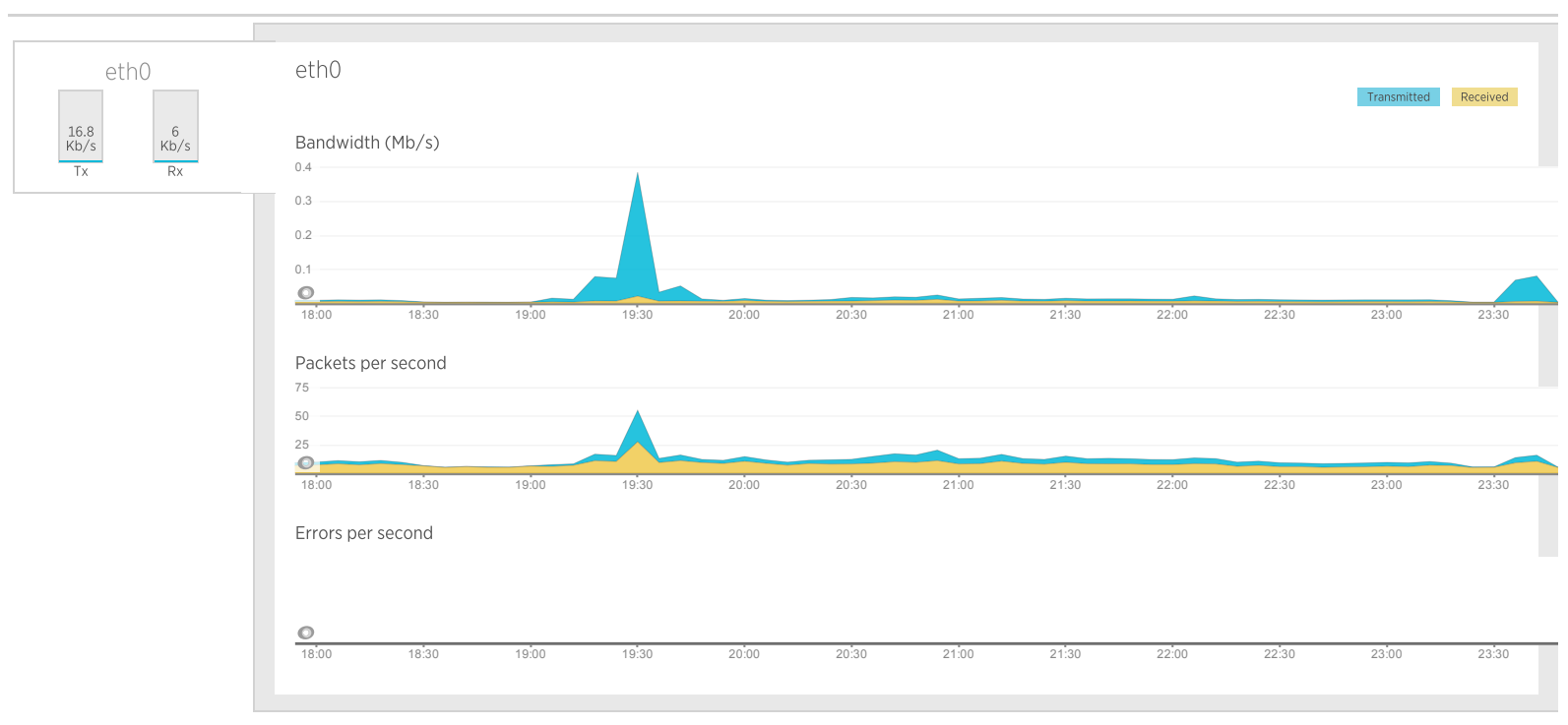


Figura 42 - Visão geral do uso de recursos pelos processos no dia 19/01/2015 - Dia 1 de curso
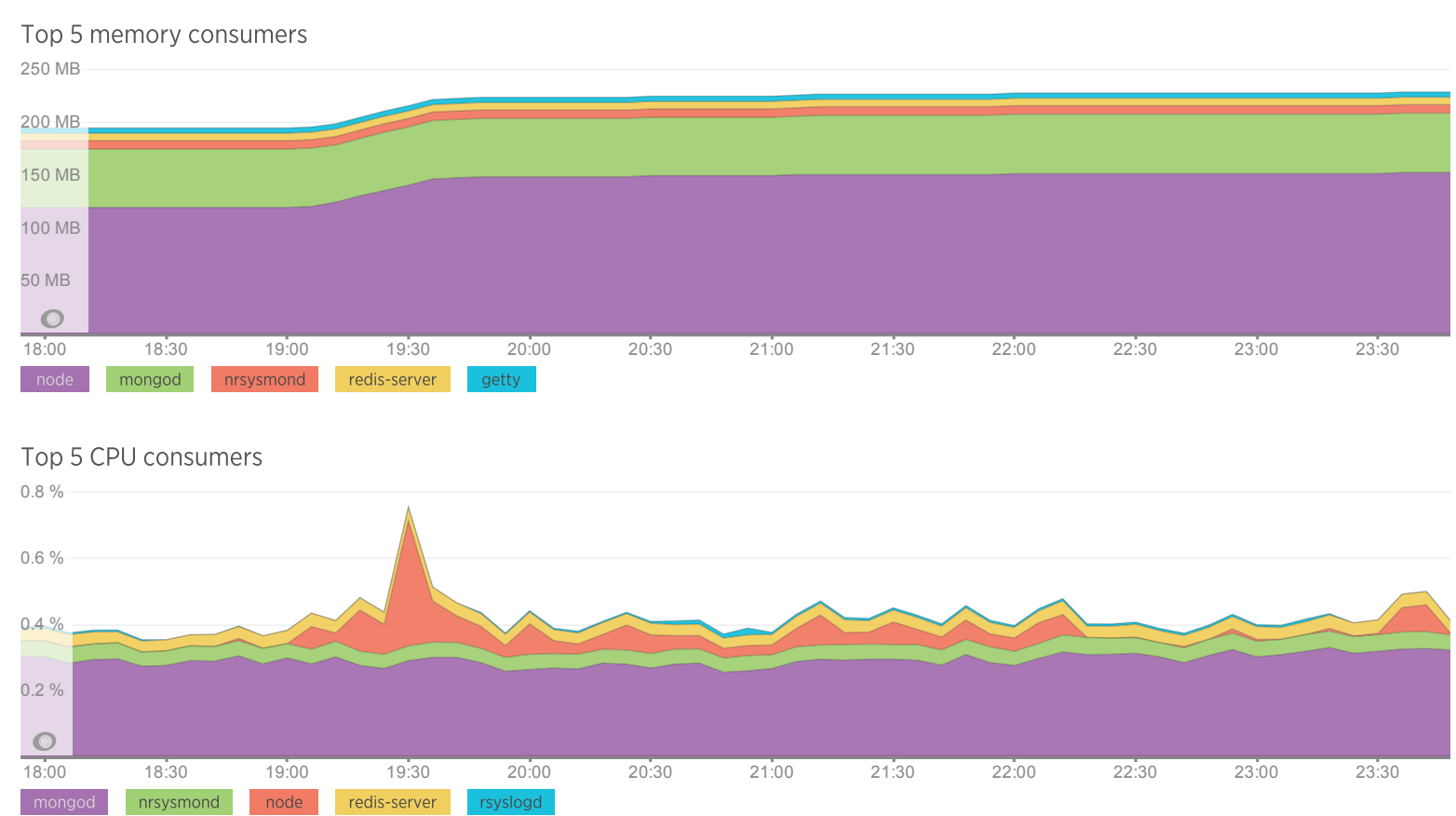

Fonte: Tulio Faria, 2015

Figura 43 - Visão geral do consumo de recursos no dia 20/01/2015 - Dia 2 de curso

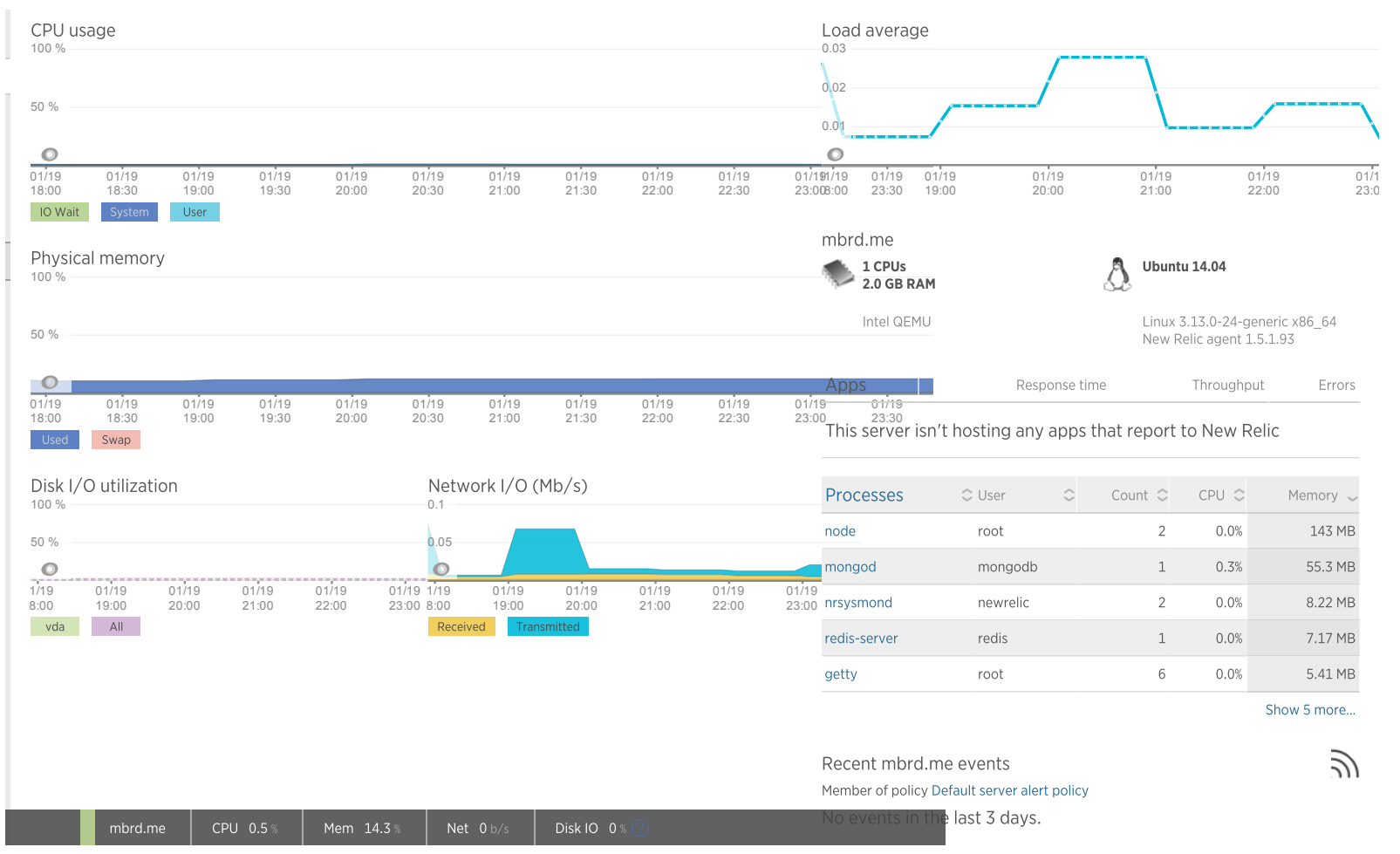

Fonte: Tulio Faria, 2015 
Figura 44 - Visão geral do uso de disco rígido no dia 20/01/2015 - Dia 2 de curso

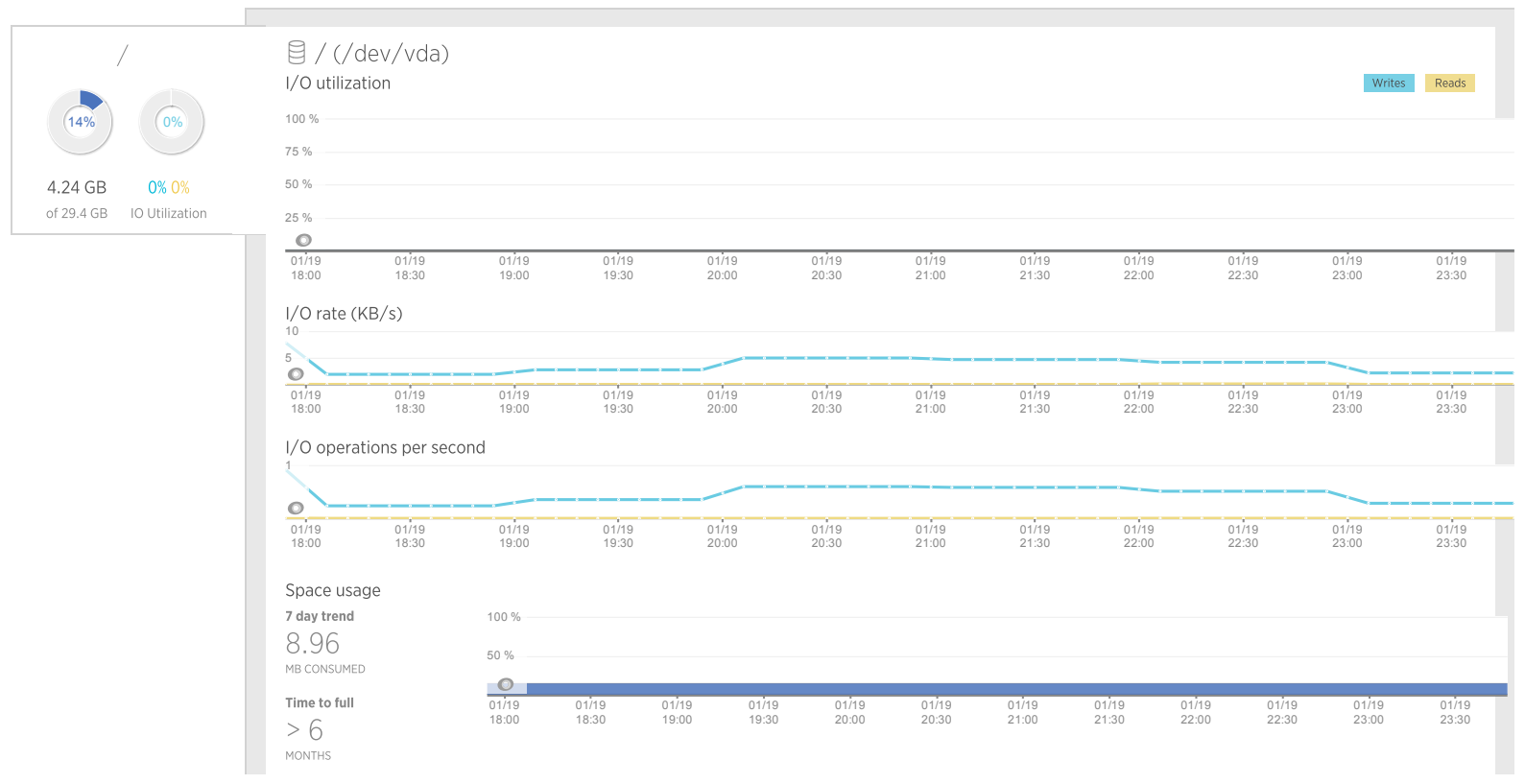

Fonte: Tulio Faria, 2015

Figura 45 - Visão geral do uso de rede no dia 20/01/2015 - Dia 2 de curso

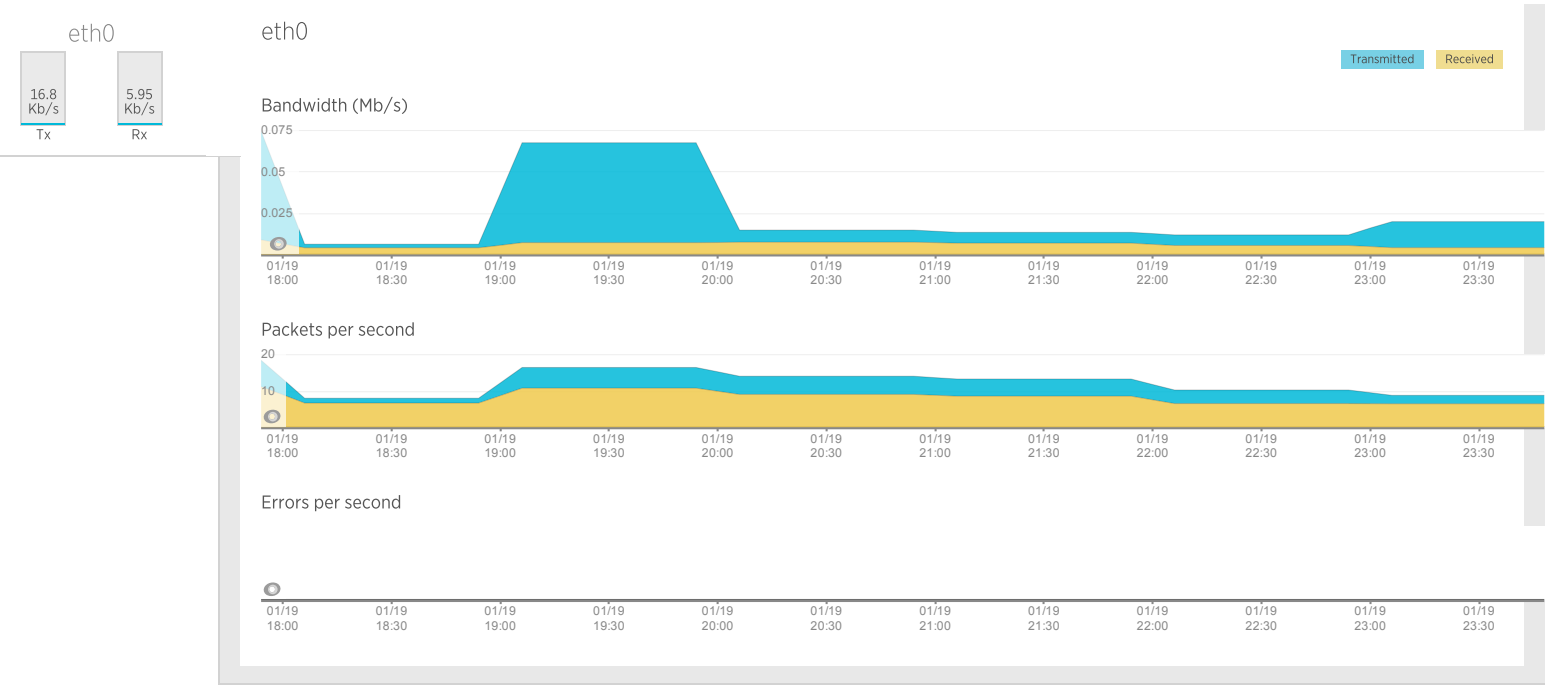

Fonte: Tulio Faria, 2015 
Figura 46 - Visão geral do uso de recursos pelos processos no dia 20/01/2015 - Dia 2 de curso
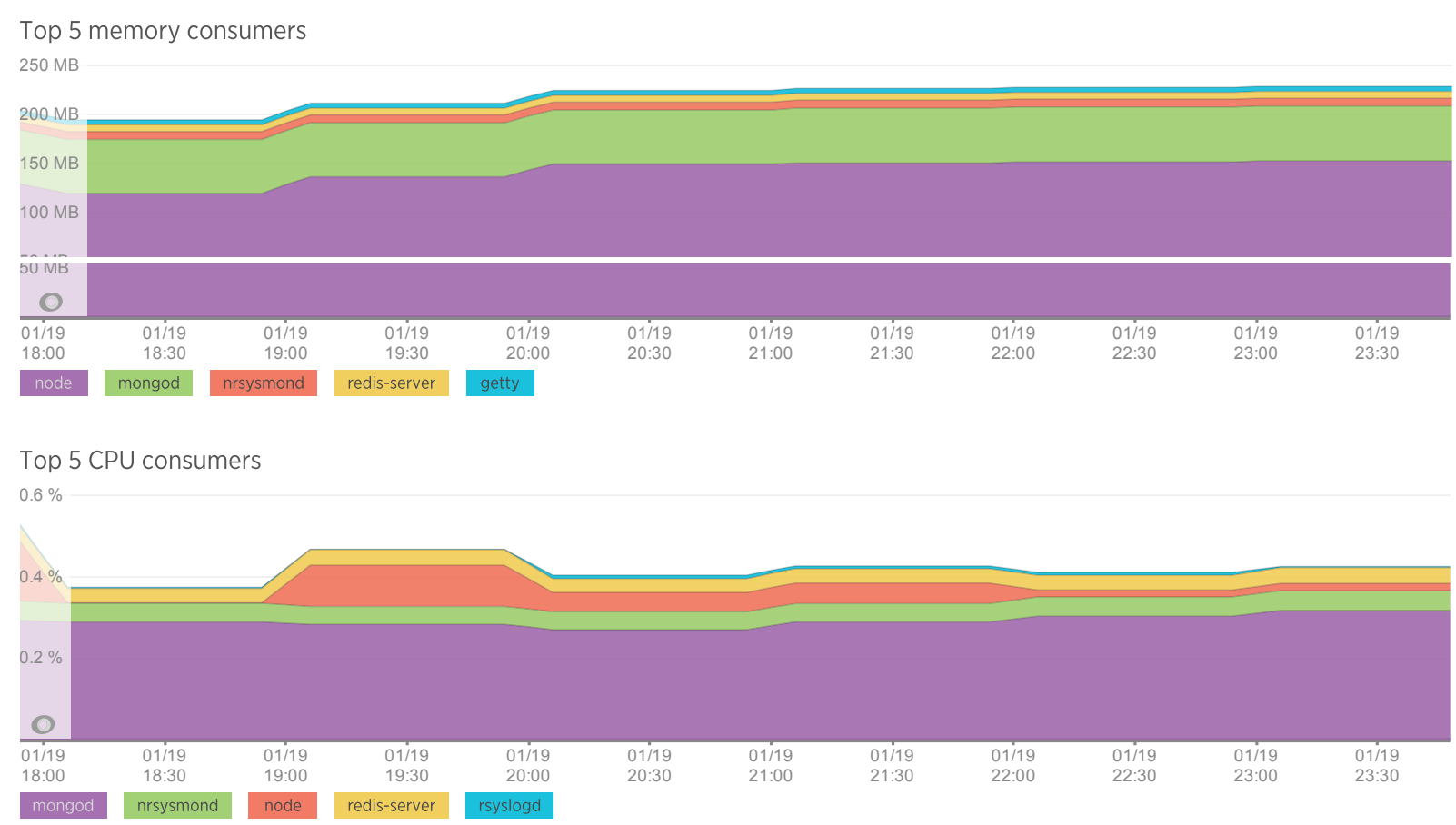

Fonte: Tulio Faria, 2015

Figura 47 - Visão geral do consumo de recursos no dia 21/01/2015 - Dia 3 de curso

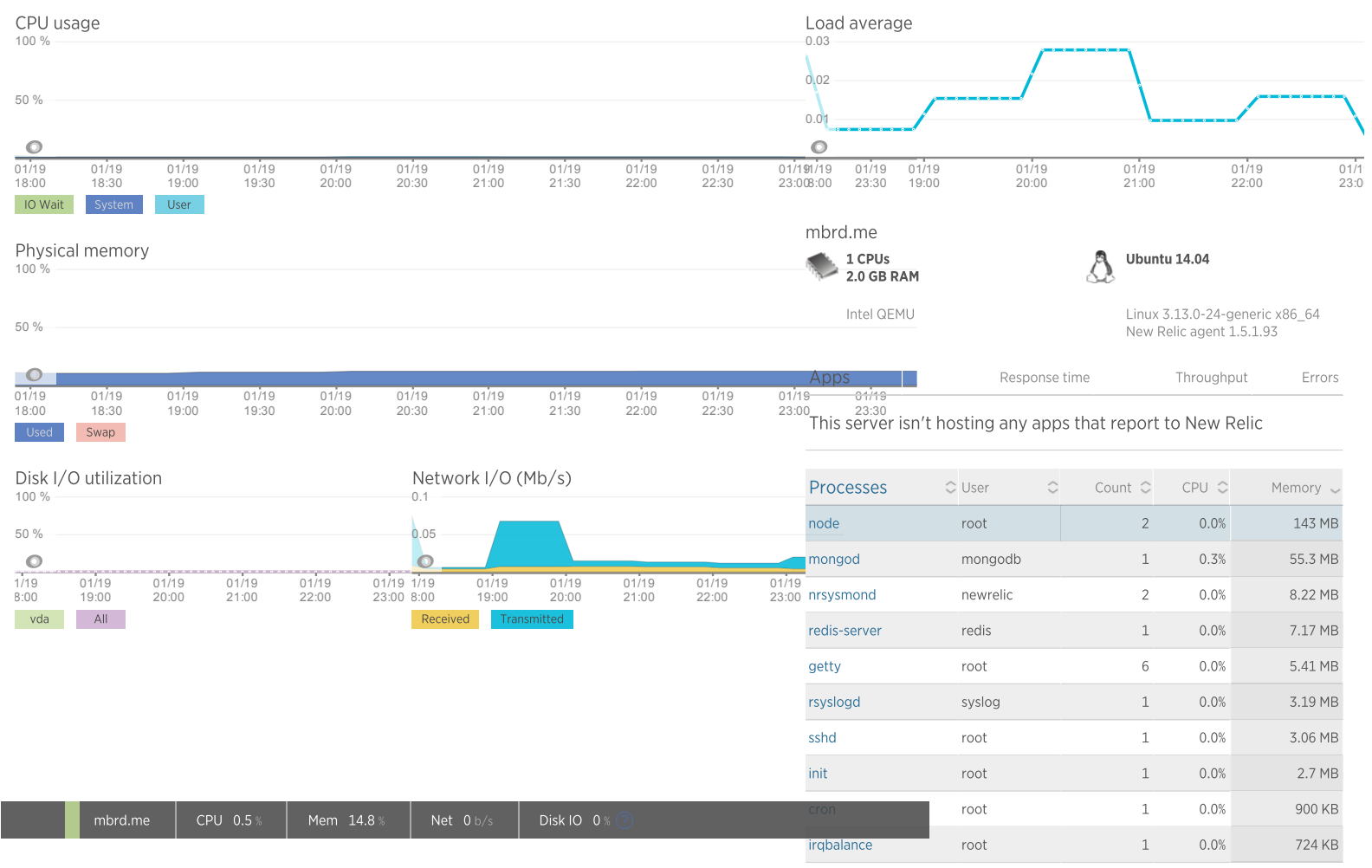

Fonte: Tulio Faria, 2015 
Figura 48 - Visão geral do uso de disco rígido no dia 21/01/2015 - Dia 3 de curso

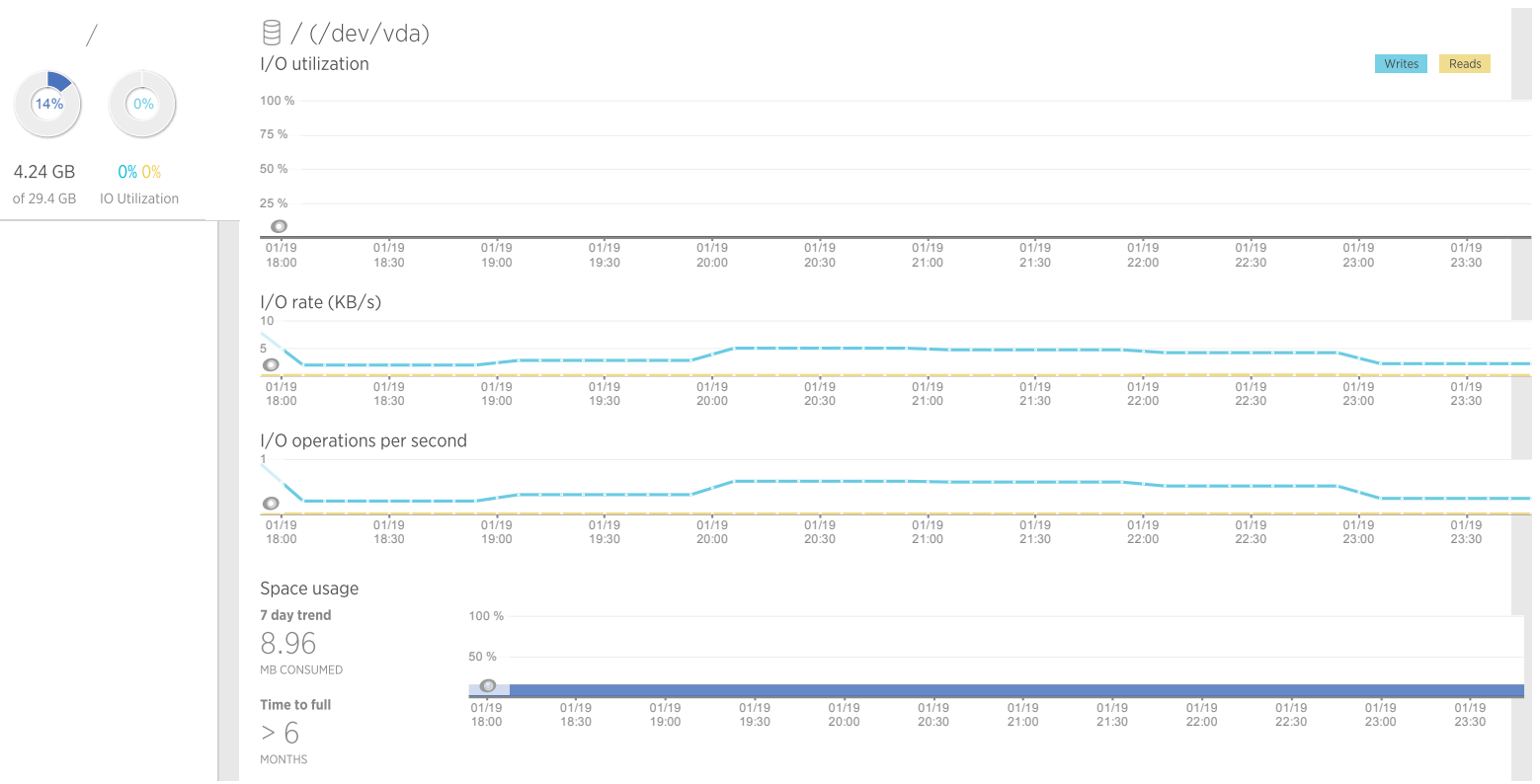

Fonte: Tulio Faria, 2015

Figura 49 - Visão geral do uso de rede no dia 21/01/2015 - Dia 3 de curso

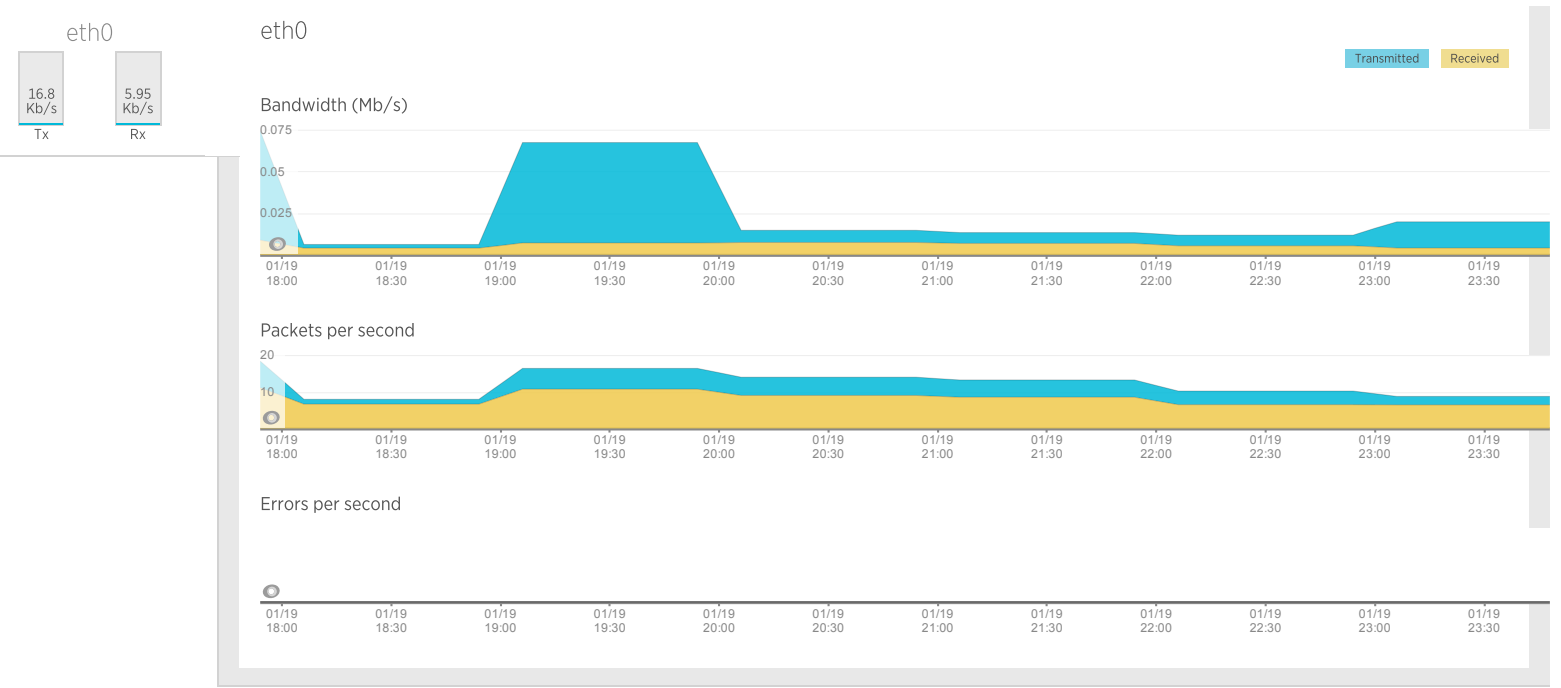

Fonte: Tulio Faria, 2015 
Figura 50 - Visão geral do uso de recursos pelos processos no dia 21/01/2015 - Dia 3 de curso
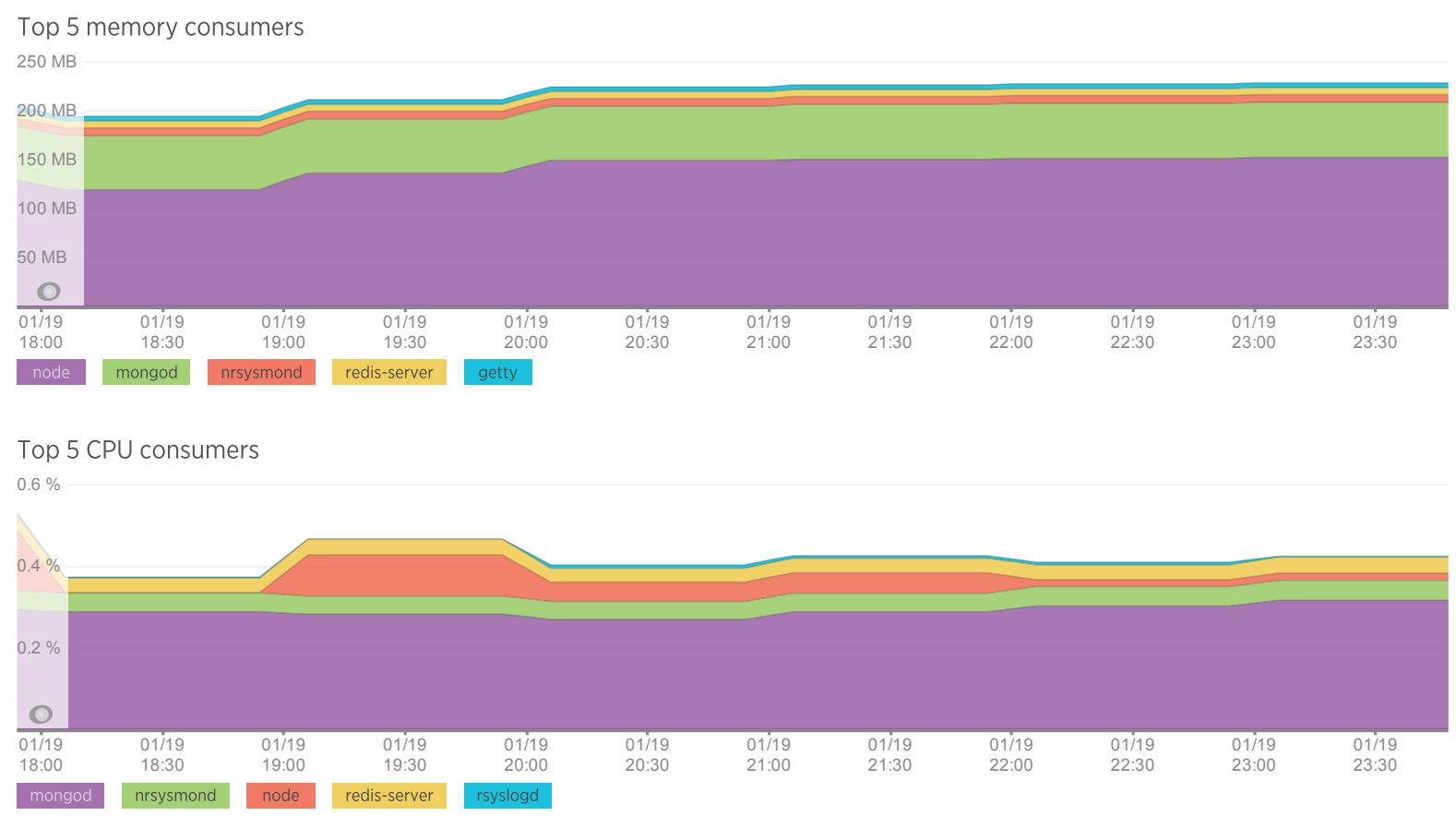

Fonte: Tulio Faria, 2015

Figura 51 - Visão geral do consumo de recursos no dia 22/01/2015 - Dia 4 de curso

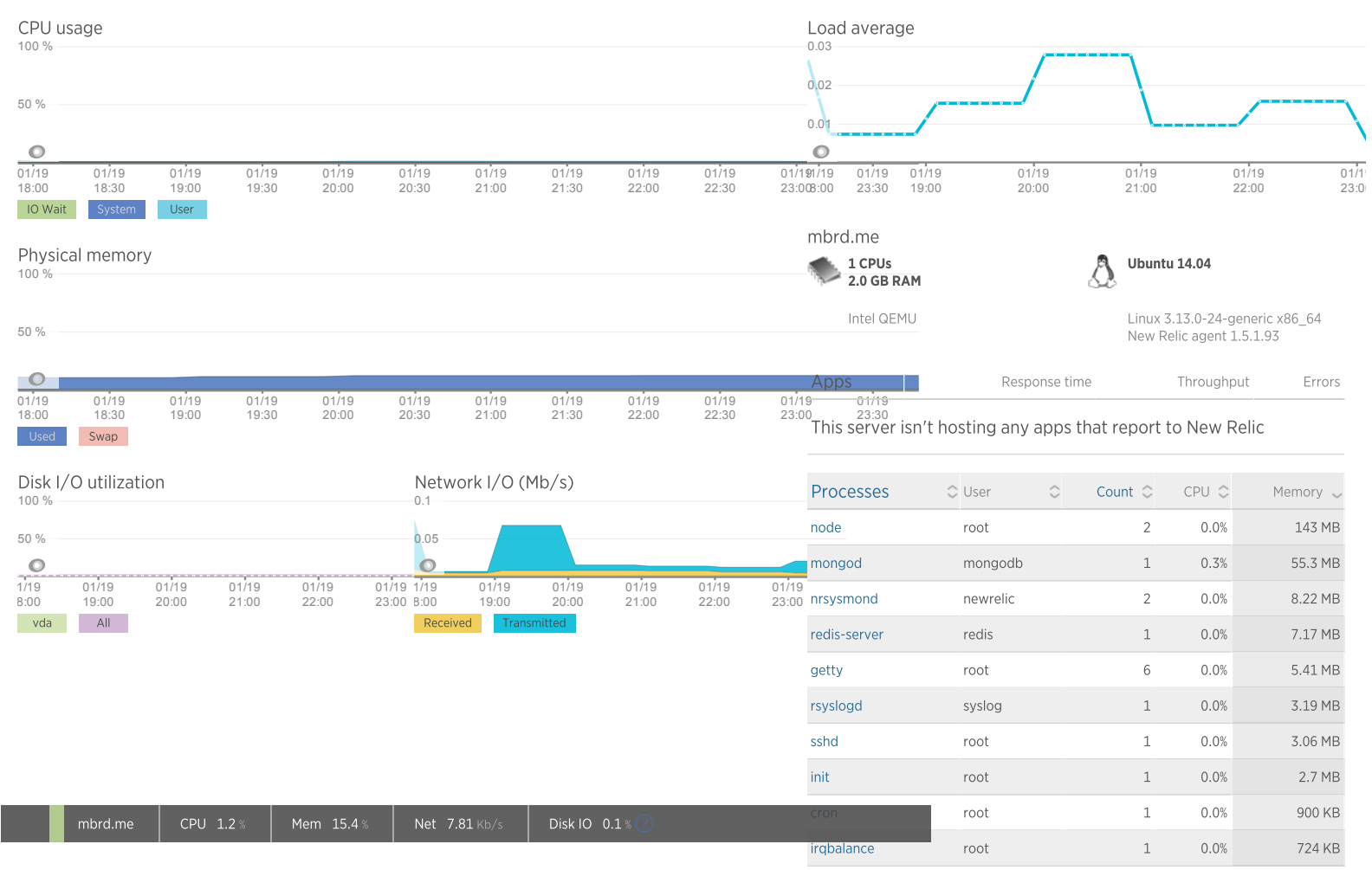


Figura 52 - Visão geral do uso de disco rígido no dia 22/01/2015 - Dia 4 de curso

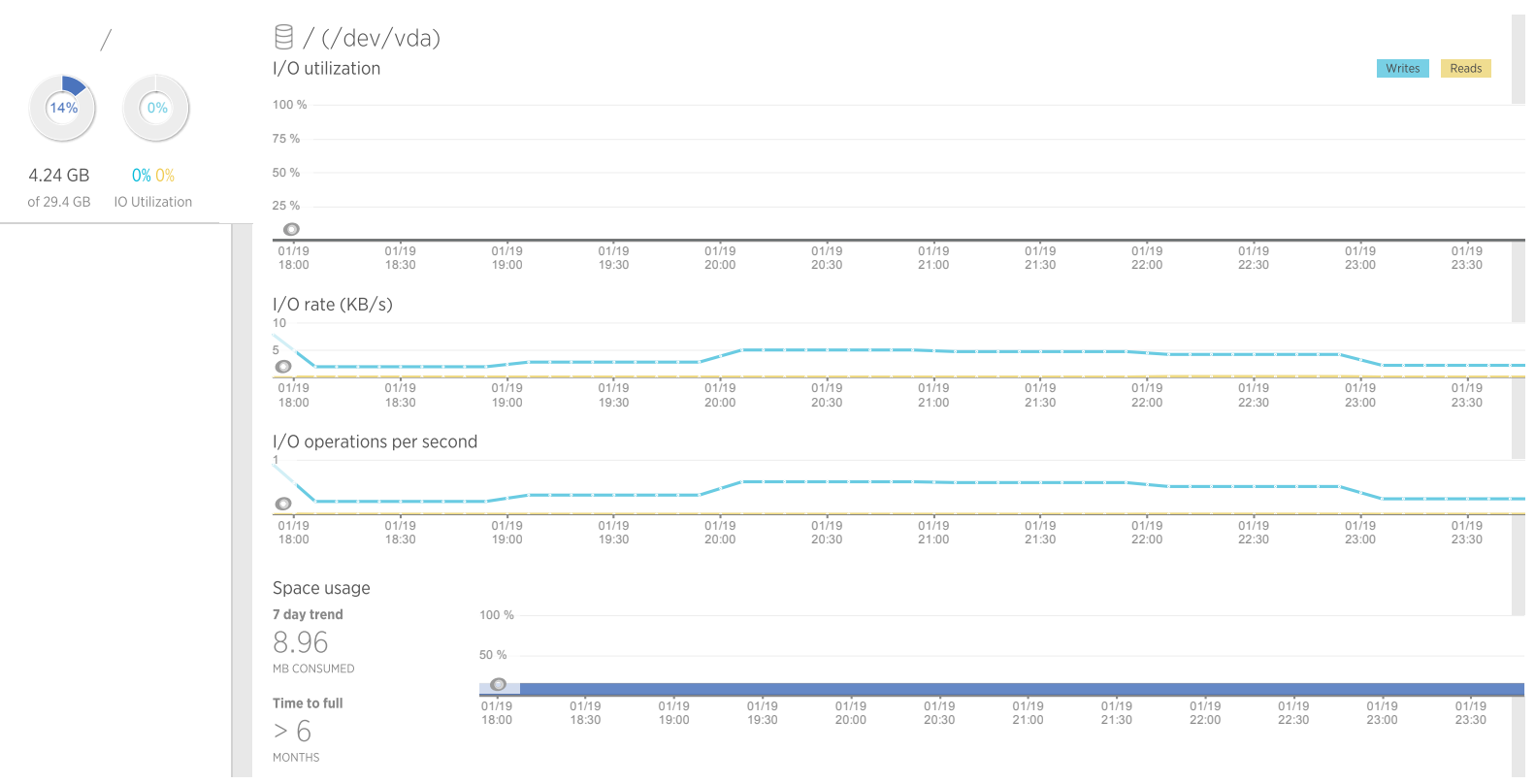

Fonte: Tulio Faria, 2015

Figura 53 - Visão geral do uso de rede no dia 22/01/2015 - Dia 4 de curso

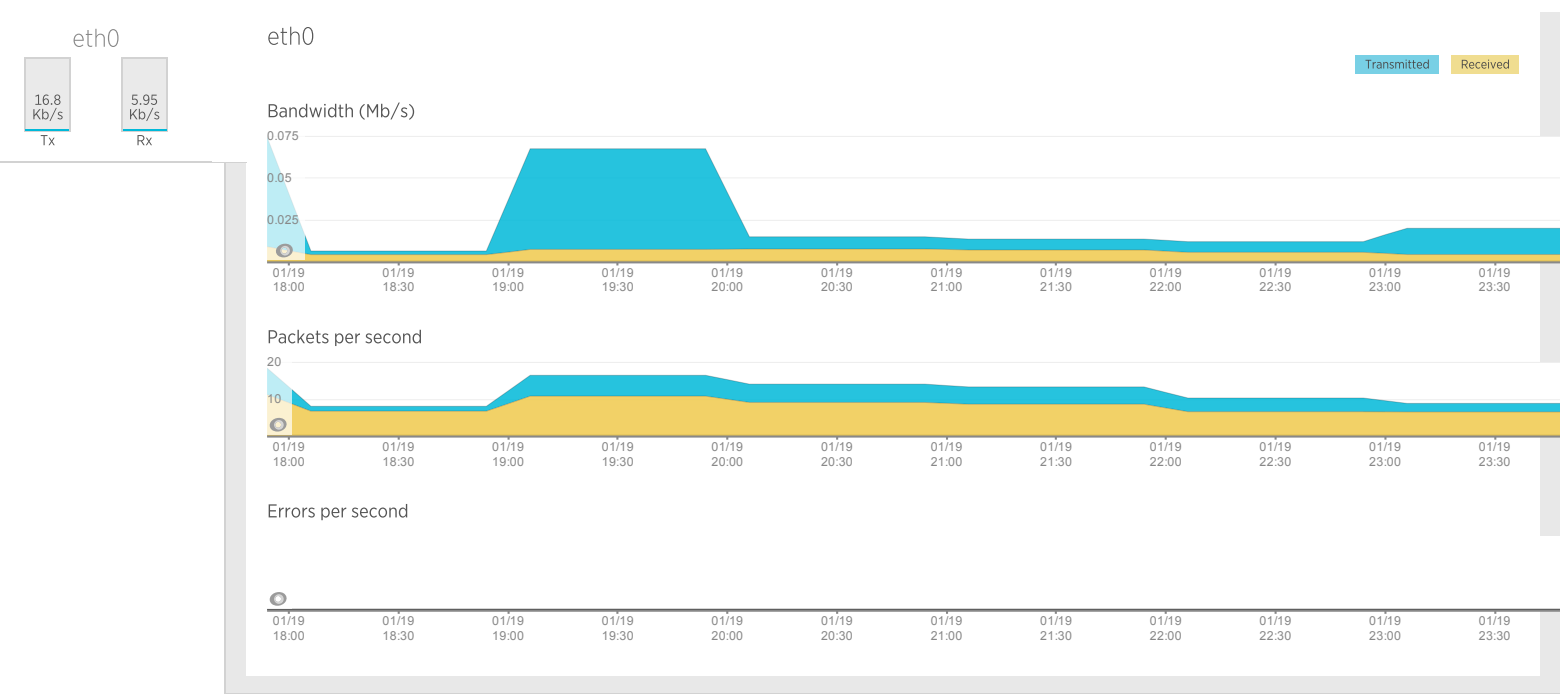

Fonte: Tulio Faria, 2015 
Figura 54 - Visão geral do uso de recursos pelos processos no dia 22/01/2015 - Dia 4 de curso
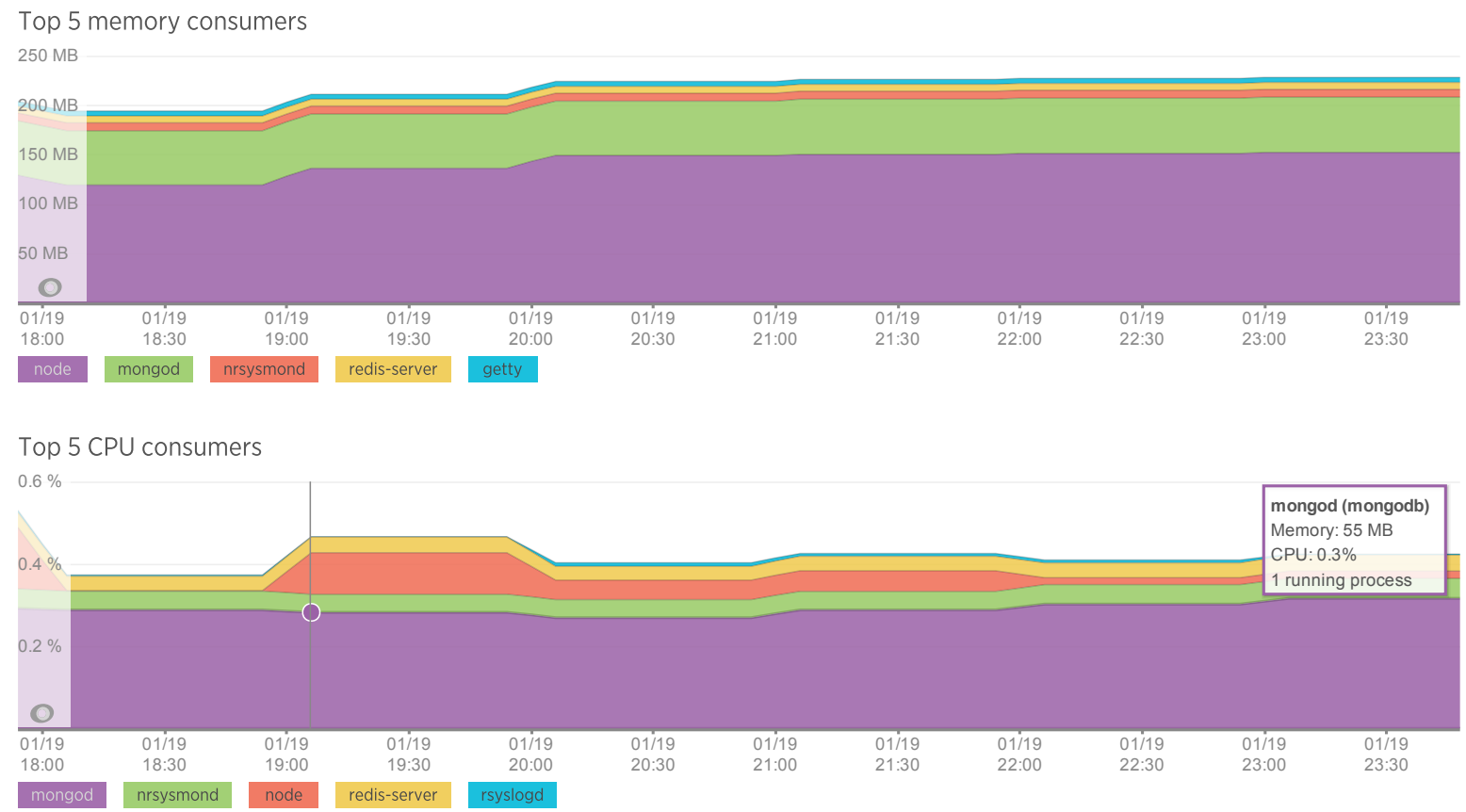

Fonte: Tulio Faria, 2015 